\title{
Assessment of Sodium Conductor Distribution Cable
}

June 1979

Contract No. EC-77-C-01-5041

Prepared for:

U.S. Department of Energy

Assistant Secretary for

Energy Technology

Electrical Energy Systems 


\section{DISCLAIMER}

This report was prepared as an account of work sponsored by an agency of the United States Government. Neither the United States Government nor any agency Thereof, nor any of their employees, makes any warranty, express or implied, or assumes any legal liability or responsibility for the accuracy, completeness, or usefulness of any information, apparatus, product, or process disclosed, or represents that its use would not infringe privately owned rights. Reference herein to any specific commercial product, process, or service by trade name, trademark, manufacturer, or otherwise does not necessarily constitute or imply its endorsement, recommendation, or favoring by the United States Government or any agency thereof. The views and opinions of authors expressed herein do not necessarily state or reflect those of the United States Government or any agency thereof. 


\section{DISCLAIMER}

Portions of this document may be illegible in electronic image products. Images are produced from the best available original document. 
Available from:

National Technical Information Service (NTIS)

U.S. Department of Commerce

5285 Port Royal Road

Springfield, Virginia 22161

Price: Printed copy: $\$ 10.75$

Microfiche: $\quad \$ 3.00$ 
DOE/ET-5041-1

Dist. Category UC97-a

\section{Assessment of Sodium Conductor Distribution Cable}

June 1979

Prepared by:

Westinghouse Research and Development Center

Pittsburg, PA 15275

Contract No. EC-77-C-01-5041

Prepared for:

U.S. Department of Energy

Assistant Secretary for

Energy Technology

Electrical Energy Systems

Washington, D.C. 20585

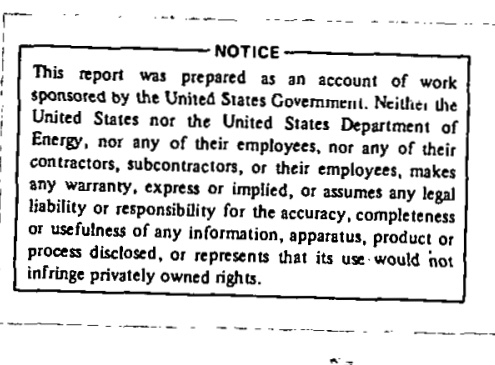

This report was prepared as an account of work sponsored by the United States Govemmernt. Neithit Uhe Energy, nor any of their employes, nor any of their

lisility ar express or implied, or assumes any legal

oz useful esponsibuly for the accuracy, completeness 


\section{NOTICE}

This report was prepared as an account of work sponsored by the United States Government. Neither the United States nor the United States Department of Energy, nor any of their omployees, makes any worraily, express or implied, or assumes any legal liability or responsibility for the accuracy. completeness, or usefulness of any information, apparatus, product, or process disclosed, or represents that its use would not infringe privately owned rights. Reference herein to any specific commercial product, process, or service by trade name, mark, manufacturer, or otherwice, does not necessarily constirute or imply its endorsement, recommendation, or favoring by the United States Government or any ojemcy thereot. The views and opinions of authors expressed herein do not necessarily state or reflect those of the United States Government or any agency thereof. 


\section{Table of Contents}

Acknowledgements

1. Summary

2. Conclusions

3. Introduction

4. Goals of the Study

4.1 Basis for Comparison

4.2 Methodology of Study

5. Information Sources

5.1 Literature Search

5.2 Utility Survey

5.3 Conclusions from Informational Sources

6. Environmental and Safety Considerations

6.1 Sodium Description and Properties

6.2 Cable Handling by Manufacturer, Shipper, and Utility Contractor

6.3 Field Installations

6.4 Dig-in Consequences

6.5 Fault Consequences

6.6 Scrap Handling

6.7 Discontinued Circuit Removal and Abandonment

6.8 Conclusions for Environmental and Safety Considerations

7. Electrical Performance

7.1 Electrical Basis for Comparison of Cables

7.2 Choice of Type of Cable for Comparison

7.3 Baeie for Choice of Type and Thicknees of Ineulation

7.4 Description of Ampacity Calculation

7.5 Results of Equivalence Calculations

7.6 Sensitivity of Results to Changes in Assumed Parameters

7.7 Possibilities for, and Consequences of, Thinner Insulation

7.8 Connectors

7.9 Conclusions for Electrical Performance

8. Energy and Materials Impact

8.1 Energy Requiremente of Cable Material

8.2 Energy Expended Per Unit Length of Cable

8.3 Energy Requirements and Savings

8.4 Material Avallability and Long Term Market Projections

8.5 Conclusions for Energy and Materials 


\section{Table of Contents}

(continued)

9. Economic Analysis

9.1 Methodology Used

9.2 Construction of Cable Costs

9.3 Comparison of Aluminum and Sodium Cable Costs

9.4 Salvage and Disposal Costs

9.5 Future Market Survey for Energy Savings

9.6 Conclusions from the Economic Analysis

Referenres

Appendix Al - Annotated Bibliographies of Pubilcations Related to Sodjum Conductor Cahle

Appendix A2 - Questionnaire for Utility Survey

Appendix A3 - Ampacity Tables

Appendix A4 - Aluminum and Sodium Cable Cost Details

Appendix A5 - Connector Cost Details

Appendix A6 - Additional Application Cost Data

Appendix A7 - Functions Used in Computer Analysis of Present Worth Costs and Cable Material Costs 


\section{LIST OF TABLES}

Table 2-1 Barriers Against Using Sodium Conductor Distribution Cable Table 2-2 Incentives for Using Sodium Conductor Distribution Cable.

Table 3-1 Ampacity Ratings $A_{1 j}$ for Curductor Cables (Aluminum Cable)

Table 3-2 Ampacity (Conductor Diameter) Ratings for Program Conductor Cables (Sodium Cable)

Table 5-1 Utility Survey: Installed Sodium Cable Specifications

Table 5-2 Comparison of Diameter, Weight and d-c Resistance (@ $25^{\circ} \mathrm{C}$ and $75^{\circ} \mathrm{C}$ ) for Copper and Sodium Conductors

Table 5-3 Ampacities of Polyethylene Insulated Copper and Sodium Conductors in Air and Earth

Table 5-4 Utility Survey: Sodium Cable Load History

Table 5-.5 Utility Survey: Sodium Cable Failure History

Table 5-6 Utility Survey: Sodium Cable Installed Cost

Table 5-7 Utility Survey: Compilation of Reported Installed Cost for Direct Burfed $\mathrm{Al}$ and $\mathrm{Cu}$ Cable

Table 5-8 Utility Survey: Compilation of Reported Cost Breakdown for Installing Direct Buried $\mathrm{Al}$ and $\mathrm{Cu}$ Cable

Table 5-9 Utility Survey: Summary of Installation Experience for Sodium Conductor Cable

Table 5-10 Major Advantages and Disadvantages of Sodium Cable as Reported in the Utility Survey

Table 6-1 Physical Properties and Characteristics of Sodium

Table 6-2 Possible Personnel Hazards from Handling Sodium

Table 6-3 Safety Precautions for Handling Sodium Conductors

Table 6-4 Sodium Scrap Disposal Test

Table 7-1 PE and XLPE Cable Yield Strength vs. Temperature

Table 7-2 Permeability of Polyethylene Cable to Moisture 


\section{LIST OF TABLES}

(continued)

Table 7-3 Resistance Increases of Five-Month Water-Immersed Sodium Cables and Calculated Times for this Increase to Occur

Table 7-4 Summary of the Properties of Sodium Cable Compared to the Equivalent Aluminum Cable

Table 7-5 Resistivity of Molten Sodium at Various Temperatures

Table 8-1 Energy Expended to Obtain Materials

Table 8-2 Data to Calculate Energy Expended to Obtain Feedstock Materials for Cable

Table 8-3 Comparison of Equivalently Rated Aluminum and Sodium Cable to Obtain Energy Expended for Materials

Table 8-4 Comparison of Energy Expended for Base Materials for Aluminum and Equivalent Sodium Cable

Table 9-1 Material Specific Gravities and Insulation Thickness Used in Constructing Cable Material Costs

Table 9-2 Material Prices Used in Estimating the Cable Costs

Table 9-3 Cable Material Cost Forecasts ( $c / 1 b)$

Table 9-4 Estimated Cost of Cable to Electric Utilities ( $\mathrm{c} / \mathrm{ft}$ )

Table 9-5 Comparison: Sodium and Aluminum Cable Costs ( $c / f t$ )

Table 9-6 Aluminum and Sodium Cable Owning and Operating Costs; Thermal Ampacity Limit, Loss Factor $=1.0$, Peak Responsibility Factor $=1.0$

Table 9-7 Aluminum and Sodium Cable Costs Neglecting Losses

Table 9-8 Sensitivity of Aluminum and Sodium Cable Owning and Operating Costs to Changes in Application Parameters

Table 9-9a Connector Cost Per Foot of Cable; Based on Application Shown in Figures 9-2 and 9-3 - (a) Three Phase Primary Feeder

Table 9-9b Connector Cost Per Foot of Cable; Based on Application Shown in Figures 9-2 and 9-3 - (b) Single Phase Lateral 


\section{LIST OF TABLES}

(continued)

Table 9-9c Connector Cost Per Foot of Cable; Based on Application shown in Figures $9-2$ and $9-3$ - (c) 600V Secondary and Service Cable ( $c$ per ft.)

Table 9-10 Total Present Worth Savings' ( $\left.\$ / f t_{.}\right)$

Table 9-11 Details of Present Worth Savings ( $\$ / f t$.

Table 9-12 Present Worth Savings: Present, 10 Years, and 25 Years in the Future for $15 \mathrm{kV}$ Cable

Table 9-13 Present Worth Savings: Present, 10 Years, and 25 Years in the Future for $35 \mathrm{kV}$ Cable

Table 9-14 Estimated Installed Costs Per Foot for Sodium and Aluminum Cable

Table 9-15 Cable Salvage and Disposal Costs Per Foot

Table 9-16 Annual Energy Savings of Sodium Over Aluminum Cable for Specified Market Penetration

Table A3-1 DC Resistivities of Sodium and Aluminum vs. Temperature \& A3-2

Table A3-3 Aluminum Cable Ampacity at Normal Load, Direct Burial (Conductor at $90^{\circ} \mathrm{C}$ )

Table A3-4 Aluminum Cable. Ampacity at Overload, Direct Burial (Conductor at $130^{\circ} \mathrm{C}$ )

Table A3-5 Sodium Cable Ampacity at Overload, Direct Burial (Conductor at $95^{\circ} \mathrm{C}$ )

Table A3-6 Sodium Cable Conductor Temperature at Normal Load Current, Direct Burial

Table A3-7 Aluminum Cable Ampacity at Normal Load (Conductor at $90^{\circ} \mathrm{C}$ ) and at Overload (Conductor at $130^{\circ} \mathrm{C}$ ), Direct Burial, 600 Volt Cable

Table A3-8 Sodium Cable Ampacity at Overload (Conductor at $95^{\circ} \mathrm{C}$ ) and Conductor Temperature at Normal Load Current Direct Burial, 600 Volt Cable, IPCEA Insulation Thicknesses 
$\frac{\text { LIST OF TABLES }}{\text { (cOMEInUEd) }}$

(continued)

Table A3-9 Sodium Cable Ampacity at Overload (Conductor at $95^{\circ} \mathrm{C}$ ) and Conductor Temperature at Normal Load Current, Direct Burial, 600 Volt Cable, Insulation Thickness 0.160 inches.

Table A3-10 Sodium Cable Ampacity at Overload (Conductor at $95^{\circ} \mathrm{C}$ ) and Conductor Temperature at Normal Load Current, Direct Burial, 600 Volt Cable, Insulation Thickness 0.205 inches.

Table A3-11 Aluminum Cable Ampacity at Normal Load, Cable in Duct (Conduetor at $90^{\circ} \mathrm{C}$ )

Table A3-12 Aluminum Cable Ampacity at Overload,Cable in Duct (Cunductor at $130^{\circ} \mathrm{C}$ )

Table A3-13 Sodium Cable Ampacity at Overload, Cable in Duct (Conductor at $95^{\circ} \mathrm{C}$ )

Table A3-14 Sodium Cable Conductor Temperature at Normal Load Current Cable in Duct

Table A3-15 Aluminum Cable Ampacity at Normal Load (Conductor at $90^{\circ} \mathrm{C}$ ) and at Overload (Conductor at $130^{\circ} \mathrm{C}$ ), Cable in Duct, 600 Volt Cable

Table A3-16 Sodium Cable Ampacity at Overload (Conductor at $95^{\circ} \mathrm{C}$ ) and Conductor Temperature at Normal Load Current, Cable in Duct, 600 Volt Cable, TPC.EA Insulation Th1cknesses

Table A3-17 Sodium Cable Ampacity at Overload (Conductor at $95^{\circ} \mathrm{C}$ ) and Conductor Temperatureat Normal Load Current, Cable in Duct, 600 Volt Cable, Insulation Thickness 0.160 inches

Table A3-18 Sodium Cable Ampacity at Overload (Conductor at $95^{\circ} \mathrm{C}$ ) and Conductor Temperature at Normal Load Current, Cable In Ducl, 600 Vull Calle, Insulation Thicknejy 0.205 inchoo

Table A3-19 Sensitivity of Sodium Cable Ampacity to Insulation Thickness, Direct Burial, Sodium at $69^{\circ} \mathrm{C}$

Table A3-20 Sensitivity of Sodium Cable Ampacity to Insulation Thickness, Cable in Duct, Sodium at $69^{\circ} \mathrm{C}$

Table A3-21 An Example of Na-Al Equivalence at $\rho_{e}=130$

Table A3-22 An Example of Na-A1 Equivalence at $\alpha=1$ 


\section{LIST OF TABLES}

(continued)

Table A3-23 Cable in Duct Ampacity Calculations to Verify Against IPCEA Tables

Table A3-24 Direct Burial Ampacity Calculations to Verify Against IPCEA Tables

Table A4-1 $15 \mathrm{kV}$ Aluminum and Sodium Cost Details

Table A4-2 $25 \mathrm{kV}$ Aluminum and Sodium Cost Details

Table A4-3 $35 \mathrm{kV}$ Aluminum and Sodium Cost Details

Table A4-4 600V Aluminum and Sodium Cost Details 


\section{LIST OF FIGURES}

Figure 3-1
Figure 3-2 $\begin{aligned} & \text { Deriving the equivalent diameter and steady state } \\ & \text { temperature of sodium conductor cable with respect to } \\ & \text { aluminum conductor cable. }\end{aligned}$
$\begin{aligned} & \text { Calculation of present worth of sodium and aluminum } \\ & \text { conductor distribution cable total cost as function } \\ & \text { of cable diameter for one rated ampacity } A_{i j} \text {. (Direct } \\ & \text { Burial) }\end{aligned}$

Figure 4-1 Example of equivalent cable dimensions (Al:Na) for $35 \mathrm{kV}$, 1000 k.s mil rating (A1).

Figure 4-2 Methodology sequence for sodium cable assessment study.

Figure 7-1 Construction of cables of this report.

Figure 7-2 Ampacity of sodium cable as a function of insulation thickness and conductor size.

Figure 7-3 Thermal geometry of a buried cable.

Figure 7-4 Skin-effect @ $60 \mathrm{~Hz}$ for round wire or stranded cable vs. ratio of cross-sectional area $A$ to resistivity $P D C$.

$A$ in thousands of circular mils (KCM), $P_{D C}$ in microhm $\mathrm{cm}$.

Figure 8-1 Relationship of energy expended to obtain materials for sodium vs. aluminum conductor cables.

Figure 8-2 Ore grade variation, World $\mathrm{Al}$ and $\mathrm{Cu}$

Figure 8-3 Effect of ore grade on energy required per ton of product shipped.

Figure 9-1 Cable cost components.

Figure 9-2 Distribution feeder application.

F1gure 9=3 Transtormer-accondary-bervicu application.

Figure 9-4 An extensive primary feeder c1rcuit showing extended use of three-phase mains and single-phase laterals - suburbanurban area distribution.

Figure 9-5 Histogram representation of the present worth savings for case studies. 


\section{LIST OF FIGURES}

(Continued)

Figure 9-6 Sodium and aluminum cable present worth costs vs. conductor size - $15 \mathrm{kV}$ direct buried.

Figure 9-7 Present worth of cable costs and operating losses vs. size - $15 \mathrm{kV}$ direct buried.

Figure 9-8 Sodium and aluminum cable total present worth costs vs. conductor size $-15 \mathrm{kV}$ in ducts.

Figure 9-9 Present worth of cable costs and operating losses vs. size - $15 \mathrm{kV}$ in ducts.

Figure 9-10 . Sodium and aluminum cable total present worth costs vs. conductor size - 600 volt secondary application.

Figure 9-11 Present worth of cable and operating costs vs. size 600 volt secondary.

Figure 9-12 Sodium and aluminum cable total present worth costs vs. conductor size - 600 volt secondary, neglecting conductor costs.

Figure 9-13 Present worth of cable costs and operating losses vs. conductor size - $600 \mathrm{~V}$ secondary, no connectors.

Figure A5-1 Typical cable connectors similar to those used in estimating costs for 15 and $25 \mathrm{kV}$. (from Elastimold Catalogue)

Figure 45-2 Typical cable connectors similar to those used in estimating costs for $35 \mathrm{kV}$. (from Elastimold Catalogue)

Figure A5-3 Sodium cable connectors (from 'Sodium is New Cable Conductor' Power, September 1968).

Figure A5-4 Typical 600 volt secondary connection scheme used in estimating costo.

Figure A5-5 Typical connector cover used in cost. estimating.

Figure A5-6 Typical copper type secondary connectors used in developing the 'pin type' connection costs in this report.

Figure A5-7 600 volt sodium cable connectors (from 'Sodium is New Cable Conductor' by N. Peach, Power, Sept. 1968). 


\section{LIST OF FIGURES \\ (Continued)}

Figure A6-1 Total present worth costs versus conductor size $35^{\circ} \mathrm{kV}$ direct buried.

F1gure A6-2 Present worth costs vs. conductor size $35 \mathrm{kV}$ main feeder, 3 phase.

Figure A6-3 Total present worth costs vs. conductor size 600 volt service.

Figure A6-4 Present worth of cable, connector and operating losses G00 volt service. 


\section{ACKNOWLEDGEMENTS}

This study for the analysis of the barriers and incentives for using sodium conductor distribution cable was conducted by the Westinghouse Electric Corporation Research and Development Center. Acknowledgement is due to the following R\&D Center staff members: Dr. A. I. Bennett for the electrical performance analysis, Mr. A. R. Keeton for the utility survey as well as the safety and environmental analysis, Dr. P. F. Schweizer for the economic analysis, Dr. F. G. Arcella for the energy of materials analysis, and Mr. S. F. Mauser for overall program consultation.

Many other individuals and organizations contributed generously with their time and service toward the data base for this study. Our conversations and analytical discussions, their opinions, test data, experience, and catalogue data are gratefully acknowledged. We must point out that these contributors do not endorse or refute the conclusions of this study, but were extremely helpful in making available the information necessary for the conduct of this study.

A spectal acknowledgement is made to the Union Carbide Corporation for providing sodium cable technical data and manufacturing, testing, and cable distribution records (Nacon Corporation); and especially to Dr. R. M. Elchhorn of that organization for his cooperation, advice, and candid discussions.

We wish to thank the following people and their organizations for the helpful information supplied in response to the utility survey: 


\section{Name}

J. Taylor and P. Shoda

J. Medek and A. Wroblewski

E. Verheiden, R. James, N. Wight, Portland General Electric

C. Jensen and P. Harvison

F. Licini and H. Farnsler

C. Brown

Regional Utilitico

L. Burleson

J. Campbe11

W. Jones

A. Maguire and G. Brazil

H. Wilson, Jr.

E. Geary and W. Roche

J. Harper and G. Myers

E. Gruchalla

T. KIng and W. Schroeder

R. Ewing and W. Burnett, Jr.

E. Talhelm

H. Thomas

J. Alvarez

R. Braly

E. Battaglia and L. Roufllier
Organization

Whitley County Remc

Commonwealth Edison Company

Pennsylvania Power \& Light Company

Florida Power \& Light, Co.

City of Galnesville

P.U.D. No. 1 of Snohomisk County

Withlacoochee River Electric Coop.

Sacramento Municipal Utility Co. .

Arkansas Power \& Light Co.

Duke Power Co.

Boston Edison Company

Arizona Public Service Co.

Houston Lighting \& Power Co.

Wisconsin Power \& Light Co.

Texas Power \& Lighr Co.

Public 3ervice Company of Indiano

Long Island Lighting Co.

Salt River Project

Baltimore Gas \& Electric Co.

Gulf Power Co.

\section{Location}

Columbia City, Indiana

Maywood, Illinols

Portland, Oregon

Allentown, Pennsylvania

Miam1, F1or1da

Galnesville, Flurida

Everett, Washington

Dade City, Florida

Sacramento, California

L1ttle Rock, Arkansas

Clarlotte, North Carolina

Doston, Massachusetts

Phoenix, Arizona

Houston, Texas

Madison, Wisconsin

Dallas, Texas

Plainfield, Indiana

Hicksville, New York

Phoenix, Arizona

Baltimore, Maryland

Pensacola, Florida 
Name

T. Wray

B. Wise and H. Hildebrand

H. Stefanetti

G. Edwards

B. Corder and L. King

D. Mestas

K. Roberts

R. Ager

S. Gold

D. Trupp

E. Holcomb and D. Parvin

J. Lozes, Jr.

R. Craven, Jr.

H. DePriest

J. McBurney

C. Seaver

A. Crey

.T. Raudean
Organization,

Public Service Company of New Mexico

Ohio Power. Co.

Pacific Gas and Electric Co.

City of Anaheim

Garland Electric Dept.

Tampa Electric Co.

Jacksonville Beach Municipal Electric Dept.

Pennsylvania Electric Co.

Southern California Edison Co.

City of Tipp City Light and Power

Dallas Power \& Light Co.

New Orleans Public Service Inc.

Carolina Power \& Light Co.

Electr1c Power Board of

Chat tanooga

Wellesley Municipal Light

Texas Electric Service Co.

Appalachian Power Co.

Loulsiana Power \& Light Co.
Location

Albuquerque, New Mecixo

Canton, Ohio

San Francisco, California

Anaheim, California

Garland, Texas

Tampa, Florida

Jacksonville, Florida

Erie, Pennsylvania

Rosemead, California

Tipp C1ty, Ohio

Dallas, Texas

New Orleans, Louisiana

Raleigh, North Carolina

Chattanooga, Tennessee

Wellesley, Massachusetts

Fort Worth, Texas

Roanoke, Virginia

- $)$

New Orleans, Louisiana 
Extremely helpful technical consulation was also provided by

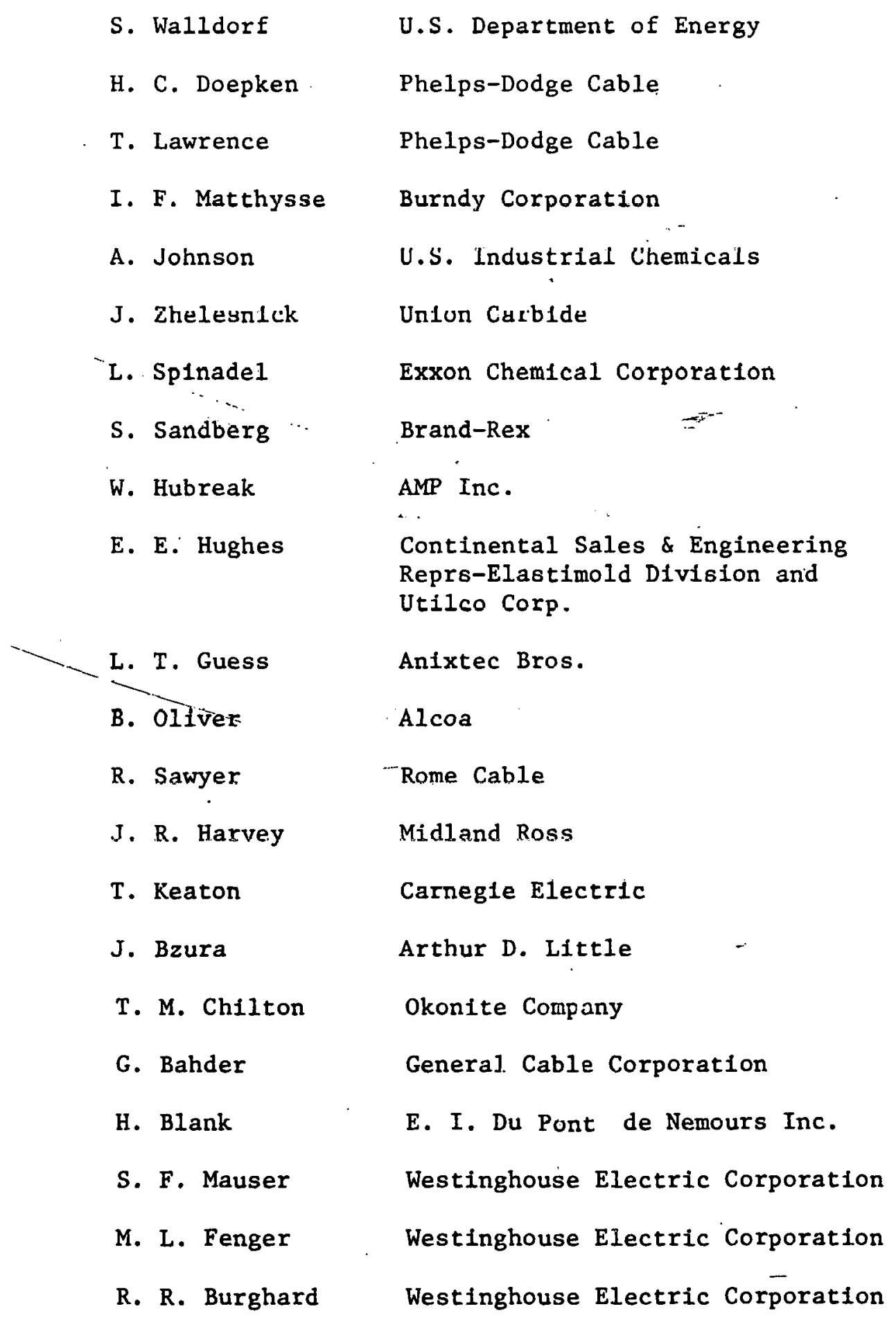


T. W. Dakin

Anita Newell

M. A. Braithwaite
Westinghouse Electric Corporation

Westinghouse Electric Corporation R\&D Library

Westinghouse Electric Corporation R\&D Library 


\section{SUMMARY}

Due to the recent energy consciousness of the nation and the need to conserve energy, a review of the barriers and incentives for using sodium conductor distribution cable was performed. With escalating energy costs, fuel costs, material costs, etc., it was felt that more economic distribution cable conductor metals (sodium over aluminum) and distribution cable with lower losses might provide sufficient incentive for the utility and commercial markets to switch to cable constructed with other materials. The Nacon Corporation, a sodium conductor distribution cable company which operated in the sixties, its customers, and their experiences formed the primary data base for this study: A detailed computer index and library literature search was performed. Interviews with Nacon Corporation technical people, utility engineers and tradesmen, and cable manufacturers were also conducted. The design of sodium conductor cable, terminations, installation, safety, handling, dig-ins, faults, performance, etc., were analyzed in comparison with aluminum conductor cable. Economic analyses were also performed for typical distribution installations and first cost, discounted cost of losses, future cost of capital, etc. were considered in the comparison. As a result of considering these environmental, safety, energy conservation, electrical performance, and economic factors, barriers and incentives for using sodium conductor distribution cable were derived. 


\section{CONCLUSIONS}

After extensive analysis, interviews, and discussions with interdisciplinary study team members, the following conclusions were formed for the barriers and incentives for using sodium conductor distribution cable:

\section{Historical, Safety, Environmental}

- A considerable amount of sodium cable experience (hundreds of mile-yeurs) has been amassed over the past 13 years, and this experience is: well documented in the literature.

- There is no doubt about the technical merit and performance of sodium cable as an electrical conductor, particularly for direct buried underground application.

- Terminals for sodium cable have been the cause of more than $98 \%$ of the sodium cable failures. Further connector development is required.

- Safety hazards relating to the sodium-water reaction are the greatest concern of utility personnel in relation to codium cable use. Ilowever, the safuty record relating to the manufacture, transportation, installation and operation of sodium cable over the past 13 years has been excellent.

- Most utilities report that sodium cable would have to show a clear-cut, substantial, total installed cost advantage before it would be seriously considered for widespread use. 
- In addition, sodium cable terminals and other hardware would have to be reliable, with availability assured, before sodium cable would be acceptable to most utilities.

- Sodium cable should only be employed in direct buried or duct installations.

\section{Electrical Performance}

- On the basis of equivalent overload ampacity, the electrical performance of sodium conductor cable is equal to or better than that of aluminum or copper cable.

- Polyethylene insulation thicknesses specified by IPCEA, NEMA, and ÁEIC for conventional cable will provide sufficient mechanical pull strength for sodium cable installation in ducts. Cross-1inked polyethylene will not be required.

- A vapor barrier facket appears necessary for the long life performance of sodium conductor cable if it is operated at rated ampacity_and high moisture conditions.

- The corona onser voltage behavior of sodium cable is better than that of the equivalent aluminum or copper cable.

\section{Economic Considerations}

- The present worth costs of owning and operating sodium distribution cable on a typical underground primary distribution system yields a savings of approximately $10 \%$ when compared to aluminum. 
- Generally, there are no savings on a secondary distribution system with existing connector designs because of the increased cost and larger number of connectors required.

- With an optimistic market penetration, energy savings could approach 2 billion $k$ Th annually by the year 2000. (One nuclear power plant produces 7 billion $\mathrm{kWh}$ annually base load).

Energy aud Materials

- The difference 1n energy expended to obtain sudium electrical cable materials over aluminum cable materials is less than $1 \%$ of the difference in energy losses between these two equivalent cables over a 25 year life.

- Although the energy required to refine aluminum is expected to drop due to a new process, and that of cupper should increase due to lower concentration ores, and sodium refining energies should remain unchanged, these conolderatiois should present no serious impact on the relative energies or costs of sodium or aluminum cable.

- World and United States supplies of copper, aluminum, and sudlum are projected to be adequate to permit manufacture of cable from any of these conductor materials.

The tolluwling rables present the barriers (Table 2-1) and incentives (Table 2-2) for using sodium conductor distribution cable. Although both tables could be of considerable length, only items considered to be of major pertinence have been presented. 


\section{TABLE 2-1}

Barriers Against Using Sodium Conductor Distribution Cable

- Concern about safety because of the highly reactive nature of sodium with water.

- The reliability, expense and availability of sodium cable connectors and other hardware.

- Reluctance to change.

- Concern about special training of personnel for handling sodium cable.

- Concern about liability of abandoned sodium cable or the expense of removal and disposal of discontinued circuits.

- Possibility of sodium cable failure due to a long term slight overload causing the sodium to liquify.

- Possible requirement for a vapor barrier jacket.

- Connector costs at present are significantly higher (1.1 to 2 times) for sodium than aluminum. Even with improved designs there are reasons to believe sodium connector costs will remain above aluminum. 
TABLE 2-2

Incentives for Using Sodium Conductor Distribution Cable

- Owning and operating costs $10 \%$ less than aluminum cable for a typical distribution system. This could be $30 \%$ for express type feeder.

- Lightweiglil and flexible nature of sodium cable makes handling easier.

- Greater resistance to installation damages.

- Ability of sodium cable to withstand high short circuit, short duration currents without insulation failure.

- High corona inception voltage of sodium cable.

- The elose thermal expansion match of sodium and polyethylene. 


\section{INTRODUCTION}

In 1965 the Union Carbide Corporation announced the development of a new underground cable using sodium as a conductor. For five years the Nacon Corporation promoted sodium conductors and over $1 / 2-m i 11$ ion conductor feet of sodium conductor solid dielectric distribution cable was installed and energized at many utilities. The espoused economic advantages did not materialize - utility demand for the cable was insufficient to support the capital investment in plant and facilities. In mid-1970 Nacon announced that it was withdrawing from the sodium conductor market. The sodium cable failed commercially because the cost savings on a complete installation basis did not yet yield the advantages that the base metal cost analysis indicated and the utilities expressed serfous concerns over safety and disposal (these specific problems were not at that time addressed in sufficlent detall to provide informed answers).

Recently, the economic situation has changed significantly as the cost of energy has increased. From an energy conservation standpoint and an economic viewpoint, sodium distribution cables may be economically fustifiable, but the utility safety concerns over the use of sodium conductur cables have never been fully quantified.

The objective of this study has been to assess the barriers and incentives for using sodium conductor distribution cable. The assessment has considered environmental, safety, energy conservation, electrical performance and economic factors. Along with all of these factors considered in the assessment, the sodium distribution cable system was also compared to the present day alternative - an aluminum conductor system. 
A literature search and utility survey were conducted to determine the current use and problems associated with sodium distribution cables in service or those removed after trial evaluations. The following information was obtained: (1) Cable specifications; (2) Load history, operating experience and operating expenses; (3) Installed cable cost and difficulties encountered during installation; (4) Maintenance cost and special procedures followed; and (5) Safety problems if any.

The amount of feedstock materials required to fabricate sodlum vs. aluminum va. rnpper cablc was fouml, all the energy expended to obtain those feedstocks from raw materials was noted. Continued malerlals availability and long-term market profections for base materials were made.

Environmental and safety considerations were developed for sodium conductor cable and included: ' (1) Cable handling by the manufacturer, shipper, and utility contractor; (2) Field installation; (3) Dig-in consequences; (4) Fault consequences, either system fault or cable breakdown; (5) Scrap handling; and (6) Discontinued circuit removal or abandonment.

An economic assessment was also completed. It included considerations of: (1) Cable costs; (2) Installation - both direct buried and in ducts; (3) Operating and maintenance costs over a 25 year life; (4) Cost of losses capitalized to 1977, using referenced cost and annual carrying charges; and (5) Ultimate disposal costs.

An analytic computer program was written for the economic analysis and was operated with input data for sodium and for aluminum cinduclur Ilstribucion cable. The program was general so that future use would be possible with appropriate data in that use period. Also, provision was made for the future inclusion of copper conductor data by others. Economics and energy use factors were considered in three time frames - present, 10 years in future, and 25 years in the future. All future extrapolation of expected costs, material availability, energy costs, etc. were based (and documented) on extrapolations by 
accepted industry sources. The economic analysis considered the $600 \mathrm{~V}, 15 \mathrm{kV}, 25 \mathrm{kV}$ and $35 \mathrm{kV}$ voltage classes with equivalent aluminum conductor sizes of $250-\mathrm{kcmil}, 350-\mathrm{kcmil}, 750-\mathrm{kcmil}$, and $1000-\mathrm{kcmil}$ as a minimum consideration.

Considerable explanation must be presented at this point to clarify the selection for basis upon which to perform the comparative $\mathrm{Na}$ :A1 conductor analysis. Consider Figure 3-1a. Each of the commercially rated aluminum conductor distribution cables of Table 3-1 (i.e., ampacities $A_{i j}$ ) were evaluated for rated performance at a steady state conductor temperature of $90^{\circ} \mathrm{C}$ at a ground temperature of $20^{\circ} \mathrm{C}$ and a ground thermal resistivity (rho) of $90\left({ }^{\circ} \mathrm{C} \mathrm{cm} /\right.$ watt). The overload rating (i.e., steady state $A_{i j}^{\prime}$ ) of the same aluminum conductor cable at a conductor temperature of $130^{\circ} \mathrm{C}$ was also identified, i.e., Figure 3-1b.

The steady state overload ampacity rating of the aluminum conductor cable for the $130^{\circ} \mathrm{C}$ conductor temperature was also selected as the overload ampacity of the sodium cable. However, the steady state overload temperature of the sodium conductor was selected as $95^{\circ} \mathrm{C}$. Thus the sodium, for normal overload and fault conditions, was not permitted to liquify. This conservative appruach was expected to be more palatable to potential utility customers, and would reserve the heat of fusion of the liquid sodium as an overload short circuit delay to permit breakers and other equipment to operate.

The $A_{i j}^{\prime}$ overload ampacity at a $95^{\circ} \mathrm{C}$ conductor temperature allowed the diameter of the sodium cable to be determined (Figure 3-1c). Since the electrical insulation will act as a thermal barrier, several iterations of the diameter calculation were made with varying insulation thicknesses to observe the impact of such insulation thickness variations on the overload diameter. The sodium cable insulation thickness was not influenced by other parameters such as required tensile strength for duct installation (i.e., pull strength), water vapor intrusion protection, as well as existing insulation thickness standards for voltage ratings and conductor sizes. 

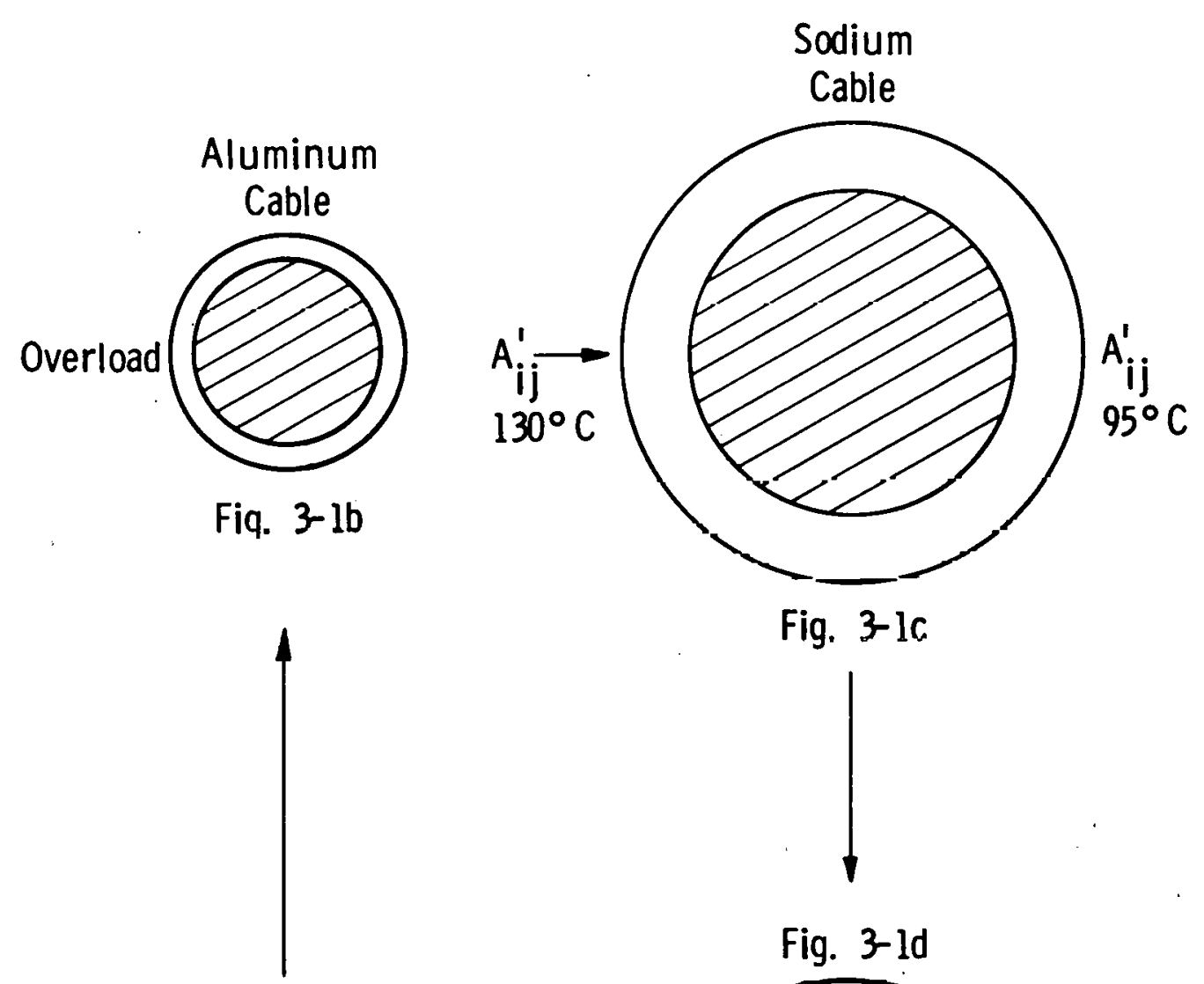

Fig. 3-1c.

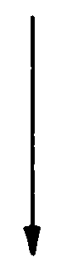

Fig. 3-ld

Fig. 3-la

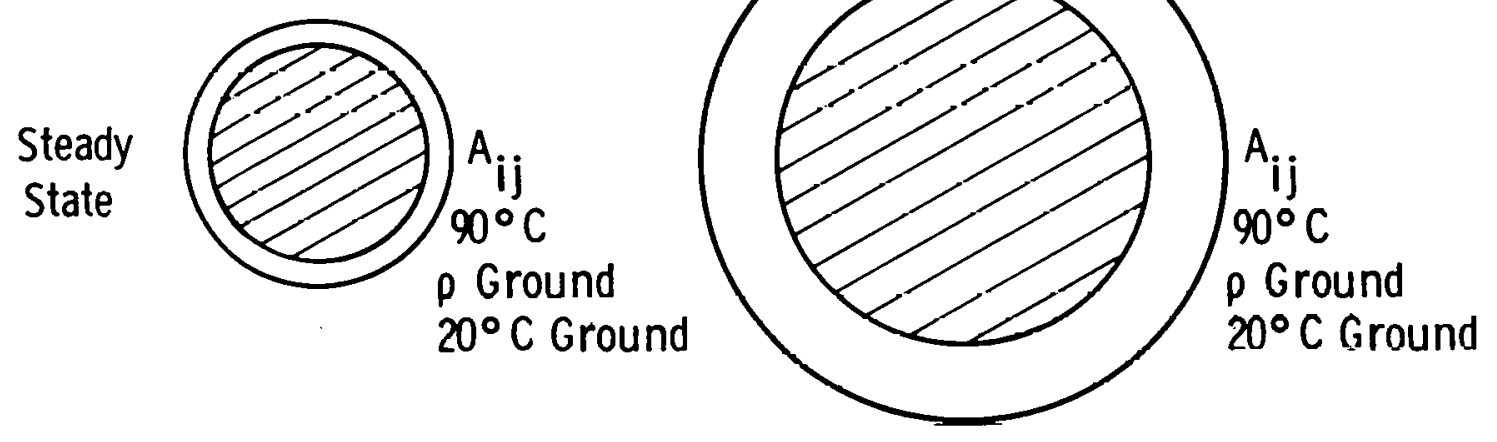

Fig. 3-1 - Deriving the equivalent diameter and steady state temperature of sodium conductor cable with respect to aluminum conductor cable 
TABLE 3-1

\section{Ampacity Ratings $A_{i j}$ for Conductor Cables (Aluminum Cable)}

$\begin{array}{ccccc}\begin{array}{c}\text { Conductor } \\ \text { Area }\end{array} & \text { 600V } & \underline{15 \mathrm{kV}} & \underline{25 \mathrm{kV}} & \underline{35 \mathrm{kV}} \\ 250-\mathrm{kcmil} & \mathrm{A}_{11} & \mathrm{~A}_{12} & \mathrm{~A}_{13} & \mathrm{~A}_{14} \\ 350-\mathrm{kcmil} & \mathrm{A}_{21} & \mathrm{~A}_{22} & \mathrm{~A}_{23} & \mathrm{~A}_{24} \\ 750-\mathrm{kcmil} & \mathrm{A}_{31} & \mathrm{~A}_{32} & \mathrm{~A}_{33} & \mathrm{~A}_{34} \\ 1000-\mathrm{kcmil} & \mathrm{A}_{41} & \mathrm{~A}_{42} & \mathrm{~A}_{43} & \mathrm{~A}_{44}\end{array}$


Once the overload diameter for a $95^{\circ} \mathrm{C}$ conductor temperature for the sodium conductor cable was established, the steady state operating condition at normal ampacity ratings (i.e., $A_{i j}$ ) was determined. The same ground thermal resistivity and earth temperature $\left(20^{\circ} \mathrm{C}\right)$ as those of Figure 3-1a prevalled. Thus, Table 3-2, the ampacity: diameter ratings for sodium conductor distribution cable, was formed. These diameters were the smallest diameters that one would use in fabricating a sodium conductor distribution cable of ampacity rating $A_{i j}$.

The amparity ratinge $\Lambda_{i j}$ of Tablco 31 and $3-2$ were employed to generate Figures such as that shown in Figure 3-2. The $y$-axis is present worth in $\$ / f t$ (installed) and the $x$-axis is conductor diameter. Plots of Figure 3-2 were made for each of the three time periods (present, 10 years, 25 years future). The materials cost increases with increasing diameter for each, whereas the cost of losses decreases with increasing diameter of each. The optimum minimum present worth occurs at a different diameter and temperature for each, but not necessarily at the same present worth. The graphics were calculated as follows:

The present worth of the cost of installed rahle $\mathrm{PW}_{\mathrm{cos}}$ is $\$ / \mathrm{ft}$ and/or $\$ / \mathrm{mi}$. + Installed connector + energy losses + capacity costs + operation and maintenance and salvage, and can be written as:

$$
\begin{aligned}
\mathrm{PW}_{C C}= & \sum_{i=1}^{N} \frac{\left(\mathrm{C} \Lambda \mathrm{B}_{0}+\mathrm{CON}_{0}\right)}{(1+\mathrm{d})^{i}} \operatorname{ACC} 1 \\
& \sum_{1=1}^{N} \frac{(1+\mathrm{g})^{2 i}}{(1+\mathrm{d})^{1}} I_{0}^{2} r\left[\left(1+e_{c}\right)^{i} P_{c_{0}}+P_{\phi_{0}}\left(1+\theta_{0}\right)^{i}\left(L_{s} F\right)\right] \\
+ & O A M+S A L
\end{aligned}
$$




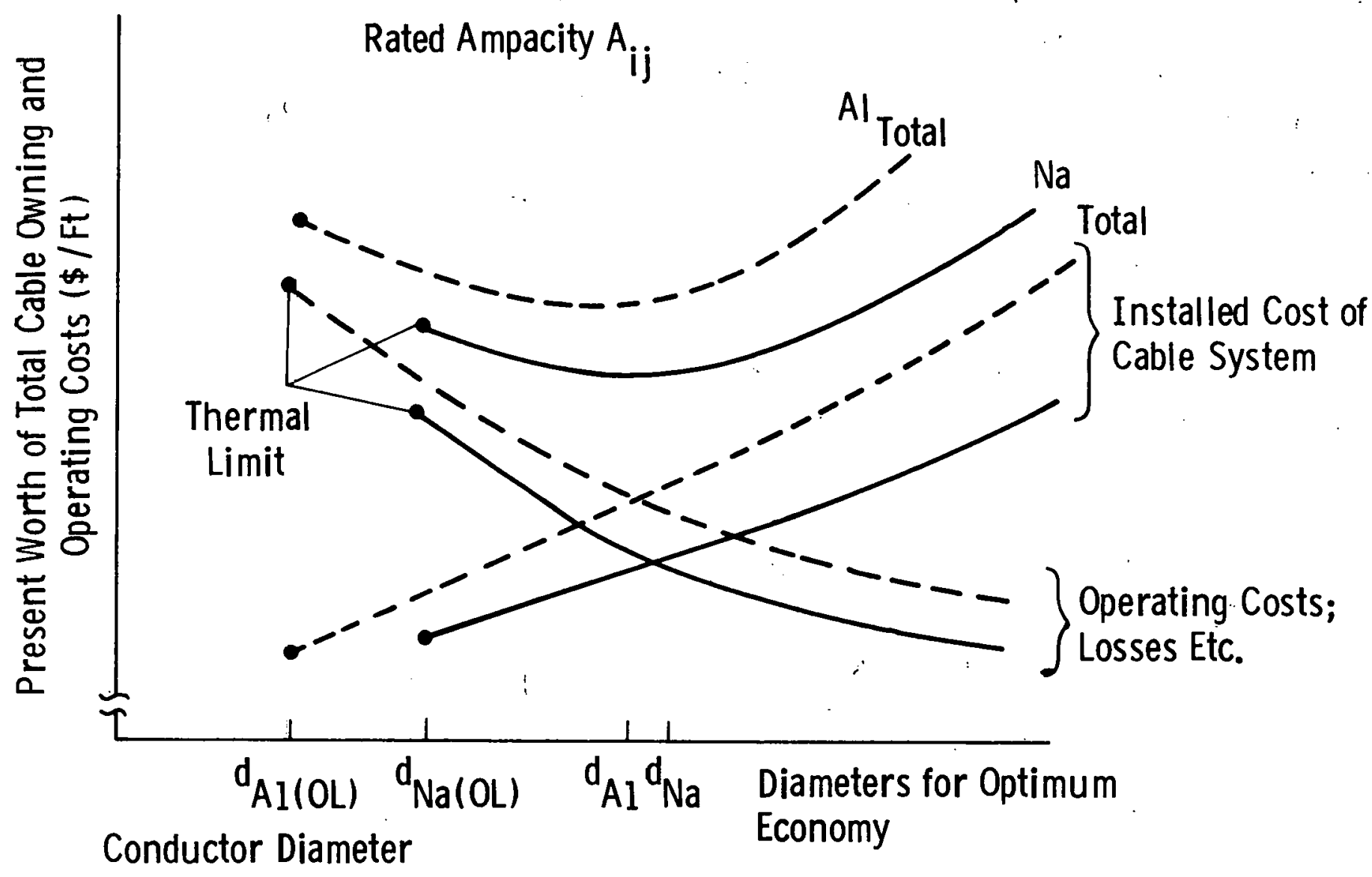

Fig. 3-2- Calculation of present worth of sodium and aluminum conductor distribution cable total cost as function of cable diameter for one rated ampacity $A_{i j}$ (Direct burial) 


\section{TABLE $3-2$}

Ampacity (Conductor Diameter) Ratings for Program Conductor Cables (Sodium Cable)

$$
\begin{array}{llllllll}
A_{11}\left(D_{11}\right)^{*} & A_{12} & \left(D_{12}\right) & A_{13} & \left(D_{13}\right) & A_{14} & \left(D_{14}\right) \\
A_{21} & \left(D_{21}\right) & A_{22} & \left(D_{22}\right) & A_{23} & \left(D_{23}\right) & A_{24} & \left(D_{24}\right) \\
A_{31} & \left(D_{31}\right) & A_{32} & \left(D_{32}\right) & A_{33} & \left(D_{33}\right) & A_{34} & \left(D_{34}\right) \\
A_{41}\left(D_{41}\right) & A_{42} & \left(D_{42}\right) & A_{43} & \left(D_{43}\right) & A_{44} & \left(D_{44}\right)
\end{array}
$$

* where $A_{1 j}$ is the same as the ampac1ty for aluminum conductor cable shown in Table $3-1$, but $D_{i j}$ identifies a sodiüm conductor diameter (area). 
where

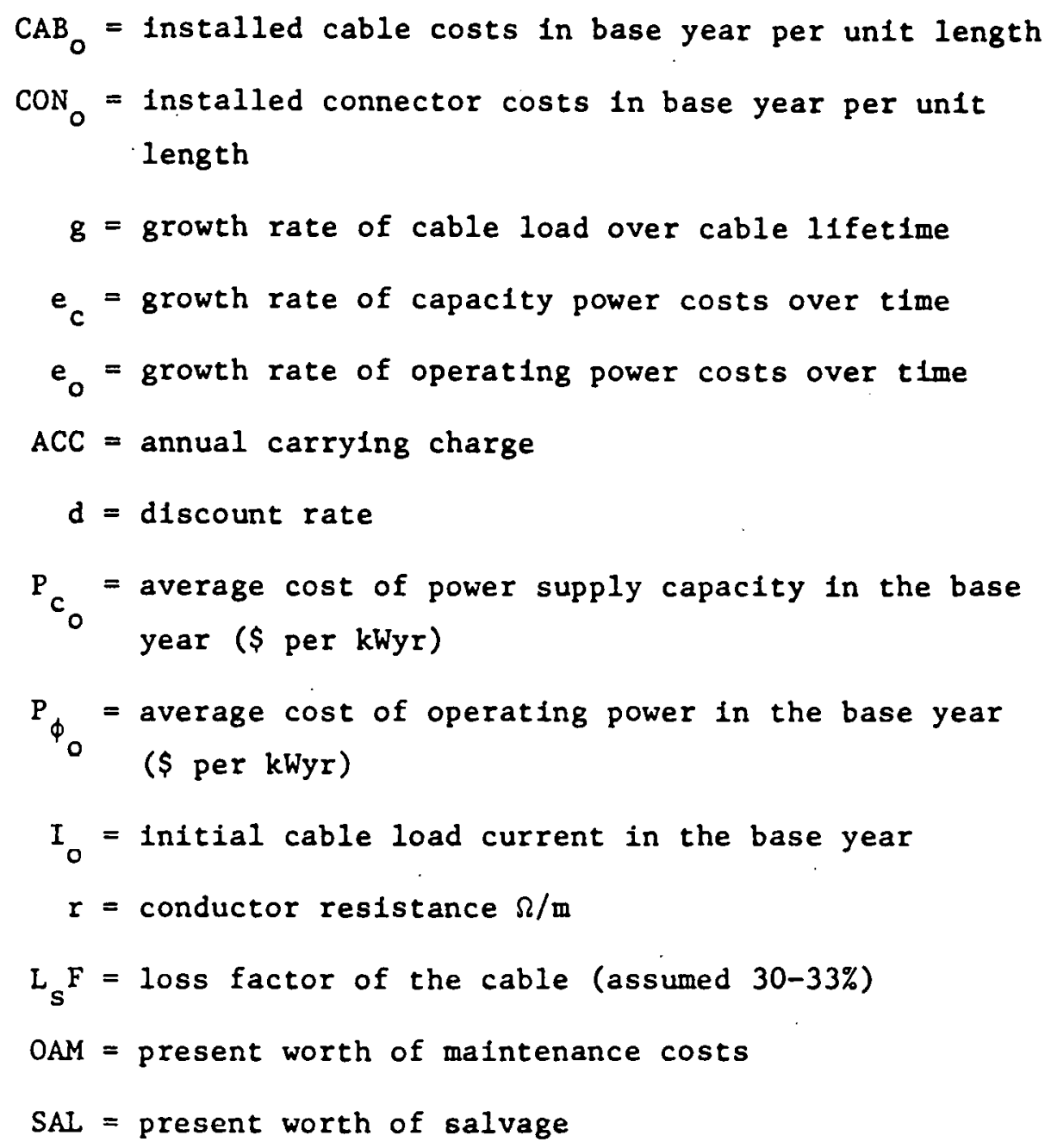


A splice to a riser was used for the sodium conductor cable analysis since most centers presently use a heavier riser to the distribution center. Different thicknesses of insulation were considered for direct burial versus duct installation of sodium conductor cable. The selection of insulation material polyethylene (PE) vs. cross-linked polyethylene (XLPE), was based upon thermal, mechanical, and electrical stress considerations. The cost of insulation was also considered as a function of time. The growth rate of load current ( $g$ ) over the çable lifetime was used to show sensitivity for one voltage r.lass for each case. The growth rates of power cost $\left(e_{c} \& \cdot e_{0}\right)$ over time can vary by factors of 6 or 7 depending upon area of country and utility selected. Appropriate rationale for the selected values of " $e_{c} \& e_{0}$ " was presented in the analysis. To cost the sodium conductor distribution cable installation, a typical network system was assumed to join an existing, operating facility, thus permitting easy expansion.

An assessment of the electrical capability of the sodium vs. aluminum conductor cables was performed and included consideration of: (1) Normal vs. emergency ampacity; (2) Fault consequences; (3) Temperature limitations and consequences of a thermal runaway situation; (4) Dig-in consequences; (5) Splice and termination limitations; and (6) Jacket limitations. $\Lambda$ part of the electrical perfornance capabillty assessment included consideration of insulation thickness requirements for electrical, installation, and thermal performance of the sodium conductor distribution cable. Equal pulling lengths of aluminum and sodium conductor cable were used to set the cross-sectional area of polyethylene (PE) or cross-linked polyethylene.(XLPE). Sidewall pressures were included in consideration in determining pull strength, 1.e., bearing on 1nsulacion thickness. It was assumed that a concentric neutral (or ground wire) provides no strength. All strength was assumed to derive from the insulation and conductor. The pull strength required was calculated using the highest temperature nurully found during installations ( $\sim 100-120^{\circ} \mathrm{F}$ in sumner); for a duct installation, the active cable was assumed to be at the lower duct temperature. A 
rationale for when to use or not use XLPE was developed based not only on pull strength, but temperatures, electrical stress, etc.

All of these considerations, environmental, safety, economic, energy conservation, etc., were included in the assessment of the barriers and incentives for using sodium conductor distribution cable; and are described in detail in their respective sections of this report. 


\section{GOALS OF THE STUDY}

The goals of the study, after a thorough assessment of safety, economic, environmental, and electrical performance characterlstics of both sodium and aluminum conductor distribution cable, are to project whether oufficient ineentive/barrlers exist fur a iledi declslun to be made for or against the employment of sodium conductor distribution. cable. The selection of the basis for comparison between these two cables was thought to be critical to this assessment in the economic and electrical performance analysis, but not to the more subjective safety, environmental, etc. analysis. The criterion of equivalent ampacity at overload conditions, with sodium cable at $95^{\circ} \mathrm{C}$ maximum (i.e., - solid), was conservatively chosen as being must acceptable to potential utility and commercial customers. Fortunately, the economic analysis showed larger diameter conductors for both cables to be lower in overall cost (i.e., including losses discounted to the present) and thus supported the basis for comparison as a lowest diameter allowable. Figure 4-1 reiterates earlier figures (1,e.. Figure 3-1) in showing that comparing $\mathrm{Na}: \mathrm{Al}$ at equal overload ampacities (maximum steady state

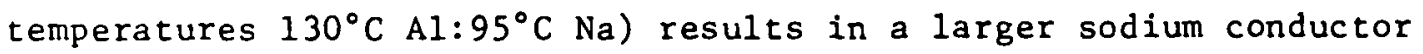
dlameter, and a lower operating temperature at rated ampacity. The methodology of performing the study is shown in Figure 4-2. which shows the natural progression of analysis from Information Source, to Performance Analysis, to Economic Comparison, to Conclusions. Each area of analysis or consideration was performed by a specialist in that area, and crosslinking of analytical considerations was achieved in project team meetings. 
Dwg. 6447A43

4. lb-Overload Ampacity: 912

4. $\mathrm{lC}$ - Limit $95^{\circ} \mathrm{C}$ at Overload

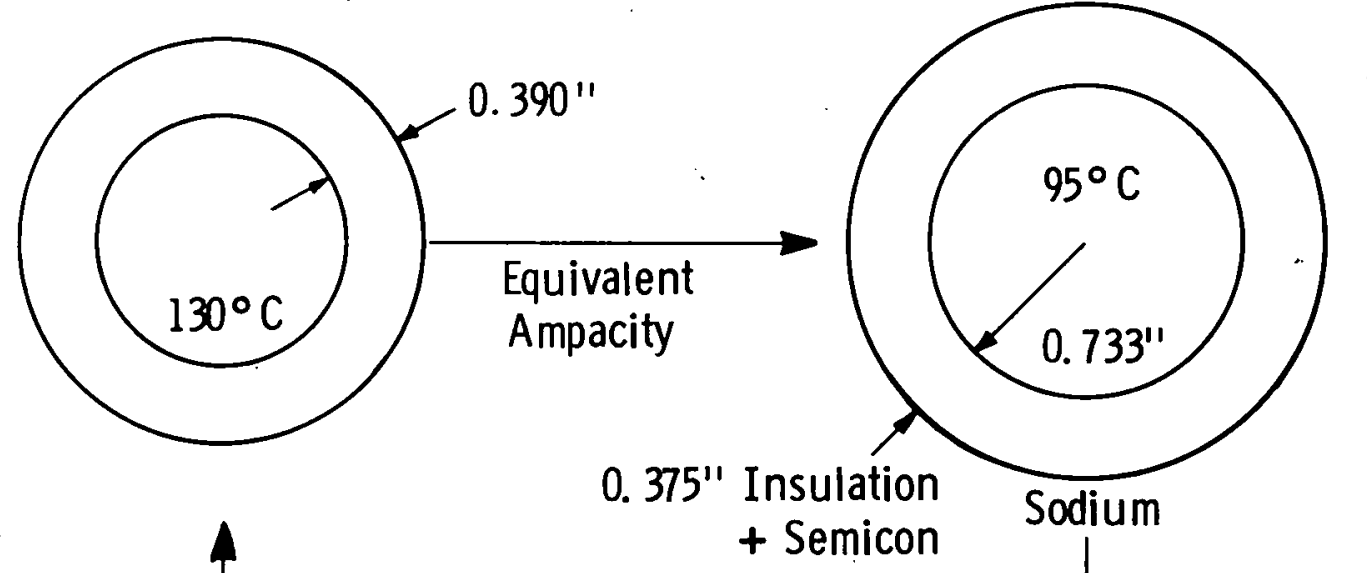

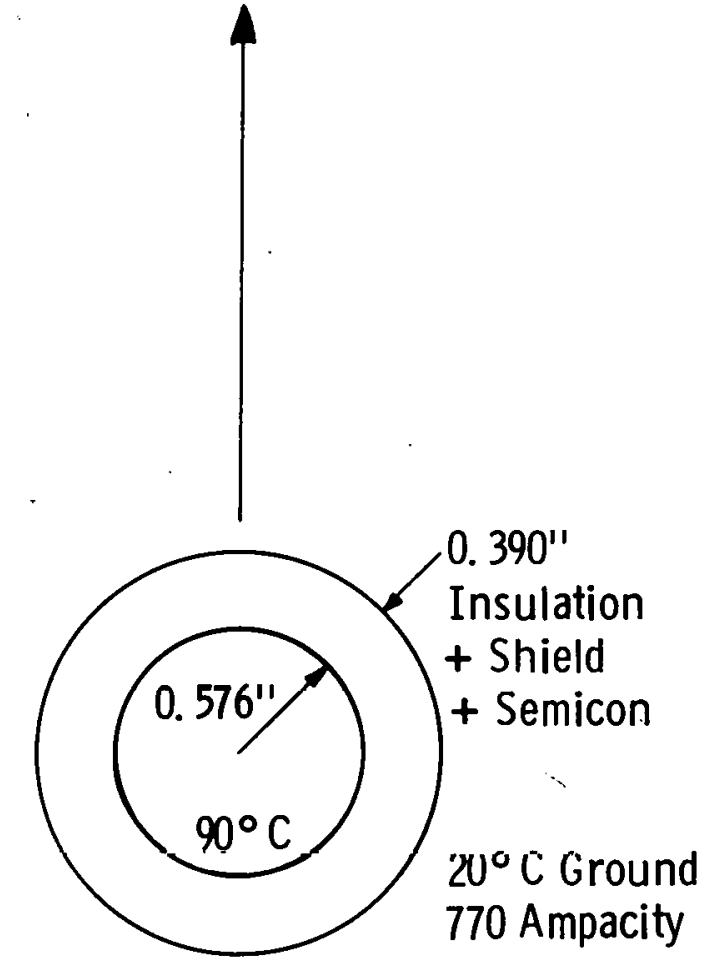

4. la - Aluminum at Rated Ampacity

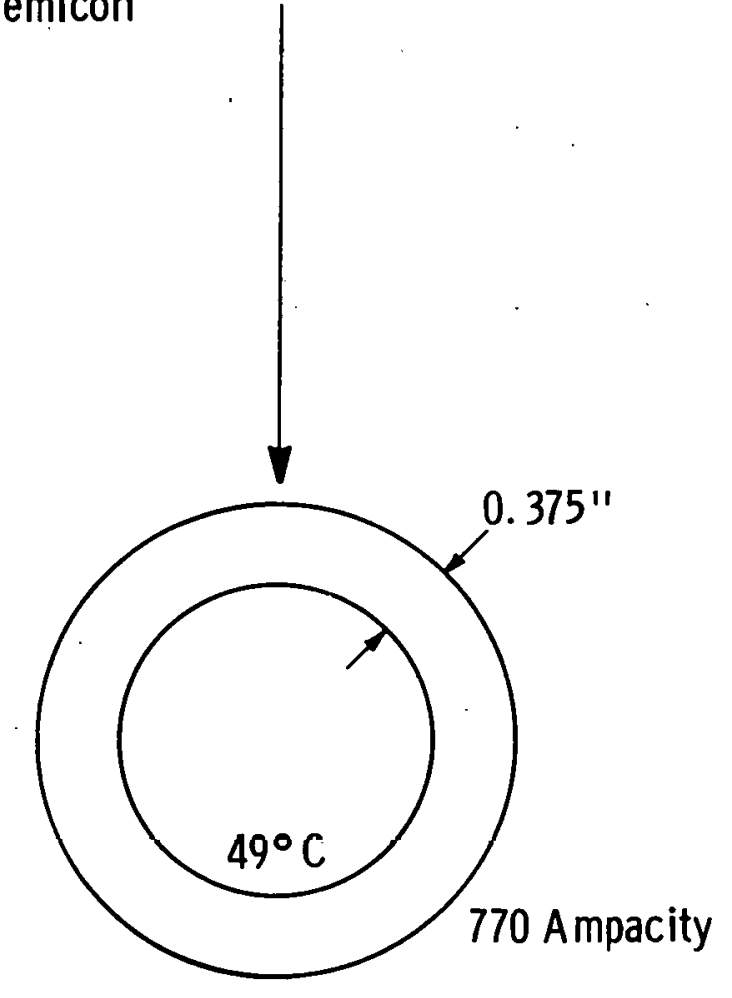

4. 1d - Sodium at Rated Ampacity

Fig. 4-1 - Example of equivalent cable dimensions ( $\mathrm{Al}: \mathrm{Na}$ ) for $35 \mathrm{kV}$, $1000 \mathrm{kC}$ mil rating (Al) 


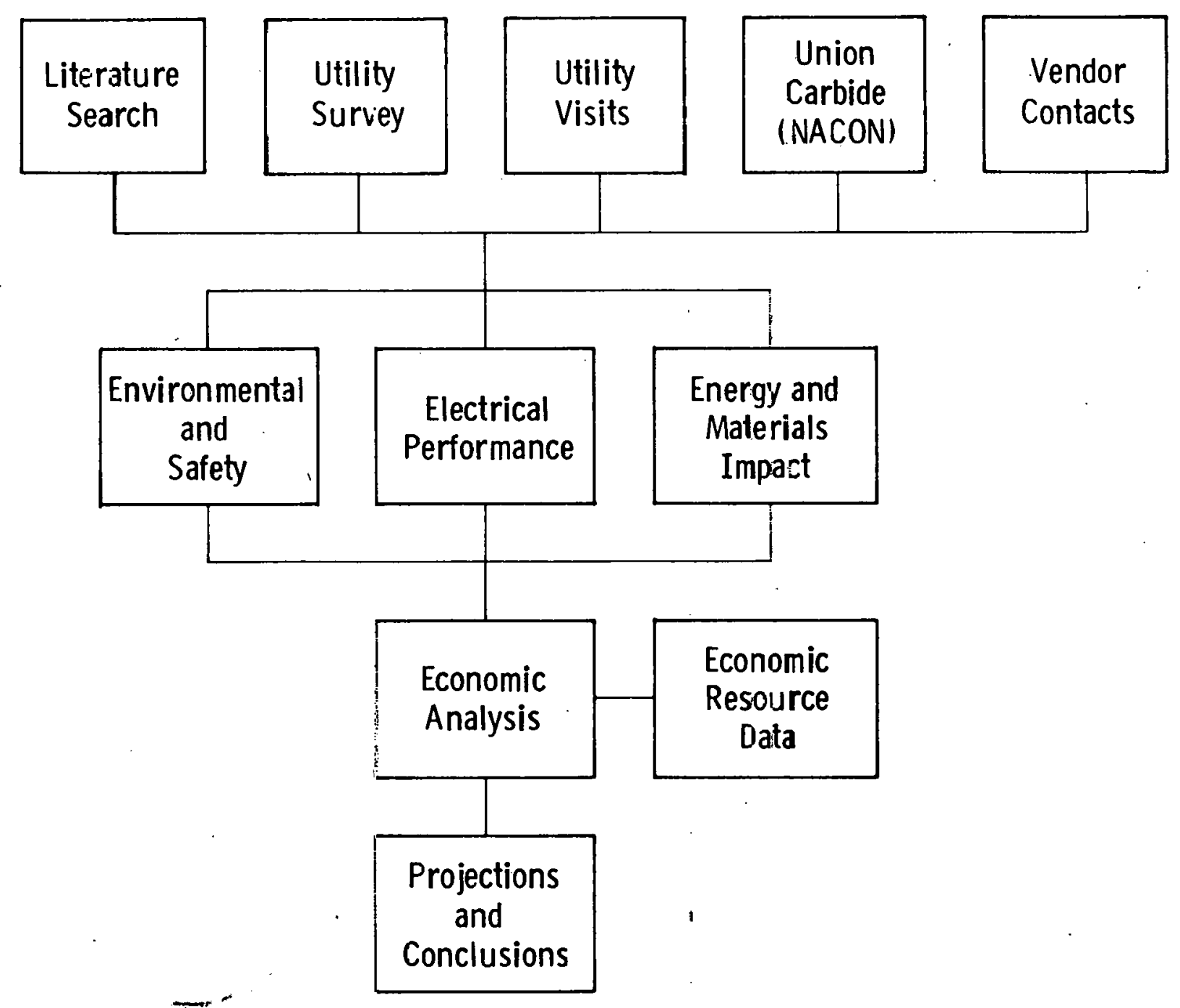

Fig. 4-2-Methodology sequence for sodium cable assessment study 


\section{INFORMATION SOURCES}

\subsection{Literature Search}

\section{1 .1 Methodology}

A literature search was conducted for information relating to sodium conductor cable experience. The major thrust of the search centered on the computer search of relevant data bases. These include NTIS (National Technical Information Service) 1964-1977, INSPEC (Electrical and Electronics Abstracts) 1969-1977, COMPENDEX (Engineering Index) 19701977, and EDB (U.S. Department of Energy Data Base) 1976-1977.

Various strategies were employed in the search. The most successful coupled the keyword "sodium" with various other keywords such as "cable," "conductor" or "underground transmission." The most productive data base was COMPENDEX which produced 9 references directly applicable.

A manual search was also conducted of "Electrical Engineering Abstracts" from 1955-1975. This search was not very productive, turning up only 5 references, 4 of which had already been listed in the computer search. A search was made of the references listed in each applicable sodium cable paper received and several additional relevant publications were found.

\subsubsection{Bibliography of Publications}

A total of 40 publications concerned with sodium conductor cables was collected from the literature search. These are listed in Appendix Al along with an abstract or summary of each publication if available.

\subsubsection{Pertinent References}

All of the 40 publications listed in Appendix Al have some relevance for those interested in sodium cable. The 12 publications listed. below, however, cover the important aspects of sodium cable experience up to the early 1970 's. 
1. "Evaluation of Sodium Conductor Power Cable," A. E. Ruprecht and P. H. Ware, IEEE Transactions on Power Apparatus and Systems, Vo1. PAS-86, No. 4, April 1967.

The suitability of the newly developed polyethylene insulated sodium conductor for use in electrical power cables was evaluated electrically and mechanically. Polyethylene-insulated sodium conductors are shown to lend themselves to a wide range of constructions manufactured on standard cable-fabricating equipment. Because of the plastic nature of metallic sodium, neither conductor stranding, nor helical assembly in the case of multiconductor cables, is required for flexibility.

2. "Insulated Sodium Conductors," L. E. Humphrey, R. C. Hess, and G. I. Add1s, IEEE Transactions on Power Apparatus and Systems, Vol. 86, No. 7, July 1967.

The development and characterization of a new polyethylene insulated sodium conductor are described. The resistivity, specific gravity, and cost of sodium are compared to corresponding properties of copper and aluminum. While the alkali and alkaline earth metals have relatively good electrical conductivity, sodium was chosen because of its light weight, low cost, and availability. Physical properties of the polyethylene insulated sodium conductor were determined. Potential areas of question, such as service life, reaction of water with damaged cables, and combustion characteristics are covered in detail.

3. "The Development of Connectors for Insulated Sodium Conductor," I. F. Mathysse and E. M. Scoran, IEEE Transactions on Power Apparatus and Systems, Vol. 86, No. 7, July 1967.

The characteristics of insulated sodium conductor required the development of a new type of connector and a new installation technique. The problems involved making stable electrical contact to the sodium, sealing against chemical attack, installation with a minimum exposure of sodium, securely gripping the insulation, effects of the melting point of sodium, and temperature limitations of the insulation. 
4. "Field Trials on $15-\mathrm{kV}$ and 600 Volt Sodium Cable," Edward J. Steeve and James A. Schneider, IEEE Transaction on Power Apparatus and Systems, Vol. 86, No. 7, July 1967.

The use of sodium conductor cable presents an opportunity for reduction in cost of cable for underground residential distribution systems. In order to evaluate its usage a direct buried test installation was made involving both $15 \mathrm{kV}$ and 600 volt sodium cable. Testing the $15 \mathrm{kV}$ cables consisted in load cycling, short-circuit faulting, and fault location tésts. After the completion of tests on the $15 \mathrm{kV}$ sodium cable, a service installation was made in a rural area west of Chicago. Load cycle tests were also made on the 600 volt sodium cable. This included an overload which resulted in the failure of the cable at the terminal. Insulation damage tests were made to determine the corrosive properties of the conductor. Fault locating tests made on the 600 volt cable, as on the $15 \mathrm{kV}$ cable, showed that presently available equipment should be adequate.

5. "Improved Connectors for Insulated Sodium Conductors," S. Gerhard, Paper 45, PRN, IEEE Winter Power Conference, January 1968.

Progress toward the development of a new connector for insulated sodium power conductor is reported. Performance and design criteria are outlined and the development program to achieve the criteria is discussed. The connector construction and installation techniques are described and préliminary perfumance lest data presentcd:

6. "Dig-in Tests on Sodium Cables," E. J. Steeve, IEEE Winter Power Meeting, New York, New York, January 28 - February 2, 1968.

Two sets of dig-in tests on sodium conductor, polyethylene insulated. cables were made by the Commonwealth Edison Company. The first series of. tests were made on de-energized $15 \mathrm{kV}$ and 600 volt cables using both power machinery and hand tools. About one year later, a second series of dig-in tests was made on 600 volt cables energized at 120/240 alternating volts, using three types of power machinery. In most cases, the degree of reaction was less than expected despite extremely wet soil 
conditions from heavy rainfalls previous to the tests. It appears that the probability of causing human injury due to the cutting of an energized sodium conductor cable is no greater than that for either a copper or an aluminum conductor cable. However, during various digging operations, there is always a chance that small raw sodium chips can be brought to the surface of the ground; this presents a possible safety hazard if they are not removed.

7. "A Progress Report on Sodium Conductor Power Cable," T. H. Kelly and C. G. Gnerre, IEEE Paper No. 68, CP 62-PWR (1.968).

Experimental sodium cuuductor cables, insulated with polyethylene were manufactured without strand shielding and tested to determine the suitability of this construction for service under high humidity conditions and for voltages above $15 \mathrm{kV}$. Samples were tested after-five-. months immersion in $75^{\circ} \mathrm{C}$ water with no significant decrease in corona level. Cable samples rated at $34.5 \mathrm{kV}$ and $69 \mathrm{kV}$ and without strand shielding have been evaluated by dielectric strength and load cycle tests with satisfactory results.

8. "Irradiated Polyethylene Insulation for Sodium Conductor Cable," R. M. Eichhorn and G. I. Addis, IEEE Winter. Power Meeting, New York (January 1968).

Laboratory studies of severely overloaded sodium conductor cables, insulated with both normal and irradiated polyethylene, have been made. Excessive overloads cause melting of the sndium and subsequent open circuiting of the conductor. In an overloaded vertical riser, pressure develops from the formation of a hydrostatic head. Irradiated polyethylene provides two advantages over regular polyethylene in this situation. First $1 \mathrm{t}$ withstands the hydrostatic pressure and prevents the release of molten sodium and second it provides moderately longer Iife under the given overload. 
9. "Bistable Operating Temperatures and Current Rating of Sodium Conductors," J. Hus, IEEE, Feb. 1968, PAS-87, pp. 367-371:

Unlike conventional cables, the operating temperature of sodium cable lies close to its melting point. Although this does not affect the current rating at normal ambients, one cannot reap the full current rating benefits which normally accrue from a lowered ambient temperature. This paper describes how the ambient temperature affects the maximum operating temperature of sodium cable.

10. "Field Service Experience with Sodium Conductor Cable," R. L. Garrison, IEEE Conf. Rec. Special Tech. Conf. on Underground Distribution, Anaheim, California, pp. 386-95, May 12-15, 1969.

This paper discusses the experience with sodium conductor cables in field service installations. It includes:

1. Summary of the sizes and voitage classes of sodium cable installed by the utilities.

2. Description of typical installations of various voltage classes.

3. Accessory hardware problems encountered.

4. Observations from the field on work practices and results recorded to date.

5. Product modifications designed to assist operating Departments in the handling of the sodium conductor cable.

6. Conclusions .

11. "Measurement of Water Vapor Transmission Through Polyethylene Electrical Insulation," R. M. Eichhorn, Polym. Eng. Sci., Vol. 10, No. 1, pp. 32-7, January 1970.

A method is described for measuring the rate of water vapor transmission through thick sections of polyethylene used as insulation on electrical conductors of pure sodium metal. The technique could be 
generally useful for materials which do not react with sodium, and for cylindrical samples which can be filled with molten sodium in a dry box. For samples with uniform dimensions the results are extremely precise because sensitive electrical measurements are used. Specimens of products in final form can be employed to determine the effects of variations in processing.

12. "PP\&L Co. Experience with $15 \mathrm{kV}$ Sodium Conductor Cables,"

Frank R. Nickel, Pennsylvania Power \& Light Co., Nllentown, Pennsylvania, Doble. C1ient Conferanco, Booton, MassachusetLs, April 13, 1970.

This paper describes the experience of the Fennsylvanla Power and Light Company with a $15 \mathrm{kV}$ sodium cable installation including preliminary background tests and acceptance testing the cable.

\subsection{Utility Survey}

\subsubsection{Methodology}

A survey was conducted to obtain sodium conductor cable experience information from utilities that have installed the cable for test or service. Forty-nine utilities with sodium cable experience were identifled from records supplied by the Union Carbide Corporation. A questionnaire was mailed to forty-three of these utilities, three utilities were surveyed by telephone, and three by personal visits. These utilities were distributed geographically across the United States and were both large and small, rural and urban. The three utilities visited were "Whitley County REMC," Columbia City, Indiana, "Commonwealth Edison Company," Chicago, Illinois and "Portland General Electric," Portland, Orteyull. These were selected because of their considerable experience with sodium cable and because they represent a cross section of urban and rural locations. In depth interviews were conducted at each location with discussions held not only with management and cngineering personnel but also with workmen that had installed and repaired sodium cable. Information gained in these discussions is included in the survey results in Section 5.2 .3 . 


\subsubsection{Questionnaire}

A questionnaire was devised (see Appendix A2) to gather the following information about sodium cable experience:

- quantity installed

- cable specifications

- installation description

- load history

- operating experience

- operating expenses

- installed cable cost

- installation experience

- maintenance

- safety provisions

- opinions, observations and recommendations

- cost of conventional distribution cable installations

\subsubsection{Results of the Survey}

Thirty-seven of the forty-nine utilities surveyed (75.5\%) responded with at least partially completed questionnaires. (See the $\%$ of response to each question on questionnaire in Appendix A2). The respondees reported a total of $142,529 \mathrm{ft}$. $(43,443 \mathrm{~m})$ of sodium cable installed; $64 \%$ or $91,044 \mathrm{ft} .(27,750 \mathrm{~m})$ was rated at 600 volts while $36 \%$ or $51,485 \mathrm{ft}$. $(15,693 \mathrm{~m})$ was rated at $15 \mathrm{kV}$. Some of the cable was in operation for only short term tests (a few hours) while other cable has been in normal service for about 13 years. The total sodium cable experience reported was 249 mile-years ( 401 kilometer-years) of operation.

\subsubsection{Cable Specifications}

All of the sodium cable reported in the survey was supplied by Nacon Corporation, Boston, Massacliusetts, and was rated for either 600 volts or $15 \mathrm{kV}$. Table 5-1 gives the number of circuit feet of each copper equivalent ( $\mathrm{CuE}$ ) size for each voltage class reported. A comparison of diameter, weight and $d-c$ resistance for copper and sodium conductors 


\section{TABLE 5-1}

Utility Survey: Installed Sodium Cable Specifications

\begin{tabular}{|c|c|c|c|c|}
\hline $\begin{array}{l}\text { Voltage } \\
\text { Class }\end{array}$ & $\begin{array}{l}\text { Sizz } \\
\text { SuE } \\
\end{array}$ & $\begin{array}{l}\text { Cross Linked } \\
\text { Polyethylene }\end{array}$ & $\begin{array}{l}\text { Ourer } \\
\text { Semicon } \\
\text { Layər } \\
\end{array}$ & $\begin{array}{l}\text { Conc. } \\
\text { Neutral } \\
\end{array}$ \\
\hline $600 \mathrm{~V}$ & $2 / 0$ & yes & no & no \\
\hline $600 \mathrm{~V}$ & $2 ! 0$ & no & no & no \\
\hline $600 \mathrm{~V}$ & $4 ! 0$ & yes & no & no \\
\hline $600 \mathrm{~V}$ & 4,0 & no & no & no \\
\hline$E 00 \mathrm{~V}$ & $350 \mathrm{kcm}$ & yes & no & no \\
\hline $600 \mathrm{~V}$ & $5 \mathrm{CO} \mathrm{kcm}$ & no & no. & no \\
\hline $15 \mathrm{kV}$ & \# 4 & no & $y \in S$ & yes \\
\hline $15 \mathrm{kV}$ & $\# 2$ & yes & $y \in s$ & yes \\
\hline $15 \mathrm{kV}$ & $\# 2$ & no & yes & yes \\
\hline $15 \mathrm{kV}$ & $1 / 0$ & no & yes & yes \\
\hline $15 \mathrm{kV}$ & $2 / 0$ & no & yes & yes \\
\hline $15 \mathrm{kV}$ & $4 / 0$ & no & yes & yes \\
\hline $15 \mathrm{kV}$ & $500 \mathrm{k}=\mathrm{m}$ & no & ye:s & yes \\
\hline $15 \mathrm{kV}$ & $750 x \mathrm{xm}$ & no & yes & yes \\
\hline
\end{tabular}


reported by the Nacon Corporation is given in Table 5-2. A comparison of the ampacities of some sizes of polyethylene insulated copper and sodium conductors also repcrted by the Nacon Corporation is shown in Table 5-3.

Most of the sodium cable was manufactured with hịg molecular weight polyethylene (HMWPE) insulation (approximately 10,000 ft. of the $142,529 \mathrm{ft}$. reported was crosslinked, see Table 5-1). The $600 \mathrm{~V}$ secondary cable consisted of a solid core of pure sodium with 0.100 inches to 0.150 inches of HMWPE insulation. The $15 \mathrm{kV}$ cable was insulated with 0.175 inches to 0.220 inches of HMWPE and typically contained a semiconducting polyethylene outer shield 0.030 inches thick and a one third concentric neutral of tinned copper wire. These cables were reported to meet the requirements of IPCEA S-61-402.

\subsubsection{Installation Description}

Approximately 93\% $(132,694 \mathrm{ft})$ of all the sodium cable installations reported in the survey were direct buried. About half of these installations terminated the sodium cable below ground while the other half reported bringing the sodium cable above ground to make the termination. Approximately $7 \%(9,585 \mathrm{ft})$ of the sodium cable was installed in ducts and only $250 \mathrm{ft.}(\sim 2 \%)$ was installed as aerial cable.

\subsubsection{Load History}

Exact records of the load history of individual cables are not routinely available from the industry. However, nineteen of Lhe thirty-seven questionnaire responses did provide some information about the load history of their sodium cables. This information is compiled in Table 5-4 and indicates a range of cable loading from very light to heavy. One cable was reported to have been operated at $138 \%$ of its rated current for $21 / 2$ hours, which caused it to fail. 
Comparison of Diameter, Weight and $d-c$ Resistance (@ $25^{\circ} \mathrm{C}$ and $75^{\circ} \mathrm{C}$ ) for Copper and Sodium Conductors*

Copper Conductors N. T.

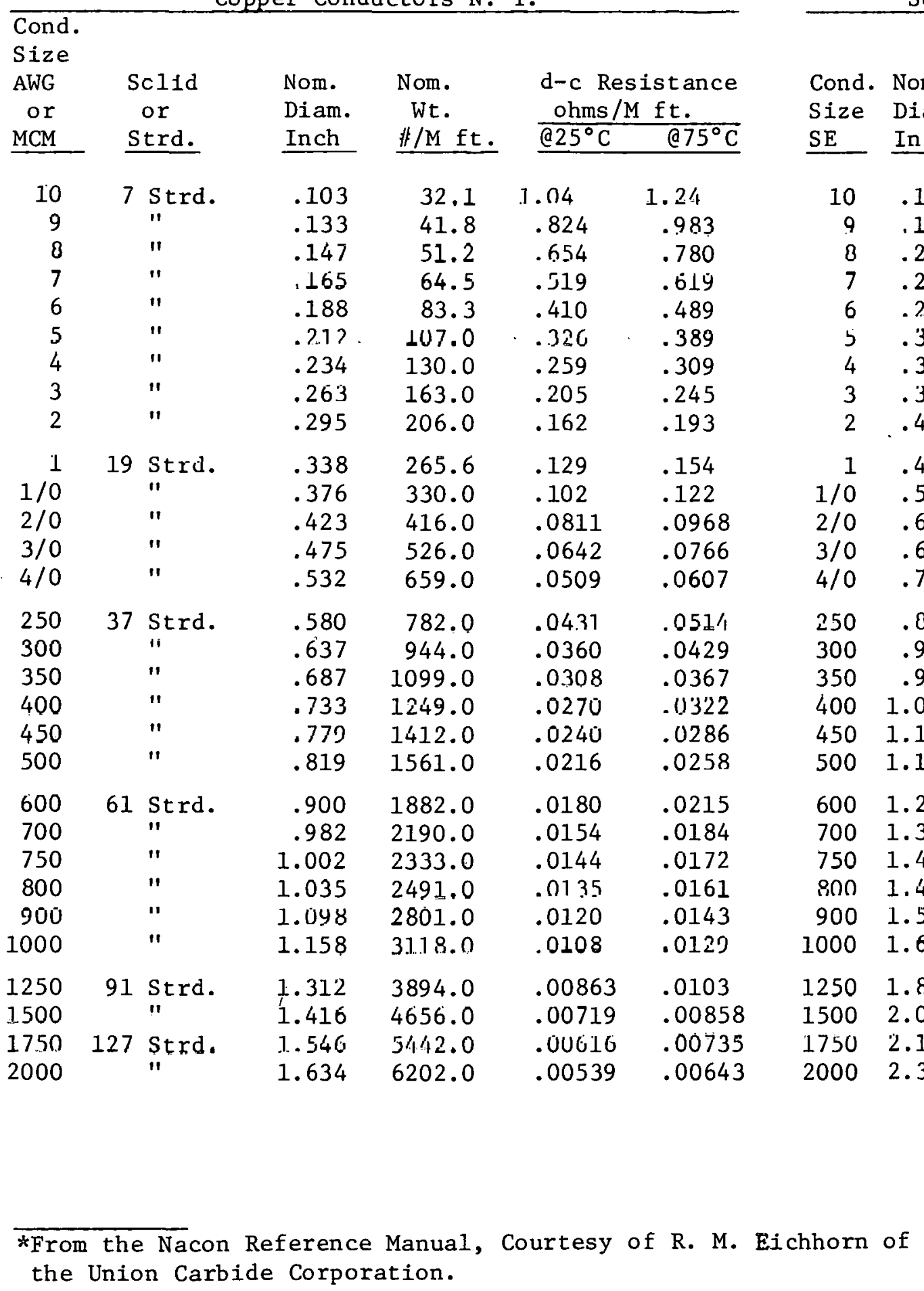

Sodium Solid Conductors

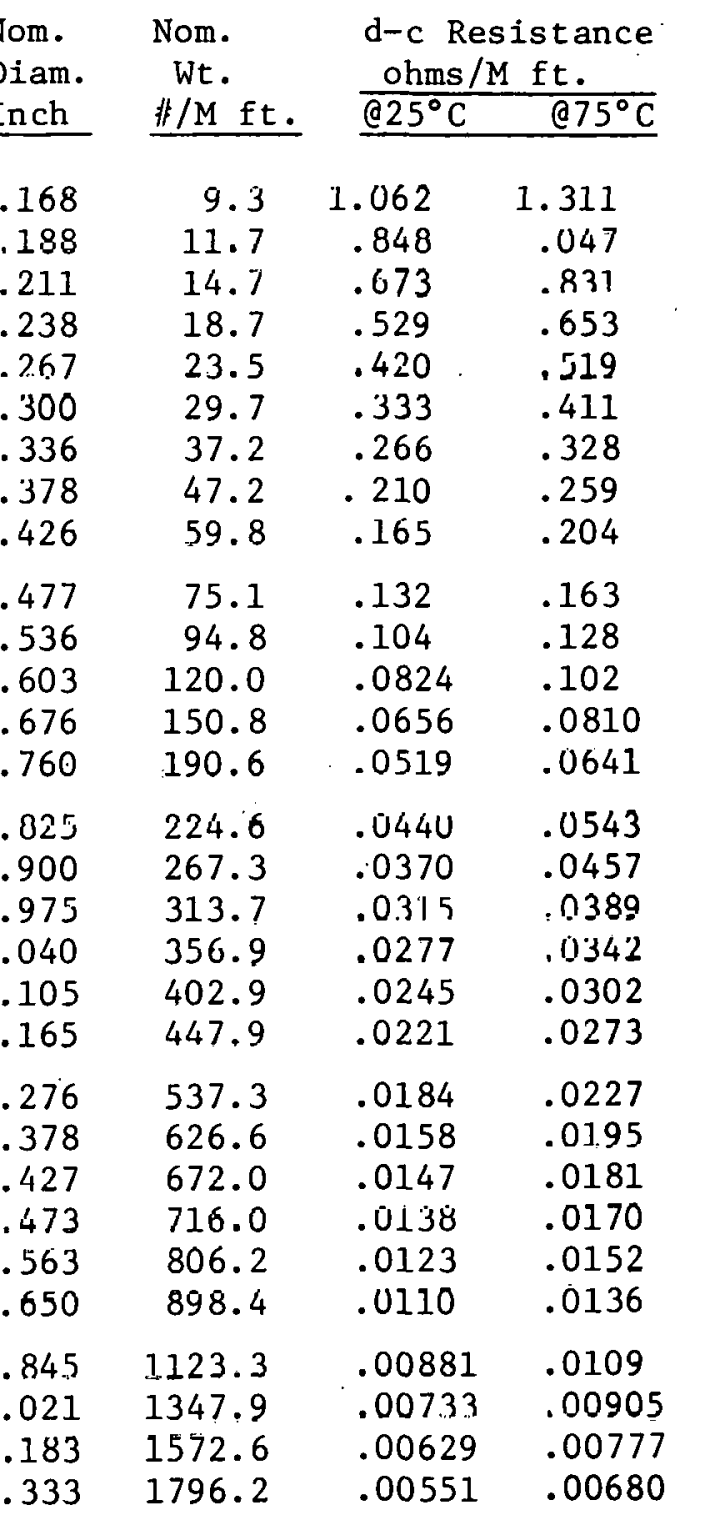


Ampacities of Polyethylene Insulated Copper and

Sodium Conductors in Air and Earth

I. Stranded Copper Conductor

\begin{tabular}{|c|c|c|c|c|c|c|c|c|}
\hline & \multirow[b]{2}{*}{ Diameter } & \multirow{2}{*}{$\begin{array}{l}\text { Cable } \\
\text { Volts } \\
\mathrm{KV} \\
\end{array}$} & \multirow{2}{*}{$\begin{array}{l}\text { Ohms/M } \\
\mathrm{Rdc} \\
25^{\circ} \mathrm{C}\end{array}$} & \multirow{2}{*}{$\begin{array}{l}\text { ft. } \\
\text { Rac } \\
75^{\circ} \mathrm{C} \\
\end{array}$} & \multicolumn{2}{|c|}{ In Air* } & \multirow{2}{*}{$\frac{\text { Direct }}{\mathrm{R}^{\prime} \mathrm{ca}}$} & \multirow{2}{*}{$\frac{\text { Buried }}{\text { Amps }}$} \\
\hline Cond. & & & & & $\mathrm{R}^{\prime} \mathrm{ca}$ & Amps & & \\
\hline 2 & $.295^{\prime \prime}$ & 5 & .162 & .193 & 7.34 & 157 & 5.73 & 226 \\
\hline $4 / 0$ & $.532^{\prime \prime}$ & 5 & .0509 & .0609 & 5.82 & 316 & 5.55 & 405 \\
\hline 750 & $1.002^{\prime \prime}$ & 5 & .0144 & .0178 & 4.10 & 695 & 5.14 & 775 \\
\hline 2 & $.295^{\prime \prime}$ & 15 & .162 & .193 & 6.49 & 168 & 6.09 & 217 \\
\hline $4 / 0$ & $.532^{\prime \prime}$ & 15 & .0509 & .0609 & 5.14 & 335 & 5.60 & 402 \\
\hline 750 & $1.002^{\prime \prime}$ & 15 & .0144 & .0178 & 3.93 & 708 & 5.36 & 760 \\
\hline
\end{tabular}

II. Solid Sodium Conductor

$\begin{array}{lcccccccc}2-S E & .426 " & 5 & .165 & .204 & 6.42 & 163 & 5.33 & 225 \\ 4 / 0-S E & .760^{\prime \prime} & 5 & .0519 & .0642 & 4.65 & 343 & 4.93 & 417 \\ 750-S E & 1.426 " & 5 & .0147 & .0187 & 3.26 & 760 & 4.83 & 783 \\ & & & & & & & & \\ 2-S E & .426 " & 15 & .165 & .204 & 5.75 & 173 & 5.65 & 218 \\ 4 / 0-S E & .760^{\prime \prime} & 15 & .0519 & .0642 & 4.38 & 354 & 5.16 & 408 \\ 750-S E & 1.426 " & 15 & .0147 & .0187 & 3.21 & 765 & 5.02 & 767\end{array}$

$*^{\prime} c a=$ Total thermal resistance of the circuit.

Ampacity calculations based on:

(a) In air; $\mathrm{T}_{\mathrm{C}}=75^{\circ} \mathrm{C}, \mathrm{T}_{\mathrm{A}}=40^{\circ} \mathrm{C}, 3-1 / \mathrm{C}$ triplexed in air, $30-100 \% \mathrm{LF}$.

(b) D.B.; $\quad \mathrm{T}_{\mathrm{C}}=75^{\circ} \mathrm{C}, \mathrm{T}_{\mathrm{A}}=20^{\circ} \mathrm{C}, 3-1 / \mathrm{C}$ spaced $7.5^{\prime \prime}$ in trench, 3-ft. deep,

Thermal resistivity of polyethylene $=360^{\circ} \mathrm{C} \mathrm{cm} /$ watt.

\footnotetext{
†rom the Nacon Reference Manual, Courtesy of R. M. Eichhorn of. the Union Carbide Corporation.
} 
TABLE $5-4$

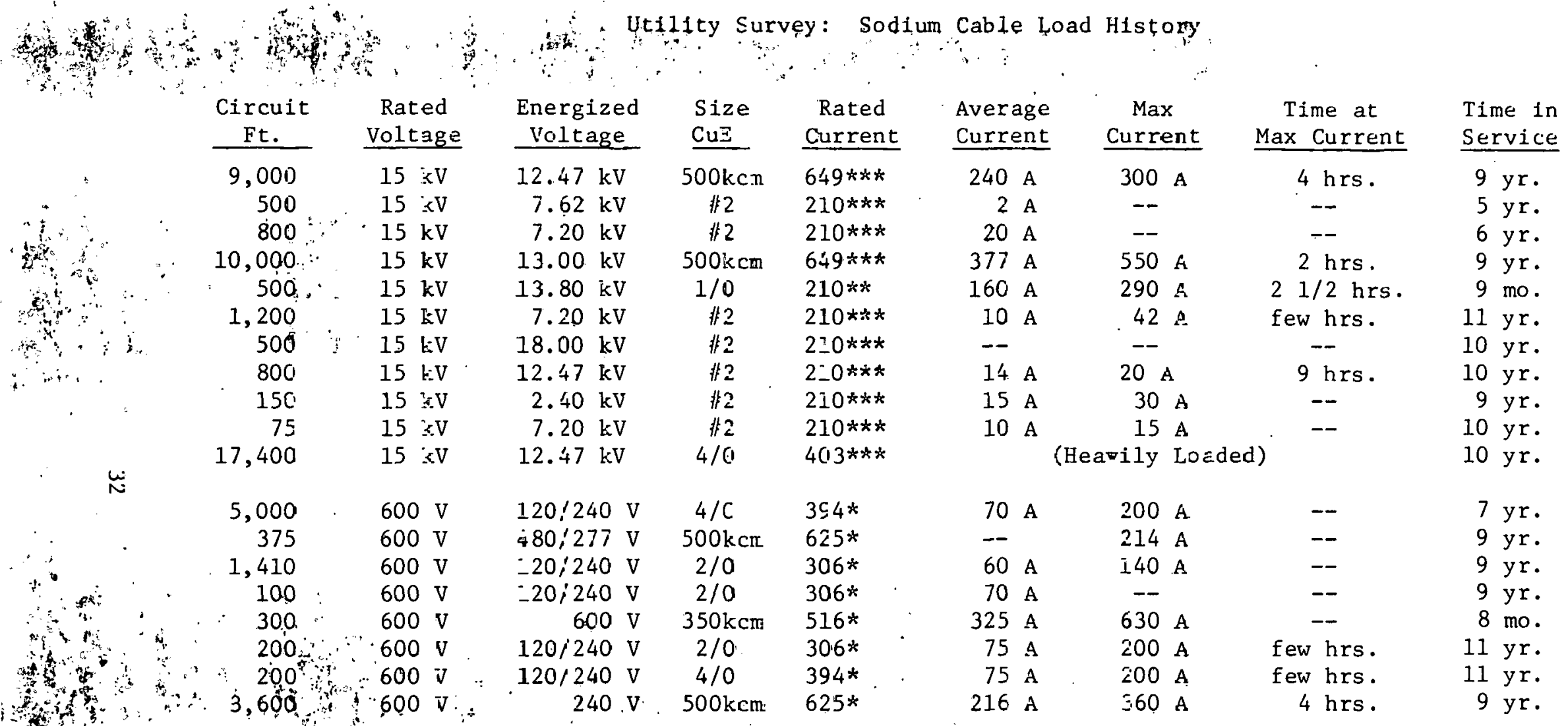

\footnotetext{
*Ampacity of difect burled, single conductor, polyethylene insulated, sodium cable.

* Industry rating of similap copper comductor cable located in a "U" guara with the conductor temperature at $75^{\circ} \mathrm{C}$ and air ambient at $20^{\circ} \mathrm{C}$. i. $\because$,

***inquistry rating of single çonductor, diréct bufied, shielded coppef, 1/C groups buried $36^{\circ}$ deep, $71 / 2^{\prime \prime}$ center , conductor temperatore $90^{\circ} \mathrm{C}$, earth ambient $20^{\circ} \mathrm{C}$, earth $\mathrm{RHO} 90$ :
} $\because \quad \therefore \quad \therefore$

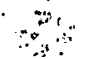




\subsubsection{Operating Experience}

The operating experience :eported for sodium cable does not differ greatly in most cases from that for aluminum or copper. In a few instances a very high failure rate for sodium cable compared to other types of cable was reported. See sec $\therefore$ 5.2.3.5 for a discussion of sodium cable failures. At one utility, customer complaints about lights dimming, TV picture roll, and other problems associated with low or fluctuating voltage have been fewer for homes serviced with sodium cable than for those serviced by aluminum cable.

\subsubsection{Sodium Cable Failures}

Twenty-seven of the 37 reporting utilities, representing $432,591 \mathrm{ft}$-years ( 82 mile-years) of sodium cable operation, reported zero sodium cable failures. The remaining ten utilities reported. a total of 237 failures, indicating an overall failure rate of about one failure per mile-year of operation. Table 5-5 lists the sodium cable failure history for all 37 respondees.

The sodium cable failure rate was much higher for 600 volt secondary cables than for $15 \mathrm{kV}$ primary cables. Two hundred thirty-two failures were reported for the 600 volt cables, indicating a failure rate of 1.59 failures per mile-year, while there were only 5 failures reported for the $15 \mathrm{kV}$ cable indicating a failure rate of .0556 failures per mile-year. The main reason for this difference in failure rate can probably be related to the mode of failure.

Two hundred thirty-four of the 237 reported failures $(98.7 \%)$ occurred at the sodium cable terminals. Most of the terminal failures were related to the penetration of moisture to the sodium. The moisture reacted with the sodium gradually, causing the conducting area to diminish. At some point the increased resistançe caused overheating at the terminal causing the polyethylene insulation to fail. The $15 \mathrm{kV}$ terminals appear to be more effective in preventing moisture ingress into the cable than the 600 volt terminals, thus the lower failure rate. Of course, there are normally fewer terminals per mile of $15 \mathrm{kV}$ cable than for 600 volt 
TABLE 5-5

Utility Survey: Sodius: Cable Failure History

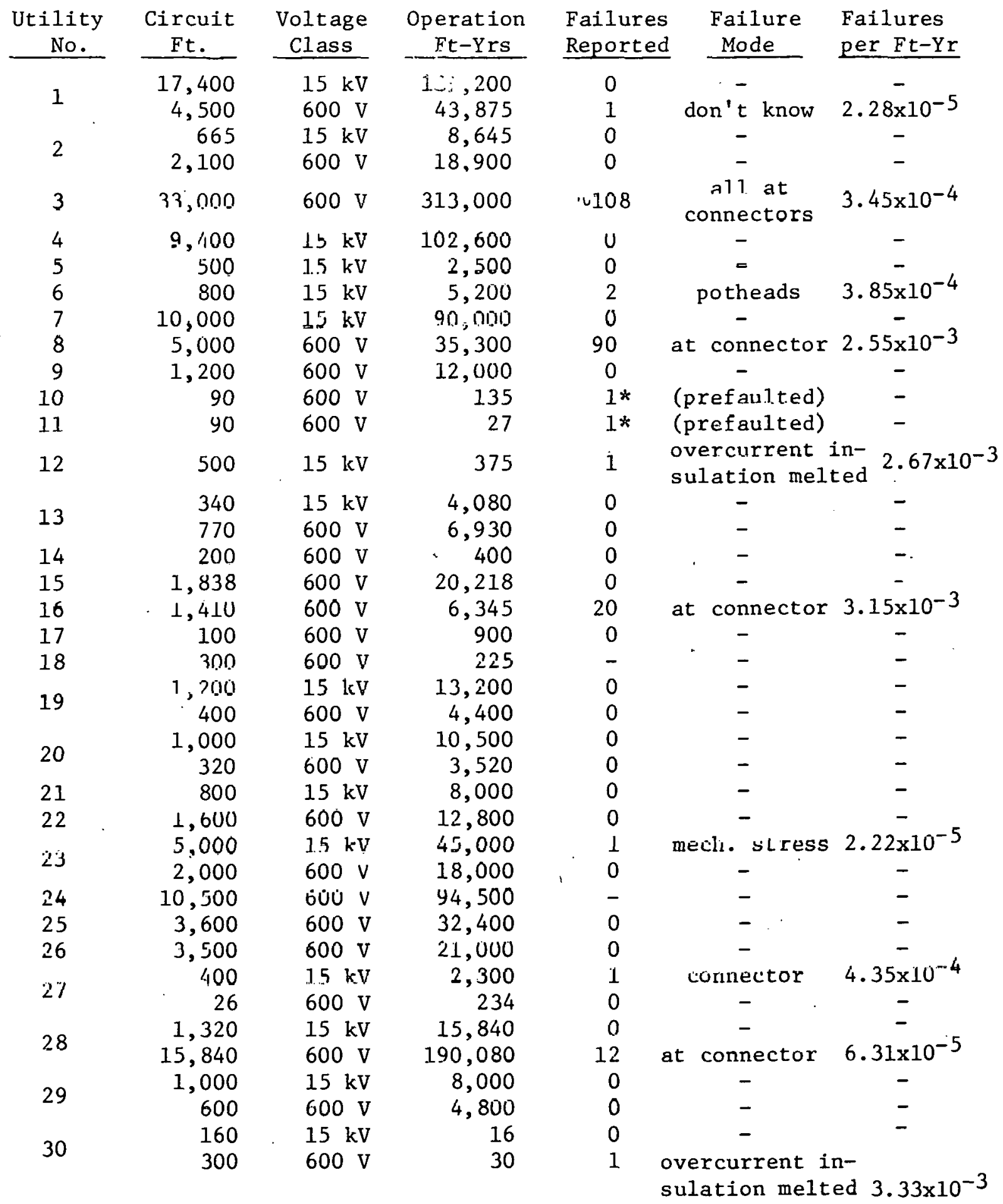




\section{TÁBLE 5-5 (Cont'd)}

Utility Survey: Sodium Cable Failure History

\begin{tabular}{|c|c|c|c|c|c|c|}
\hline $\begin{array}{c}\text { Utility } \\
\text { No. } \\
\end{array}$ & $\begin{array}{c}\text { Circuit } \\
\text { Ft. } \\
\end{array}$ & $\begin{array}{c}\text { Voltage } \\
\text { Class } \\
\end{array}$ & $\begin{array}{c}\text { Operation } \\
\text { Ft-Yrs } \\
\end{array}$ & $\begin{array}{l}\text { Failures } \\
\text { Reported }\end{array}$ & $\begin{array}{l}\text { Failure } \\
\text { Mode }\end{array}$ & $\begin{array}{l}\text { Failures } \\
\text { per Ft-Yr }\end{array}$ \\
\hline 31 & 150 & $15 \mathrm{kV}$ & 1,350 & 0 & - & - \\
\hline 32 & 90 & $600 \mathrm{~V}$ & 45 & 0 & - & - \\
\hline 33 & 300 & $600 \mathrm{~V}$ & 410 & $1 *$ & (prefaulted) & - \\
\hline 34 & 150 & $600 \mathrm{~V}$ & 75 & $1 *$ & (prefaulted) & - \\
\hline 35 & 75 & $15 \mathrm{kV}$ & 750 & 0 & - & - \\
\hline & 300 & $15 \mathrm{kV}$ & 2,700 & 0 & - & - \\
\hline 36 & 1,300 & $600 \mathrm{~V}$ & 11,700 & 0 & - & - \\
\hline 37 & 0 & 0 & 0 & - & - & - \\
\hline
\end{tabular}

*A failure occurred but was not counted because the cable had been prefaulted as part of a test. 
cable, therefore the number of failures is higher for $600 \mathrm{~V}$ circuits: One utility reported that a plastic sleeve designed to protect the terminal of 600 volt sodium cables had resulted in a near $100 \%$ failure rate when utilized. Experience showed that taping the terminal with rubber tape covered with plastic tape was effective in preventing terminal failure. This utility reported that there have been no terminal failures when this taping method was employed. Two of the 237 reported failures were caused by sustained overcurrents. If the sodium cable is operated above its rated ampacity for an extended period of time, the resulting heat buildup can cause the sodium to liquify and/or the polyethylene insulation to fail. The failure is most likely to occur in an area of poor cooling surh as a riocr in " $U$ " gudrd. "lhe tinal fatlure of the 237 was attributed to mechanical stress on the cable, which was an aerial installation.

\subsubsection{Uperating Expense}

Nune of the $3 /$ survey respondees professed any knowledge of the power loss or other operating expenses associated with their installed sodium cable. Two did venture that the losses appeared to be less than with similar aluminum s.ahle.

\subsubsection{Installed Cable Cost}

Information about installed sodium cable cost was not well reported in the survey. Information that was reported is compiled in Table 5-6. Some of this information is qualitative with statements that the sodium cable installation cost was more, less or the same as that for alumlnum cable. The two cases that give fairly complete information indicate that the Installed cost for secondary sodium cable is higher than that for primary sodium cable. This is probably because of Llie high cost of terminals, and bccanse the numbcr of termindls per uñit length is greater for secondary cable than primary.

A section of the survey questionnaire was devoted to the average installed cost for aluminum and copper cables. Table 5-7 is a compilation of these reported costs and Table 5-8 gives a breakdown on the distribution of these costs. There is considerable variation in 
Utility Survey: Sodium Cable Installed Cost

\begin{tabular}{|c|c|c|c|c|c|c|c|c|}
\hline $\begin{array}{l}\text { Circult } \\
\text { Ft. }\end{array}$ & $\begin{array}{l}\text { Voltage } \\
\text { Class }\end{array}$ & $\begin{array}{l}\text { Size } \\
\text { CuE }\end{array}$ & $\begin{array}{l}\text { Total Installed Cost } \\
\text { Sodium Aluminum }\end{array}$ & $\begin{array}{l}\text { Cable } \\
\text { Cost } \\
\end{array}$ & $\begin{array}{l}\text { eparing } \\
\text { h or Duct }\end{array}$ & $\begin{array}{l}\text { Installing } \\
\text { Cable } \\
\end{array}$ & $\begin{array}{c}\text { Making } \\
\text { Terminations } \\
\end{array}$ & $\begin{array}{c}\text { Terminal } \\
\text { Cost } \\
\end{array}$ \\
\hline 800 & $15 \mathrm{kV}$ & : 非 2 & $\$ 1.01 / \mathrm{ft}$ & $19 \%$ & $31 \%$ & $5 \%$ & $15 \%$ & $30 \%$ \\
\hline & $600 \mathrm{~V}$ & $2 / 0$ & $\$ 1.82 / \mathrm{ft}$ & $44.3 \%$ & & & Higher & Higher \\
\hline $\begin{array}{c}9,000 \\
500\end{array}$ & $\begin{array}{l}15 \mathrm{kV} \\
15 \mathrm{kV}\end{array}$ & $\begin{array}{l}500 \mathrm{kcm} \\
\not \# 2\end{array}$ & $\begin{array}{l}\mathrm{Na} 10-15 \mathrm{c} / \mathrm{ft} \text { less } t \\
\text { Sodium more expensiv }\end{array}$ & $\begin{array}{l}\text { han } \$ 1.00 / \mathrm{ft} \text {. } \\
\text { e than Aluminum }\end{array}$ & same & s ame & for $\mathrm{Na}$ & for $\mathrm{Na}$ \\
\hline 3,600 & $600 \mathrm{~V}$ & $500 \mathrm{kcm}$ & $\mathrm{Na}$ same as $\mathrm{Al}$ & $\$ .861 / f t$ & - & - & - & - \\
\hline 150 & $15 \mathrm{kV}$ & \#2 & $\mathrm{Na}$ less than $\mathrm{Al}$ & $\$ .45 / \mathrm{ft}$ & - & - & - & - \\
\hline
\end{tabular}




\section{TABLE 5-7}

Utility Survey: Compilation of Reported Installed Cost for Direct Buried $\mathrm{Al}$ and $\mathrm{Cu}$ Cable

\begin{tabular}{cccc}
$\begin{array}{c}\text { Voltage } \\
\text { Class }\end{array}$ & Size & $\begin{array}{c}\text { Conductor } \\
\text { Material }\end{array}$ & $\begin{array}{c}\text { Installed Cost } \\
\text { Per Conductor Ft. }\end{array}$ \\
\hline $600 \mathrm{~V}$ & $2 / 0$ & $\mathrm{Al}$ & $\$ 1.15$ \\
$600 \mathrm{~V}$ & $3 / 0$ & $\mathrm{Al}$ & 1.97 \\
$600 \mathrm{~V}$ & $4 / 0$ & $\Lambda 1$ & 1.02 \\
$600 \mathrm{~V}$ & $4 / 0$ & $\mathrm{Cu}$ & 1.55 \\
$600 \mathrm{~V}$ & $250 \mathrm{kcm}$ & $\mathrm{Al}$ & 2.59 \\
$600 \mathrm{~V}$ & $250 \mathrm{kcm}$ & $\mathrm{Cu}$ & 2.31 \\
$600 \mathrm{~V}$ & $350 \mathrm{kcm}$ & $\mathrm{Al}$ & 1.46 \\
$15 \mathrm{kV}$ & & & 2.31 \\
$15 \mathrm{kV}$ & $\$ 2$ & $\mathrm{Al}$ & 2.65 \\
$15 \mathrm{kV}$ & $1 / 2$ & $\mathrm{Cu}$ & 2.41 \\
$15 \mathrm{kV}$ & $\mathrm{Cu}$ & 1.94 \\
$15 \mathrm{kV}$ & $\mathrm{Al}$ & 1.75 \\
$15 \mathrm{kV}$ & $3 / 0$ & $\mathrm{Al}$ & 2.85 \\
$15 \mathrm{kV}$ & $4 / 0$ & $\mathrm{Al}$ & 6.85 \\
$25 \mathrm{kV}$ & $750 \mathrm{kcm}$ & $\mathrm{Cu}$ & 9.26 \\
$35 \mathrm{kV}$ & $750 \mathrm{kcm}$ & & 4.43 \\
$35 \mathrm{kV}$ & $250 \mathrm{kcm}$ & $\mathrm{Al}$ & 6.85
\end{tabular}

*Utility survey conducted in 1978, however, no common base for dollars was established. 


\section{TABLE 5-8}

Utility Survey: Compilation of Reported Cost Breakdown for Installing Direct Buried $\mathrm{Al}$ and $\mathrm{Cu}$ Cable

\begin{tabular}{|c|c|c|c|c|c|c|}
\hline & $\begin{array}{l}\text { Cable } \\
\text { Cost } \\
\end{array}$ & $\begin{array}{c}\text { Preparing } \\
\text { Ditch } \\
\end{array}$ & $\begin{array}{c}\text { Installing } \\
\text { Cable } \\
\end{array}$ & $\begin{array}{c}\text { Making } \\
\text { Terminations } \\
\end{array}$ & $\begin{array}{c}\begin{array}{c}\text { Terminal } \\
\text { Cost }\end{array} \\
\end{array}$ & $\begin{array}{c}\text { Installed } \\
\text { Cost } \\
\end{array}$ \\
\hline $\begin{array}{l}\text { Secondary } \\
600 \mathrm{~V}\end{array}$ & $33.5 \%$ & $51.5 \%$ & $7.5 \%$ & $4.5 \%$ & $3 \%$ & $100 \%$ \\
\hline $\begin{array}{l}\text { Primary } \\
15 \mathrm{kV}\end{array}$ & $35 \%$ & $16 \%$ & $11 \%$ & $21 \%$ & $17 \%$ & $100 \%$ \\
\hline $\begin{array}{c}\text { TOTAL } \\
\text { Al1 Classes }\end{array}$ & $45 \%$ & $29 \%$ & $10 \%$ & $8 \%$ & $8 \%$ & $100 \%$ \\
\hline
\end{tabular}


these reported costs, but as expected, in most cases the copper cable is more costly than aluminum cable. Also, the higher the voltage and size, the more costly the cable. A comparison of the breakdown of costs for sodium, aluminum, and copper cables show that terminal cost for sodium cable is higher, but the cable cost is less. These costs are analyzed in more detail in Section 9.

\subsubsection{Installation Experience}

Generally, there were no major difficulties reported in inotalling oodium conductor cablc. Tho moro frequent romarkc woro that moro care had to be exercised with sodium cable than with aluminum. More

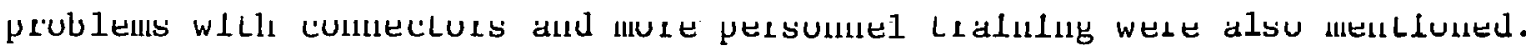
Table 5-9 lists the installation experience summary of the 37 responding utilities. Thirteen indicated that sodium cable was more difficult to install, 3 said it was easier, and 17 stated it was about the same as aluminum for installation effort.

\subsubsection{Maintenance}

There was nn routine maintenance performed and no maintenance. problem reported by any of the respondees except for the failures discussed in section 5.2.3.5 and a tew accidental dig-ins.

\subsubsection{Safety Provisions}

Most of the survey respondees reported that the workmen installing sodium cable wore eye protection and gloves. One utility stated that their workmen wore face shields because eye protection alone was not considered sufficient. Special precautions were also taken in the sodium cable storage area. The cable ends were taped to exclude moisture and the cablc wao otored out of the wather. Signe identifying the sodium were posted and special fire extinguishers were located nearby.

In must cases the cut-off ends of the sodium cable were reported to be sealed in a bag or can and sent back to the manufacturer for disposal. A few of the utilities reported axially slitting the 
TABLE 5-9

Utility Survey: Summary of Installation Experience for Sodium Conductor Cable

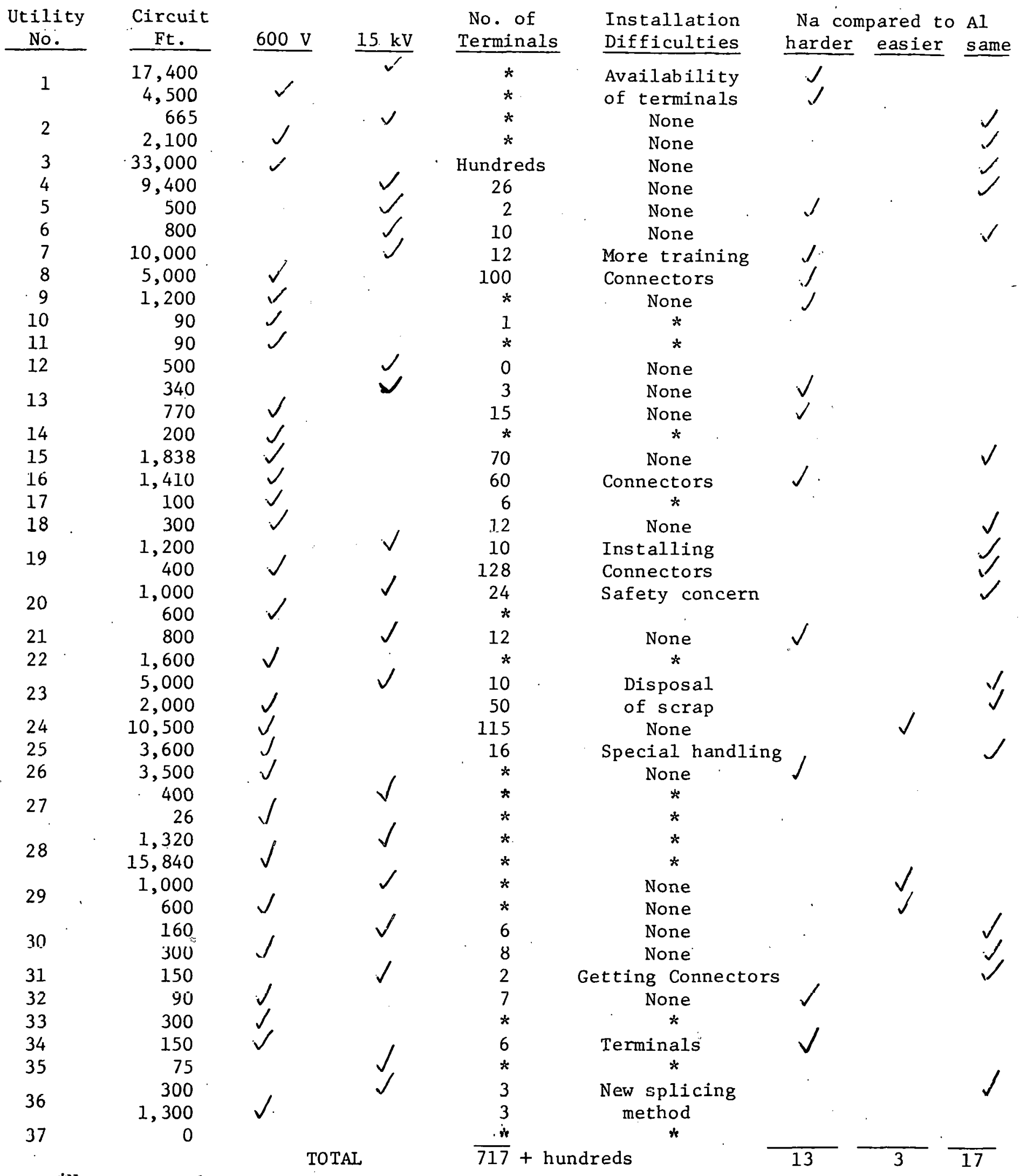

*Not reported 
insulation on short cable sections and burying them. A few also reported disposing of the sodium cable ends directly in water or by burning.

In answer to the question, "What was done or what do you plan to do with the sodium cable when removed from service," $43 \%$ said they would remove the cable, $24 \%$ said they would abandon the cable in place, and $5 \%$ didn't know what they would do. Forty-six percent considered an abandoned cable a hazard while $22 \%$ said it was not.

\subsubsection{Opintone, Obeervatione and Recommendat ions}

In answer to the question, "What are your observations and feelings about the sodium cable used by your organization?": Fifty-one percent indicated that the sodium cable experience has been satisfactory, $22 \%$ indicated that it was unsatisfactory, $19 \%$ had no comment, and $8 \%$ thought the advantages and disadvantages cancelled.

The question, "Would you recommend that your organization use sodium cable if it were readily available and if there was a cost advantage?" was answered as follows: Twenty-four percent indicated yes, $19 \%$ indicated no, $43 \%$ indicated possibly (with some qualifications stated), and $14 \%$ didn't know or did not respond. The major advantages and disadvantages reported by the respondees are listed in Table 5-10. The percentage figures at the left in the table show the percent of the respondees that indicated each of these advantages and disadvantages.

\subsection{Conclustons}

- Sodium cable experience has been well reported in the litcraturc with more than forty publications;

- Response to the utility survey was very high ( $>75 \%)$ indicating $a$ willingness on the part of the utilities to share their sodium cable experience and let their views be known; 
TABLE 5-10

Major Advantages and Disadvantages of Sodium Cable as Reported in the Utility Survey

ADVANT AGES :

$(51 \%) *$ Possible Lower Cost

(32\%) Easier Handling, Lighter Weight, More Flexible

(11\%) Future Availability of Sodium Assured

( $5 \%$ ) Nurie

( $3 \%$ ) Less Susceptible to Installation Damage

DISADVANT AGE :

(51\%) Safety Hazard of Sodium

(49\%) Terminal Installation, Cost and Reliability

(27\%) Disposal of Scrap Sodium

(27\%) Need for Special Training and Installation Techniques

( $8 \%$ ) Liability Problem with Abandonment and Storage

( $8 \%$ ) Low Emergency Ampacity

( 5\%) No Economic Advantage

( $5 \%$ ) Need to Stock Special Cable Accessories

*Percent of survey respondees citing this factor 
- Generally, the utilities with the greatest sodium cable experience were the most positive about sodium cable, while utilities with very limited sodium cable experience were the most negative about it;

- Most of the survey respondees mentioned a problem with sodium cable connectors or an opinion that more connector development is required;

- Information about sodium cable operating and installation costs is not readily available or kept by the utilities. 


\section{ENVIRONMENTAL AND SAFETY CONSIDERATIONS}

\subsection{Sodium Description and Properties}

Sodium is the sixth most abundant metal on earth and the most abundant of the alkali metals. It is a silvery metal, soft and ductile and has a density slightly less than that of water. (Density of sodium (c) $\left.20^{\circ} \mathrm{C}=0.968 \mathrm{~g} / \mathrm{cm}^{3}\right)$. Sodium melts at about $98^{\circ} \mathrm{C}\left(208^{\circ} \mathrm{F}\right)$ to form a silvery liquid having about 0.7 the viscosity of water at $20^{\circ} \mathrm{C}$. Its volume change on melting is $+2.7 \%$ at one atmosphere ${ }^{(1)}$.

Sodium metal is manufactured comercially by the electrolysis of a eutectic mixture of $\mathrm{NaCl}^{-\mathrm{CaCl}_{2}}{ }$. It is used principally in chemical manufacturing ${ }^{(2)}$ and as a heat transfer medium. Approximately 300 million pounds of sodium are consumed annually in the U.S.A.

Sodium reacts violently with water to form sodium hydroxide and hydrogen. The reaction is exothermic and may ignite the hydrogen gas liberated. Sodium forms an explosive mixture with halogenated hydrocarbons, carbon tetrachloride, and with carbon dioxide in any form. Refer to the National Fire Protection Association (3), "Manual of Hazardous Chemical Reactions," for a compilation of such reactions of sodium.

The sodium/water reaction rate depends on a number of factors (i.e., temperature, contact area, pressure, ratio of sodiumwater, and mixing rate). If the eodium is in the eolid state and the water is in the liquid state and complete reaction is assumed, the final condition of a sodium/water reaction can be expressed by the following equation ${ }^{(1)}$ :

$$
\mathrm{Na}+\mathrm{H}_{2} \mathrm{O} \rightarrow \mathrm{NaOH}+1 / 2 \mathrm{H}_{2}+33.92 \mathrm{Kcal} \text { (per mole) at } 25^{\circ} \mathrm{C}
$$

Calculations of the free energies show that the reaction of sodium and. water below the melting point of sodium hydroxide. $\left(i 315^{\circ} \mathrm{C}\right)$ will proceed to sodium hydroxide and hydrogen even in excess sodium. If the temperature 
is allowed to exceed the melting point of sodium hydroxide, then sodium hydroxide will react with additional sodium to produce sodium oxide and hydrogen.

The physical properties and characteristics of sodium are given in Table 6-1. This information is from The Manufacturing Chemists Association (4) Chemical Safety Data Sheet SD-47 on the properties and essential information for safe handling and use of sodium. It is recommended that anyone involved with sodium handling become familiar with Chemical Safety Data Sheet S̈D-47.

\subsection{Cable Handling by Manufacturer, Shipper and Utility Contractor}

Sodium electrical cable manufactured by coextruding sodium and polyethylene ${ }^{(5)}$ is inherently safer than bulk sodium because the polyethylene insulation functions as an effective barrier to air and water. The major danger occurs at the ends of the cable or if the polyethylene insulation is breached. The danger is in the form of fire, explosion and/or corrosivity.

The ignition temperature of sodium in air is above $115^{\circ} \mathrm{C}$ $\left(239^{\circ} \mathrm{F}\right)$, but the high thermal conductivity of sodium makes maintenance of combustion in electrical cables difficult. L. É. Humphrey et al (5) reported on experiments to study the effects of igniting insulated sodium conductors with a torch. A 0.5 inch $(1.27 \mathrm{~cm})$ diameter sodium cable was held in a horizontal position and the open end ignited with a gas torch. The insulation took fire and burned until the torch was removed and Lifen exllngulshed ILself. The sudlum dld hul Lake flie bul lediled rapidly, forming a hard tenacious crust of oxide or carbonate which protected it from further reaction.

Another sample of the same insulated conductor, held in a vertical position, was similarly ignited at the lower end. Again the polyethylene insulation took fire as expected, but upon removal of the torch it soon extinguished itself. The sodium was expected to melt and flow from the insulation, but again the oxide or carbonate 
TABLE 6-1

Physical Properties and Characteristics of Sodium*

Physical state and Density

Boiling Point (760 mm)

Color

Corrosivity

Critical Pressure

Critical Temperature

Deliquescence

Heat of Fusion

Heat of Vaporization

Hygros copicity

Ignition Temperature

Ignition Temperature; Autogenous

Melting Point

odor

Resistivity

Reactivity

Specific Heat

Thermal Conductivity

Water Solubility

Threshold Limit Value (OSHA)
Solid at $0^{\circ} \mathrm{C} 0.9725$

Solid at $20^{\circ} \mathrm{C} 0.9684$

Liquid at M.P. 0.9516

Liquid at $882.9^{\circ} \mathrm{C} 0.7414$

$882.9^{\circ} \mathrm{C}\left(1621^{\circ} \mathrm{F}\right)$

Silvery white changing to gray on exposure to air

In presence of moisture; it will be caustic

$343 \mathrm{~atm}$

$2000^{\circ} \mathrm{C}\left(3632^{\circ} \mathrm{F}\right)$

With moisture from the air, it forms caustic which is deliquescent

$27.05 \mathrm{cal} / \mathrm{gm}$

$1138.9 \mathrm{cal} / \mathrm{gm}$ at $882.9^{\circ} \mathrm{C}\left(1637^{\circ} \mathrm{F}\right)$

Hygroscopic

In excess of $115^{\circ} \mathrm{C}\left(239^{\circ} \mathrm{F}\right)$

In dry air, near its boiling temperature

$97.83^{\circ} \mathrm{C}\left(208^{\circ} \mathrm{F}\right)$

Odorless

$4.879 \mathrm{microhm}-\mathrm{cm}$ at $20^{\circ} \mathrm{C}\left(68^{\circ} \mathrm{F}\right)$

Very active; violently reactive with water, hallogen hydrocarbons and solid $\mathrm{CO}_{2}$

Solid at $0^{\circ} \mathrm{C} 0.2930 \mathrm{cal} / \mathrm{gm}$

Solid at $97.6^{\circ} \mathrm{C} 0.3266 \mathrm{cal} / \mathrm{gm}$

Liquid at $97.7^{\circ} \mathrm{C} 0.334 \mathrm{cal} / \mathrm{gm}$

Liquid at $150^{\circ} \mathrm{C} 0.337 \mathrm{cal} / \mathrm{gm}$

At $0^{\circ} \mathrm{C} 0.335 \mathrm{cal} / \mathrm{cm}$ deg. sec.

At $75^{\circ} \mathrm{C} 0.270 \mathrm{cal} / \mathrm{cm} \mathrm{deg}$. sec.

Reacts, to form $\mathrm{NaOH}$ and Hydrogen

$2 \mathrm{mg} / \mathrm{cu} . \mathrm{m}$. in moist air, as $\mathrm{NaOH}$

*Chemical Safety Data Sheet SD-47, Manufacturing Chemists Association, Washington, D.C. 20009 
crust which formed at the surface prevented dripping of the sodium even though the lower portion of the sodium in the conductor was molten. Thus, in either case, ignition proceeds in much the same manner as with a conventional conductor with the sodium contributing little, if any, toward combustion.

The major difference, then, between sodium cable and conventional cable as far as fire is concerned is the possibility of starting a fire with water. T., E. Humphrey et al (5) alsu reported on experiments to study the effects of watcr on insulaled sudlum conductors suhjected to varying degrees of insulation damage. A series of holes ranging in size from $1 / 32$ inch $(.794 \mathrm{~mm})$ to $1 / 4$ inch $(6.35 \mathrm{~mm})$ were drilled through the insulation to the sodium. The prefaulted cable was then immersed in water and the reaction studied. Even with the $1 / 4$ inch $(6.35 \mathrm{~mm})$ hole size the reaction subsided within a few minutes due to formation of a salt layer and a gas cushion in the drilled hole. The $1 / 4$ inch (6.35 mm) hole represents approximately the largest size hole which will automatically seal itself against reaction with free water.

The open end of a 0.5 inch $(1.27 \mathrm{~cm})$ sodium conductor was partially immersed in free water with the result that evolved hydrogen gas caught fire. The flame was readily extinguished by cuvering the exposed end with loose sand, soil or even mud. In another case the open end of a 0.5 inch $(1.27 \mathrm{~cm})$ sodium conductor was plunged into a puddle of mud. There was essentially, no reaction except for a few gas bubbles percolating to the-surface of the mud.

reported ${ }^{(8)}$ results of tests on $15 \mathrm{kV}$, \#2 CuF sndium cable:

Frauk R. N1ckel of Pennsylvania Power and Light Company (PP\&L)

1. "A short length of cable was cut and a blowtorch played over the exposed cable end. The polyethylene insulation burned just as it does w1th copper or alumnum cable. The sodium conductor burned back into the polyethy lene insulation approximately one-half Inch and stopped burning.

-. The polyethylene Insulation stopped burning approximately 10 seconds after the flame was removed.

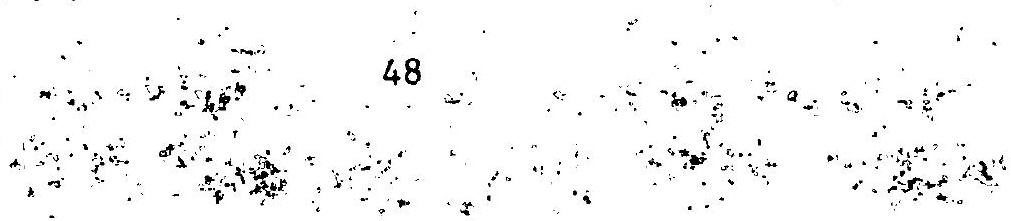


2. A heavy, sharp-edged piece of steel arranged like a guillotine was dropped on a section of sodium cable energized at 7200 volts to ground and buried under approximately five inches of wet earth. When the guillotine was dropped on the energized cable, the protective fuse link operated immediately and there was very little visible reaction of the exposed sodium conductor with the wet earth. Water was poured onto the cable which had been cut approximately three-quarters of the way through. The sodium reacted with the water as it was poured, but the reaction was not at all explosive.

3. Short pieces of cable were cut and completely submerged in a pail of water in order to demonstrate the violent reaction of sodium metal with water. Our tests confirmed that the degree of violence resulting from the reaction with water depends upon the amount of surface exposed.

These tests convinced PP\&L Co. that their personnel could safely handle and install sodium conductor cable if they utilized safe work practices."

Corrosivity connected with sodium conductors is a result of moisture reacting with sodium to form sodium hydroxide. Sodium hydroxide is hygroscopic and will form an aqueous solution which is highly caustic and can caues chemical burns upon rontact with the skin. It is also highly corrosive to most common metals and could thus result in damage to equipment stored, transported or installed with the sodium conductor.

Possible hazards that could be encountered in the handling of sodium are listed in Table 6-2. Although these hazards are real, some simple precautions reduce the potential hazard to a very low probability. These are listed in Table 6-3. 


\section{TABLE $6-2$}

Possible Personnel Hazards from Handling Sod1um

a. Fire and explosion from hydrogen evolved if the sodium comes in contact with water.

b. Sodium hydroxide burns from the residue of a oodium water reaction.

c. Eye injuries from small pieces of sodium or caustic soda.

d. Burns from clothing ignited by clinging particles of burning sodium.

e. Irritation of the eyes and mucous membranes of the nose and throat due to breathing fumes from burning sodium.

f. Flesh burns from contact with sodium. 
TABLE 6-3

Safety Precautions for Handling Sodium Conductors

a. Education and training of all personnel involved with handling sodium is essential.

b. Precautionary labeling must be used to identify the sodium, the possible danger, and to specify methods of fire fighting and first aid.

c. Store and transport sodium conductors so that contact with water is avoided.

d. Do not store sodium conductors in an area without adequate ventilation (to prevent the buildup of hydrogen).

e. Wear eye protection and dry gloves when handing sodium.

f. Avoid contact of sodium with any part of the body. 


\subsection{Field Installations}

More than $1 / 4$ million conductor feet of sodium cable reportedly have been installed and energized at more than 50 utilities around the country. These installations range from small 30 foot long test installations to thousands of conductor feet in normal electrical service. No serious sodium related accident has been reported with workmen installing sodium cable in the field.

l'he major environmental and safety concern with sodium conductors being installed in the field 1nvolves the cable terminatione. Terminating sodium conductors ${ }^{(6)}$ requires cutting the cable to the desired length thus exposing the sodium core. The exposed sodium must not be allowed to come into contact with water or any part of the person. Also tonls or equipment that contact the sodium must be wiped clean of any residue. When the cable is terminated, there are usually scrap end sections which must be disposed. See Section 6.6 for a discussion of scrap handling.

The most serious accident. that is likely to nrcur when terminating a sodium conductor is eye damage due to particles of sodium or sodium hydroxide entering the eye. This can he prevented by the wurkmen wearing safety goggles. Thermal and chemical burns can occur if the sodium comes into contact with wet or damp skin. Protective clothing such as dry leather gloves and heavy work clothes should prevent this kind of a burn. In the event that sodiun gets smeared on the clothing, sodium hydroxide will form and probably cause chemical burns if the clulhling is not removed soon after. Serious personnel injury can be avoided by immediate removal of the contaminated clothing and flushing the affected area with copinus quantitics of water. The clothing should be washed before being worn again.

Most sodiun conductor field installation safety hazards involve water. If there is standing water around the handling area and the exposed end of a sodium conductor is accidently dropped in, then sparking, small explosions, smoke, fire, and flames could result. 
In most cases the fire would extinguish itself in a short time, but secondary fires could result if flammable materials were nearby. Also, some of the burning sodium could be sprayed on personnel. This could be prevented by not allowing sodium conductor work to proceed when there is standing water in the vicinity.

Another possible danger involves the accumulation of hydrogen in areas that are not properly ventilated. If sodium is exposed to moisture, hydrogen will be generated at a rate determined by the mixing rate of the moisture and the sodium. If the hydrogen were allowed to accumulate, an explosive mixture could result. Although this is not likely to happen in open trench installations, occurrence in ducts, transformer vaults and other enclosures is a possibility.

Field installations, where sodium conductors are used above ground, present a possible hazard to the general public. A sodium conductor in a trial installation (7) failed due to a sustained overload with the result that sodium escaped the polyethylene insulation and caught fire. No one was injured in this accident and the fire caused no extensive damage, but the potential for injury and property damage is obvious. It would appear from an environmental and safety viewpoint that sodium conductors can best be utilized underground.

\subsection{Dig-in Consequences}

The consequences of an accidental dig-in to sodium conductor cable has concerned potential cable customers since the cable was first introduced. In 1968 , E. J. Steeve reported ${ }^{(9)}$ the results of sodium conductor cable dig-in tests by Commonwealth Edison Company. "The following are conclusions based on these tests:

1. "The hazard of injury to personnel during the damaging of live secondary, sodium conductor cables is no greater than with conventional copper or aluminum cables. Because of the stretch and snapreaking action of the sodium cable, the danger to electrical shock is probably less than it is for other type cables. 
2. It is difficult to cut sodium conductor cable with hand digging tools. If a workman does manage to cut a cable there is probably no serious hazard presented to him unless free standing water is in contact with the raw sodium.

3. The reaction of the exposed sodium conductor to wet soil during or after dig-ins does not appear to be a ecrious safety hazard, Apparenlily frep warer must be present lefuie selluus flare ups or explosions can take place. The auger, because of its grinding actiul, expuses a relatively large amount of raw sodium to the loosened soil and some of the sodium may be brought to the surface as the tool is raised. However, the limited supply of oxygen in the auger hole minimizes the reaction.

4. There does not appear to be any great problem in handling the damaged cable in wet soil so that repairs can be made to restore service. However, gloves and goggles should always be worn as a minimum satety prccaution."

An accidental dig-in was reported by E. P. Verheiden

of Portland General Electric as follows:

"A water district crew in PGE's service territory cut an energized sodium secondary to an incomplete house, and several weeks passed before PGE crews knew it. After roughly locating the break by inspecting the terrain, PGE's crew had to pump water from the hole before they could get down and locate and repair the cable. The break, once located, was easily repaired by cutting off several inches of cable on each side of the open spot and installing two sodium cable terminators. The terminators were connected with a compression sleeve, taped. and buried again. 
The damaged PE jacket around the sodium allowed it to react to water, and the reaction quickly subsided sealing itself off with a caustic layer."

Other accidental dig-ins were reported by R. L. Garrison (11) of Nacon Corporation as follows:

"Three actual dig-ins have been reported in service installations by two utilities through October, 1968. All three were secondary cables, and were repaired by splicing in short lengths of equivalent copper cable and returned to service with no difficulty."

During the utility survey (see Section 5.2) several dig-in incidents were mentioned. None of these resulted in injury, however, there were reports of unaware equipment operators being frightened when a sodium conductor was dug into in the presence of water.

Two main conclusions can be drawn from these reported dig-ins :

1. The consequence of a dig-in to a powered sodium conductor is no greater than a similar occurrence with a conventional cable.

2. A dig-in to an unpowered sodium conductor could be a greater safety hazard. In the presence of water, small explosions and burning of sodium could results. In dry conditions, the sodium particles could be handled by unaware persons and cause skin burns or eye injury.

\subsection{Fault Consequences}

The consequences of an electrical fault in respect to sodium conductor cables can be considered from two aspects:

1. A fault in the sodium conductor cable such as a dig-in or insulation breakdown.

2. A fault at some other location in the circuit other than the sodium conductor that subjects the cable to high currents. 
The most likely type of fault in the first case is the result of a dig-in. Results of dig-in tests by Commonwealth Edison Company were reported by Edward J. Steeve ${ }^{(9)}$ and by Steeve and Schneider ${ }^{(12)}$. Dig-in tests were conducted on 600 volt 2/0 CUE sodium cable energized at $120 / 240$ volts from a $371 / 2$ kVA transformer. The primary of the transformer was protected by a 15-A type-K fuse and oil circuit breaker, but there was no circuit protection on the secondary side. The circuit was loaded to about 60 amperes and an oscillograph was installed to record values of fault current.

Three separate dig-in tests were made, one each using an eight inch chain type trencher, a 21-inch power auger, and an 18 -inch back hoe. 'There was no visual or audible evidence of a cable failurc when it was dug through by the trencher. There were no flare-ups or other Indications of serious reaction. No fault current was recorded and the load current was broken cleanly.

The dig-in with the auger produced some minor muffled explosions from beneath the loosened dirt. Fau1,t currents recorded by the oscillograph showed evidence of the grinding action of the auger with a peak value of 145 amperes for four cycles, fnllowed by about 36 cycles aind the connected load of 68 amperes before a clean break to zero current. During the next six a aconda abul Len small disturbances were recorded, ranging from four amperes up to 85 amperes and lasting. from one to six cycles each.

The recorda of the back hoc dig-ius showed a clean break of load to zero current with nn pvidenoc of faull current. 'lhe sodium conductor necked down to about $50 \%$ of the original cross section hefore. it broke. There were no flare-ups or other indications of serious reactions by the exposed sodium conductors.

Simulated dig-in tests were conducted on $15 \mathrm{kV}$ sodium cable by inflicting deliberate damage on 20-foot lengths of energized sodium conductor cable on top of the ground. Faulting was accomplished by driving a needle through the insulation by means of a 0.22 caliber blank fired by a device positioned vertically over the cable. 
Repeated strikes of fault current were obtained by the use of an oil circuit recloser and fuse connected in series with the 7200 volt source and test cable. Variations in current magnitude and duration were obtained by using different size fuses and by inserting or bypassing a line reactor at the generating station $12 \mathrm{kV}$ bus.

Six fault tests were made with fault currents from 2300 amperes to 6000 amperes for durations from $11 / 2$ to $81 / 4$ cycles and recloser spacings from 2 to $31 / 2$ seconds. Observations indicated that the sodium cable behaves much like a standard aluminum conductor cable. Heat generated by the arc from the fault melted the polyethylene around the fault. Some conductor material was melted out or eroded away by the arc. There was no subsequent reaction of the sodium after the circuit breaker recloser locked out except when the test was conducted under water. When the cable was faulted under water, the reaction continued for approximately six minutes after the recloser locked out. See Section 6.4 for dig-in test conclusions.

other likely types of damage to sodium conductor cables besides dig-ins are:

1. Damaged insulation caused by handling and installation.

2. Failure at the terminations and connectors.

3. Insulation breakdown due to a high voltage spike surh as frnm lightning.

4. Failure of the insulation due to excessive overcurrent. Experience has indicated that sodium conductor cables are more resistant to handling and installation damage than conventional cables. This is because the soft sodium core yields under pressure, preventing damage to the polyethylene, while aluminum and copper are quite hard by comparison. Steeve reported ${ }^{(9)}$ that"a long-handled, pointed garden shovel was used to dig a hole directly over some 600 volt sodium cables. Despite numerous attempts by two persons, none of the 600 volt 
cables could be severed by the shovel. Had the cables been against a solid surface such as a rock then it probably would have been possible to sever them."

This resistance to damage was noted in field tests reported in Residential Underground Distribution Research Program No. 51 (13) which states:

"The appearance of the cable samples after being installed, energized for 18 months in the earth, and removed was of interest. There was a noticeable absence of tool marks which are usually present on cables with copper or aluminum conductors that have been removed from the earth. A possible explanation is that the sodium conductor offers almost no resistance to external pressure. The polyethylene insulation tends to distort rather than be cut when struck by a digging tool such as the edge of a shove1."

If the polyethylene insulation is breached, chances are quite high that the cable will fail. Results of field tests $(13,14,15)$ indicated a 75\% failure rate of buried sodium cable after 6 months where the polyethylene insulation had been deliberately punctured. These results contradict the predicted reaction of the sodium self sealing a small hnle in the insulation that was demonstrated in the laboratory tests ${ }^{(5)}$. The differences between the laboratory tests and the fleld tests were that the field tests were conducted over a longer period of time and the sodium core was energized at $120 \mathrm{~V}$ to $480 \mathrm{~V}$. The energized core possibly caused an electrochemical reaction which prevented the puncture trom plugging and accelerated the sodium-moisture reaction.

Sodium cable experience has indicated that this mode of failure is very rare where the cable is used in normal service. There have been no reported failures of a sodium cable at an insulation breach except at connectors, and with the exception of an extended overcurrent ${ }^{(7)}$ where the insulation was melted or where the cable was under mechanfcal stress.

Failure at the termination or connector is the most frequent mode of sodium cable failure. The utility survey (see Section 5.2) 
revealed that the connector and terminator failure rate with sodium cable is much higher than that with aluminum or copper. The probable mechanism for failure in most cases is the ingress of moisture causing the sodium cross section to decrease thereby increasing electrical resistance. This causes the temperature of the cable-connector interface to increase until the insulation melts, causing the cable circuit to open. The failure rate of 600 volt secondary cable connectors is higher than $15 \mathrm{kV}$ primary connections. The probable reason for this is that the $15 \mathrm{kV}$ connectors are better protected from moisture ingress.

Sodium cable performance during a fault at some othu: part of the circuit has been investigated. Fault conditions were simulated in tests reported by Steeve and Schneider ${ }^{(12)}$ by short circuiting one end of a sodium cable to ground, then subjecting the other end to $7.2 \mathrm{kV}$. An oil. circuit recloser was used in series with fuses of various sizes to provide a group of fault loadings. A recorder was placed in the circuit to monitor the magnitude and duration of the fault currents. Temperature was monitored by means of a thermocouple taped to the surface of the cable: Short circuit currents were: 2400 amperes for 2 cycles, 3200 amperes for 3 cycles and 2700 amperes for 4 cycles. Eight to fifteen minutes elapsed between each current level. No temperature change could be detected at the surface of the jacket of the sodium cable. Resistance measurements showed that continuity of the conductor was maintained after each high momentary overload.

Several utilities in the survey (Section 5.2) indicated that their sodium cable had been subjected to through fault currents. L. B. Burleson of P.U.D. No. 1 of Snohomish County (WA) stated that, "each $3 \phi$ circuit has had approximately 25 through faults. The magnitude of these faults ranged up to 8700 amps at $13 \mathrm{kV}$. These cables withstood theac through faul,t.s without any sproblem." There has been no sodium cable failure reported as a result of a through fault. 


\subsection{Scrap Handling}

One problem that is unique to sodium cable installations is the disposal of scrap containing sodium. Cut off ends and unused sodium cable cannct be left scattered around a job site. These could become a hazard if picked up by the public or if somehow placed in a standard rubbish container. The result could be a burn, or eye injury, or the starting of a fire.

\section{R. L. Garrison ${ }^{(11)}$ reported the following on scrap handling:}

"Scrap Disposal. Original rccommeidalluns of the manufacturer were to tape all loose ends in the field, collect them in a cuntalner, and return them to the manufacturer's plant for disposal. Containers were made available for this purpose. Also, a triangular metal container has been developed that fastens between the radial spoi.es of the returnable shipping reel. Scrap can be put into this : $\mathrm{Cl}$ idiner and returned to the manufacturer with the reel. Longer sections of cable have been returned on the metal reel after re-applying the thin sheet metal liner and wood lagging to the reel.

Some utility operating departments have expressed ton cern for the excra time and labor required to handle scrap in this manncr, and suggested burying small scrap pieces dfrectly in the treinch. Initial results of sodium cable scrap buried directly in the ground indicate that burial of short lengths of scrap having exposed ends would be an effective method of disposal in areas of moderate rainfall (Table 6-.4).

Sodium cable scraps three incheo or less ill length with ends exposed will completely decompose within seven months. If the cable scraps are slit longitudinally before burial rnmplete decompooition will occur in less than two months. It is seldom necessary to cut more than two inches off the end of the cable to prepare it for the connector."

An incident was related in the utility survey (see Section 5.2) that emphasized the importance of sodium cable scrap control: 
TABLE 6-4

Sodiun Scrap Disposal Test

Cable set

\begin{tabular}{|c|c|c|c|c|}
\hline$\underline{\text { Conductor Size }}(\mathrm{CuE})^{a}$ & Buried $^{\mathrm{b}}$ & Examined & Rainfal1 & $\begin{array}{l}\text { Sodium } \\
\text { Reacted }\end{array}$ \\
\hline $\begin{array}{l}2 / 0-\text { ends exposed }^{c} \\
4 / 0 \text { - ends exposed }\end{array}$ & $\begin{array}{c}4 / 6 / 68 \\
11\end{array}$ & $6 / 3 / 68$ & $11.14 \mathrm{in}$. & $\begin{array}{l}.75 \mathrm{in.} \\
.88 \mathrm{in} .\end{array}$ \\
\hline $500 \mathrm{MCM}$ - ends exposed & $"$ & $"$ & $"$ & $\begin{array}{l}.00 \text { in. } \\
.75 \text { in. }\end{array}$ \\
\hline $2 / 0-$ slitd & $"$ & $"$ & $"$ & Complete \\
\hline $4 / 0$ - slit & $"$ & $"$ & $"$ & " \\
\hline $500 M C M-$ slit & $"$ & $"$ & $"$ & $"$ \\
\hline
\end{tabular}

Cable Set \#2

\begin{tabular}{|c|c|c|c|c|}
\hline \multirow[b]{2}{*}{ Conductor Size (CuE) } & & \multirow[b]{2}{*}{ Rainfall } & \multirow{2}{*}{$\begin{array}{l}\text { Sodium } \\
\text { Reacted } \\
\end{array}$} \\
\hline & Buried & Examined & & \\
\hline $\begin{array}{l}2 / 0 \text { - ends exposed } \\
4 / 0 \text { - ends exnosed }\end{array}$ & $\begin{array}{c}4 / 6 / 68 \\
11\end{array}$ & $11 / 3 / 68$ & 25.53 in. & 1.63 in. \\
\hline 500MCM - ends exposed. & $"$ & $"$ & $"$ & 1.56 in \\
\hline $2 / 0-$ slit & $"$ & " & $n$ & Complete \\
\hline $4 / 0-$ slit & $" 1$ & $"$ & $"$ & 11 \\
\hline $500 \mathrm{MCM}$ - slit & $"$ & $"$ & $"$ & $"$ \\
\hline
\end{tabular}

$$
\begin{aligned}
& \text { a - All samples } 6 \text { inches long } \\
& \text { b - All samples buried in } 14 \text { inches of loam } \\
& \text { c - Both ends of sample exposed } \\
& \text { - d -... Samplec olit, into half cylinders } \\
& \text { e - Third set still under test }
\end{aligned}
$$$$
\text { * } f \text { - Several ends were partially plugged with a crust sodium }
$$
hydroxide but this did not appear to inhibit decomposition.

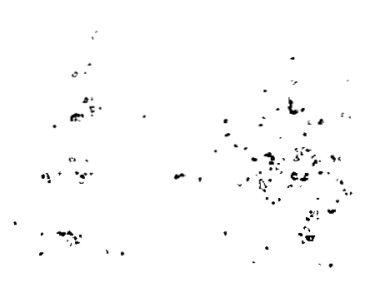


A lineman making a repair on a sodium cable accidently disposed of several small pieces of cable in a standard trash can. When the can was emptied into a garbage truck, a fire started. The truck operator poured water on the fire which caused several small explosions as the sodium reacted. No serious damage was done but the potential for property damage and injury is obvious.

\subsection{Discontinued Circuit Removal and Abandonment}

What should be done with a buried sodium cable once it is removed from service? Every user of sodium cable will have to resolve that question sooner or later. The choices are:

1. Abandon the cable.

2. Dig-up, remove and dispose of the cable.

3. Develop a technique for removing the sodium without digging up the cable.

The consequence of abandoning the cable is the possibility of injury or property damage at some later date due to a dig-in and handling of sodium cable pieces by inexperienced people. The location of the buried cable could have an effect on the decision. If the cable were locaced on utility property, dig-ins could be controlled by proper record keeping. If located elsewhere, however, record keeping would not prevent dig-ins.

The utillty could seek insurance for this type of hazard. The underwriter would need to assess the probability of the occurrence of an injury or property damage. The major factors affecting this probability are the amount of cable abandoned, the location of this cable and the length of time until the sodium would no longer be reactive.

Another important consideration for the underwriters would be the probable severity of an accident. The probability of the abandoned sodium cable causing death is very, very small. Also very small is the probability of several people being injured. The most severe injury 
that would be postulated is an eye injury or skin burns caused by handling pieces of sodium cable exposed by a dig-in. Property damage caused by a fire started by dug-up sodium cable is another possibility.

The surest method for disposing of the abandoned cable is to dig it up and dispose of it by burning ${ }^{(4)}$ or controlled burial. This would be the most expensive technique but would prevent possible future liability problems.

An interesting compromise between the above two methods of removing sodium cable from service is to remove the sodium without removing the cable. The technology exists for controlled reaction of the sodium by inserting a flexible tube into one end of the cable and injecting a reactant. The tube would be pushed through the polyethylene shell as the sodium was reacted away. This technique would require development.

\subsection{Conclusions}

- The use of sodium conductor cable involves hazards not present with aluminum or copper cables.

- These hazards result from the highly reactive nature of sodium with water.

- Experience has shown that properly trained personnel can safely handle sodium conductor cable.

- After thirteen years of sodium cable production, installation and maintenance by more than 50 different crews, there has been no reported incident of serious injury or property damage.

- The use of sodium conductor cable above ground presents a continuous potential hazard because of the possibility of sodium escaping the polyethylene insulation.

- The potential for serious injury to personnel installing and maintaining sodium conductor cable is much less than the hazard presented by electrically active cable. 


\section{ELECTRICAL PERFORMANCE OF SODIUM CABLE}

\subsection{Electrical Basis for Comparison of Cables}

In order to compare sodium cable to aluminum cable, it is of course first necesssary to decide what sodium and what aluminum cables shall be compared. In this study, aluminum cables of four voltage classes and four conductor sizes, specified in Paragraph 7.4.3, were compared with sodium cables of the same voltage class and same overload ampacity. The definition of this equivalence is given in section 3 and in Paragraph 7.1.1, and the required calculations are described in Section 7.4 .

\subsubsection{Definition of Equivalent Sodium Cable}

In comparing sodium cable to aluminum cable, it is first necessary to define the parameters for the particular sodium cable which is considered equivalent to a given aluminum cable. In this study, equivalence implies equal overload ampacities for both cables. The definition is made by a four-step process:

1. The ampacity $I_{1}$ of the aluminum cable at normal conditions (conductor at $90^{\circ} \mathrm{C}$ ) is determined.

2. The overload ampacity $I_{2}$ of this same aluminum cabie (conductor at $130^{\circ} \mathrm{C}$ ) is also determined.

3. The oonductor diameter for a sodium eable which, for the same overload current $I_{2}$, will operate at a conductor temperature of $95^{\circ} \mathrm{C}$, is determined,

4. The conductor temperature at which this sodium cable will operate with the normal current $I_{1}$ is determined. 
The sodium cable with conductor diameter determined as in Step 3

above is defined as the equivalent of the aluminum cable of Steps 1 and 2. The methods of calculation used in these steps are described in section 7.4 .

\subsection{Choice of Type of Cable for Comp: n}

In this section we discuss the general type of construction of the cables to be compared, and the chosen types of installation and the installation parameters. The chosen structure is the only one in which both sodium and aluminum cable have been made; the installation is typical of a majority of URD cable, and the installation parameters are in accord with IPCEA $(16,18,19)$ NEMA $(16,18,19)$ and AIEC ${ }^{(17)}$ specifications.

\subsubsection{Type of Construction}

The construction of the cables considered in this study is shown in Figure 7-1. For 600 volt operation, each cable is simply a heavy insulated wire, comprising only a central conductor (stranded for the aluminum, solid for the sodium) and a surrounding insulation; no semiconducting shieids or outer jackets are employed. For the 15,25 , and $35 \mathrm{kV}$ cables, concentric neutral wires and a semiconducting outer shield are employed, and a semiconducting conductor shield around the stranded aluminum conductor (but none around the solid sodium) is also included. This type of construction was chosen as a basis for coniparison lecause aluminum cable of this type is approved by $\operatorname{IrCEA}(16,18,19)$ (Insulated Power Cable Engineers Association) and $\mathrm{AEIC}^{(17)}$ (Association of Edison Illuminating Companies) and is widely used, and because the only sodium cable ever made, that produced by the NACON Corporation, is of this design. (20)

\subsubsection{Types of Installation}

For illustration, two types of installation have been considered - installation in ducts and direct burial in earth. In each case a single balanced three-phase circuit of three equally-spaced cables buried at a common depth is assumed; all calculations will refer 


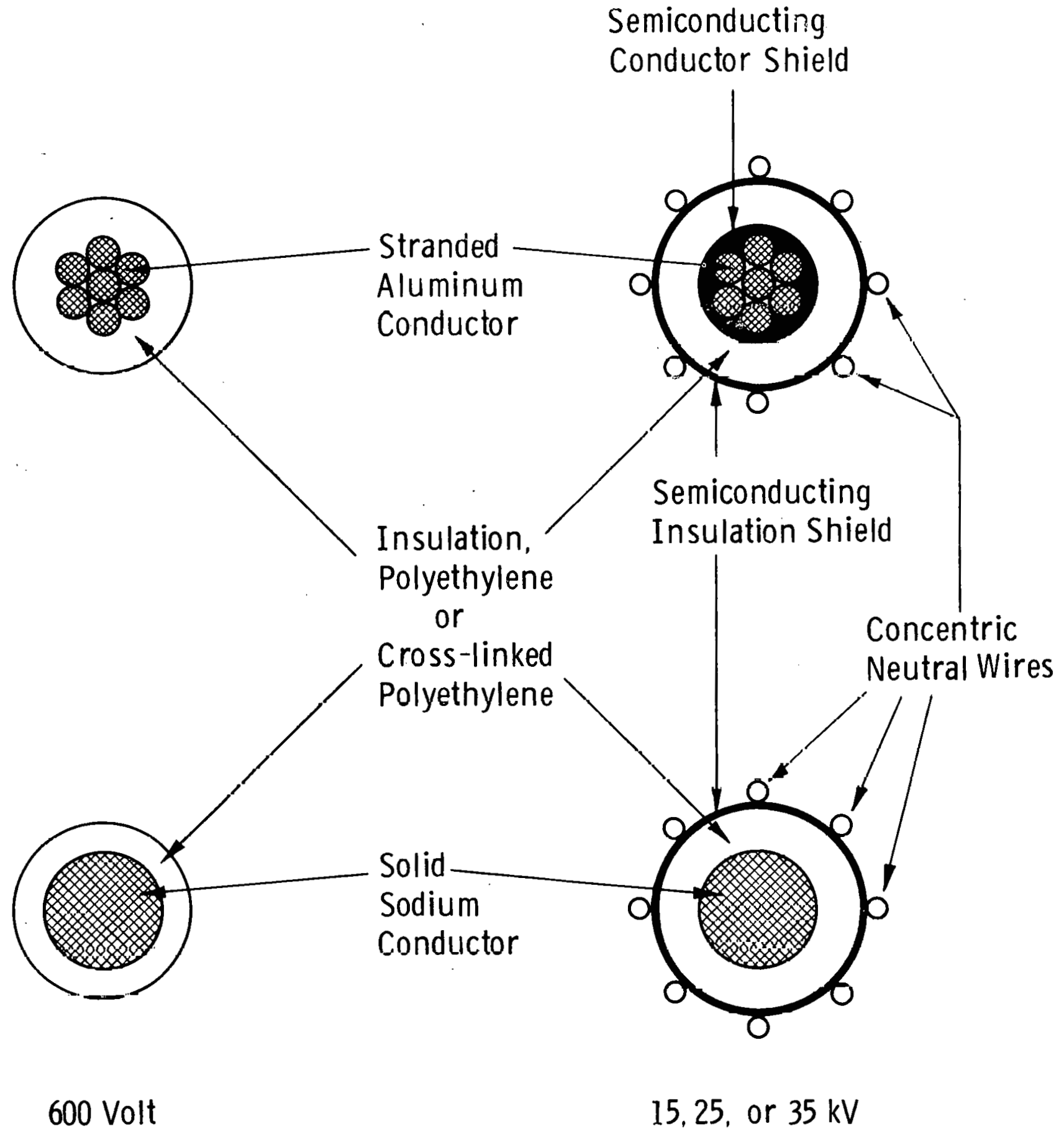

Fig. 7.1-Construction of cables of this report 
to the central cable, the hottest of the three by virtue of being heated by both outér cables as well as by its own losses. No special backfill material has been assumed. In the duct case, fiber ducts embedded in concrete or placed directly buried in earth (these two cases are considered equivalent by $\operatorname{IPCEA}^{(16)}$ were assumed. It was further assumed that each installation of cable requires a new installation of duct as well, so that each cable is installed in an otherwise vacant duct.

\subsubsection{Installation Parameters}

Directly buried cables are assumed buried $91.4 \mathrm{~cm}$ (36 in.) deep and $19 \mathrm{~cm}$ (7.5 in.) apart (dimensions to cable centers). Ducts, when used, are assumed buried $91.4 \mathrm{~cm}$ (36 in.) deep to duct center and spaced $19 \mathrm{~cm}$ ( $7.5 \mathrm{in.})$ between centers. Fiber ducts of $12.7 \mathrm{~cm}$ (5 in.) I.D. and $.64 \mathrm{~cm}(1 / 4 \mathrm{in.})$ wall are used, the material having a thermal resistivity of $480^{\circ} \mathrm{C} \mathrm{cm} /$ watt. Earth thermal resistivity is taken as $90^{\circ} \mathrm{C} \mathrm{cm} /$ watt, and the earth ambient temperature as $20^{\circ} \mathrm{C}$.

\subsection{Basis for Choice of Type and Thickness of Insulation}

The comparisons made in this report will for the most part be based upon polyethylene or cross-linked polyethylene insulation, using the same values for thickness for sodium cable as are presently specified and used for aluminum and copper cable. IPCEA specifies the insulation thickness for $15 \mathrm{kV}, 1000 \mathrm{KCM}$ (KCM denotes thousands of circular mils; $1000 \mathrm{KCM}=0.78654 \mathrm{in}^{2}=5.067 \mathrm{~cm}^{2}$ ) and smaller as $0.445 \mathrm{~cm}(0.175 \mathrm{in.})^{(16)}$; for $15 \mathrm{kV}$, over $1000 \mathrm{kCM}, 0.483 \mathrm{~cm}(0.190 \mathrm{in.})$; for $35 \mathrm{kV}, 1000 \mathrm{KCM}$ or less, $0.876 \mathrm{~cm}$ (0.345 in.); and for $35 \mathrm{kV}$, over $1000 \mathrm{KCM}, 0.914 \mathrm{~cm}$ (0.360 in.). AEIC ${ }^{(17)}$ agrees, adding a specification of $0.660 \mathrm{~cm}$ ( $0.260 \mathrm{in.})$ for $25 \mathrm{kV}, 1000 \mathrm{KCM}$ or 1ess. For 600 volt cable, NEMA and IPCEA both specify polyethylene thicknesses as $0.241 \mathrm{~cm}$ $(0.095 \mathrm{in.})$ for a 225 to $500 \mathrm{KCM}^{(18)}(0.239 \mathrm{~cm}(0.094 \mathrm{in.})$ for crosslinked polyethylene) ${ }^{(19)} ; 0.279 \mathrm{~cm}(0.110 \mathrm{in.})$ for 501 to $1000 \mathrm{KCM}$ $\left(0.277 \mathrm{~cm}(0.109 \mathrm{in.})\right.$ for cross-1inked ${ }^{(19)}$; and $0.318 \mathrm{~cm}(0.125 \mathrm{in.})$ for over $1000 \mathrm{KCM}$. The semiconducting insulator shield thickness was assumed as $0.076 \mathrm{~cm}(0.0301 \mathrm{in}$ ) for all cables but the 600 volt, for which it was omitted. The bases for these choices will be discussed in the following sections. 


\subsubsection{Polyethylene vs. Cross-Linked Polyethylene vs. Ethylene- Propylene Rubber}

Ethylene-propylene rubber (EPR) was initially considered as a candidate insulation material because it is extensively used by okonite

Company ${ }^{(21)}$ in its cables. However, no aluminum cable of the construction described in 7.2.1, and no sodium cable, is available with EPR insulation. EPR was therefore not considered further in this study. Instead, polyethylene and cross-linked polyethylene were considered. The difference between these two materials will appear primarily in the thermal and mechanical properties of the materials.

\subsubsection{Electrical Strength.}

The electrical strengths of polyethylene (PE) and of crosslinked polyethylene (XLPE) are not significantly different, and their electrical loss tangents are also similar; ${ }^{(22)}$ further, the insulation dielectric losses are negligibly small compared to conductor ohmic losses in the cases studied here. Electrically, therefore, these two may be considered equivalent. There is some divergence of opinion on the relative susceptibility of the two to trccing (the formation, by repeated electrical discharge, of elongated treelike void channels in the materlal, eventually resulting in electrical failurc). Okonite, for instance, does not use XIPE in their. higher-voltage cables because of concern for its susceptibility to treeing. (21) Recent comparative studies indicate that XLPE is more resistant to treeing than PE. $(23,24)$ For purposes of this study, the electrical differences are insignificant.

\subsubsection{Thermal and Mechanical Propertips: C.ahle Tnstallation}

The thermal and mechanical properties of the insulation are significant in relation to the inotallation of the cablu, and to its overload and short-circuit operation. Regarding installation, since the sodium has negligible tensile strength, the insulation must furnish the entire tensile strength needed to pull the cable into the duct or to deploy it from a reel and protect the conductor during burial or plowing-in. The required pulling strength for duct installation 
depends on the length of the cable run, the coefficient of friction of the cable aginst the duct Inner surface, the welght of the cable, the number and severity of the bends in the duct, and the stiffness of the cable (horizontal runs are assumed). The insulation tensile strength depends on the temperature of the cable when installed; utilities generally specify this as up to $35^{\circ} \mathrm{C}\left(95^{\circ} \mathrm{F}\right)$, but $49^{\circ} \mathrm{C}$ $\left(120^{\circ} \mathrm{F}\right)$ was used in this study as a possible upper limit. The question is whether the insulation thicknesses normally specified for PE-insulated aluminum cable will provide sufficient pulling strength . in sodium cable, or whether thicker insulation, or XIPE, will be required.

Before looking at this question, some specific examples of actual tensile measurements and pull tests can be cited. Ruprecht and Ware ${ }^{(25)}$ report that a set of three PE-insulated sodium conductors, of $1.27 \mathrm{~cm}(0.500 \mathrm{in.})$ conductor diameter and with $0.127 \mathrm{~cm}(0.050 \mathrm{in.})$ thick insulation, were pulled into a $6.35 \mathrm{~cm}(2-1 / 2 \mathrm{in.})$ diameter steel duct $30.5 \mathrm{~m}$ (100 ft.) long, with four standard $90^{\circ}$ bends, with a total pulling force of 289 newtons (65 pounds), or 96.4 newtons (21.7 pounds) per cable (temperature not reported). Each conductor weighed 0.174 $\mathrm{kg} / \mathrm{m}(0.117 \mathrm{lbs} / \mathrm{ft}$.$) . Since the PE cross-section per cable was 0.557 \mathrm{~cm}^{2}$ $\left(0.0864 \mathrm{in}^{2}\right)$, these results give a stress of $173 \mathrm{~N} / \mathrm{cm}^{2}(251 \mathrm{ps} 1)$ on the PE. No difficulty was experienced in this pull, and on the basis of this stress none would be expected, as the next example will show. Humphrey, Hess and Addis ${ }^{(26)}$ report tensile tests on $15 \mathrm{kV}$ sodium cable, which they rated equivalent to $\# 4$ copper. These cables had sodium conductors of $1.27 \mathrm{~cm}(0.500 \mathrm{in.})$ diameter, and were insulated with $0.559 \mathrm{~cm}(0.220 \mathrm{ln}$.) of PE covered with a $0.076 \mathrm{~cm}(0.030 \mathrm{in.})$ semiconducting PE shield, giving a total PE cross-section of $3.85 \mathrm{~cm}^{2}$ $\left(0.589 \mathrm{In}^{2}\right)$; cables of both high molecular welght $\mathrm{PE}$ of specific gravity about 0.92 and XLPE insulation were tested for tensile strength vs. temperature. Their results for yield strength, to which we have added yield stress calculated by dividing the yield strength by the above insulation cross-section, are given in Table 7-1. 
TABLE 7-1

$\mathrm{PE}$ and XLPE Cable Yield Strength vs. Temperature (After Humphrey, Hess and Addis ${ }^{(26)}$ )

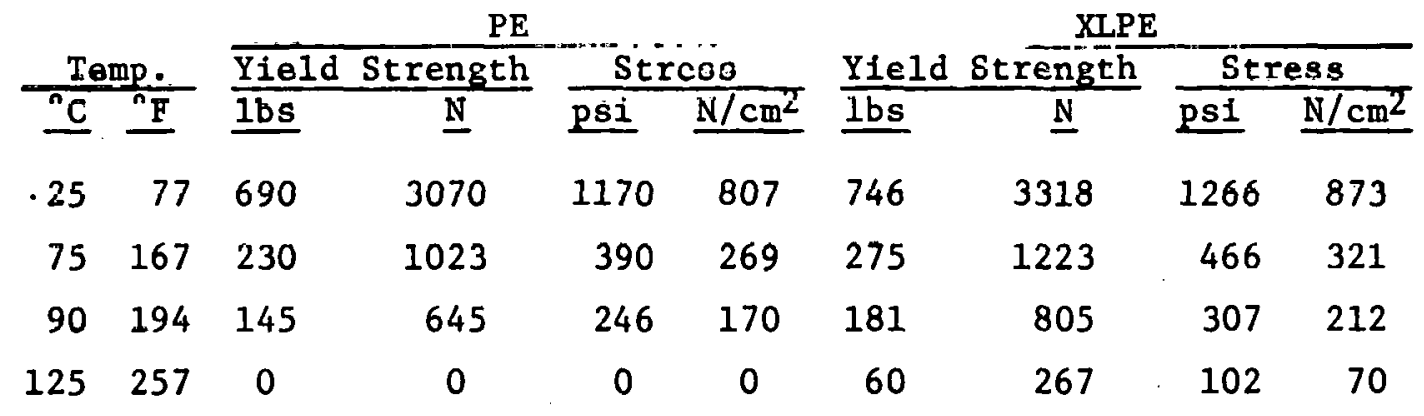


From these stress values it appears that the $173 \mathrm{~N} / \mathrm{cm}^{2}$ (251 psi) stress In the installation reported by Ruprecht and Ware ${ }^{(25)}$ was less than $22 \%$ of the PE yield stress at $25^{\circ} \mathrm{C}$, and about one-third of the expected yield stress at $120^{\circ} \mathrm{F}$ or $49^{\circ} \mathrm{C}$. These figures indicate that, for this installation, even this rather thin PE insulation wall would have possessed adequate strength at $49^{\circ} \mathrm{C}\left(120^{\circ} \mathrm{F}\right)$. Similar tensile strengths have been reported by Matthysse and Scoran. (28)

Consider now the more general case of pulling a cable into a duct, which we assume unoccupled by any other cables. We denote the total cable cross-sectional area in square inches as $B$, and the fraction of this which is insulation as $\lambda$, so that the insulation cross section is $\lambda B$. Since the specific gravity of sodium is 0.97 while that of the PE normally used for cable insulation is about 0.92 , the average density of the cable is very nearly $0.94 \mathrm{gms} / \mathrm{cc}$ no matter what $\lambda 1 \mathrm{~s}$, and the cable welght in $1 \mathrm{bs} / \mathrm{ft}$ is then $0.41 \mathrm{~B}$. If the cable length is $\mathrm{F}$ feet, its weight is then $0.41 \mathrm{BF}$; and if the coefficient of friction between cable and duct surface is $n$, the frictional pulling force is $0.41 \mathrm{BF}$. The tensile stress $S$ on the insulation is then, in pounds per square inch,

$$
S=\frac{0.41 \mathrm{BF} \eta}{\lambda \mathrm{B}}=\frac{0.41 \mathrm{Fn}}{\lambda}
$$

From this relation we can estimate the required insulation fraction $\lambda$ from values of $S, F$, and $\eta$. Typical ut1lity pull distances are about 180 meters (600 feet), and a reasonable maximum appears to be about 240 meters ( $800 \mathrm{feet})$. The coefficient of friction for polyethylene-insulated conductors, with or without concentric neutral wires, has been measured against fiber surfaces at $25^{\circ} \mathrm{C}$, as about 0.3 to 0.4 . The data from the tensile tests of Humphrey et al ${ }^{(26)}$, interpolated, suggest a PE yield stress at $49^{\circ} \mathrm{C}\left(129^{\circ} \mathrm{F}\right)$ of about $503 \mathrm{~N} / \mathrm{cm}^{2}$ (730 psi) which is about $63 \%$ of that at $25^{\circ} \mathrm{C}\left(77^{\circ} \mathrm{F}\right)$. Tensile strength data reported by comercial suppliers for polyethylene of this density is somewhat higher than these values; one report ${ }^{(27)}$ gives $1310 \mathrm{~N} / \mathrm{cm}^{2}(1900 \mathrm{psi})$ at $25^{\circ} \mathrm{C}\left(77^{\circ} \mathrm{F}\right)$, with 
about $65 \%$ of this value ratained at $49^{\circ} \mathrm{C}\left(120^{\circ} \mathrm{F}\right)$. This latter value is for an elongation rate, as specified by ASTM $D 638$, of $0.085 \mathrm{~cm} / \mathrm{sec}(2 \mathrm{in} / \mathrm{min}$ ). The elongation rate for the cable tests of Humphrey et al is not specified, but was probably considerably less than $2 \mathrm{in} / \mathrm{min}$ and would thus be expected to show a lower yield stress. One can therefore assume $S=730 \mathrm{ps}$ at $120^{\circ} \mathrm{F}$, which with $\eta=0.4$ and $F=800 \mathrm{ft}$ gives

$$
\lambda=\frac{0.41 F \eta}{S}=.18
$$

L.e., the polyethylene must occupy $18 \%$ of the cable cross-section, or its thickness must be at least $10.5 \%$ of the conductor radius in order for conventional polyethylene insulation to afford sufficient strengths for a $240 \mathrm{~m}(800 \mathrm{foot})$ duct pull-1n at $49^{\circ} \mathrm{C}\left(120^{\circ} \mathrm{F}\right)$. The insulation thicknesses assumed in the sodium cables to be described are all well In excess of this value; the smallest $\lambda$ for any case is that for a 600-volt sodium cable of conductor radius $1.89 \mathrm{~cm}(0.745 \mathrm{in.})$ and Insulation thickness $0.318 \mathrm{~cm}(0.125 \mathrm{in.})$, giving $\lambda=0.27$, a safety factor of 1.5 even under these extreme conditions. It is possible that at such high installation temperatures the coefficient of friction $n$ will exceed 0.4 ; this might affect the preceding conclusion for the largest cables of the 600 volt class. For the smaller cables, and for all of the higher-voltage cables, $\lambda$ is considerably larger; further, a11 of the higher-voltage cables are wrapped with concentric neutral wires whose coefficlent of friction with the duct will not vary apprertably with installation temperature. The ingulation tensile strength is thus st111 more adequate for these cases.

Some Idea of the relative effects of beids lu the ducts may be gained from consideration of the installation reported by Ruprecht and Ware ${ }^{(25)}$. The weight of their conductors, quoted by them and verified by calculation, was $0.174 \mathrm{~kg} / \mathrm{m}(11.71 \mathrm{bs} / 100 \mathrm{feet})$. With a coefficient of friction of $\eta=0.4$, the pulling force due to friction alone for a stralght duct would have been $21 \mathrm{~N}$ (4.7 1bs) per conductor. Since the total was $96.5 \mathrm{~N}(21.7 \mathrm{lbs})$ per conductor, the remaining 
$75.5 \mathrm{~N}$ (17 lbs) can be ascribed to the four $90^{\circ}$ bends. If evenly distributed, this would mean about $19 \mathrm{~N}(4.3 \mathrm{lbs})$ per bend, making a $90^{\circ}$ bend equal to about $27 \mathrm{~m}$ (90 feet) of straight duct as regards pulling force. If instead $n=0.3$ is assumed, this figure becomes $40 \mathrm{~m}(130 \mathrm{ft})$. It is not expected that the effects of these bends would add IInearly; the tension, and therefore the friction, at the bend closest to the pulled end of the cable must be more than at the next bend, and so on. However, as a rough guide, these figures suggest that a $90^{\circ}$ standard bend is about the equivalent of $30 \mathrm{~m}$ (100 feet) of duct in pulling force.

Many thousands of feet of sodium cable with conventional PE insulation have been installed in ducts and directly buried. No difficulties have ever been reported in installing any of these cables. On the basis of this field experience and the foregoing analysis, it appears that sodium cables insulated with conventional polyethylene in accordance with IPCEA, NEMA, and AEIC recommendations as described at the beginning of Section 7.3 will have adequate strength for direct burlal or new duct installation under all anticlpated circumstances, including lengths up to $240 \mathrm{~m}$ ( 800 .feet) at cable temperatures up to $49^{\circ} \mathrm{C}\left(120^{\circ} \mathrm{F}\right)$, and that the extra strength afforded by XLPE or by thicker insulation is not required on the basis of tensile strength for installation.

\subsubsection{Thermal and Mechanical Properties: Overload Performance}

The second area in which the thermal and mechanical properties of the insulation are important is the cable overload performance. For buried or duct installations, the mechanical strength of conventional polyethylene is quite adequate in all cases where the sodium conductor remains solid. This study has recommended that the sodium stay solid even under overload conditions. However, since short circuits or inadvertent excessive overloads might result in core melting, this circumstance must be considered.

The fact that the heat of fusion of the sodium is advantageous in limiting the cable temperature rise in short circuits of a few cycles to a few seconds duration is well recognized. $(25,29,30)$ Ruprecht and Ware ${ }^{(25)}$ have analyzed such fault behavior in delail, and find that the 
short circuit ampacity of sodium cable is roughly 1.5 times that of copper or aluminum for short-circuit durations of a few seconds or less, assuming that in each case the inftial temperature 1 s $75^{\circ} \mathrm{C}$, the conductor temperature rise is $150^{\circ} \mathrm{C}$, and the duration is short enough that the heat transferred to the insulation is negligible.

For longer-duration faults, this advantage is reversed, because the resistivity of sodium increases by about $42 \%$ upon melting resulting in more rapid heating thereafter. Hus ${ }^{(29)}$ has discussed this case in detail, noting that after melting, a new, higher steady-state temperature will be attalned. See also Paragraph 7.5 .4 of this report.

The course of events after melting is initlated w11l vary with the cable Insulation and installation. If the Insulation is PE, sustained operation with a molten conductor will very likely cause considerable softening of the PE. If the cable is burled, the surrounding earth w11l probably maintain the insulation nearly in its original shape if the overload is not too severe; if the insulation eventually ruptures, a small amount of sodium will escape and possibly interrupt the current. It is unlikely that any damage will result other than the need to repair the cable at the rupture. In a duct installation of PE cable, this same process might occur more readily because of the lack of earth restraint around the cable; alternatively, sufficient local softening and swelling might develop a gap in the conductor which would terminate the current without insulation rupture. This self-fusing action of sodium cable has been noted by several investigators, some of whom consider it an advancage. $(31,32,36)$

Another mode of fallure on sustalned overload has also been observed in PE cables ${ }^{(31)}$ in which, after softening, the insulation slowly contracts on the liquid sodium, constricting the conductor and eventually completely pinching it off and interrupting the current. This is another example of a self-fusing mechanism. This type of fallure does not occur with XIPE, nor with thick PE; only fairly thi.s PE fails in this manner. 
In aerial installations, such as overhead cables or vertical pole risers, the possibility of molten sodium being forctbly expelled represents a significant hazard. One such failure of an overhead cable actually occurred on September 23, 1966, after 2-1/4 hours at a $40 \%$ overload. $(33,34)$ Laboratory tests of risers under overload have shown ${ }^{(31)}$ that PE-Insulated cables may fuse (1.e., Interrupt the current) with or without rupture of the insulation and expulsion of sodium; XLPE-Insulated cables, on the other hand, likewise fused under overload but never ruptured or expelled sodium, and in fact distorted only very slightly. More work in this area is required to establish safe practice. On the basis of available data, it is recommended that for aerlal installations, either overhead or riser, that XIPE insulation be used because there seems to be no way of insuring that occasional long-term overloads may not occur, which could result in discharge of molten sodium. For direct-burled or ducted cable, the likelihood of sodium escape and the hazard if 1 toes are both much reduced, and $\mathrm{PE}$ appears satisfactory for these applications.

\subsubsection{Molsture Diffusion}

The diffusion of molsture into the insulation of sodium cable is potentially a more significant problem than for copper or aluminum cable. The indiffusing water will react with the surface of the sodium conductor to form nonconducting sodium hydroxide, thereby progressively reducing the conductor cross-section. This wellrecognized process $(26,28,33)$ has indeed been used by Eichhorn (35) as the basis for a rather complete and accurate determination of the rate of moisture diffusion in the particular polyethylene (high molecular weight, melt index 0.2 ; low density, about $0.92 \mathrm{gms} / \mathrm{cc}$ ) used for cable insulation. He measured the change in resistance with time for cables. (sodium conductor diameter $0.508 \mathrm{~cm}(0.200 \mathrm{in.})$, insulation thickness $0.102 \mathrm{~cm}(0.040 \mathrm{in.}))$ immersed in water at controlled temperatures between 40 and $80^{\circ} \mathrm{C}$, or in air at controlled relative humidity and temperature. The results were consistently described by the relation 


$$
t=\frac{.00085 d^{2} \times f}{P(d+x) H}
$$

where $d=$ conductor diameter, $\mathrm{mils}$

$$
\begin{aligned}
& x=\text { insulation thickness, mils } \\
& f=\text { fraction of } \mathrm{Na} \text { converted to } \mathrm{NaOH}(0 \leq \mathrm{f} \leq 1.0) \\
& P=\text { permeability of insulation to water, } \frac{\text { gram mils }}{100 \mathrm{in}^{2} \text { day }} \\
& \mathrm{H}=\text { relative humidity fraction }(0 \leq \mathrm{H} \leq 1.0) \\
& t=\text { time in yedrs to convere a fraction } \mathrm{f} \text { of the } \mathrm{Na} \text { cross- } \\
& \quad \text { reaction to } \mathrm{NaOH}
\end{aligned}
$$

The permeability calculated from these data was found to vary with temperature according to the relation

$$
P=9.63 \times 10^{11} \exp (-8580 / \mathrm{T})
$$

where $P$ is in the preceding units, chosen by Eichhorn for practical reasons, and $T$ is average Insulation temperature in ${ }^{\circ} \mathrm{Kelvin}$. (Some of the units of the above equations differ from those used by Eichhorn).

Values of $P$ calculated from Equation $7-4$ are presented in Table 7-2 for a range of tempratures from 0 to $95^{\circ} \mathrm{C}$. With these values and Equation 7-3 it is possible to calculate, for various cable geometries, the service lifetime for a sodium cable conductor to be Leduced $10 \%$ in area. On the basts of such calculations, Humphrey et al (26) have said, " $\Lambda$ woeful service 11 fe of 40 years under normal ambient conditions is predicted for direct-buried [polyethylene insulated sodium] cable." For unjacketed cable of the construction of Flgure 7-1, as made by Nacon, these predictions appear to be far too optimistic if the cable is assumed to operate at full rated load and high humidity from the date of installation. The relevant calculations by Humphreys were not published, but appear to have been based on an average insulation temperature in the neighborhood of $25^{\circ} \mathrm{C}$, indicating a very 1 ightly loaded 
TABLE 7-2

Permeability of Cable Polyethylene to Moisture
(After Elchhorn) (35)

\begin{tabular}{|c|c|c|}
\hline \multirow[b]{2}{*}{$\mathrm{T}^{\circ} \mathrm{C}$} & $\mathrm{gmmils}$ & $\mathrm{gm}$ \\
\hline & 100 in $^{2}$ day & $\mathrm{cm} \mathrm{sec}$ \\
\hline 0 & .0216 & $9.84 \times 10^{-13}$ \\
\hline 5 & .0380 & $1.73 \times 10^{-12}$ \\
\hline 10 & .0656 & $2.99 \times 10^{-12}$ \\
\hline 15 & .111 & $5.06 \times 10^{-12}$ \\
\hline 20 & .185 & $8.43 \times 10^{-12}$ \\
\hline 25 & .302 & $1.38 \times 10^{-11}$ \\
\hline 30 & .485 & $2.21 \times 10^{-11}$ \\
\hline 35 & .768 & $3.50 \times 10^{-11}$ \\
\hline 40 & 1.20 & $5.47 \times 10^{-11}$ \\
\hline 45 & 1.84 & $8.38 \times 10^{-11}$ \\
\hline 50 & 2.80 & $1.28 \times 10^{-10}$ \\
\hline 55 & 4.20 & $1.91 \times 10^{-10}$ \\
\hline 60 & 6.22 & $2.83 \times 10^{-10}$ \\
\hline 65 & 9.10 & $4.15 \times 10^{-10}$ \\
\hline 70 & 13.2 & $6.01 \times 10^{-10}$ \\
\hline 75 & 18.9 & $8.61 \times 10^{-10}$ \\
\hline 80 & 26.8 & $1.22 \times 10^{-9}$ \\
\hline 85 & $37: 6$ & $1.71 \times 10^{-9}$ \\
\hline 90 & 52.3 & $2.38 \times 10^{-9}$ \\
\hline 95 & 72.1 & $3.29 \times 10^{-9}$ \\
\hline
\end{tabular}


cable. It will be shown in Section 7.5 that the full-load conductor operating temperature for sodium cable, as defined in Section 7.1 , is about $69^{\circ} \mathrm{C}$ (ambient $20^{\circ} \mathrm{C}$, rise $49^{\circ} \mathrm{C}$ ) for most circumstances, and that the thermal drop across the insulation is no more than $10^{\circ} \mathrm{C}$ in nearly all cases. The average insulation temperature is then about $65^{\circ} \mathrm{C}$, and the appropriate value of $P$ is, from the table, $9.1 \mathrm{gm} \cdot \mathrm{mils} / 100 \mathrm{in}^{2}$ day. Assuming the pessimistic combination of constant full 10 ad and $100 \%$ relative humidity, we may then calculate a minimum life for sodium cable from Equation 7-3 by secting $\mathrm{f}=0.1, \mathrm{P}=9.1$, and $\mathrm{H}=1$. Choosing, for example, a $15 \mathrm{kV}$ sodlum cable equivalent to $1000 \mathrm{KCM}$ of aluminum (which from Table A $3-6$ has $d-3.73 \mathrm{~cm}$ (1468 mills). $x=0.521 \mathrm{~cm}$ (20.5 in11s)) one finds that $t=2.46$ years. Choosing as another example a 600 volt cable equivalent to $750 \mathrm{KCM}$ of aluminum (which from Table A3-8 has $\mathrm{d}=3.246 \mathrm{~cm}(1278 \mathrm{mils})$ and $\mathrm{x}=0.406 \mathrm{~cm}$ (125 mils), the same insulation thickness actually used by Nacon for cable of this voltage class but with $d=1165 \mathrm{mils}$ ) one finds that $t=1.36$ years.

These disturbingly low predicted lives raise the questions, "What about the service record of cables already installed?" and "What other data are available to check these predictions?" Regarding the second question, Keliy and Ginerre ${ }^{(37)}$ report on measurements on three cables which were immersed in water at $75^{\circ} \mathrm{C}$ for five months; conductor resistance measurements were made monthly at $25^{\circ} \mathrm{C}$. Table $7-3$ shows their cable dimensions and the resistance change over five months; added in the last two columns are the times which are predicted by Equation 7-3 to reach those resistance changes, using $H=1.0$ and $P=$ $18.9 \mathrm{gm} \mathrm{mils} / 100 \mathrm{in}^{2}$ day. It can be seen that these are from 1 to 3 months, in fair agreement with observed values. It is curious that Kelly and Gnerre were not alarmed by this rapid degradation; apparently they too felt that service temperatures would be far below $75^{\circ}$. It should be added here that they found no decrease of corona onset voltage with time; apparently the sodium hydroxide forms as a dense and void-free insulator. 
TABLE 7-3

Resistance Increases of Five-Month Water-Immersed Sodium Cables (After Kelly and Gnerre (37) and Calculated Times* for This Increase to Occur (Equation 7-3)

\begin{tabular}{|c|c|c|c|c|c|c|c|}
\hline \multirow[b]{2}{*}{ Cable } & \multirow[b]{2}{*}{$\mathrm{d}, \mathrm{mils}$} & \multirow[b]{2}{*}{$x$, mils } & \multicolumn{2}{|c|}{ Resistance } & & \multirow[b]{2}{*}{$t$ tyrs } & \multirow[b]{2}{*}{$t_{\text {mos }}{ }^{*}$} \\
\hline & & & In1tial & Final & & & \\
\hline \#4 CuE & 335 & 175 & .281 & .266 & .0564 & .097 & 1.2 \\
\hline$\# 2 / 0 \mathrm{CuE}$ & 603 & 100 & .0871 & .0810 & .0753 & .174 & 2.1 \\
\hline$\# 1 / 0 \mathrm{CuE}$ & 534 & 50 & .143 & .117 & .222 & .243 & 2.9 \\
\hline
\end{tabular}

Concerning the service record of installed sodium cable, it is probable that their observed longevity is due to the fact that high temperature and high humidity have not occurred simultaneously. (In this connection see Table 5-4, which shows very light load service for almost all sodium cables). It is in fact to be expected that if the cable is hot, water will migrate away from it; $(16,38,39)$ this, and the consequent increase in local soil thermal resistivity, is the basis on which IPCEA specifies ${ }^{(16)}$ a maximum earth interface temperature. Conversely, if soll is wet, the temperature of the cable may be below tabulated values, reducing the permeability. $P$. Further, in a practical case, it is to be expected that newly installed cable will initially be lightly loaded, and will not approach rated load and temperature for some years. In such a situation the assumptions of maximum temperature and humidity are probably too stringent; an operating temperature of, for example, $45^{\circ} \mathrm{C}$ rather than $65^{\circ} \mathrm{C}$, and humidity of $\mathrm{H}=0.5$ rather than unity, would result in ten times the life calculated for $\mathrm{T}=65^{\circ} \mathrm{C}$ and $\mathrm{H}=1.0$. For any assumed curve of load vs. time (and corresponding hymidity) Equation 7-3 can be used to determine the fraction of reacted sodium for each time segment and thus the expected life. In the extreme cases where one must assume constant full load and wet conditions $\left(\mathrm{T}=65^{\circ} \mathrm{C}, \mathrm{H}=1.0, \mathrm{P}=9.1 \mathrm{gm} \mathrm{mils} /\right.$ 100 in $^{2}$ day), it is clear from Equation 7-3 that no reasonable insulation 
thickness will provide enough moisture resistance to assure a 40 year iife. To pick an extreme case, if one considers a sodium conductor diameter of $3.73 \mathrm{~cm}(1468 \mathrm{mils})$ as in the first case, and an insulation thickness of $1.27 \mathrm{~cm}$ (500 mils), then $t=5.1$ years for $10 \%$ sodium reaction. It appears, therefore, that for operation at rated ampacity and wet conditions polyethylene-insulated sodium cable should have a vaporbarrier jacket, although in many practical installations load and humidity may be low enough that a jacket can be omftted.

This jacket, when required, thust furnish an adequate vapor barrier at a cable surface temperature of about $65^{\circ} \mathrm{C}$. This might be provided by, for example, efther a very thin metallic sheath, or a PVC jacket. PVC is stated ${ }^{(40)}$ to have a permeability to water vapor of less than $2 \%$ of that of cable polyethylene. However, this value depends very strongly on crystallinity and presence of fillers; the foregoing ratio is stated to be for crystalline PVC and "somewhat crystalline" PE. Even in conventional (aluminum or copper) cables it is sometimes argued that a waterproof sheath is necessary to prevent cable fallure by water treeing caused by indiffusing moisture. Opinion of both utilities and cable manufacturers is divided on this point; some manufacturers will only furnish, and some utilities only install, lead-sheathed cable, while others find unsheathed cable satisfactory. Even a thin layer of helically half-lapped aluminum adhesive tape (probably protected from abrasion by a plastic outer jacket) would probably be adequate, even though small amounts of moisture might diffuse through along the adhesive layer. Since it is not at this time clear what the jacket will be, the jacket has been ignored in the ampacity calculations of this study. In Paragraphs 7.3.6 and 7.7.4, which describe the sensitivity of ampacity to insulation thickness, it is shown that the effect of the jacket on ampacity will be very small.

The effect of crosslinking on the molsture permeability of polyethylene is generally negliglble; crosslinking links chains together locally but does not greatly affect the overall molecular structure. On the basis of moisture transmission, therefore, PE and XIPE are 
essentially equivalent. In the following presentations, it will be assumed that moisture protection, if deemed necessary, will be provided by a jacket, and will therefore not be a determining factor in the choice of insulation material or thickness.

\subsubsection{Sensitivity of Ampacity to Insulation Thickness}

IPCEA $(16,18,19)$ and AEIC ${ }^{(17)}$ have specified insulation

thicknesses for polyethylene-insulated cables with aluminum or copper

conductors. Since, however, in sodium cable the mechanical tensile strength is derived almost entirely from the insulation, it is a priori possible that thicker insulation might be required than for aluminum or copper. It is therefore of interest to know how such thicker insulation will affect the ampacity of sodium cable, and this was accordingly calculated by methods which are described in Section 7.4 . Results are shown in Figure 7-2 for several conductor sizes, both for duct installation and for direct burial. The conductor temperature assumed for this calculation is $69^{\circ} \mathrm{C}$, because this is the operating temperature obtained in step 4 of the comparison equivalency procedure of Section 7.1.1 for a wide range of cable sizes. It can be seen that for the direct burial case, increasing the insulation thickness reduces the ampacity as is to be expected on the basis that thickening the insulation merely replaces some of the earth, having a thermal resistivity of $90^{\circ} \mathrm{C} \mathrm{cm} /$ watt, with insulation of a higher thermal resistivity). For the duct case, the dependence is much less and may be in either direction. The $2196 \mathrm{KCM}$ cable shows a slight but continuous decrease in ampacity as insulation thickness increases over the range of 0.318 to $1.067 \mathrm{~cm}(0.125$ to $0.420 \mathrm{in.})$. The 530 KCM shows a slight continuous increase, and the 1000 and $1690 \mathrm{KCM}$ stzes show broad maxima of ampacity at about 0.838 and $0.457 \mathrm{~cm}(0.330$ and 0.180 in.) thicknesses respectively. For practical purposes, in these duct cases, the ampac1cy is lidependent of insulation thickness. The figure also demonstrates the varlation of ampacity with conductor cross-section. 


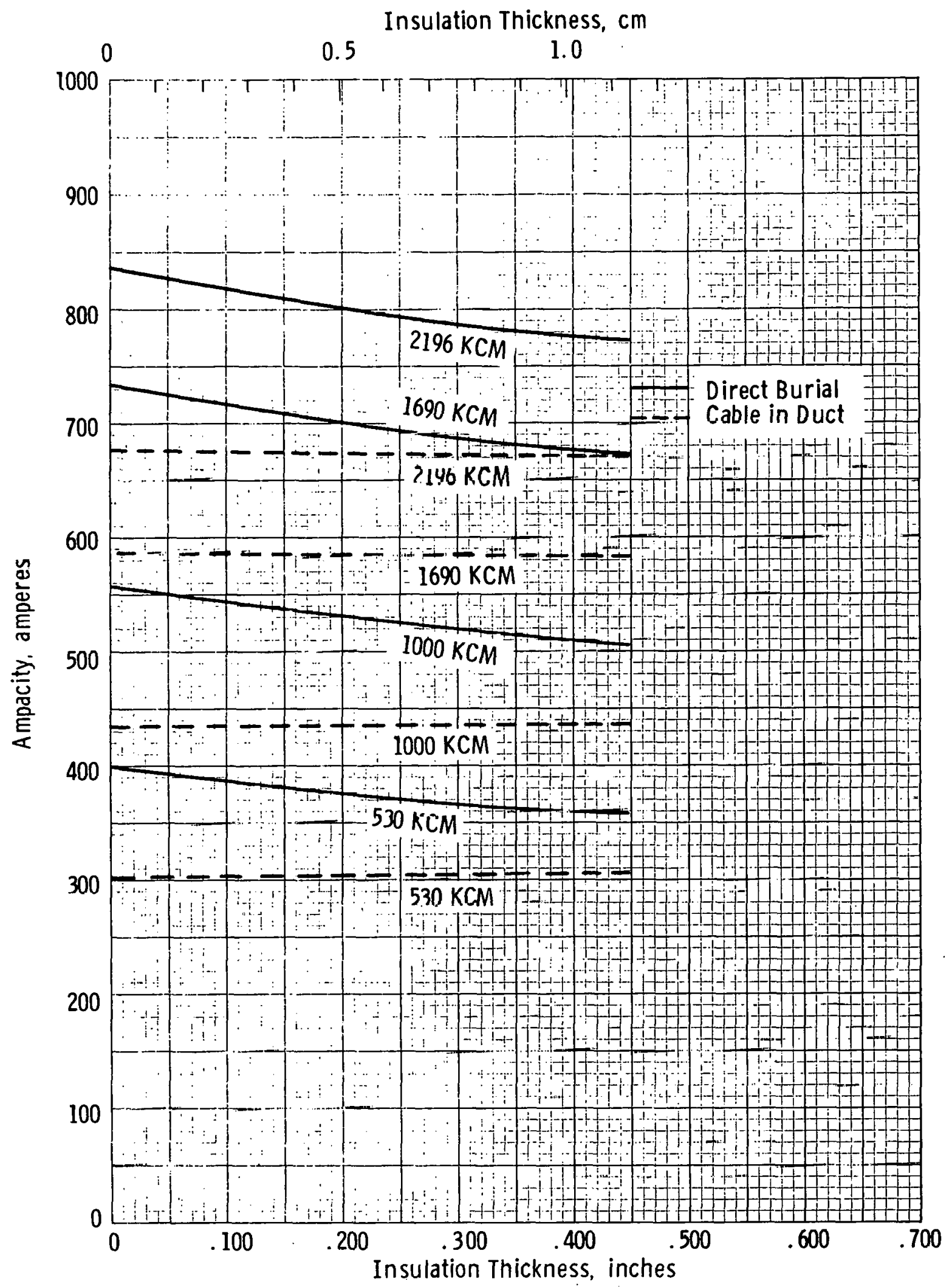

Fig. 7-2-Ampacity of sodium cable as a function of insulation thickness and conductor size 


\subsection{Description of Ampacity Calculation}

The calculation of cable ampacity is rather complicated and depends on many variables. The procedure which is used here is based on the work of Neher and McGrath, (41) which has, since its publication in 1957, become the accepted standard of the cable industry. Because of its sound mathematical basis and wide industrial acceptance, this work has been adhered to as closely as possible in developing a set of equations for ampacity calculation. These equations were then tested by comparing their predictions for conventional aluminum and copper cable to the standard IPCEA ampacity tables, (16) with which they agreed excellently. Following this verification, the equations were used to determine sodium and aluminum equivalent cables. The following sections describe the calculations in detail.

\subsubsection{Derivation of Basic Equations}

The following procedure, 1ike that of Neher and McGrath,

is based upon treating the cable system as a set of line heat sources, and calculating the cable current required to cause a specified temperature rise at the conductor as a result of the flow of the generated heat from the conductors, through the cable insulation, into the surroundings. It is conventionally assumed $(39,41)$ that the earth surface is an isotherm at the ambient temperature, here taken as $20^{\circ} \mathrm{C}$. Considering first the case of directly buried cable, it was assumed that within the cable all heat is generated in the conductor and flows radially and uniformly outward. Outside the cable, heat flow is as though from parallel line sources of strength $Q$ and $-Q$ watts/cm, located a distance $h$ below and above a horizontal midplane respectively, in an infinite and thermally uniform medium. Then the midplane temperature $\mathrm{T}_{0}$ will be uniform and will be that of the medium far away. The midplane then represents the surface of the earth, and the heat flow below the midplane models the actual heat flow in the earth. 


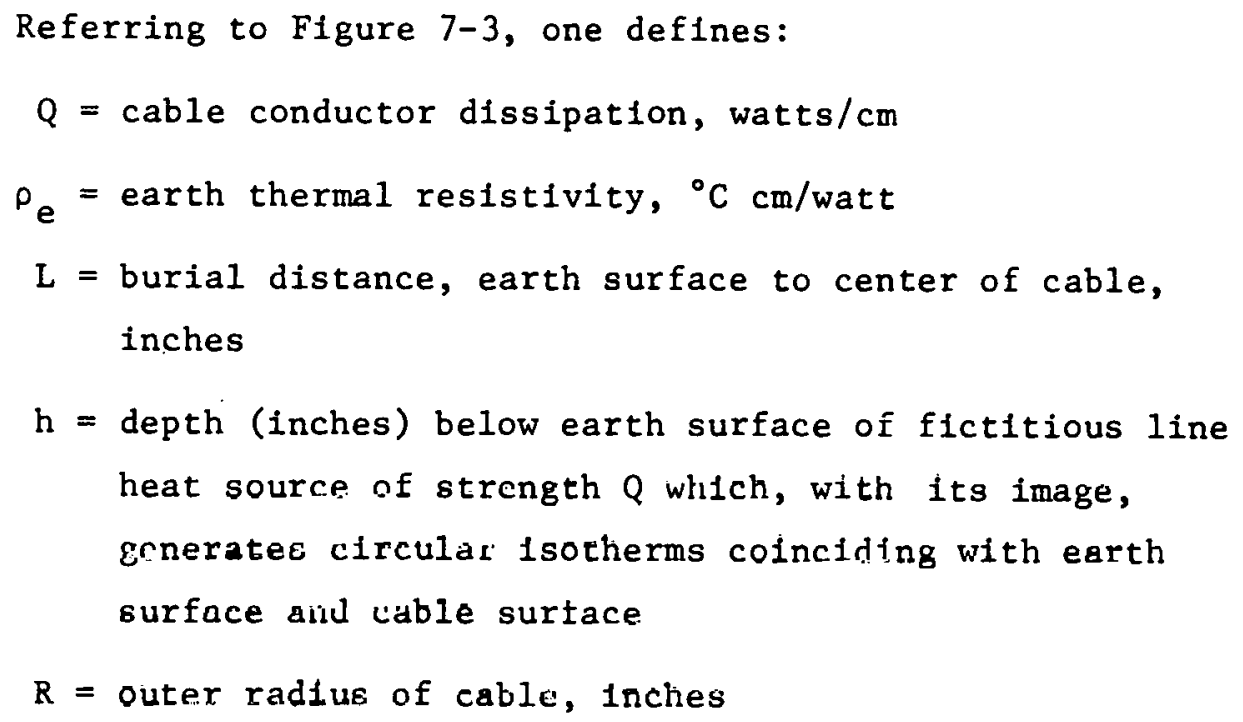

The temperature rise $\delta \mathrm{T}$ above ambient at any point $\mathrm{x}, \mathrm{y}$ distant $\mathrm{d}_{1}$ from the lower heat source and $d_{2}$ from the upper (image) heat source is then given by

$$
\delta T=\frac{Q p}{2 \pi} \ln \frac{d_{2}}{d_{1}}
$$

where

$$
d_{1}=\sqrt{x^{2}+(y-h)^{2}} \text { and } d_{2}=\sqrt{x^{2}+(y+h)^{2}}
$$

Note that $h$ is not the location of the cahle centor the vircular isotherm generated by this heal source and its image, and which represents the outside of the rable, ia centesed at a depth L slightly greater than $h$. It can be shown $(39)$ that $h=-7 L^{2}-R^{2}$. Then for the particular case where $y=L$

$$
\delta T=\frac{Q \rho_{e}}{2 \pi} \ln \frac{\left[x^{2}+\left(L+\sqrt{L^{2}-R^{2}}\right)^{2}\right]}{\left[x^{2}+\left(L-\sqrt{\left.L^{2} R^{2}\right)^{2}}\right] 1 / 2\right.}=\frac{Q \rho_{e}}{4} \ln \frac{x^{2}+\left(L+\sqrt{L^{2}-R^{2}}\right)^{2}}{x^{2}+\left(L-\sqrt{L^{2}-R^{2}}\right)^{2}}
$$


Dwg. 6450A23

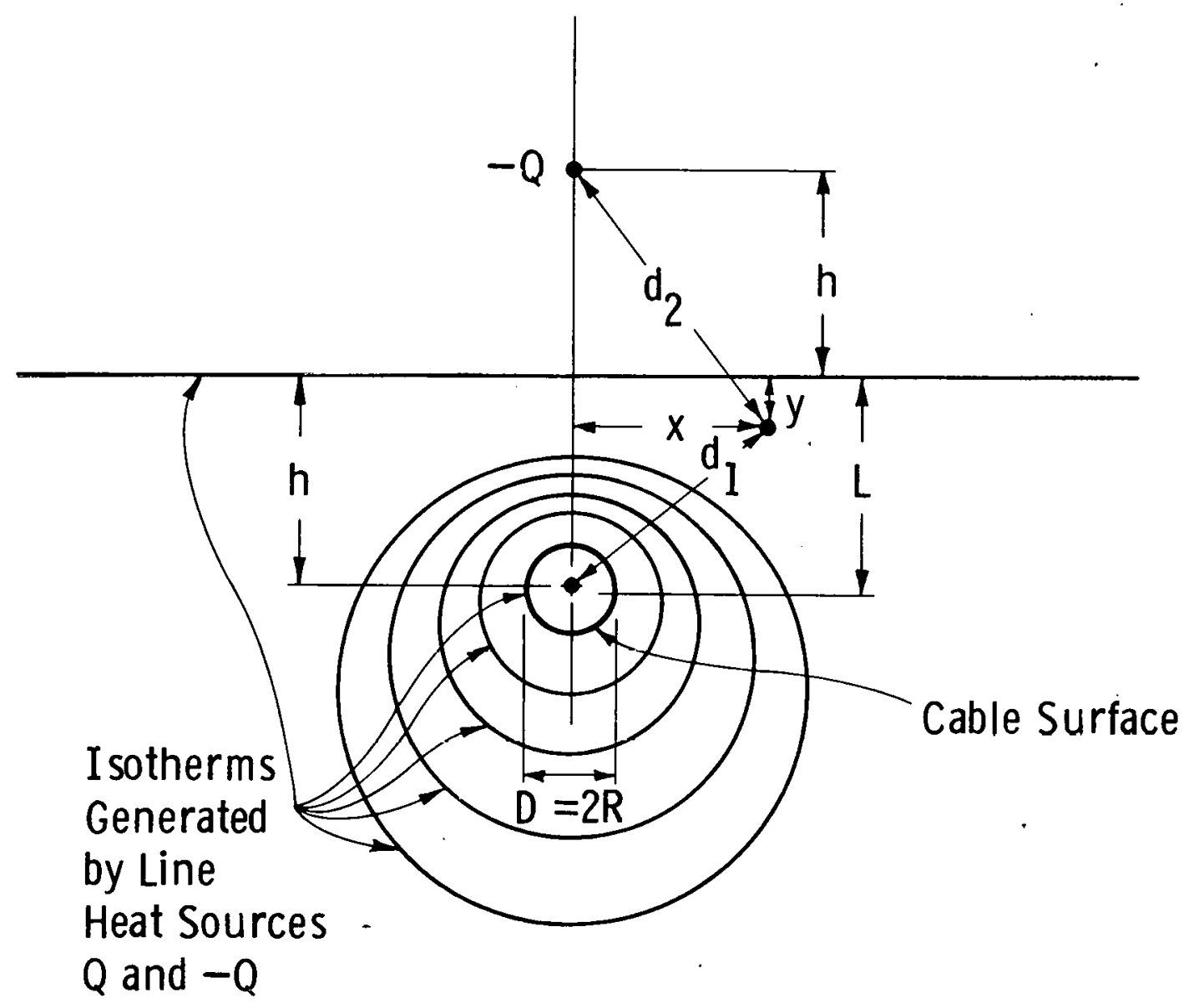

Fig. 7-3-Thermal geometry of a buried cable 
For a three-phase group of three cables buried at equal depths $\mathrm{L}$ and separated by $x$, the rise $\delta \mathrm{T}_{\mathrm{m}}$ (mutual heating) at the central cable caused by the heat from both outer cables will be twice this figure. To this must be added the rise $\delta \mathrm{T}_{s}$ (self-heating) caused by the heat from the central cable itself, which is

$$
\delta T_{S}=\frac{Q \rho e}{2 \pi} \ln \frac{L+\sqrt{L^{2}-R^{2}}}{R}
$$

Thus the total rise $\delta \mathrm{T}_{\mathrm{cs}}$ ac che surface uf the central cable io given by

$$
\delta \mathrm{T}_{\mathrm{cs}}=\delta \mathrm{T}_{\mathrm{m}}+\delta \mathrm{T}_{\mathrm{s}}
$$

This assumes that all three cables are identical heat sources of $Q$ watts $/ \mathrm{cm}$. If losses in conducting shields are significant, this $Q$ should be replaced by $(1+\alpha) Q$ where $\alpha$ is the ratio of shleld losses to conductor losses.

Within the cable all heat is assumed to be generated at the conductor and to flow radially outward. (Because of the very low losses in polyethylene, dielectric heating can be neglected as in the IPCEA tables). The temperature rise $\delta T_{I}$ (internal heating) from the cable outer surface to the conductor surface caused by this heat flow is given by

$$
\delta T_{I}=\frac{Q \rho_{i}}{2 \pi} \ln \frac{R}{r_{1}}
$$

where $\rho_{i}$ is the thermal resistivity of the insulation in ${ }^{\circ} \mathrm{C} \mathrm{cm} /$ watt, $r_{1}$ is the conductor radius in inches and $R$ and $Q$ are as defined earlier. The insulation thickness $t_{i}$ is then given by $R-r_{1}$. In calculating $\delta T_{I}$, the insulation thermal resistance must include not only that of the electrical insulation but also that of the semiconducting shields at the conductor and at the cable outer surface, if these are present. 
Since these are composed of a carbon-loaded polyethylene and have thermal characteristics essentially identical to those of the unfilled polyethylene, they are properly accounted for by taking the insulation thickness to include all three.

The total temperature rise $\delta \mathrm{T}$ of the conductor above the ambient (earth surface) temperature is then given by

$$
\begin{aligned}
& \delta \mathrm{T}=\delta \mathrm{T}_{\mathrm{m}}+\delta \mathrm{T}_{\mathrm{S}}+\delta \mathrm{T}_{\mathrm{I}} \text { or } \\
& \delta T=\frac{Q}{2 \pi}\left[\rho_{e}\left(\ln \frac{x^{2}+\left(L+\sqrt{\left.L^{2}-R^{2}\right)^{2}}\right.}{x^{2}+\left(L-\sqrt{\left.L^{2}-R^{2}\right)^{2}}\right.}+\ln \frac{L+\sqrt{L^{2}-R^{2}}}{R}\right)(1+\alpha)+\rho_{1} \ln \frac{R}{r_{1}}\right]
\end{aligned}
$$

The loss $Q$ in watts/cm is in turn euqal to $10^{6} I^{2} R_{a c}$ where $I$ is the current in amperes and $R_{a c}$ is the conductor alternating-current resistance in microhms $/ \mathrm{cm}$. Then $I=\sqrt{Q / 10^{6} \mathrm{R}}$, or

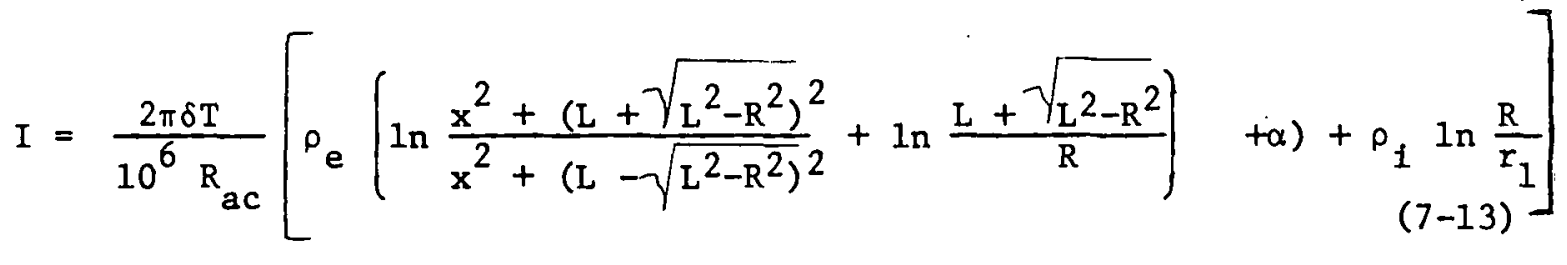

This is the relation used to calculate the ampacity for directly buried cable. Nlthough the units of $x, L, R$, and $r_{1}$ were all specified as inches, they can equally well all be specified as $\mathrm{cm}$ in Equation 7-13.

The conductor resistance $R_{a c}$ which is required for this calculation is greater than the direct-current resistance $R_{\text {dc }}$ because of the phenomenon called skin effect, in which alternating currents in a conductor are crowded toward the outer surface of the conductor by the magnetic fields produced by the current. Because the effect depends on the rate of change of the magnetic field, it is a function of frequency. A rigorous mathematical treatment of this effect can be given for a solid round conductor ${ }^{(43)}$, for this case, numerical results 
are given by Dwight in the Radio Engineers Handbook. (42) Values for conventional stranded conductors are given in the Standard Handbook for Electrical Engineers. (44) If the skin-effect ratio $\beta=\mathrm{R}_{\mathrm{ac}} / \mathrm{R}_{\mathrm{dc}}$ is plotted against the ratio of conductor cross-sectional area $A$ to the dc resistivity $\rho_{\mathrm{dc}}$, it is found that the curves for solld and stranded conductors are identical to within the tabulated accuracy, so that a single relation suffices for both. A plot of $A / \rho d c$ vs. $R_{a c} / R_{d c}-1$, i.e., $\beta-1$, is given in Figure 7-4. Here $A$ is in thousands of circular mils and $\rho_{\mathrm{dc}}$ in microhm $\mathrm{cm}$. This curve applies, within its range, to both solid and stranded ronductors of any material.

It io also nectssary to know the relation brtween conduclur radius and cross-sectional area. For solid conductors, this is fust $A=4000 r^{2}$, where again $A$ is in thousands of circular mils and $r$ 1s in inches. For stranded conductors, the data given in the standard Handbook for Electrical Engineers ${ }^{(44)}$ are described very closely by the relation $A=3016 \mathrm{r}^{2}$.

With these relations it is possible to write a simple calculatur program for calculating ampacity. For this purpose it is conventent to have an analytical relation for the dependence of $\beta$ on $\Lambda / \rho_{\text {de }}$ from Figure 7-4. This curve is very clusely fie by the relation

$$
\beta-1=2.388 \times 10^{-7} x^{2}\left(1+\frac{0.6605}{\frac{x}{172}+\frac{172}{x}}\right)
$$

which was employed in our program.

It is aloo necessary lu know the conductor de resistivity as a function of temperature. For aluminum, the resistivity is taken as (45)

$$
\rho_{\mathrm{A} 1}=2.8624+0.0115(\mathrm{~T}-20)
$$




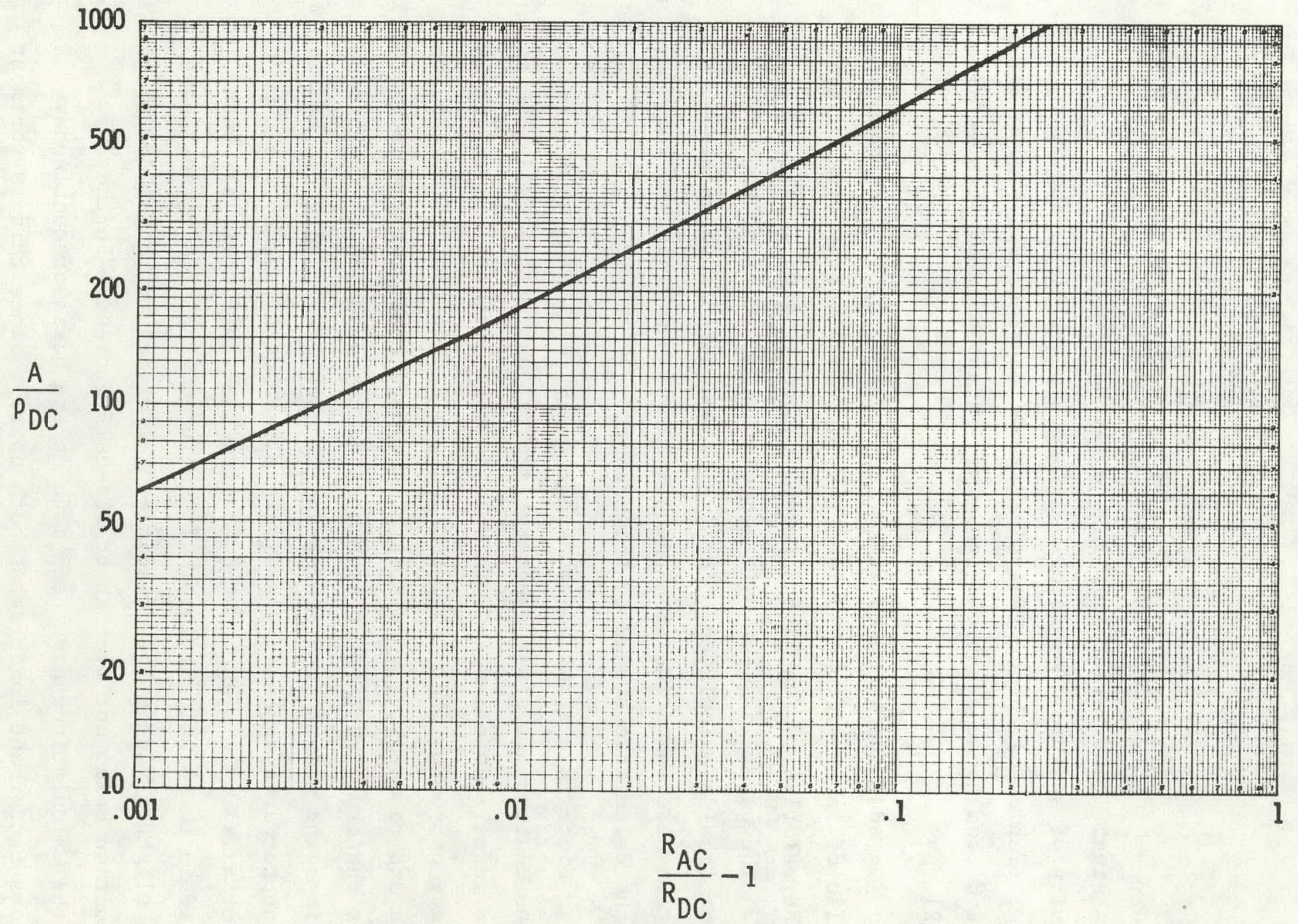

Fig. 7-4-Skin-effect @ $60 \mathrm{~Hz}$ for round wire or stranded cable vs. ratio of cross-sectional area A to resistivity $P D C$

$A$ in thou sands of circular mils (KCM), PDC in microhm $\mathrm{cm}$ 
where $\rho$ is in microhm $\mathrm{cm}$ and $\mathrm{T}$ in ${ }^{\circ} \mathrm{C}$. For sodium the resistivity is (46)

$$
\rho_{\mathrm{Na}}=4.290+0.01993 \mathrm{~T}+9.848 \times 10^{-6} \mathrm{~T}^{2}
$$

There is significant variability in the literature concerning the resistivity of sodium. The relation given appears to be the most reliable. Tables of the dc resistivities of aluminum and sodium as calculated from these equations are given in Appendix A3 (Tahles A3-1 and $\mathrm{A} 3-2$ ).

In aldiliun to calculating the ampacity of a given cable, it is also of interest to calculate the individual components of the total thermal rise, which have already been designated as $\delta \mathrm{T}_{\mathrm{m}}, \delta \mathrm{T}_{\mathrm{s}}$, and $\delta \mathrm{T}_{\mathrm{I}}$. The power loss per unit length, $Q$, in watts/cm, in the conductor is also calculated. The inputs and outputs for these calculations are summarized in Appendix A3 which contains tables of all of the calculations used in this report.

Since in a stranded conductor the strands wind helically about the center, all strands but the central one are somewhat longer than the actual cable length. This leads to a slightly higher actual resistance per unft length for stranded cable than that calculated on the area and resistivity (the area of stranded conductor is conventionally taken as the cross-section of each strand, taken normal to the strand axis, times the number of strands, and is thus less than would be the conductor area exposed by a single plane cut normal to the conductor axis). This correction, called the lay factor, has been neglected in these calculations. If included, its effect would have been to slightly reduce the ampacities calculated for stranded cable, the reduction being not over about one-half precent. Further, all of the calculations have been made on the basis of continuous load (loss factor and load factor both unity), since this is the most severe circumstance. 
For cable installed in buried ducts, the calculation must be modifled to include the thermal resistance of the duct walls and of the cable-to-duct air gap. Referring again to the direct-burial ampacity equation, it is evident that this can be considered as of the form

$$
\delta \mathrm{T}=\mathrm{Q} \sum_{\mathrm{k}} \mathrm{R}_{\mathrm{k}}
$$

or

$$
I=\sqrt{\frac{\delta \mathrm{T}}{10^{6} \mathrm{R}_{\mathrm{ac}}\left[\mathrm{j}_{\mathrm{k}} \mathrm{R}_{\mathrm{k}}\right]^{-1}}}
$$

where the coefficients $R_{k}$ are effective thermal resistances, relating the heat flow $Q$ to the various thermal drops. In the cable-in-duct case, one now has for $R_{m}$ (the thermal resistance relating $Q$ to the thermal rise of the outside wall of the center duct due to the heat from the outer two cables) the relation

$$
R_{m}=\frac{e}{2 \pi} \ln \frac{x^{2}+\left(L+\sqrt{L^{2}-R_{D}^{2}}\right)^{2}}{x^{2}+\left(L+\sqrt{L^{2}-R_{D}^{2}}\right)^{2}}
$$

where $R_{D}$ is the outside radius of the duct. The thermal resistance $R_{S}$ relative to the corresponding thermal rise due to the central cable is given by the relation

$$
R_{S}=\frac{\rho}{2 \pi} \ln +\frac{L+\sqrt{L^{2}-R_{D}^{2}}}{R_{D}}
$$

IPCEA ${ }^{(16)}$ defines a standard duct as being 5,6 , or 8 inches inside diameter. The standard wall thickness for fiber duct is $1 / 4$ inch. Minimum diametral clearance between cable O.D. and duct I.D. is specified as $3 / 4 \mathrm{inch}$, so that a 5-inch $I . D$. duct could accommodate a 4-1/4 inch O.D. cable. Since none of the cables considered in this report is that large, and since every new cable-in-duct installation 
is assumed to involve new duct as well, a 5-inch I.D. fiber duct of 1/4-inch wall has been assumed throughout, with a thermal resistivity of $\rho_{D}$ of $480^{\circ} \mathrm{C} \mathrm{cm} /$ watt. Again a burial depth of $\mathrm{L}=36$ inches and spacing of $x=7.5$ inches has been assumed. With $R_{D}=2.75$ 1nches, these values yield

$$
\begin{aligned}
& R_{s}=0.5194 \rho_{e} \\
& R_{m}=0.7212 . \rho_{e}
\end{aligned}
$$

where $R_{s}, R_{m}$, and $\rho_{0}$ are all in ${ }^{\circ} \mathrm{C} \mathrm{cm} /$ watt. The duct wall thermal resistance $R_{d w}$ is a constant throughout the calculations since the duct is fixed; from Neher-McGrath ${ }^{(41)}$

$$
R_{d w}=0.0104 \rho_{D} \frac{t}{D-t}
$$

where $\rho_{D}$ is the thermal resistivity of the duct material and $D$ and $t$ are the outside diameter and wall thickness. $\mathrm{Th}_{\text {te }}$ foregoing values then yield

$$
R_{\mathrm{dw}}=7.246
$$

For the cable-to-duct air-gap thermal resistance $\mathrm{R}_{\mathrm{ag}}$. Neher and McGrath (41) specify a semi-empirical expression which, for this duct, reduces to

$$
\mathrm{R}_{\mathrm{ag}}=30.48\left[\frac{17}{1+\mathrm{K}(4.84+0.040 \mathrm{UT} \mathrm{T}}\right]
$$

where $R$ is, as before, the cable outer radius. The internal thermal resistance of the cable is the same as for direct burial. The ampacity equation for cable in duct then becomes 


$$
\begin{aligned}
I & =\sqrt{\frac{\delta T}{10^{6} R_{a c}}}\left((1+\alpha) \quad 1.2406 \rho_{e}+7.246+\frac{518.2}{1+R(4.84+0.048 \delta T}\right. \\
& \left.+\frac{\rho_{I}}{2 \pi} \ln \frac{R}{r_{1}}\right)
\end{aligned}
$$

for the foregoing assumed conditions. In this equation $R$ and $r_{1}$ must be in inches, because the numerical constants are not dimensionless.

For the cable-in-duct case, the program was written to calculate the same components of the thermal rise as were done for direct burial, and in addition the differences $\delta \mathrm{T}_{\mathrm{dw}}$ across the duct wall and $\delta \mathrm{T}_{\mathrm{ag}}$ across the cable-to-duct air gap. These results are included in the ampacity tables in Appendix A3.

\subsubsection{Verification of Ampacity Equations by IPCEA Tables}

Before applying these equations to sodium cable, it was felt desirable to compare their predictions for conventional aluminum and copper cables to the standard IPCEA ampacity values; this was done for 15 and $35 \mathrm{kV}$ cable, of $1000,750,500,350$ and $212 \mathrm{KCM}$ size, for assumed $\rho_{e}$ values of 90 and $120^{\circ} \mathrm{C} \mathrm{cm} /$ watt, for both direct and duct burial. A $100 \%$ load factor and no shield losses $(\alpha=0)$ were assumed. Results generally agreed with IPCEA values to within a percent or less; a table of the comparisons is given in Appendix A3. Th1s close agreement indicates that ampacities calculated by the foregoing formulae are consistent with industry standards, and that they are reliable for the cases of this report.

\subsubsection{Description of Procedure for Calculation of Equivalent Sodium Cable}

With the previously developed ampacity relations, the process outlined in Section 7.1 .1 can now be implemented. This was done for a matrix of sixteen cases each for direct burial and for duct; 600 volt, $15 \mathrm{kV}, 25 \mathrm{kV}$; and $35 \mathrm{kV}$ in sizes of aluminum conductor of 1000, 750 , 350, and $250 \mathrm{KCM}$ : For each case, the aluminum cable ampacity at normal load (conductor at $90^{\circ} \mathrm{C}$, ambient $20^{\circ} \mathrm{C}$, therefore $\delta \mathrm{T}=70^{\circ} \mathrm{C}$ ) and at 
overload (conductor at $130^{\circ} \mathrm{C}, \delta \mathrm{T}=110^{\circ} \mathrm{C}$ ) was determined. The sodium conductor size required to give a conductor temperature of $95^{\circ} \mathrm{C}$ for the aluminum overload current was then found, and finally the conductor operating temperature was calculated for this sodium conductor at the normal-load aluminum current.

\subsubsection{Choice of Shield Loss Factor, and Other Parameters}

It was desirable to choose fixed values of some of the parameters, such as $\alpha$ and $\rho_{e}$,for the equivalence calculations. This then required that the sensitivity of the results to these choices be estimated. For $\alpha$, it seemed reasonable and convenient to choose $\alpha=0$ (open or ungrounded shields, no shield losses); for $\rho_{e}$, the generally-accepted value of $90^{\circ} \mathrm{C} \mathrm{cm} /$ watt was chosen. $(38,41)$ The effect of other choices for these parameters is discussed in Section 7.6. Ambient temperature was taken as $20^{\circ} \mathrm{C}$, excepting for the calculations to verify the procedure against IPCEA tables where it was taken as $25^{\circ} \mathrm{C}$ as in the IPCEA tables. Burial depth and spacing were everywhere taken as $91.5 \mathrm{~cm}$ (36 in.) and $19.1 \mathrm{~cm}$ ( $7.5 \mathrm{in.}$ ), as specified by IPCEA. (16)

The insulation thicknesses for the sodium cable were chosen to be equal to those for the corresponding aluminum cable. This was done because, as stated earlier, these thicknesses appear to be mechanically sufficient, and because they satisfy IPCEA and AEIC electrical requirements. The IPCEA-AEIC thickness specification for outer semiconducting shield thickness was also followed for sodium, but no semiconducting conductor shield was assumed. This is because, as might be expected and as has been experimentally found, the sodium conductor surface is very smooth and tightly bonded to the polyethylene. The conductor shield, whose purpose is to present to the inner surface of the insulation an electrically smooth and void-free conducting surface without stress-concentrating asperities, is thus unnecessary with sodium (see also Paragrph 7.7.1). 


\subsection{Results of Equivalence Calculations}

This section discusses the results of the equivalence calculations, whose basis has already been described. Complete results of all calculated cases are tabulated in Appendix A3. Table 7-4 summarizes the results of these calculations. Several interesting conclusions which appear to be valid for all voltage and ampacity ratings are presented. In connection with the discussion of temperature distribution and power losses, it has also appropriate to consider molten sodium conductor operation, which has some properties quite different from those found with aluminum or copper conductors.

\subsubsection{Tables of Equivalence Results}

The results of the calculations described above show that the diameter of the sodium conductor corresponding to a given aluminum conductor is quite insensitive to the voltage classification or type of installation of the cable. Table 7-4 shows a summary of the crosssections for sodium equivalent to $1000,750,350$, and $250 \mathrm{KCM}$ of aliminum, in $600 \mathrm{~V}, 15 \mathrm{kV}, 25 \mathrm{kV}$, and $35 \mathrm{~V}$ ratings, buried directly or in duct, and also shows the ratio of the sodium cross-section to that of the aluminum. For the cases considered, this ratio ranges from 2.108 to 2.220. Thus follows the general conclusion that, with a 2-1/2 percent accuracy, the sodium cross-section equivalent to a given aluminum cross-section is 2.16 times that of the aluminum, independent of cable rating or installation.

\subsubsection{Operating Temperatures at Thermal Full Load}

The temperature at which the conductors of these equivalent sodium cables will operate at the normal full load current of the equivalent aluminum cable (conductor at $90^{\circ} \mathrm{C}$ ) is also included in the table. Again it is observed that this number, $69^{\circ} \mathrm{C}$, or $65^{\circ} \mathrm{C}$ for 600 volt cables, is practically independent of rating or installation, except that it is lower for $600 \mathrm{~V}$ cables than for the others. One can conclude that, to within one-half degree accuracy, the conductor 


\section{TABLE $7-4$}

Summary of the Properties of Sodium Cable Compared to the Ectivalent Aluminum Cable

Aluminum

Area, KCM

1000

750

\begin{tabular}{|c|c|c|c|c|c|c|c|}
\hline \multicolumn{4}{|c|}{ Direct Buria1 } & \multicolumn{4}{|c|}{ Cable in Duct } \\
\hline $600 \mathrm{~V}$ & $15 \mathrm{kV}$ & $25 \mathrm{kV}$ & $35 \mathrm{kV}$ & $600 \mathrm{~V}$ & $15 \mathrm{kV}$ & $25 \mathrm{kV}$ & $35 \mathrm{kV}$ \\
\hline 2196 & 2155 & 2149 & 2149 & 2220 & 2214 & 2214 & 2208 \\
\hline 2.196 & 2.155 & 2.149 & 2.149 & 2.220 & 2.214 & 2.214 & 2.208 \\
\hline 45 & 49 & 49 & 49 & 44.5 & 48.5 & 48.5 & 48.5 \\
\hline .647 & .736 & .738 & .738 & .655 & .720 & .719 & .721 \\
\hline 22.9 & 16.8 & 15.9 & 15.1 & 12.9 & 10.5 & 10.6 & 10.5 \\
\hline 1633 & 1608 & 1603 & 1598 & 1654 & 1649 & 1649 & 1649 \\
\hline 2.177 & 2.144 & 2.137 & 2.131 & 2.205 & 2.199 & 2.199 & 2.199 \\
\hline 45 & 49 & 49 & $\angle 9$ & 44.5 & 48.5 & 48.5 & 48.5 \\
\hline .643 & .736 & .740 & .741 & .654 & .717 & .717 & .717 \\
\hline 22.5 & 16.4 & 15.5 & 14.8 & 12.4 & 10.2 & 10.1 & 10.1 \\
\hline 760 & 740 & 740 & 740 & $764^{\circ}$ & 767 & 764 & 764 \\
\hline 2.171 & 2.114 & 2.114 & 2.114 & 2.183 & 2.191 & 2.183 & 2.183 \\
\hline 44.5 & 49 & 49 & 49 & 44.5 & 48.5 & 48.5 & 48.5 \\
\hline .624 & .739 & .740 & .744 & .656 & .715 & .716 & .714 \\
\hline 22.6 & 15.3 & 14.3 & 13.6 & 10.9 & 9.1 & 9.2 & 9.2 \\
\hline 542 & 530 & 527 & 527 & 545 & 548 & 548 & 545 \\
\hline 2.168 & 2.120 & 2.108 & 2.108 & 2.180 & 2.192 & 2.192 & 2.180 \\
\hline 44.5 & 49 & 49 & 49 & 44.5 & 48.5 & 48.5 & 48.5 \\
\hline .623 & .740 & .741 & .742 & .655 & .712 & .714 & .715 \\
\hline 22.4 & 14.9 & 13.9 & 13.1 & 10.3 & 8.8 & 8.8 & 9.0 \\
\hline
\end{tabular}


operating temperature at rated current for the equivalent sodium cable (selected by our overload criterion) will be $65^{\circ} \mathrm{C}$ for $600 \mathrm{~V}$ cable and $69^{\circ} \mathrm{C}$ for 15,25 , or $35 \mathrm{kV}$ cable, regardless of rating or installation.

\subsubsection{Temperature Distributions and Power Losses}

It is also of interest to compare the power dissipated by the equivalent sodium cable at normal current (or at any other current) to that for the aluminum cable at the same current. This ratio is also given in the table; for the 600 volt cable it is between 0.623 and 0.656; for the higher-voltage classes it is between 0.736 and 0.744 for direct burial and between 0.712 and 0.721 for duct installations. Therefore, within about 2-1/2 percent error, one can conclude that, over the entire range studied, power dissipation losses in 600 volt sodium cable will be $64 \%$ of that in the equivalent aluminum cable, and for the higher voltages will be $73 \%$ of that in equivalent aluminum cable.

All of these conclusions are based on the assumption that the insulation thicknesses presently specified for aluminum cable will be mechanically strong enough for sodium. In view of the earlier calculations of Section 7.3.3, and of operating experience, this assumption appears reasonable. If thicker insulations are deemed necessary, the ratio of the equivalent sodium cross-section to the aluminum will increase. The amount of that increase can be readily determined froin Figure 7-2, which shows the variation of ampacity with insulation thickness and conductor area. The first of these three conclusions will thus be modified. The other two, however, are essentially independent of insulation thickness, assuming of course that for each choice of thickness the sodium cross-section is chosen according to Section 7.1.1. Detailed calculations from which these conclusions are drawn are included in Append1x A3.

The distribution of the total temperature rise among the various cable components has already been discussed in Section 7.4.1. These temperature increments are, as noted, individually tabulated in Appendix A3. In this connection it may be noted that the "earth 
interface temperature" $T_{e}$, i.e., the temperature at the cable outer surface for direct burial or of the duct outer surface for cable in direct-buried ducts, is often of some concern. If too high, it results in a drying of the soil $(16,38,39)$ and a resulting increase in the soil thermal resistivity $\rho_{e}$, thus causing further rise of temperature and possibly even thermal runaway. Because of the lower heat loss in the equivalent sodium installations selected, $\mathrm{T}_{\mathrm{e}}$ is less and the problem of thermal runaway is therefore less severe. For either directly buried cable, or duct installation, one finds $\delta \mathrm{I}_{e}=\delta \mathrm{I}_{\mathrm{m}}+\delta \mathrm{T}_{\mathrm{s}}$, where $\delta \mathrm{T}_{e}=\mathrm{I}_{\mathrm{c}}$ $\mathrm{T}_{\text {ambient; }}$ the different $\delta^{2} \mathrm{~T}_{\mathrm{e}}=\delta \mathrm{T}_{\mathrm{e} \mathrm{Al}}-\delta \mathrm{T}_{\mathrm{e}} \mathrm{Na}$ is a measure of how much lower the earth interface temperature w111 be for sudium cable than for aluminum. This difference is also tabulated in Table 7-4. It will be seen that $\mathrm{T}_{e}$ is from 9 to $23^{\circ} \mathrm{C}$ lower for sodium than for aluminum, thus reducing the likelihood of thermal runaway.

\subsubsection{Molten Conductor Operation}

It has been recommended throughout this report that both normal and overload operation of sodium cable should occur with a solid conductor. All cable, ratings have been calculated on that basis, reserving the heat of fusion of the conductor for the absorption of short circuit current or similar thermal transients. Occasionally, utility operation of cables at sustained overloads beyond the overload rating of the cable will occur $(33,34)$. The behavior of a sodium cable in this situation is quite different from that of an aluminum or copper cable. If the sodium cable is operating near but below 1ts conductor melting point (e.g., at the overload ampacity as we have defined it), and if a moderate increase of current temporarily occurs, oufficient to melt the conductor but not to trip associated protective devices, the conductor will not resolidify when the current is reduced to its previous overload value. The sodium conductor will remain molten, and its temperature will rise to a new equilibrium value near $140^{\circ} \mathrm{C}$. In order to resolidify the core, the current will have to be reduced below a steady-state value no more than 85 percent of the original overload rating. The aluminum or copper, on the other hand, will 
return to its overload temperature when the current returns to its overload value. This situation has been treated in detail by Hus. (29) One can easily establish the aforementioned temperature figures as follows. At normal overload ampacity, the sodium temperature is $95^{\circ} \mathrm{C}$, just below the $97.8^{\circ} \mathrm{C}$ melting point. The heat flow from the $I^{2} \mathrm{R}$ losses to the surroundings generates a rise of $75^{\circ} \mathrm{C}$ above the $20^{\circ} \mathrm{C}$ ambient. Assuming that the same current is maintained after core melting by a temporary current increase, and that the thermal resistances of the surroundings do not change, one finds the higher resistivity of the liquid just above the melting point $(9.6 \Omega \mathrm{cm})$ to be 1.4 times that of the solid just below melting. Thus, the heat evolution, and temperature rise above ambient, will be 1.4 times as great, or $105^{\circ} \mathrm{C}$, leading to a temperature of $125^{\circ} \mathrm{C}$. The further rise in resistivity at this temperature, in turn, causes a still higher rise in temperature, and an eventual equilibrium temperature is reached at which the resistivity is in the same ratio to that of the solid just below melting as the ratio of the temperature rise is to $75^{\circ} \mathrm{C}$. Values of the liquid-sodium resistivity from Sittig ${ }^{(47)}$ are given in Table 7-5; from these this equilibrium temperature is simply found as about $141^{\circ} \mathrm{C}$. In order to resolidify the sodium, the heat dissipation must be reduced to its previous overload value, but since the liquid sodium at the melting point will have a resistivity 1.4 times that of the original solld, the current will have to be reduced below the original overload current divided by the square root of 1.4, or about 85 percent of the original overload rating. This analysis makes the pessimistic assumption (in the case of three direct-burled cables in three-phase) that all three conductors melt, whereas in fact only the central one will melt, at least at first. However, the extra heat from the central cable will probably then melt the outer two as well. Temperatures of this order would almost surely result in failure of $P E$ insulation with release of a quantity of sodium, although XIPE could probably survive such temperatures for a considerable time without rupture. Even though such a usage is well beyond the cable rating, its 
TABLE $7-5$

Resistivity of Molten Sodium at Various Temperatures

$\begin{array}{lc}\underline{\mathrm{T}}{ }^{\circ} \mathrm{C} & \begin{array}{c}\text { Liquid Sodium } \\ \text { Resistivity, } \Omega \mathrm{cm}\end{array} \\ 97.8 & 9.6 \\ 100 & 9.68 \\ 110 & 10.02 \\ 120 & 10.37 \\ 130 & 10.71 \\ 140 & 11.06\end{array}$


possible occurrence must be considered because of the different behavior of sodium cable. It should also be noted that while in the molten state, the sodium cable does not have the advantage of its heat of fusion for absorption of transients, and is in fact at a considerable disadvantage because of its higher resistivity when molten.

\subsection{Sensitivity of Results to Changes in Assumed Parameters}

Some examples were calculated to show the effect of variations in the selection of the cable or earth parameters, particularly $\alpha$ and $\rho_{e}$. For example, for $25 \mathrm{kV} 1000 \mathrm{KCM}$ direct buried aluminum cable, the radius of the equivalent sodium conductor is $1.862 \mathrm{~cm} \cdot(0.733$ in.) for $\alpha=0$, and $1.877 \mathrm{~cm}(0.739 \mathrm{in.})$. for $\alpha=1$ (equal conductor and shield losses). From this consideration, it appears that the results will be essentially independent of the choice of $\alpha$. These results are for $\rho_{e}=90^{\circ} \mathrm{C} \mathrm{cm} /$ watt. For $\alpha=0$ but $\rho_{e}=130^{\circ} \mathrm{C} \mathrm{cm} /$ watt, the radius of the sodium is $1.869 \mathrm{~cm}$ ( $0.736 \mathrm{in.})$ rather than $1.862 \mathrm{~cm}$ ( $0.733 \mathrm{in.).} \mathrm{These} \mathrm{results} \mathrm{suggest} \mathrm{that} \mathrm{the} \mathrm{selected} \mathrm{values} \mathrm{of} \alpha$ and $\rho_{e}$ are reasonable and that the equivalence results are not significantly sensitive to these choices. Sensitivity of ampacity to insulation thickness has already been discussed in Paragraph 7.3.6 and Figure 7-2. All of the remaining parameters are well specified, and sensitivity to variations in them is not relevant.

\subsection{Possibilities for, and Consequences of, Thinner Insulation}

This section explores the possibility of reducing the insulation thickness for sodium cable below the values specified by industry for aluminum cable, and considers the effects on electrical stress, thermal distribution, mechanical strength, ampacity, and moisture penetration, and the cost savings which might result. The general conclusion of these considerations is that appreciable reductions in thickness of insulation are probably permissible; it is not yet clear if the savings in cable cost, installation, and operation will be significant. 


\section{7 .1 Electrical Stresses}

The possibility of using thinner insulation on sodium cable is suggested by the observed fact that the surface of the sodium conductor in coextruded cable as manufactured by Nacon appears very smooth and tightly bonded to the polyethylene. There is therefore considerably reduced likelihood of voids between conductor and insulation or of electrical stress concentrations at the conductor surface such as are sometimes caused by mechanical damage to aluminum or copper conductors before their insulation is applled. Such voids are absent in sodium because the conductor is liquid at the time of cahle manufacture, and because the sodium is soft and flexible to mecharical impact. For these reasons, as well as because of the stranded nature of aluminum and copper conductors, a semiconducting conductor shield of carbonfilled polyethylene is applied directly over the conductors of conventional cable. However, in addition to this extra cost and complication, this shield also causes its own electrical problems in the form of conducting protrusions into the surrounding insulation, caused primarily by die bleed at the face of the conductor shield die. This process can also inject conducting clumps into the high-field regions of the insulation. This would not occur with sodium cable, which has no conductor shield. A recent study ${ }^{(48)}$ on extruded-dielectric transmission cables listed the three most important factoro in dielectric strength, in order of importance, as electrical smoothness of the conductor shield, conductive contaminants within the insulation, and voids within the insulation and at the insulation-conductor shie1d interface. Sodium cable has evident advantages on all three counts. It should further be noted that because sodium conductors are larger than their equivalents in copper or aluminum, the electric field at the sodium cunductor w11l be somewhat less, typically 3 to 4 percent less.

A significant indicator of the electrical quality of the insulation in a cable is the corona onset voltage, the voltage at which internal partial discharges begin. The few data reported for sodium cable in the literature ${ }^{(25,39)}$ give values typically 1.5 to 2 times the 
minimum specified by IPCEA. On the above basis, it is reasonable to expect that, insofar as electric strength is concerned, significant reductions in insulation thickness are permissible for sodium cable, perhaps to 65 percent of presently accepted values for aluminum and copper cables. Further measurements would be necessary to confirm this.

\subsubsection{Thermal Distribution and Ampacity}

The effect of a reduced insulation thickness on the thermal distribution would be to reduce the insulation thermal drop which has been denoted as $\delta T_{I}$. This assumes that the conductor crosssection and current were held the same. This would also result in a lower conductor temperature and resistance, and hence a small increase in ampacity for the same loss. Also, a larger Increase in ampacity would result for the same (original) conductor temperature, or a smaller power loss for the original current. Thus, the conductor diameter might be decreased for the original current and temperature, or still other tradeoffs can be made. These effects will probably not be very large, however If the same conductor temperature is maintained, the effect of a reduced insulation thickness would also be to raise the earth interface temperature $T_{e}$ slightly, although not to the values presently found in the equivalent aluminum cable. However, this rise would not be significant. As can be seen from the tables of Appendix $A 3$, the insulation thermal drop $\delta \mathrm{T}_{I}$ is generally only a rather small part of the total thermal rise $\delta \mathrm{T}$. Thus, moderate insulation thickness reductions will not alter the thermal distribution significantly nor will they significantly raise ampacities. For low voltage cables, especially the 600 volt class, $\delta \mathrm{T}_{\mathrm{I}}$ is so small that even if it were eliminated entirely the increase in ampacity would only be of the order of $3 \%$. For the higher voltage cables, the possible increases are not much greater, as is evident from Figure 7-2. It can be concluded that moderate insulation thickness reductions are permitted by thermal considerations and would yield small increases in ampactty. 


\subsubsection{Mechanical Strength}

It has already been shown in Section 7.3 t:at if the ratio $\lambda$. of insulation cross-section to total cable cross-section were at least 18 percent (insulation thickness at least 10.5 percent of the conductor radius), then $P E$ insulation would provide sufficient tenstle strength for duct installation in $240 \mathrm{~m}$ ( $800 \mathrm{foot}$ ) straight runs at a cable temperature of $49^{\circ} \mathrm{C}\left(120^{\circ} \mathrm{F}\right)$. In all of the cables tabulated in this report, $\lambda$ is considerably abuve 18 percent, the closest case being the largest 600 volt cable (conductor radius $1.892 \mathrm{~cm}(.745 \mathrm{in.}$.) insulation thickness $0.318 \mathrm{~cm}(0.125 \mathrm{in}),. \lambda=27$ percent $)$. A possible exception to this 18 percent figure was noted for large 600 volt cable at high installation temperatures, if the coefficient of friction of $P E$ on the duct surface were to rise above 0.4. For the higher-voltage cables, the presence of concentric neutral wires will prevent insulationto-duct contact so that the friction is not dependent on installation temperature. It appears that so far as tensile strength for installation is concerned, the insulation thicknesses for all of the high-voltage PE-insulated cables ( $15 \mathrm{kV}$ or more) could be reduced considerably. For the tabulated thicknesses, the range of $\lambda$ for those cables is from 38 percent to 76 percent, while, for the 600-volt class, $\lambda$ ranges from 27 percent to 41 percent. Reduction of these to 30 percent would still leave a comfortable safety factor over the 18 percent necessary for installation strength.

\subsubsection{Cost Savings}

To the extent that the material cost of the insulation is a significant part of the total cost of the cable, it may be possible in the higher-voltage elasses to make an appreciable saving by reducing insulation thickness. For the high-voltage cables, the insulation thickness specified by IPCEA ${ }^{(16)}$ appears to be more than adequate for mechanical strength (since it has been concluded that for the same conductors, the much lower insulation thickness of the 600-volt class is mechanically adequate). If the projections of Paragraph 7.7 .1 are 
realized, perhaps one-third of the insulation could be eliminated. This would also result in a somewhat lighter, smaller, and more flexible cable, which might reduce installation costs. However, until firm data on electrical and mechanical performance and installation become available, the matter remains speculative.

\subsubsection{Moisture Penetration: Jacket Requirements}

The subject of moisture diffusion through the PE or XLPE insulation was discussed in detail in Paragraph 7.3.5. It was concluded that earlier predictions by others ${ }^{(26)}$ of 40 -year life times for unfacketed cables were probably in error by virtue of their cholce of an unrealistically low cable operating temperature $\left(25^{\circ} \mathrm{C}\right)$. Typical expected lifetimes at a reasonable operating temperature of $65^{\circ} \mathrm{C}$ are $I$ to 5 years. It was therefore recommended that all PE or XLPEinsulated sodium cable have a vapor-barrier jacket. With this provision, moisture resistance is no longer a determining factor in insulation thickness. Thus, if thickness reductions are permitted by other considerations, they may be carried out.

The proposed jacket will be entirely responsible for molsture protection of the cable. Such protection is certainly attainable by a metallic foil covering which is so thin that it is completely insignificant in the thermal analysis. Such a foil barrier would require a mechanically protective covering, for example of $P E$ or PVC, but this can also be negligibly thin as shown by the thermal analysis In Figure 7-2. Even if the barrier is to be furnisined entirely by a plastic jacket, it is probable that this will have only a small effect on cable ampacity.

\subsubsection{Other Materials}

Insulations other than PE or XLPE have not been discussed in Lhls repurl because these are the only ones with which sodium cable hac yet been manufactured. Other possibilities which might be considered are butyl rubber, and ethylene-propylene rubber (EPR) or terpolymer. 
These have been widely used as cable insulation, and are reported $(18,19)$ to have less permeability to water vapor than PE (quoted relative values, in $\mathrm{gm} \mathrm{mils} / 100 \mathrm{in}^{2}$ day at $25^{\circ} \mathrm{C}$, are butyl rubber at 0.04 and EPR at 0.18 compared to $\mathrm{PE}$ at 0.30 ). It is possible that butyl rubber might be sufficiently impermeable to permit its use in an unjacketed cable which would still have an acceptable service life (compare Paragraph 7.3.5). This cannot be decided without data on moisture permeability at higher temperatures. It would also be necessary to determine whether adverse chemical reactions might occur with the sodium, especially if molten, or with sodium hydroxide formed at the oodium surface by whatever moisture diffusion occurred. There is also evidence (50) that water vapor transmisston through sume polymers is grearly enhanced by electric fields of the magnitudes found in cables, although this did not appear to occur for polyethylene. Other information and further reference on water vapor permeability of polymers are given in References 36 and 37 .

\subsection{Connectors}

The most critical technical needs for the implementation of sodium cable appear to be in the development of connectors. Two general types of connectors have been made; one ${ }^{(28)}$ had an auger-shaped bit which was screwed into. the sodium, while the other (53) emplnyed a cylindrical element with a conical point which was pushed into the sodium without rotation. Opinions of the utilities (54-58) who tried these were quite varled. Some reported that the connectors were quite satisfactory while others felt that major developments were still needed. Primary concern in the present report is the cable itself, and the design of connectors was not addressed. However, the nature of sodium cable generates connector requirements which are not shared by conventional cable, and it appears appropriate to denote those requirements here.

\subsubsection{Availability}

The Burndy Corporation, Norwalk, Connecticut, in cooperation with the Union Carbide Corporation, developed connectors $(16,17)$ for the sodium 
cable produced by the Nacon Corporation. These connectors were manufactured by Burndy in the late $1960^{\prime}$ 's and distributed through the normal Burndy representatives. The manufacture of sodium cable connectors was discontinued by the mid 1970's and these connectors are no longer available commercially. Several utilities with large quantities of installed sodium cable still have a small inventory of connectors for their own use. The Utility Survey (Section 5.2) indicated, however, that most utilities have very few, if any, sodiun connectors in stock. The lack of availability of these connectors is a major concern to many of the utilities with sodium cable in service.

\section{8 .2 Cost}

This section summarizes a detailed cable connector cost analysis which appears in Section 9.3.5.

The expense of connectors associated with the sodium cable installation in the 1966-1969 period were a frequently cited source of concern in the Task 1 Survey. It is also recognized that these first sodium connectors (see Figure A5-3) were hastily designed and were not cost-improved in any measure. In our comparison of connectors, some might argue that optimized and cost improved aluminum designs are being compared to prototype sodium designs. While this is true, the connector data and costs available at present preclude any other analysis. The connector systems used in this cost comparison could be available now with very minor design modifications.

There are two basic facts which imply that sodium cable connectors might be more expensive than those for aluminum cable even with an improved design. The first involves the low tensile strength of the sodium metal. Relatively complicated designs (Figure A5-7) are needed to take advantage of the strength of the insulation in making connections. This is especially a concern in h00V seconndary and service applicationo where "standard aluminum practice" involves tightening an Allen type set screw directly against a stranded aluminum conductor (Figure A5-4). The second fact is that since sodium and aluminum react, copper is most probably required in even the improved designs. Just on a materials cost basis, this results in a $25 \%$ cost penalty over aluminum. 
For an aluminum cable system, deadbreak type elbow connectors similar to those shown in Figures $A 5-1$ and $A 5-2$ might be used. In calculating these costs, list prices were used for the various size connectors as given below:

$\begin{array}{ccc}\text { Voltage } & \text { Size } & \text { Deadbreak Elbow Connector Cost } \\ & \text { 250-400 MCM } & \$ 42.50 \text { each } \\ & 500-1000 \mathrm{MCM} & \$ 94.00 \\ & 1000-1500 \mathrm{MCM} & \$ 141.00 \\ 35 \mathrm{kV} & 250-400 \mathrm{MCM} & \$ 85.50 \\ & 500-1000 \mathrm{MCM} & \$ 169.40 \\ & 1000-1500 \mathrm{MCM} & \$ 2.54 .10\end{array}$

Theso costs were allonated nver a tutal of 2 miles $(10,560 \mathrm{ft})$ of three phase primary feeder circuit to obtain per foot costs for aluminum cable. For the sodium cable system "copper pin type" connectors similar to those shown in Figure A5-3 and A5-7 were assumed to be used. The copper rod or pin extension of the sodium conductor was then used with a standard loadbreak elbow connector as in the aluminum cable connections. These "copper pin type" connectors were priced by comparing their size, weight and conductor termination with a price list for similar copper connectors shown in Figure A5-6. Thus the sodium per foot connection costs were increased over the aluminum by the cost of a "copper pin type" connector. Sodium cable connectors were found to be approximately 0.5-3.0 cents per $3 \phi$ foot more expensive than aluminum cable connectors for $3 \phi$ primary feeder.

While it is recognized that splice costs would also be higher for sodium than aluminum, these costs have been neglected. The number of splices would be considerably less than the number of connections and would not alter the comparative economics significantly.

For single phase laterals, a connector cost analysis for 12 customers per pad-mounted transformer and 37.5 KVA per transformer resulting in 14 transformers per lateral and a total lateral length of $5400 \mathrm{ft}$ was performed. 
Two "loop through" type primary connections were used at each transformer with two connections at the switch tie point to the primary feeder. This resulted in 26 connections per lateral. Deadbreak elbow connectors were used for the aluminum and "copper pin type" connectors with elbow connectors for the sodium. The resulting per unit length costs showed sodium cable connectors to be 0.7 to 5.0 cents per foot more expensive than aluminum cable connectors for single phase laterals.

Costs for both aluminum and sodium connectors were estimated based on list prices from Reference 80 as shown below:

\section{$600 \mathrm{~V}$ Secondary-Service}

\begin{tabular}{lccc} 
Size & $\begin{array}{c}\text { Aluminum } \\
\text { Connector } \\
\text { Costs }(\$ \text { ea.) }\end{array}$ & $\begin{array}{c}\text { Sodium } \\
\text { Connector } \\
\text { Costs }(\$ \text { ea.) }\end{array}$ \\
\cline { 2 - 2 } $250 . \mathrm{MCM}$ & $\$ 2.15$ & & $\$ 3.70$ \\
350 & $\$ 2.48$ & & $\$ 4.35$ \\
750 & $\$ 6.24$ & $\$ 11.45$ \\
$1000 \mathrm{MCM}$ & $\$ 12.50$ & $\$ 23.28$
\end{tabular}

The costs on a per unit length basis showed sodium connectors to cost roughly double that of aluminum connectors. Many more connections are made in the secondary-service system than in the primary system on a per unit length basis. This results in a cost penalty for sodium connectors that negates the savings made in the cable itself for the secondary service system (see section 9.3.5). 


\subsubsection{Ease of Installation}

Installation of connectors on sodium cable requires cutting off the end of the cable to expose new unoxidized sodium. First generation Burndy connectors utilized a copper cork screw that threaded into the soft sodium core. The joint was sealed by compressing the outer sleeve of the cork screw assembly with a standard compression tool. Although this type of connector was adequate electrically, the rost was relatively high; therefore a second generation connector wao dovoloped.

'The second generation connector was constructed of a pointed copper rod with a lug attached to the end. The pentrator rod was installed by first threading a thermopiastic fitting into the ID of the sodium cable insulation, then driving the penetrator into the sodium by threading a thermoplastic nut onto the titting. The cost of this connector was lower because less copper was used and installation was claimed to require only a pair of pliers and a wrench.

The extra safety precautions required (1.e., salely glasses and leather gloves) and disposal of the scrap sodium ends was claimed by some to bc a nuieance. Other installation groups claimed that the ease with which the cable could be cut, its lightweight, and Its flexibility made terminating sodium cable easier then aluminum cable. See Section 5.2 for results of the Utility Survey.

\section{8 .4 Rellab1lity Reyuirements}

A satisfactory connector for sodium cable must be rellable in several respects, particularly regarding mechanical strength, watertight integrity, electrical cuntinuity and thermal stability. These will be discussed in turn, although all are closely interrelated.

a. Mechanical strength. It is not likely that cable connectors will intentionally be subjected to large long-term mechanical forces, but it must be anticipated that situations may occur where a connector is inadvertently put into long-term tension or bending. Because of the 
softness and chemical reactivity of sodium, it is important, much more than in the case of copper or aluminum, that the connector not transmit stress to the conductor nor expose it to atmosphere. It must therefore maintain a firm mechanical contact with the insulation.

b. Watertight integrity. Ingress of water into the connector may lead to failure either by high-voltage breakdown across wet insulator surfaces, or by chemical reaction with the sodium conductor at the termination. It is therefore essential that the connector remain watertight, or more specifically, that it not permit water to reach either the sodium conductor or the electrically-stressed surface of the insulation at the end of the cable between conductor and outer insulation shield.

c. Electrical continuity. Because of the softness and low mechanical strength of sodium, it is necessary that the connector make reliable electrical contact to the sodium without subjecting the sodium itself to tension, or indeed to any forces excepting compression. Corkscrew connectors of the type originally made by Burndy Corporation ${ }^{(28)}$ would appear to be a good design concept frum the point of view, since the insertion of the corkscrew not only provides a large surface area of contact to the sodium but also puts the local sodium into compression, any tensile forces being almost all carried by the insulation. In their paper on these connectors, Matthysse and Scoran ${ }^{(28)}$ note the necessity for suitable surface treatment of the screw to maintain a low electrical contact resistance; the nature of this treatment is described elsewhere as the application of a mercury coating. In selection of the screw material, 
consideration should be given to the possibility that some metals may, promptly or slowly, form alloys with the sodium at the contact surface. Such alloying occurs, for example, with the mercury coated.surface described above. It is not clear whether such alloying will always be desirable, but its effects on conductor performance may be significant. Copper, however, has shown excellent long-term compatibility with sodium at ambient temperatures.

d. Thermal otability. It is clear that all of thc foregoing requisements must be malntained over the limits of the operating temperature range, including the effecly of thermal cycling. Matthysse and Scoran ${ }^{(28)}$ have described a series of thermal tests made on two versions of screw-type connectors, and have noted the need for a NEMA standard to apply to this case. Their results suggest that adequate performance can be obtained with such connectors, although further development and testing are needed.

\subsubsection{Corona Performance}

For cables of sutficiently high voltage, above about $5 \mathrm{kV}$, care must be taken to insure that the cables and connectors are free of corona (partical discharges). These discharges appear when gas-filled spaces, such as voids in the cable insulation or exposed insulation surfaces at the termination, are highly electrically stressed. Such discharges are undesirable because they locally erode the insulation and may ultimately cause failure, and because they locally erode the insulation and may ultimately cause failure, and because they cause radio interference. There is little discussion of, or data on, discharges in sodium cable connectors. This aspect must be considered in the design of connectors for high-voltage cable, although this problem is not likely to occur in 600 volt cable. It is probable that a connector of the type described by Matthysse and Scoran ${ }^{(28)}$ can be made corona-free (the voltage rating of the one they describe is not 
specified, but was later identifled as 600 volt). The termination which they show makes electrical contact to the sodium while isolating it from the atmosphere; and the problem of preventing corona over the insulation surface from the termination to the end of the stripped-back semiconducting shield is not significantly different than for aluminum cable connectors (for which the corona problem has been solved). It is thus expected that corona-free connectors can be readily designed for sodium conductor cable but it will be necessary to verify the corona performance by test.

\subsection{Conclusions for Electrical Performance}

This section summarizes the significant comparisons between the electrical performance of sodium cable and conventional cable, and the technical developments yet needed for the practical implementation of sodium cable.

\subsubsection{Overall Electrical Comparison: Sodium vs. Aluminum}

On the basis of the electrical performance of an aluminum cable compared to its sodium cable equivalent, as defined in Paragraph 7.1 .1 , the sodium cable appears to be equal to or superior to the aluminum cable. The ampacities at normal load and at overload are, be definition, equal. The normal-load resistance of the sodium cable is lower than that of the aluminum; for all of the cables studied in this report, the ratio $\mathrm{R}_{\mathrm{Na}} / \mathrm{R}_{\mathrm{Al}}$ is 0.65 to 0.66 for 600 volt cable and 0.71 to 0.74 for all others. Ihis results in less voltage drop at houses serviced by these cables, and (in the same ratio) less resistive power loss in the cables. The corona performance and voltage endurance of these cables would be expected to be excellent because of the very smooth surface of the sodium and its intimate bond to the polyethylene. This expectation is supported by observed corona data, $(25,37)$ although the necessary definitive voltage endurance tests have not yet been reported. 
A situation in which sodium cable behaves differently from aluminum or copper is that of sustained heavy overload, leading to conductor melting. $(25,29,31,33,34)$ Paragraph 7.5 .4 described the bistable nature of this case, and probable consequences of such operation. This circumstance is far in excess of the cable rating, and fallures in such a situation should probably not be blamed on the cable; nonetheless such overloads do sometimes occur in the course of utility operation, and sodium cable behavior in such a case should be considered.

\subsubsection{Remaining Electrical Requirements for Sodium Implementation}

The major remaining requirement for fmplementing the use of sodium cable is, by far, an assurance of the availability of satisfactory connectors. The connector status has been described in Section 7.8. Opinion of utilities on the merits of the two connector designs which have been manufactured has been divided. Agreement has been universal that sodium cable will not see significant use until suitable connectors are not only designed and manufactured at an acceptable cost, but are assured available in the future. This assurance of availability is at least as important as the connector performance.

The other area in which development is still required is that of a vapor-barrier jacket for sodium cable. Such a jacket has not been present on the sodium cable so far manufactured. As detailed in Paragraph 7.3.5, a 40-year service life may be uniikely without it. It is still to be shown that a suitable jacketcan be provided at a competitive cost. The presence of such a jacket will of course have some bearing on connector design as well. 


\section{ENERGY AND MATERIALS IMPACT}

A comparison of the energy expended to obtain cable materials was performed. The energy expended to mine, refine, and create cable feed stocks was evaluated. Although these energies were found to be fractions of the total energy lost during cable operation (i.e., $I^{2} R$ losses) for the projected cable lifetimes (25 years), a review of their comparative values is presented. Also, long term projections of base material availability and costs were made.

\subsection{Energy Requirements of Cable Material}

Several sources were searched for recent information concerning energy expended to obtain refined feedstock material for cable manufacture. Computer library searches of NTIS and EI. sources using keywords such as sodium, copper, aluminum, plastics, polyethylene and intersecting them with energy consumption, energy demand, energy accounting, production, manufacturing, industry, etc. failed to yield major references with the information sought. Telephone discussions with various industry associations:

Society of the Plastics Industry

Society of Plastics Eingineers

Copper Development Association

Aluminum Association, etc. were surprising in that none could supply the information sought. Several organizations had on-going active search projects in this area, but had not completed their compilations. Telephone calls to several manufacturers found them to be cooperative and interested, except that energy expended to obtain various cable materials or expended in various fabrication processes were deemed proprietary, and were thus unavailable. 
Library and journal searches were used to assemble the data presented in Table 8-1. As can be seen, the data in Table 8-1 was compiled from many sources. Energy expended to obtain raw feedstock was presented in Btu/lb, Btu/ton, $k W(t) h r / t o n, k W h(e) / t o n$, etc. An effort was made to reduce all of the data to a comparative baseline, or reference energy units. Good agreement was found for aluminum between data from the U.S. Bureau of Mines, (59) Banbury Conference, ${ }^{(60)}$ Underground Cable Corp., (61) Battelle Memorial Institute, ${ }^{(62)}$ and Copper Development Association. (63) Similarly, good cross comparisnns were found for copper (refined) from the same sources. Values for sodium metal, as produced by Downs cells, as found in references 64 and 65 were in good agreement with the U.S. Bureau of Mines data (59) and with industry sources. (66)

Extreme problems were encountered in determining the energy expended to manufacture polyethylene into a form amenable to cable fabrication. Several references $(61,62,63)$ chose to include the energy content (i.e., combustion energy) with the energy expended for manufacture. This was argued against by Roberts $(60)$ on the premise that the energy content was still recoverable through combustion. Most sources followed this tenet.

Variations in the data in Table 8-1 were found to be large in several cases and can be attributed to several factors: (1) Some data includes recycle of materials. There is an internal process plant scrap recycle, as well as an external recycle. (2) The efficiency of plant in each data base may vary depending on the process used, type of fuel consumed, plant operating practice. (3) As ore grades vary (deplete), the amount of energy expended to refine the mineral becomes greater (i.e., - more energy intensive and thus costly). (4) Some data bases will include energy costs for mining, drilling, and transporation, as well as for processing and manufacture.

Table 8-2 summarizes the findings of Table 8-1, and presents the information necessary to calculate the energy expended to obtain feedstock materials for each unit length of cable manufactured. 
TABLE 8-1

Energy Expended to Obtain Materials

\begin{tabular}{cccc} 
U.S. Bureau & (59) \\
Mines & $\begin{array}{c}\text { Banbury } \\
\text { Conference }\end{array}$ & $\begin{array}{c}\text { Underground } \\
\text { Cable Corp. }\end{array}$ & $\begin{array}{c}\text { Battelle to } \\
\text { U.S. Bur. Mines } \\
\text { and to Copper }\end{array}$ \\
\hline
\end{tabular}

Other

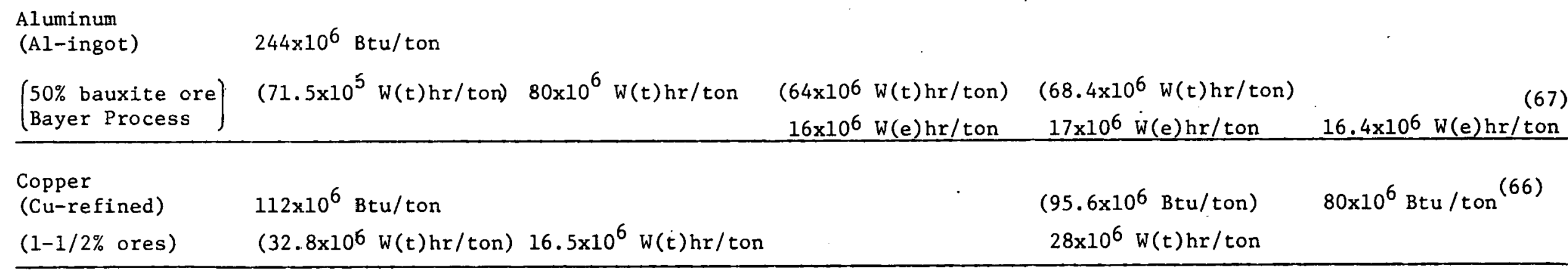

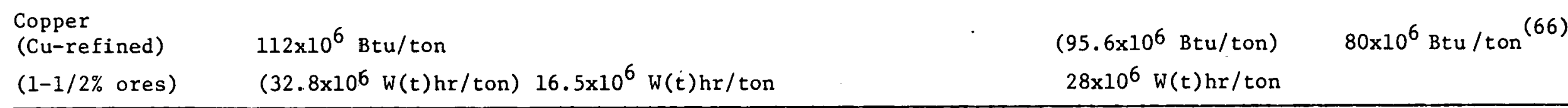

Sodium

$\stackrel{f}{*}$ (Na-metal) $92 \times 10^{6} \mathrm{Btu} / \mathrm{ton}$

$\begin{array}{lll}\text { (Downs Cells) } & \left(26.9 \times 10^{6} \mathrm{~W}(\mathrm{t}) \mathrm{hr} / \mathrm{ton}\right) & \left(32 \times 10^{6} \mathrm{~W}(\mathrm{t}) \mathrm{hr} / \text { ton }\right) \\ & \left(\sim \mathrm{i} \times 10^{6} \mathrm{~W}(\mathrm{e}) \mathrm{hr} / \text { ton }\right) & 8 \times 10^{6} \mathrm{~W}(\mathrm{e}) \mathrm{hr} / \mathrm{ton}\end{array}$

Polyethylene

(PE) 
TABLE 8-2

Data to Calculate Energy Expended to Obtain Feedstock Materials for Cable

\begin{tabular}{lcc} 
Material & $\begin{array}{c}\text { Energy Expended } \\
\text { to Obtain } \\
\text { (kW(e)hr/ton) }\end{array}$ & \multicolumn{1}{c}{$\begin{array}{c}\text { Dengity } \\
\text { (1v/ins) }\end{array}$} \\
\cline { 2 - 2 } Aluminum & 16,500 & \\
Copper & 7,500 & 0.102 \\
Sodium & 8,250 & 0.323 \\
Polyethylene & 3,000 & 0.034
\end{tabular}




\subsection{Energy Expended per Length of Cable}

The Information presented in Table 8-2 was used to calculate the energy expended to obtain feedstock materials for each foot of cable. Table 8-3 presents the dimensions for the equivalent sodium and aluminum distribution cables that were compared. The energy expended for materials per unit length of cable was then found by calculating the volume of each material per foot of length, and then multiplying by the density and energy expended per unit weight in order to obtain energy values for each feedstock material. These calculations are summarized in Table 8-4 and illustrated in Figures 8-1 ( $a$ and $b$ ).

\subsection{Energy Requirements and Savings}

As can be seen in Table 8-4, for all cases, the energy expended to obtain feedstock materials for sodium cable is roughly one-third of that needed for aluminum cable. Although the sodium conductor is larger for equivalent cable, it requires less energy for its refining and it does not use insulation for shield or conductor; thus the savings. The savings in energy expended for equivalent sodium conductor cable over aluminum conductor cable is never greater than $8 \mathrm{kWhr}(\mathrm{e}) / \mathrm{ft}$.

Section 9 of this report describes the economics of sodium vs, aluminum conductor cable and shows that for $35 \mathrm{kV}$ cable, the difference in losses between the two equivalent conductors is approximately $790 \mathrm{kWhr}(\mathrm{e}) / \mathrm{ft}$ for 20 years service at rated loads. Thus, over the cable rated lifetime, $1 \%$ of the savings in losses would equal the savings in energy expended to obtain feedstock if one used sodium conductor cable over aluminum. The energy expended to obtain sodium cable materials over aluminum cable materials is far less than the energy of losses saved by selecting equivalent sodium conductor cable over aluminum conductor.

The energy expended for materials is also a minor consideration when you increase the conductor diameter from $250 \mathrm{kc}$ mils to $1000 \mathrm{kc} \mathrm{mils}$ in all three $\mathrm{kV}$ ranges. The resulting increment in energy expended is $10 \mathrm{kWhr}(\mathrm{e}) / \mathrm{ft}$ for aluminum, or $3 \mathrm{kWhr}(\mathrm{e}) / \mathrm{ft}$ for sodium. Yet the savings in reduction in losses is considerably greater. This is described in greater detail in section 9. 

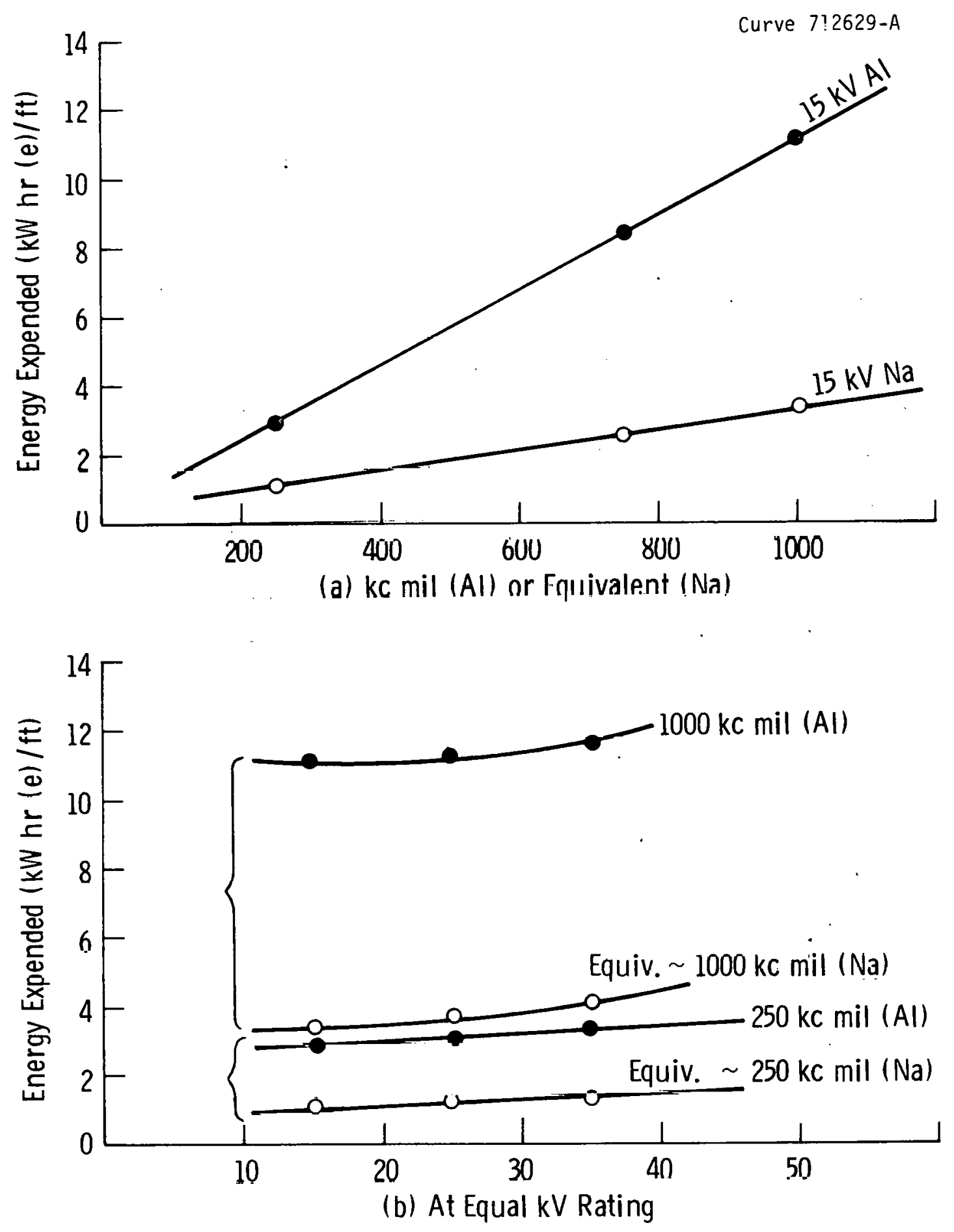

Fig. 8-1 - Relationship of energy expended to obtain materials fur sodium vs. aluminum conductor cables 
TABLE 8-3

Comparison of Equivalently Rated Aluminum and Sodium Cable to Obtain Energy Expended for Materials

\begin{tabular}{|c|c|c|c|c|c|c|}
\hline Cable Conductor & & $\mathrm{A} 1$ & & & $\mathrm{Na}$ & \\
\hline Rating (kV) & 15 & 25 & 35 & 15 & 25 & 35 \\
\hline $\begin{array}{l}\text { Conductor Shield (in) } \\
\text { Insulation Shield (in) }\end{array}$ & $\begin{array}{l}.015 \\
.030\end{array}$ & $\begin{array}{l}.015 \\
.030\end{array}$ & $\begin{array}{l}.015 \\
.030\end{array}$ & & $\begin{array}{l}\text { None } \\
\text { None }\end{array}$ & \\
\hline $\begin{array}{l}\text { Insulation Thickness (in) } \\
\text { Conductor Radius (in) } \\
250 \mathrm{kc} \mathrm{mil} \\
350 \\
750 \\
1000\end{array}$ & .175 & $\begin{array}{l}.260 \\
.288 \\
.340 \\
.498 \\
.576\end{array}$ & .345 & .175 & $\begin{array}{l}.260 \\
.365 \\
.430 \\
.634 \\
.734\end{array}$ & .345 \\
\hline
\end{tabular}




\section{TABLE $8-4$}

Comparison of Energy Expended for Base Materials for Aluminum and Equivalent Sodium Cable

Energy Expended in $\mathrm{kWh} r(\mathrm{e}) / \mathrm{ft}$

Cable

Equivalence

Cable

(kc mil)

Material

Cablc Rating
$\frac{25 \mathrm{kV}}{15 \mathrm{kV}} \quad 35 \mathrm{kV}$

250

Al

2.97

3.15

3.35

$\mathrm{Na}$

1.00

1.18

1.40

750

Al

8. 38

8.63

8.91

$\mathrm{Na}$

2.61

2.88

3.19

1000

AI

11.10

11. 37

3.39

3.70

11.68

$\mathrm{Na}$

4.04 
A comparison of the energy expended to manufacture the two cables from their feedstock materials has been done indirectly in Section 9. These values are reflected in the direct cost and cost of losses curves, since these first costs (direct) include energy costs (i.e., are largely energy costs).

\subsection{Materials Avallability and Long Term Market Projections}

There appears to be little immediate concern over the avallability of copper, aluminum, or sodium for the balance of this century. (59, 60,69) Aluminum makes up about 8 percent of the earth's crust. However, the bauxite ore from which the metal is processed is found in only a limited number of places. World reserves of bauxite have increased considerably over the last two decades. Present Australian reserves alone are equal to the known total of the earth in 1950 . (69) A recently announced new Alcoa smelting process indicates reduction in energy requirements to refine aluminum of up to 30 percent. (70) Within the next few decades aluminum is expected to be smelted in a wider variety of plants than at present. The newer processes (Toth ${ }^{(60)}$ and Alcoa $(60,70)$ ) may be operating on a large scale, providing a considerable savings in electrical energy compared with the HallHeroult process. Predictions are that as good quality bauxite ores become scarce and are exhausted (Figure 8-2) use of the more plentiful resources of anorthosite and clay type minerals will occur. No increase in cncrgy consumption per unit output. is projected. (60) Alcoa has recently purchased 8000 acres of land in Wyoming with a deposit of anorthosite that is larger than all of the world's bauxite reserves combined. (69)

Copper constitutes only one part in 20,000 of the earth's crust, yet ranks third in industrial importance. (69) Up to now, discoveries of new copper deposits have kept pace with demand. Although uncertainty clouds the future rellability of high grade copper ores in Chile, Zambia, and Zaire, much low grade ore is being developed in British Columbia, Panama, Bougainville, etc. The United States, 

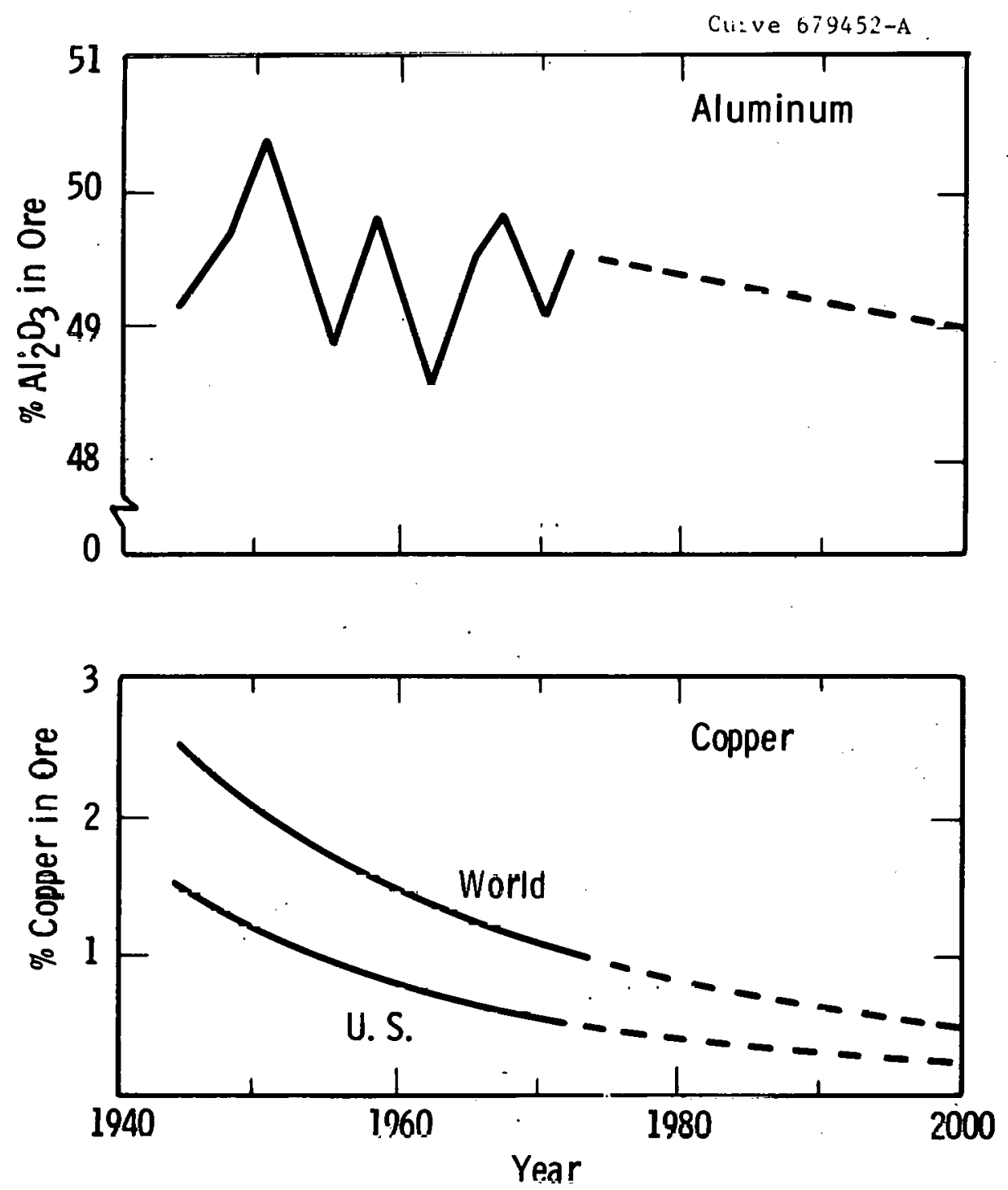

Fig. 8-2-Ore grade variation, World $\mathrm{Al}$ and $\mathrm{Cu}$ 
which relies almost entirely on low grade ores (Figure 8-2), has nearly one-fourth of the world's reserves. (69) The average grade of the U.S. ore is declining as shown in Figure 8-2, and ores containing as little as 0.4 percent are now being mined in the Southwest. If the world average copper ore being worked were to go to 0.6 percent from the 1.5 percent being worked today, then the energy to refine copper would double, approaching that of aluminum (Figure 8-3). It is unlikely that the world will run out of copper, but it will be used more selectively.

Sodium is one of the most abundant elements found in the earth's crust and is commonly formed by electrolysis processes from common salt ( $\mathrm{NaCl}$ ) mixed with halogen fluxing agents. There is no apparent concern over sodium's long range avallability, nor are any technical breakthroughs anticipated to reduce its energy requirements for manufacture.

When one considers the area of the three cable conductor materials, $\mathrm{Al}, \mathrm{Cu}, \mathrm{Na}$, only copper appears to be in danger of escalating refining costs due to depleted ores. The long term availability of both sodium and aluminum can be assumed.

\subsection{Conclusions}

Both sodium and aluminum ores are very plentiful, with the energy required to manufacture sodium being about one-half that required for aluminum. The energy required to manufacture aluminum is expected to decrease about 30 percent with the introduction of the new Alcoa smelting process, but increased energy costs could offset the gain. Sodium, also produced electrolytically, projects no changes in technology or energy for its manufacture. 

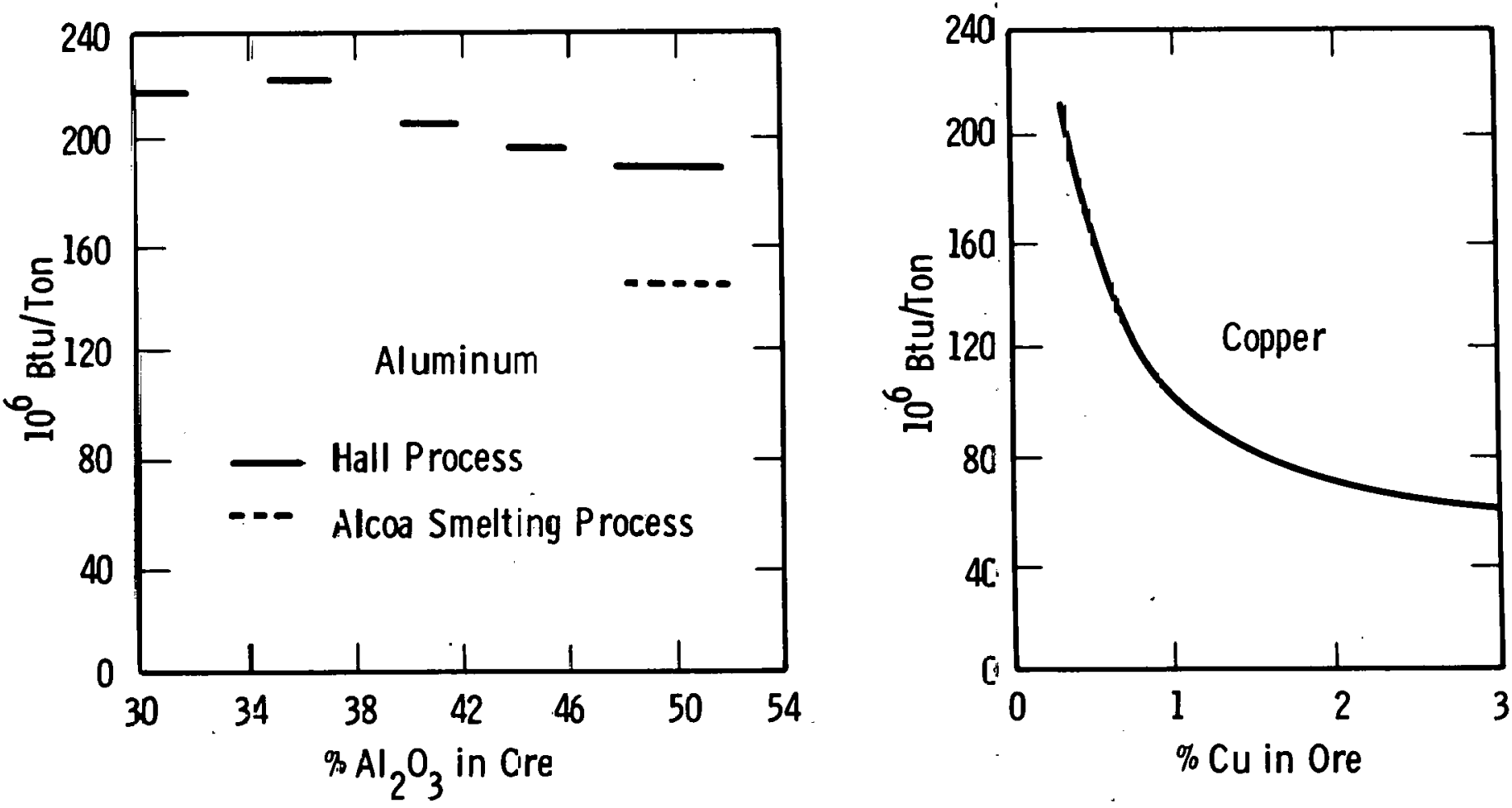

Fig. 8-3-Effect of are grade on energy required per ton of product shipped 


\section{ECONOMIC ANALYSIS}

The purpose of the Economic Analysis Task is to provide an objective comparison between the costs of owning and operating aluminum and sodium underground distribution cable. A comparison of cable costs and the present worth of operating losses for cables operating at unity load factor and at their thermal limit is first performed. Then the comparisons are evaluated for more practical application; primary feeders, laterals, and secondary service. Subsequently, the effect of connector costs, installation in ducts, salvage, and disposal are introduced into the analysis. The comparison is performed based on present costs, and costs estimated for 10 and 25 years in the future. For the applications defined, energy savings based on assumed market penetration are calculated.

\subsection{Methodology Used}

The total owning and operating costs of cables over an assumed lifetime was selected as the parameter to be compared between aluminum and sodium cables. As discussed in Section 7, the basis of comparison is the requirement that both the sodium and aluminum cables have equal overload and normal load ampacities. This is required because of the impracticality of an electric utility treating sodium and aluminum cable differently for an emergency overload condition.

The total costs for comparing cables is calculated from

$$
\mathrm{PW}_{\mathrm{t}}=\mathrm{CI}+\mathrm{CON}+\mathrm{CAB}+\mathrm{PW}_{\mathrm{L}}
$$

where $\quad \mathrm{PW}_{t}=$ present worth of total costs $(\$ / f t)(\$ / m)$

$$
C I=\text { installation costs of cable and connectors }(\$ / f t)(\$ / m)
$$


$\mathrm{CAB}=$ cable costs $(\$ / f t)(\$ / m)$

CON = connector costs

(NOTE: Actual costs are used rather than annual carrying charges. Since sodium and aluminum costs are relatively close, the present worth difference between the two methods would be negligible). $\mathrm{PW}_{\mathrm{L}}=$ present worth of cable operating losses over the life of the cable $(\$ / f t)(\$ / m)$

The preseni worch of losses, $Y W_{L}$, is evaluated using

$$
Y W_{L}=\lfloor(L S F \times P O E N G)+(P K R E S B \times P O C A P)] \times P W R_{L} \times P W F
$$

where

$$
\begin{aligned}
& \text { PWR }_{\mathrm{L}}=\text { peak power dissipation in the sable at the time } \\
& \text { of cable peak load current (kW) } \\
& \text { PWF = present worth factor over cable lifetime } \\
& \text { LSF = average loss factor of the cable defined as } \\
& \text { the ratio of cable average luss lu peak } \\
& \text { loss }(71,72) \\
& \text { PKREEB = peak responsibility factur defined as the ratlo } \\
& \text { of cable peak load that is present at the time } \\
& \text { of total electric utility system peak load (71) } \\
& \text { POENG = average annual cost of energy supplied to the } \\
& \text { distribution system }(\$ / \mathrm{kW}-\mathrm{yr}) \\
& \text { POCAP = average annual cost of supplying capacity to } \\
& \text { meet the electric utility system peak load } \\
& (\$ / k W-y r)
\end{aligned}
$$

The present worth factor sumnarizes the effects of cable load growth, electric power and energy cost increases, and discounting effect of costs in the future over the assumed cable lifetime. 
The present worth factor is calculated using

$$
\mathrm{PWF}=\sum_{i=1}^{N} \frac{(1+\mathrm{g})^{i}(1+\mathrm{e})^{i}}{(1+\mathrm{d})^{1}}
$$

where $N=$ number of years of assur. able lifetime (25 years)

$\mathrm{e}=$ annual rate of increase of electric power and energy costs

$g$ = annual growth rate of cable load

$d=$ annual discount rate for future operating costs

To evaluate the present worth of losses $\mathrm{PW}_{\mathrm{L}}$ (Equation 9-2) one must first evaluate the peak power loss $\mathrm{PWR}_{\mathrm{L}}$. This power loss is calculated ${ }^{(73)}$ by

$$
\mathrm{PWR}_{\mathrm{L}}=\mathrm{K}_{\mathrm{p}}\left(\mathrm{I}_{1}^{2}+\mathrm{I}_{1} \mathrm{I}_{2}+\mathrm{I}_{2}^{2}\right) \mathrm{R}
$$

where $I_{1}=$ peak input or feed phase current to the uniformly loaded cable being analyzed (amperes)

$I_{2}=$ peak output current from the cable section (amperes)

$\mathrm{R}=\mathrm{a}-\mathrm{c}$ phase conductor (conductor + concentric neutral for single phase lateral) resistance (ohms) at operating temperature determined by $I_{1}$ and $I_{2}$

$\mathrm{K}_{\mathrm{p}}=$ constant depending on the application

e.g., uniformly loaded feeder

$3 \phi$ balanced main feeder, $\mathrm{K}_{\mathrm{p}}=1$

I申 lateral feeder, $\mathrm{K}_{\mathrm{p}}=.6667$

secondary and service, $\mathrm{K}_{\mathrm{p}}=1$

Equations 9-1 through 9-4 are used to evaluate the total present worth for comparing all cable sizes, voltages and applications appearing in the following sections of this analysis. 


\subsection{Construction of Cable Costs}

The essential basis for any aconomic analysis is an accurate description of costs and prices. Ideally, one would like a detailed representation of all cost components as shown in Figure 9-1. For an established cable product with a ....wn volume, a given manufacturer might be able to quantify these costs. However, for a cable no longer in production such as sodium, this type of detailed cost data is unavailable.

First, an examination of what data is available guides one in the approach to be used. Prices of materials that are used in constructing both the aluminum and sodium cables are available. The purchased prices of aluminum cable in the sizes used by the electric utilities are available and were obtained in the Task 1 Survey. Selling prices for sodium cable (NACON Corp. to electric utilities) in the 1966-1968 period are available. Because of the proprietary nature manufacturers generally will not release information on scrap rates for product lines, specific fabrication costs and indirect product costs.

The U.S. Census of Manufacturers publishes data on cost of materials, value added by manufacture, and value of shipments for particular product groups within the total. wire and cable industry. Included in the cost of materials is the cost of scrap so that the actual cost of material used in manufacturing the volume of cable shipped is not known. However, the numbers do provide a general guide for estimating how much value is added for the input cost of materials. The ratio of the cost of materials to the value of shipments varies from approximately $9.5 \%$ for aluminum wire involving only a drawing operation to $67 \%$ for more complex products in the insulated wire and cable product group.

The approach finally selected for estimating the cable costs to electric utilities began with calculating the volume of material of each type used per unit length for each voltage class and size. Then using the specific gravities (Table 9-1) the weight of each material component per unit length was calculated. Using the material prices (Table 9-2), the cost of each component (e.g., conductor, conductor screen etc.) was evaluated and summed to get total material costs as given in the following. 


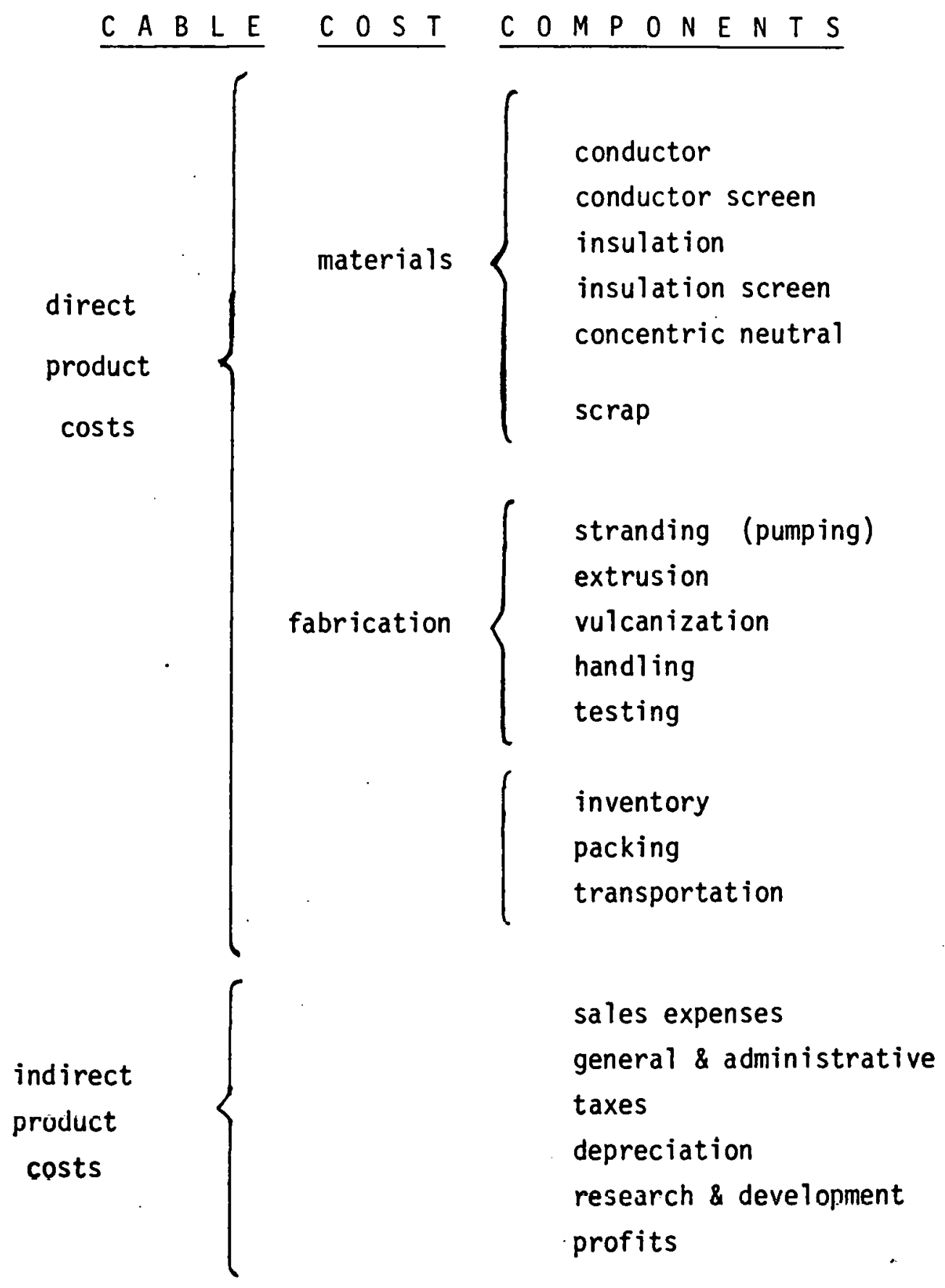

Figure 9-1 
TABLE 9-1

Material Specific Gravities and Insulation Thickness Used In Constructing Cable Material Costs

$\begin{array}{lc}\text { Aluminum } & 2.70 \\ \text { Copput } & 8.89 \\ \text { Eodiuñ } & .97 \\ \text { Polyethylene (thermoplastic) } & .92 \\ \text { Polyethylene (thermosetting) } & 1.18 \\ \text { Semi-Conductive Polyethylene } & 1.25 \\ & \text { Insulation } \\ & \text { Thickness (mils) } \\ 600 \mathrm{~V} & .095^{\prime \prime} \& .110^{\prime \prime} \\ 15 \mathrm{kV} & .175^{\prime \prime} \\ 25 \mathrm{kV} & .260^{\prime \prime} \\ 35 \mathrm{kV} & .345^{\prime \prime}\end{array}$




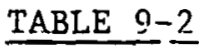

Material Prices Used in Estimating the Cable Costs

$\begin{array}{ll}\text { Aluminum } & 54 \mathrm{c} / 1 \mathrm{~b} . \\ \text { Copper } & 67 \mathrm{c} / 1 \mathrm{~b} . \\ \text { Sodium } & 37 \mathrm{c} / 1 \mathrm{~b} . \\ \text { Semiconducting Thermosetting Screen } & 76 \mathrm{c} / 1 \mathrm{~b} . \\ \text { Polyethylene (thermoplastic) } & 40 \mathrm{c} / 1 \mathrm{~b} . \\ \text { Polyethylene (thermosetting) } & 51 \mathrm{c} / 1 \mathrm{~b} .\end{array}$

*Aluminum conductor and copper concentric neutral is stranded and spiraled (assumed 3\% increase in weight per foot for spiraling) 
The cross-sectional area, A, in circular mils of any uniform covering on a cylindrical core is $D^{2}-d^{2}$ where $D$ and $d$ are the outside and inside diameters, respectively, of the covering in mils. Knowing this area $A$, the volume for a unit length is also known and the weight per unit length is calculated from

$$
W=\frac{S G \times A}{2.94 \times 10^{6}}
$$

where

$$
\begin{aligned}
& W=\text { weight per unit leilglł of a particular compnnent of } \\
& \text { the cable (1L.) } \\
& S G=\text { spectic gravity of material (Table 9-1) } \\
& A=\text { cross-sectional area of the material being considered, } \\
& \text { in circular mils }
\end{aligned}
$$

Cable material cost forecasts for 10 years and 25 years in the future are given in Table 9-3. These cost forecasts were taken directly from the Data Resources Inc. Cost Forecasting Service. (74) These costs will be used in Section 9.3.6.5 to estimate low the cost difference between aluminum and sodium cable might change in the future.

From a telephone survey of cable manufacturers and the Task I survey the selling prices of some aluminum distribution cables to electric utilities were obtained. These prices are shown in Table 9-4. The total material costs of these aluminum cables were calculated. The difference between the selling price and the materials cost was used as an aggregate for the "other direct and indirect product costs."

In developing the prir.ps for sodium cable the "other direcl and indirect product costs" for an equivalent ampacity aluminum cable were used. The reasoning for this was that a competing sodium cable would have scrap rates, sales volume, and indirect costs comparable to the aluminum in a mature market. The fabrication processes for both sodium and aluminum cable are similar enough that costs should be comparable. 
TABLE 9-3

Cable Material Cost Forecasts ( $\$ / 1 b)$

\begin{tabular}{|c|c|c|c|}
\hline & 1978 & $1988^{*}$ & $2003^{x *}$ \\
\hline Copper (WPI 10220106) & 0.67 & 2.126 & 4.1 \\
\hline Aluminum (WPI 10220101) & 0.54 & 2.291 & 6.8 \\
\hline Sodium (Electricity Price Index) & 0.37 & 1.842 & 4.6 \\
\hline $\begin{array}{c}\text { Semiconductive PE (Thermosetting) } \\
\text { (WPI 061) }\end{array}$ & 0.76 & 1.870 & 4.07 \\
\hline $\begin{array}{c}\text { Semiconductive PE (Thermoplastic) } \\
\text { (WPI 061) }\end{array}$ & 0.56 & 1.870 & 4.07 \\
\hline XLPE（WPI 061） & 0.52 & 1.870 & 4.07 \\
\hline Thermoplastic PE (WP 061) & 0.40 & 1.870 & 4.07 \\
\hline $\begin{array}{l}\text { CPI (consumer price index) } \\
\text { WPI (wholesale price index) }\end{array}$ & $\begin{array}{l}1.0 \\
1.0\end{array}$ & $\begin{array}{l}1.634 \\
1.738\end{array}$ & $\begin{array}{l}3.07 \\
3.36\end{array}$ \\
\hline $\begin{array}{l}{ }^{*} \text { Relative to } 1978 \text { (includes infla } \\
\text { Inc. Cost Forecasting Service, Fi }\end{array}$ & $\begin{array}{l}\text { 2) fro } \\
\text { Quart }\end{array}$ & $\begin{array}{l}\text { Data Re } \\
1978 .\end{array}$ & rces \\
\hline
\end{tabular}


ESTIMATED COST OF CABLE TO ELECTRIC UTILITIES $(\phi / \mathrm{ft})$

(ATuminum) (1)

\begin{tabular}{|c|c|c|c|c|}
\hline $\begin{array}{c}\text { Conductor } \\
\text { Area }\end{array}$ & $600 \mathrm{~V}$ & $15 \mathrm{KV}^{(2)}$ & $25 \mathrm{kV}^{(2)}$ & $35 \mathrm{KV}^{(2}$ \\
\hline $\begin{array}{l}250 \mathrm{MCM} \\
300 \\
350 \\
400 \\
500 \\
600 \\
750 \\
1000 \\
1250 \\
1500 \mathrm{MCM}\end{array}$ & $\begin{array}{l}41.12(3)(7) \\
48.72(3)(7) \\
57.50 \\
63.81 \\
78.81 \\
93.75(3) \\
110.00(3) \\
154.21 \\
189.96 \\
226.73\end{array}$ & $\begin{array}{l}78.35^{(5)} \\
87.21(4) \\
93.32(4) \\
104.13 \\
120.03 \\
135.19(5)(7) \\
157.02(5) \\
181.38 \\
224.72 \\
256.92 \\
\text { odium }(8)\end{array}$ & $\begin{array}{l}85.53^{(5)} \\
96.74(4) \\
106.14 \\
115.16 \\
132.40 \\
148.94(5) \\
172.62(5) \\
209.25 \\
245.74 \\
280.30\end{array}$ & $\begin{array}{l}97.60 \\
108.82 \\
116.64 \\
129.95 \\
149.82 \\
168.75 \\
195.89 \\
238.80 \\
279.62 \\
318.95\end{array}$ \\
\hline $\begin{array}{c}\text { Consturtar } \\
\text { Area }\end{array}$ & $600 \mathrm{~V}$ & $15 \mathrm{kV}$ & $25 \mathrm{kV}$ & $35 \mathrm{KV}$ \\
\hline $\begin{array}{l}250 \mathrm{MCM} \\
300 \\
350 \\
400 \\
500 \\
600 \\
750 \\
1000 \\
1250 \\
1500 \mathrm{MCM}\end{array}$ & $\begin{array}{l}18.13 \\
21.22 \\
21.89 \\
27.34 \\
33.38(9) \\
39.36 \\
50.00 \\
63.50 \\
77.57 \\
92.07\end{array}$ & $\begin{array}{l}52.04 \\
57.16 \\
60.18 \\
66.76 \\
75.59(9) \\
83.85 \\
90.30 \\
113.67 \\
130.66 \\
146.96\end{array}$ & $\begin{array}{r}56.11 \\
62.73 \\
68.08 \\
73.14 \\
82.70 \\
91.75 \\
104.50 \\
123.71 \\
142.77 \\
160.45\end{array}$ & $\begin{array}{r}63.67 \\
70.07 \\
74.27 \\
81.96 \\
92.98 \\
103.34 \\
118.03 \\
140.91 \\
162.34 \\
182.76\end{array}$ \\
\hline
\end{tabular}

(1) Aluminum conductor, 600 volt with $100 \mathrm{mi} / \mathrm{s}$ XLPE $15 \mathrm{KV}, 25 \mathrm{KV}, 35 \mathrm{KV}$ with $175,260,345 \mathrm{mils}$ of XLPE, $15 \mathrm{mil}$ conductor and $30 \mathrm{mil}$ semiconductive insulation screen.

(2) $" 1 / 3$ reduced $\mathrm{Cu}$ concentric neutral.

(3) List prices Kaiser Aluminum, May 11, 1978.

(4) From P. L. Fontaine, "Underground Distribution To Large Shopping Centers and Industrial Parks," IEEE Conference Record, 1976, Underground Transmission and Distribution Conference.

(5) Ratios developed from April 1978 Phelps Dodge and Okonite list prices. These ratios used to extrapolate values in (4).

(6) Proportioned from $25 \mathrm{KV}$ based on materials cost ratios.

(7) These prices agree with task 1 survey data within $25 \%$. Survcy data not available for other sizes or voltages.

(8) Sodium conductor, no conductor screen, copper concentric neutral.

(9) Checked against NACON price lists as follows: $\frac{\text { WPI } 1026(1978)}{\text { WPI } 1026(1968)} \times$ NACON price < Na cable prices. 
Whereas sodium requires a pumping plant, aluminum requires a wire drawing and stranding operation. A similar exiruding process is used for both. The major advantage of this approach is that differences between sodium and aluminum cable costs are traceable to differences in quantity and cost of materials used rather than some fluctuating and difficult to define "markup." Consultation with cable manufacturers has assured the author that this is a more reliable approach to use. The sodium price is then estimated by adding its materials cost to the "other direct and indirect costs" as shown in Table 9-5.

Comparing sodium and aluminum cable costs in Table 9-4 shows a significant advantage for sodium for the same size and voltage class. However, one must remember that the same size sodium and aluminum cable are not equivalent electrically as explicitly shown in Section 7 .

A more valid comparison between equivalent cables (see Section 7) is given in Table $9-5$ for the $15 \mathrm{kV}$ voltage class. The cables both have a concentric copper neutral with conductivity $1 / 3$ of that of the main conductor. As shown in Section 7, to have equal ampacity in the overload condition a $15 \mathrm{kV}, 250 \mathrm{MCM}$ Al cable must be replaced with a $15 \mathrm{kV}$, 530 MCM sodium cable.

Comparison of the conductor costs in Table 9-5 shows a metal savings of approximately $50 \%$ relative to aluminum. The required metal volume for sodium is approximately twice that for aluminum but the relative weight is $1 / 3$ and relartve cust only $2 / 3$. No condurton screen is required with sodium (Section 7) ylelding a slight savings. Since the sodium diameter is larger, both insulation and insulation screen costs are increased relative to the aluminum. The requiremert that the copper concentric neutral must have "1/3 of the conductor resistance per foot" at overload condition results in a cost disadvantage to sodium for the concentric neutral. Examination of the electrical design tables in Section 7 shows a resistance per unit length for sodium that is 73\% of that for aluminum at normal full load and operating temperatures. Requiring this lower resistance in the neutral requires about $35 \%$ more copper than in the aluminum case. This "extra conductivity" would most 


\section{TABLE 9-5}

\section{COMPARISCIN: SODILM AND ALUMINUM CABLE COSTS $(\phi / \mathrm{ft})$}

$15 \mathrm{KV}$

$$
\text { m a } t \text { e } r \text { i a } 1
$$

\section{conductor}

conductor screer $\left(A_{1} 1=15, N A=0\right)$

insulation (175 mils)

insulation screen (30 mils)

concentric neutral $(1 / 3)$

material subtotal

other direct and indirect

product costs

electric litility price

$\breve{\infty}_{\infty}$

conductor
conductor screen $(A i=5, N A=0)$
insulation $(175 \mathrm{mi}] \mathrm{s})$
insulation screen $(30 \mathrm{mi} / \mathrm{s})$
concentric neutral $(1 / 3)$
$\quad$ material subtotal
other direct and indirect
product costs
electric utility price

\section{A1 $250 \mathrm{MCM}$}

12.79

1.02

10.02

3.41

10.59

37.85

40.5

78.3

\begin{tabular}{c} 
A1 1000 MCM \\
\hline 51.17 \\
2.02 \\
17.41 \\
5.41 \\
42.37 \\
118.38
\end{tabular}

63.00

181.38

\section{MF $530 \mathrm{MCM}$}

\subsection{7}

0.0

$1 \div .61$

3.84

13.55

35.66

40.5

76.16

\begin{tabular}{c} 
NA 2155 MCM \\
\hline 27.10 \\
0.0 \\
21.11 \\
6.40 \\
55.09 \\
109.71 \\
63.00 \\
172.71
\end{tabular}

(Note: If a vapor barrier is required, then the ju drain wires would be remaved and a lead sheath concentric ( 80 mils) might be used as both vapor barrier and concentric neutral. This would add approximately $50 \mathrm{~d} / \mathrm{ft}$ to the cable prices shown. If the barrier is required on both $\mathrm{Al}$ and $\mathrm{Na}$ cable, the cost comparison is essentially unchanged. Please see Section $7(7.3 .5,7.7 .5)$ for a technical discussion of this issue. If the barrien is required only for Na, then for typical case $(15 \mathrm{kV}, 250 \mathrm{kcmil})$, the lla cable wou d cost approximately $40 \%$ more than tre Al and total present worth cost of $\mathrm{Na}$ would be $6 \%$ higher th $\equiv n$ Al.

If an LC ("copper foil") construction with PE were used as the jacket (hermetically sealed) then jacket costs would be approximataly equal to the lead sheath. Section ?.3.5 indicates that a helically nound aluminum adhesive tape may serve a: I adequate moisture barrier; $a$ lower cost than sheath barriers. 
probably be needed in the case of a fault while in the overload condition. As explained previously, the other direct and indirect costs are assumed equal for sodium and aluminum. This cost number was calculated by subtracting the total aluminum cable materials cost (37.85c) from the electrlc utility purchase price $(78.3 c)$.

Comparison of costs for this case (Table 9-5) shows only about a 2c per foot cost advantage for sodium for this particular cable. However, one must remember that the full load losses for this sodium cable are only $74 \%$ of those for the aluminum cable. A decision on savings based only on cable cost would be incorrect. A value for reduced losses is included in the comparison made in Section 9.3.

Component cost breakdowns for sodium and aluminum cable $600 \mathrm{~V}, 15 \mathrm{kV}, 25 \mathrm{kV}, 35 \mathrm{kV}, 250 \mathrm{MCM}, 350 \mathrm{MCM}, 750 \mathrm{MCM}$ and $1000 \mathrm{MCM}$ are given in Appendix A4 Tables A4-1 through A4-4.

\subsubsection{Substitution of High Molecular Weight Polyethylene (HMWPE) for XLPE}

It is interesting to evaluate the influence on cost of substituting high molecular weight polyethylene (HMWPE) for cross linkable type polyethylene (XIPE). Essentially we are substituting a thermoplastic type insulator ( $41 c$ per $1 \mathrm{~b}$. ) for the thermosetting type insulation (51c per 1b.). A thermoplastic screen material (56c/1b.) is also substituted for the thermosetting screen $(76 \mathrm{c} / 1 \mathrm{~b}$.). These substitutions reduce the $15 \mathrm{kV} 530 \mathrm{MCM}$ sodium cable cost (Table 9-5) to $72.88 \mathrm{c} / \mathrm{ft}$. and double savings relative to aluminum to $5.42 \mathrm{c} / \mathrm{ft}$. This substitution will be evaluated more fully in Section 9.3.

\subsection{Comparision of Aluminum and Sodium Cable Costs}

The total present worth of aluminum and sodium cable costs as defined by Equation 9-I are evaluated within various applications.

\subsubsection{Comparison at Unity Load Factor and Rated Thermal Ampac1cy}

A comparison of sodium and aluminum cable total present worth costs at unity load factor and full load rated ampacity is presented in Table 9-6. The simplifying assumption of unity load factor and rated 
Sluminum and Sodium Cable Owning and Operating Costs;

Therma1 Ampacity Limit (Section 7) Loss Factor $=1.0$

Peak Responsibility. Factor $=: .0$

\section{Voltage, A1 Size-Ma Size}

$600 \mathrm{~V}, 250 \mathrm{MCM}-542 \mathrm{MCM} *$

$600 \mathrm{~V}, 350 \mathrm{MCM}-760 \mathrm{MCM}$

$600 \mathrm{~V}, 750 \mathrm{MCM}-1633 \mathrm{MCN*}$

$600 \mathrm{~V}, 1000 \mathrm{MCM}-2136 \mathrm{MCM}^{*}$

$15 \mathrm{kV}, 250 \mathrm{MCM}-53 \mathrm{C} \mathrm{MCM} * *$

$15 \mathrm{kV}, 350 \mathrm{MCM}-74 \mathrm{C} \mathrm{MCM**}$

$\stackrel{5}{0}$
$15 \mathrm{kV}, 750 \mathrm{MCM}-1608 \mathrm{MCM} * *$

$15 \mathrm{kV}, 1000$ MCM - 2155 MCM $* *$

$25 \mathrm{kV}, 250 \mathrm{MCM}-530 \mathrm{MCM} * *$

$25 \mathrm{kV}, 350 \mathrm{MCM}-740 \mathrm{MCM} * \star$

$25 \mathrm{kV}, 750$ MCM - $1608 \mathrm{MCM}^{* *}$

$25 \mathrm{kV}, 100 \mathrm{MCM}-2155 \mathrm{MCH} * *$

$35 \mathrm{kV}, 250 \mathrm{MCM}$ - $530 \mathrm{MCM} * *$

$35 \mathrm{kV}, 350 \mathrm{MCM}-740 \mathrm{MCM} * *$

$35 \mathrm{kV}, 750 \mathrm{MCM}-1608 \mathrm{MCM} \approx *$

$35 \mathrm{kV}, 1000$ MCM - 2155 MCM*=

\begin{tabular}{cc}
\multicolumn{2}{c}{ Alumirum } \\
\hline Cable & Cost of \\
Costs $(\$ / f t)$. & Losses $(\$ / f t)$.
\end{tabular}

\section{.41}

.57

1.16

1.54

2.35

2.88

4.53

5.44

2.57

3.19

5.17

6.28

2.93

3.64

5.90

7.16
56.03

57.20

60.37

59.97

76.46

77.97

84.33

85.19

73.38

75.56

82.38

82.55

70.41

73.10

79.82

80.13
Sodium

\begin{tabular}{cc}
\hline Cable & Cost of \\
Costs (\$.ft.) & Losses (\$/ft.) \\
\hline
\end{tabular}

.36

.50

1.003

1.320

2. 302

2.796

4. 332

5.175

2.536

3.129

5. 066

6.073

2.910

3.60

5.79

7.008
40.35

41.37

42.28

42.54

55.14

56.75

59.36

60.42

52.83

54.62

57.60

58.44

50.70

52.82

55.80

56.72
Tota1 PW

Difference $\mathrm{Al-Na}(\mathrm{S} / \mathrm{ft}$.

\subsection{3}

15.90

18.25

17.65

21.37

21.30

25.17

25.03

20.59

21.01

24.93

24.32

19.73

20.32

24.73

23.56

*single phase cable, concuctor and insulation only **3 phase cable, $1 / 3 \mathrm{Cu}$ concentric neutral 
ampacity makes the cable cost comparison independent of the cable application. Both sodium and aluminum cables compared in Table 9-6 are operating at the same full load currents with operating temperatures specified as in Section 7.

For the $600 \mathrm{~V}$ comparisons, full load single phase current ( 1 conductor) is assumed and for all higher voltages a balanced three phase system ( 3 conductors) is considered. Cable costs for the 3 phase system are 3 times those shown in Table 9-4 for single cables.

Examination of cable costs and cost of losses in Table 9-6 shows costs of losses an order of magnitude or more higher than cable costs. This greatly increases sodium cable savings over aluminum. The savings are composed almost wholly of a savings in losses ( $30 \%$ of aluminum, PW cost). This unity load factor and full load current evaluation leads to an overemphasis of the savings in losses. From References 71 and 72 and other general information it is believed that most distribution system cables are "lightly loaded" and thus the high savings in losses would not be realized. In Sections 9.3.3 and 9.3.6 the cost of losses are evaluated under what is believed to be more realistic assumptions for load and loss factors.

Comparison of the cases in Table 9-6 shows that maximum savings is achieved for the lowest voltage, largest. size conductor $(600 \mathrm{~V}$, 1000 MCM Al, $2196 \mathrm{MCM} \mathrm{Na}$ ). The cable cost savings is largest because of the relatively higher percentage of metal in the total cables. The loss saving is higher because of the higher ampacity rating of the $600 \mathrm{~V}$ cable as compared tc the higher voltage.

To provide clarification on how the numbers in Table 9-6 were calculated, the $15 \mathrm{kV}, 250 \mathrm{MCM}$ entries are calculated below using Equation 9.2 through 9.4 in reverse order. 


$$
\begin{aligned}
& \mathrm{PWR}_{\mathrm{L}}=\mathrm{K}_{\mathrm{P}}\left(\mathrm{I}_{1}^{2}+\mathrm{I}_{1} \mathrm{I}_{2}+\mathrm{I}_{2}^{2}\right) \mathrm{R} \\
& =1\left(375^{2}+(375)(375)+375^{2}\right) 2.898 \times 10^{-6} \frac{\Omega}{\mathrm{cm}} 30.5 \frac{\mathrm{cm}}{\mathrm{ft}}=37.66 \frac{\text { watts }}{\mathrm{ft}} \text { (for A1) } \\
& =1\left(375^{2}+(375)(375)+375^{2}\right) 2.133 \times 10^{-6} \frac{\Omega}{\mathrm{cm}} 30.5 \frac{\mathrm{cm}}{\mathrm{ft}}=27.445 \frac{\text { watts }}{\mathrm{ft}} \text { (for Na) } \\
& \mathrm{PWR}=\sum_{i=1}^{N} \frac{(1+g)^{i}(1+\mathrm{e})^{i}}{(1+\mathrm{d})^{i}}=\sum_{i=1}^{25} \frac{(1 .)^{i}(1.05)^{i}}{(1.12)^{i}}=12.01 .2 \\
& P W_{L}=[(I . S F \times \text { POENC })+(\text { PKRESB } \times \text { PUCAY })\rfloor \times \text { PWRL } \times \text { PWF } \\
& P W_{L}=[(1 \times .094+(1 \times .07 b)] \times 37.66 \times 12.012=\$ 76.46 / \text { ft (for A.L) } \\
& \mathrm{PW}_{\mathrm{L}}=[(1 \times .094)+(1 \times .075)] \times 27.445 \times 12.012=\$ 55.14 / \mathrm{ft} \text { (for Na) } \\
& \text { Unity Load factor implies unity loss factor which implies a }
\end{aligned}
$$
unity peak responsibility factor.

The operating costs and capacity costs of the eiectric utility are taken from Referencco 75 and are converted to the proper units for Equation 9.2 by

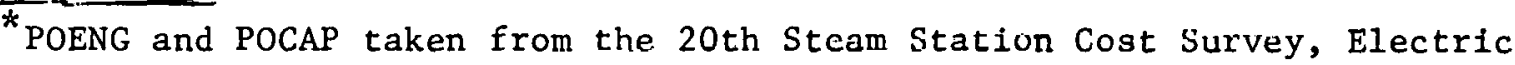
World, Nov. 16, 1977.

"e"-bus bar energy cost escalation epproxluately from 15th, 16th, 17th Electrical World Steam Station Survey. Thinking at the time of these calculations (mid 1978) was that long term electric cost escalation would approximate long term inflatinn ( $1.5 \%)$. Receul forecasts (March 14, 1979) indlcate that this number might be increased to about $8 \%$. Using $8 \%$ for e in Eq. (9-7) would increase the PWF by $35 \%$. Fur the typical $15 \mathrm{kV}$ case, this would increase $\mathrm{Na}$ savings to $11.6 \%$ from $10 \%$ uf $\mathrm{Ml}$ costs.

The 25 year life used is a planning life of the distribution cable system and is used throughout the economic analysis. The 40 year life represents the physical life (degradation, effective cross-section reduction etc.) of the cable. Because of the high discount factor, $12 \%$ of the PWF factor increases only $15 \%$ if planning life is increased to 40 years. For the nominal $15 \mathrm{kV}$ case, this would increase sodium savings by $0.8 \%$ (e.g., $10.8 \%$ of $\mathrm{Al}$ costs as contracted with $10 \%$ ).
} 


$$
\begin{aligned}
\text { POENG } & =\left(\frac{\$ .01077}{\mathrm{kwhr}}\right)\left(\frac{1 \mathrm{kw}}{1000 \mathrm{w}}\right)\left(\frac{8760 \mathrm{hr}}{\mathrm{yr}}\right) \\
& =\frac{\$ .094}{\mathrm{w}-\mathrm{yr}} \\
\text { POCAP } & =\stackrel{\text { Average Capacity Cost at Peak } \times \text { Annual }}{\text { Carrying Charge }} \\
& =\frac{\$ 415}{\mathrm{kw}}(.18)=\frac{\$ 75}{\mathrm{kw}-\mathrm{yr}}=\frac{\$ .075}{\mathrm{w}-\mathrm{yr}}
\end{aligned}
$$

As an added indication of the impracticality of unit load factor full load current for evaluating losses, one can examine the voltage drop system regulation problem.

The necessary sending end voltage to obtain 7200 volts phase to ground ( $15 \mathrm{kV}$ class line to line) at the distribution transformer would be $(76)$

$$
V_{s}=\sqrt{\left(V_{R} \cos \theta+R I\right)^{2}+\left(V_{R} \sin \theta+X I\right)^{2}}
$$

where

$$
\begin{aligned}
& V_{R}=\text { voltage at receiving end of line } \\
& \cos \theta=\text { power factor } \\
& \mathrm{R}=\text { phase conductor resistance } \\
& X=\text { phase inductive reactance } \\
& I=\text { phase current }
\end{aligned}
$$

$$
\begin{aligned}
& \begin{aligned}
v_{s} & =\sqrt{(7200(.85)+.88 \Omega 375 \text { amps })^{2}+(7200(.526)+.44375 a)^{2}} \\
& =7564 \text { volts } \\
& \quad \cdot \quad \text { regulation }=\frac{\left|v_{s}\right|-\left|v_{R}\right|}{\left|V_{R}\right|} \times 100=5.05 \%
\end{aligned}
\end{aligned}
$$

This voltage crop is well above the usual upper limit for good regulation of $3 \%$. 


\subsubsection{Comparison of Cable Costs Neglecting Losses}

The results of comparing sodium and aluminum cable when losses are neglected are presented in Table 9-7. Cost savings for sodium over aluminum cable are dramatically lower than the previous comparison in Table 9-6. The maximum savings are in the lowest voltage, largest size case $(600 \mathrm{~V}, 1000 \mathrm{MCM}$ Al - $2196 \mathrm{MCM} \mathrm{Na})$. The cable cost savings increase with size of conductor because of the larger percentage of metal content for a given volume per unit lenglh. The cost savings decrease with inrreasing voltagc because of the increased insulation costs required by the largerdiameter sodium cable. If HMWPE is substituted for XLPE, then savings for $600 \mathrm{~V} 1000 \mathrm{MCM}$ - $219 \mathrm{~h}$ MLM caeo incrcase froin $\$ .22$ to $\$ .25$ or about $15 \%$. Savings increase much more significantly for higher voltage cases. For example for $15 \mathrm{kV} 1000 \mathrm{MCM}-2155 \mathrm{MCM}$ savings Increase to $\$ .44$ or $168 \%$ of the former. For the $35 \mathrm{kV}$ case savings are increased to $\$ .40,263 \%$ of the former.

\subsubsection{Sensitivity of Costs To Application Parameters}

The data presented in Table 9-8 examine the effect on the present worth of losses of changing loss factor and peak responsibility factor. Case 1 represents the unity load factor, unity peak respunstbility factor case. Case 2 reduces the loss factor and peak responsibility factors to values more typical of secondary applications. (71) However, the load is still at the ampacity rating which would most likely result in too large a voltage drop. Case 4 reduces load current to a tolerable voltage drup level as well as lowering loss factor and peak responsibility factor, probably a more practical comparisü. Case 9 neglects losses thus underestimating savings.

\subsubsection{Defintion of the Application for Distribution System Comparison}

In the previous sections aluminum and sodium cable have been compared in what might be called a "theoretical sense." To achieve added insight these cables are now evaluated for two particular applications which are schematically shown in Figures $9-2$ and 9-3. A goal of the study 
TABLE 9-7

Aluminum and Sodium Cable Costs Neglecting Losses

\begin{tabular}{|c|c|c|c|}
\hline Voltage, Al Size - Na Size & $\begin{array}{l}\text { Aluminum } \\
\text { Cable Costs } \\
(\$ / f t) \\
\end{array}$ & $\begin{array}{c}\text { Sodium } \\
\text { Cable Costs } \\
(\$ / f t) \\
\end{array}$ & $\begin{array}{c}\mathrm{PW} \\
\text { Difference } \\
\mathrm{Al}-\mathrm{Na}(\$ / \mathrm{ft}) \\
\end{array}$ \\
\hline $600 \mathrm{~V}, 250 \mathrm{MCM}-542 \mathrm{MCM} *$ & .41 & .36 & .05 \\
\hline $600 \mathrm{~V}, 350 \mathrm{MCM}-760 \mathrm{MCM}^{*}$ & .57 & .50 & .07 \\
\hline $600 \mathrm{~V}, 750 \mathrm{MCM}-1633 \mathrm{MCM} *$ & 1.16 & 1.003 & .157 \\
\hline $600 \mathrm{~V}, 1000 \mathrm{MCM}-2196 \mathrm{MCM} *$ & 1.54 & 1.32 & .22 \\
\hline $15 \mathrm{kV}, 250 \mathrm{MCM}-530 \mathrm{MCM} * *$ & 2.35 & 2.302 & .048 \\
\hline $15 \mathrm{kV}, 350 \mathrm{MCM}-740^{\circ} \mathrm{MCM} * *$ & 2.88 & 2.796 & .084 \\
\hline $15 \mathrm{kV}, 750 \mathrm{MCM}-1608 \mathrm{MCM} * *$ & 4.53 & 4.332 & .198 \\
\hline $15 \mathrm{kV}, 1000 \mathrm{MCM}-2155 \mathrm{MCM}^{* *}$ & 5.44 & 5.179 & .261 \\
\hline $25 \mathrm{kV}, 250 \mathrm{MCM}-527 \mathrm{MCM} * *$ & 2.57 & 2.53 & .0429 \\
\hline $25 \mathrm{kV}, 350 \mathrm{MCM}-740 \mathrm{MCM} * *$ & 3.19 & 3.12 & .07 \\
\hline $25 \mathrm{kV}, 750 \mathrm{MCM}-1603 \mathrm{MCM} * *$ & 5.17 & 5.016 & .154 \\
\hline $25 \mathrm{kV}, 1000 \mathrm{MCM}-2149$ MCM** & 6.28 & 6.073 & .207 \\
\hline $35 \mathrm{kV}, 250 \mathrm{MCM}-530 \mathrm{MCM}^{* *}$ & 2.93 & 2.91 & .02 \\
\hline $35 \mathrm{kV}, 350 \mathrm{MCM}-740 \mathrm{MCM} * *$ & 3.64 & 3.60 & .043 \\
\hline $35 \mathrm{kV}, 750 \mathrm{MCM}-1608 \mathrm{MCM} * *$ & 5.90 & 5.79 & .111 \\
\hline $35 \mathrm{kV}, 1000 \mathrm{MCM}-2155 \mathrm{MCM}^{* *}$ & 7.15 & 7.008 & .152 \\
\hline
\end{tabular}

\footnotetext{
*single phase cable, conductor and insulation only **3 phase cable, $1 / 3 \mathrm{Cu}$ concentric neutral
} 


\section{TABLE 9-8}

Sensitivity of Aluminum and Sodicm Cable Owning and Operating Costs to Changes in A pplication Parameters (See Notes)

\section{Voltage, Al Size - Na Size}

(1) $600 \mathrm{~V}, 1000 \mathrm{MCM}-2196 \mathrm{MCM}^{*}$

(2) $600 \mathrm{~V}, 1000 \mathrm{MCM}-2196 \mathrm{MCM} *$

(3) $600 \mathrm{~V}, 1000 \mathrm{MCM}-2196 \mathrm{MCM*}$

(4) $600 \mathrm{~V}, 1000 \mathrm{MCM}-2196 \mathrm{KCM} *$

(5) $600 \mathrm{~V}, 1000 \mathrm{MCM}-2 i 96 \mathrm{MCM}^{*}$

\begin{tabular}{cc}
\multicolumn{2}{c}{ Aluminum } \\
\hline Cable & Cost of \\
Cosis (\$ift.) & Losses $(\$ / f t)$.
\end{tabular}

1.54

1.54

1.54

1.54

1.54
59.97

13.99

9.08

0.80

0.00

(1) Thermal ampacity 1imit (814 amps) Loss factor $=1.0$, Peak responsibility factor $=1.0$

(2) Thermal ampacity limit (814 amps)

Loss factor $=.18$, Peak responsibility factor $=.3$

(3) Thermal ampacity iimit (814 anps)

Loss factor $=.06$, Peak responsibility factor $=.266$

(4) Reduced load (271 amps)

Loss factor $=.06$, Peak respor.sibility factor $=.266$

*Maximum savings case from Table $9-7$. 
DISTKIEUTIOW EFEDH APPLICATIO

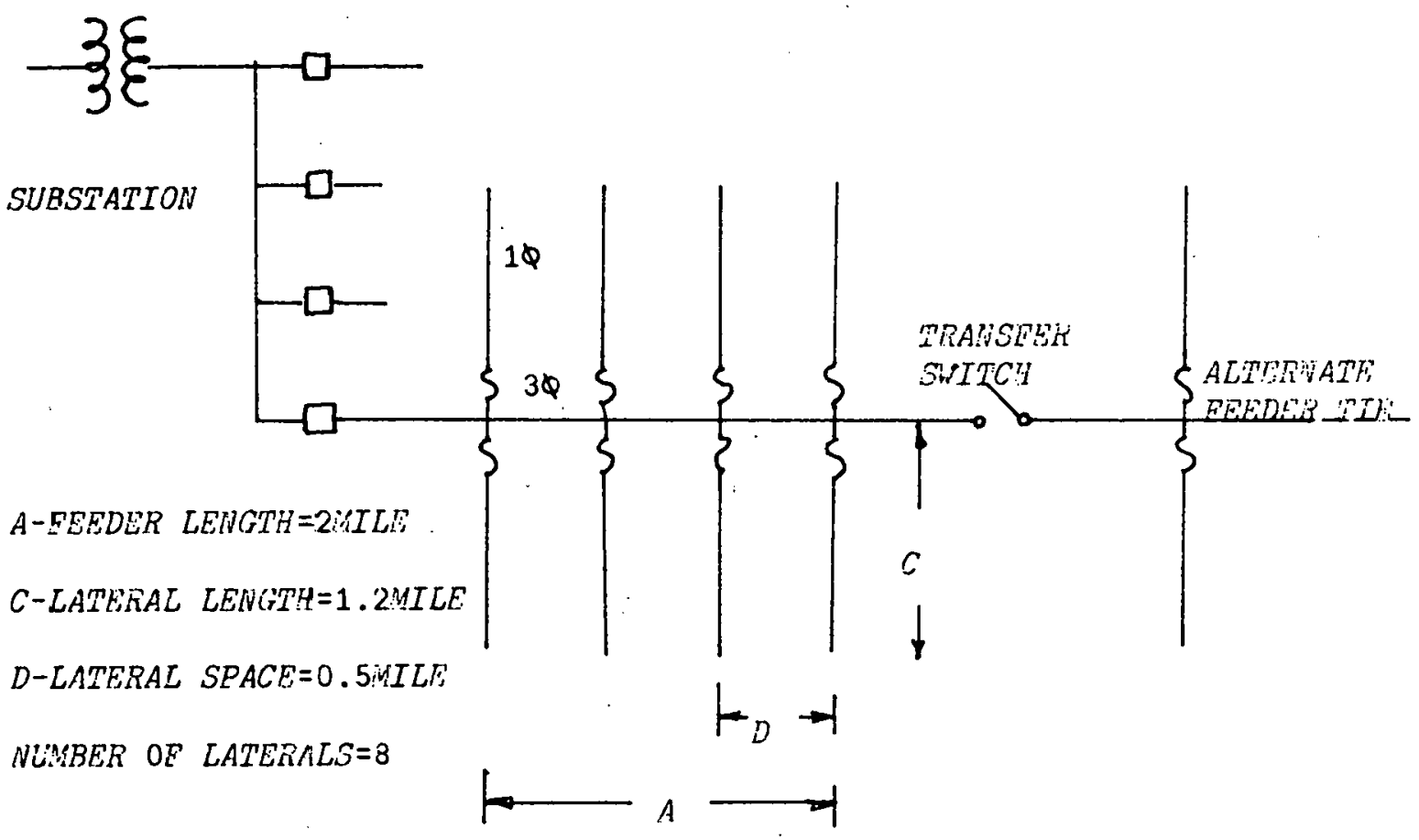

Figure 9-2 
IFAVSFORMER-SECONDARY-SERVICE APPLICATION

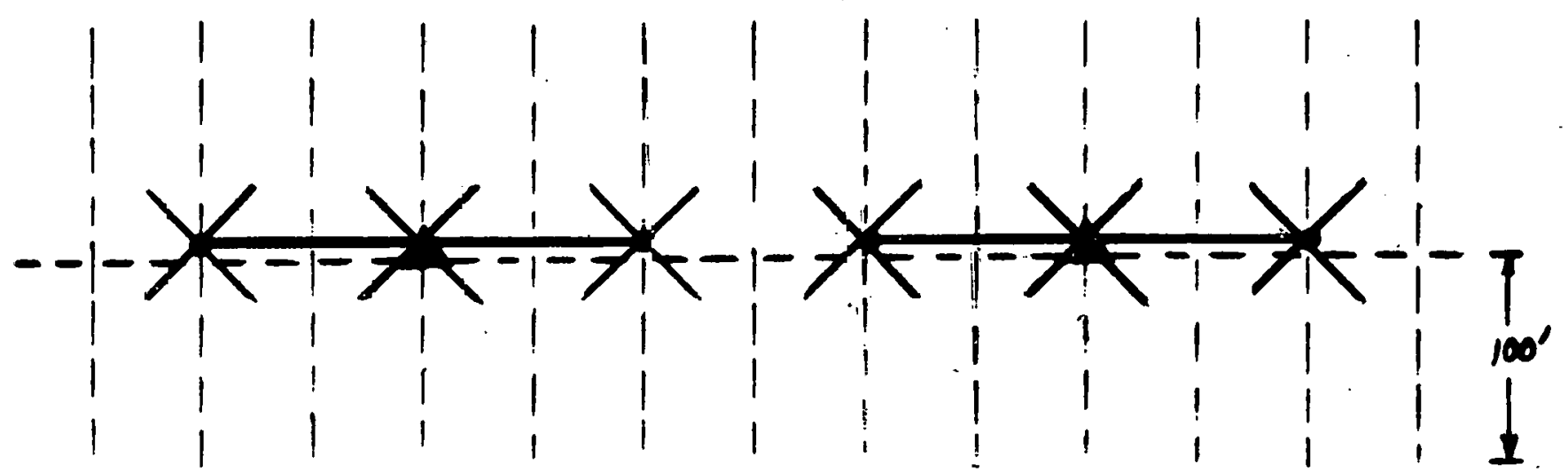

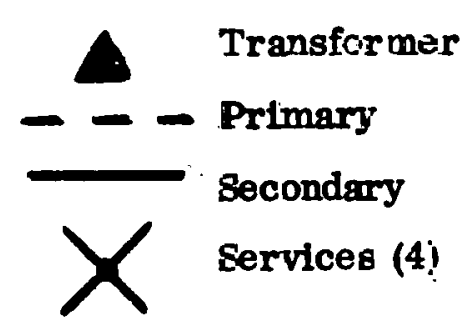

12 CUSTOMERS/TRANSFORMER

$75^{\prime}$ LOT WIDTH

$100^{\prime}$ LOT DEPTH
FRIMARY LENGTH: $\quad \mid-75^{\prime}-1$

$\frac{75 \text { Feet } \times 6 \text { Lots }}{12 \text { Cugtomers }}=37.5 \%$ CUST.

\section{SECONDARY LENGTH:}

$\frac{75 \text { Feet } \times 4 \text { Lots }}{12 \text { Customers }}=25 \%$ CUST.

SERVICE LENGTH

$1 / 2 \times \sqrt{(75)^{2}+(100)^{2}}=62.5 \%$ CUsT.

*(FROM 'TRAWSMISSIDN AND DISTRIBUTTON SYSTEM LOSS STUDY' FIVAL. DOE REPORT REPORT HO. 7T-112, SEPTEMBER 1977,REFERENCE 1)

Figure 9-3 
required evaluating the relative cost of connectors for the two cable systems. The connector number, size, voltage rating and current rating depend on the particular application. Defining an application also helps one select more practical values for load factors, loss factors, peak load currents, and cable structure (e.g., neutral or none).

In Figure 9-2 a feeder design schematic is shown. This feeder arrangement with three phase primary and a single phase lateral is used to compare $15 \mathrm{kV}, 25 \mathrm{kV}$, and $35 \mathrm{kV}$ aluminum with sodium cable. A single tie point is used thus allowing the laterals to be fed from either of two substations ${ }^{(77)}$ in an emergency condition. This contingency for emergencies requires a $40 \%$ reserve capacity in the 3 phase main feeder. Under emergency conditions the 3 phase main must feed its own laterals plus those of the adjoining feeder through the tie point. The normal peak load current must then be equal to or less than one-half of the overload rating. In the cable comparison the peak load current was set at one-half the overload rating as specified in Section 7. The load factors and loss factors for a practical feeder of this type were chosen from Reference 71 .

In Figure 9-3, a schematic diagram of the secondary service application which was used to compare sodium and aluminum cables is shown. From References 78 and 71 this is selected as a practical and probably typical underground distribution application.

\subsubsection{Estimating Connector Costs}

The connector costs developed in the following are based on the 3 phase main feeder design shown in Figure 9-2.

The expense of connectors associated with the sodium cable installation in the 1966-1969 period were a frequently cited source of concern in the Task 1 Survey. It is also recognized that these first sodium connectors (see Figure A5-3) were hastily designed and were not cost-improved in any measure. In our comparison of connectors some might argue that optimized and cost improved aluminum designs 
are being compared to prototype sodium designs. While this is true, the connector data and costs available at present preclude any other analysis. The connector systems used in this cost comparison could be available now with very minor design modifications.

There are two basic facts which imply that sodium cable connectors might be more expense than those for aluminum cable even with an improved design. The first involves the low tensile strength of the sodium metal. Relatively complicated designs (Figure A5-7) are needed to take advantage of the strength of the insulation in making ronnectiono. This is especially a conocrn in $600 \mathrm{~V}$ secondary and service applications where "standard aluminum practice" involves tightening an Allen type set screw directly against a stranded aluminum conductor (Figure A5-4). The second fact is that since sodium and aluminum react, copper is most probably required in even the improved designs. Just on materials cost basis this results in a $25 \%$ cost penalty over aluminum.

\subsubsection{Three-Phase Main Feeder Connector Costs}

Figure 9-4 provides circuit detail for the three phase main feeder and single phase lateralo showu schematically in Figure 9-3. Examining Figure 9-4 shows that there are 32 connections needed in the 3 phaoc primaly feeder. It is accumcd thal tuth tap point and disconnect switch point is brought up to a junction box. Each of these tap and switch points require two connections to the cable.

For the aluminum cable system deadbreak type elbow connectors similar to those shown in Figures $A 5-1$ and $A J-2$ might be used. In calculating these costs list prices were used lut the various size connectors as given below:

Voltage Size Deadbreak Elbow Connector Cost

$15 \mathrm{kV} \& 25 \mathrm{kV} \quad 250-400 \mathrm{MCM}$ $500-1000 \mathrm{MCM}$ $1000-1500$ MCM

$35 \mathrm{kV}$
$250-400 \mathrm{MCM}$ 500-1000 MCM 1000-1500 MCM
$\$ 42.50$ each.

$\$ 94.00$

$\$ 141.00$

$\$ 85.50$

$\$ 169.40$

$\$ 254.10$ 


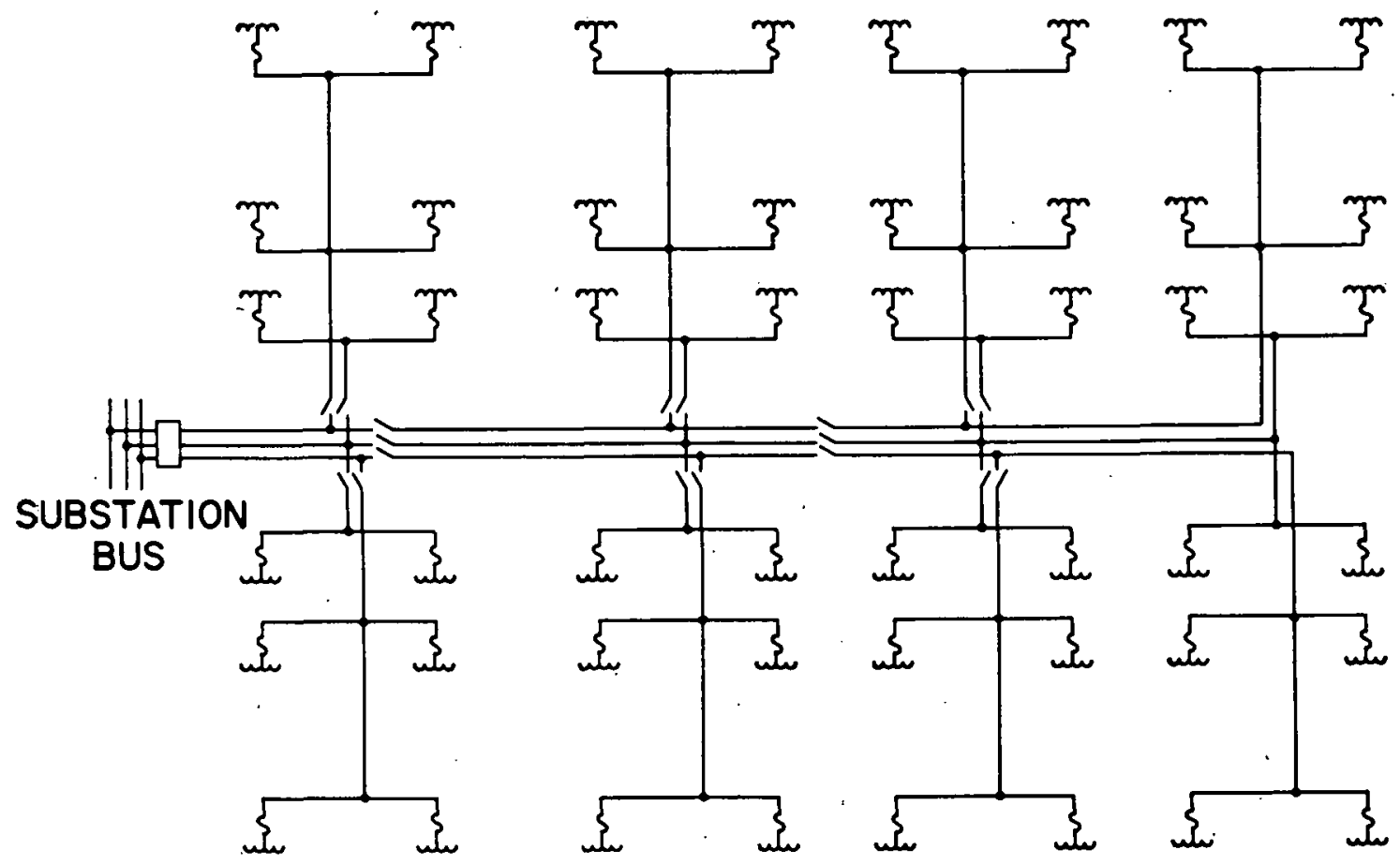

An extensive primary feeder circuit showing extended use of three-phase mains and single-phase lateralssuburban-urban area distribution.

* ERDM WESTINGIIOUSE ELECTRIC UTILITY ENGINEERING REFERENCE BOOK;DISTRIBUTION SYSTEMS,VOL.3 E. PGH. 1959)

\section{Figure 9-4}


These costs were allocated over the total 2 miles $(10,560 \mathrm{ft}$. of three phase circuit to obtain the costs shown for aluminum in Table 9-9(a).

For the sodium cable system "copper pin type" connectors similar to those shown in Figure $A 5-3$ and. $A 5-7$ are assumed to be used. The copper rod or pin extension of the sodium conductor is then used with a standard loadbreak elbow connector as in the aluminum cable connections. These "copper pin type" connectors are priced by comparing their size, welght and conductor termination with a price list for similar copper connectors shown in Figure A5-6. Thus the sodium per foot connection costs are increased over the aluminum by the cost of a "copper pin type" connector for each of the 32 connections (Table 9-9(a)).

While it is recognized that splice costs would also be higher for sodium than aluminum, these costs have been neglected. The number of splices would be considerably less than the number of connections and would not alter the comparative economics significantly.

\subsubsection{Single-Phase Lateral Connector Costs}

Fui Llie single phase lacerals shown in Figure 9-2, it has been assumed that there will be 12 customers per pad-mounted transformer and $37.5 \mathrm{KVA}$ per transformer resulting in 14 transformers per lateral. and a total lateral length of $5400 \mathrm{ft}$.

Two "loop through" type primary connections will be used at each transformer with two connections at the switch tie point to the primary feeder. This results in 26 connections per lateral. Deadbreak elbow connectors are again used for the aluminum and "copper pin type" connectors with elbow connectors for the sodium. The resulting per unit length costs are shown in Table 9-9(b).

\subsubsection{Secondary-Service Connector Costs}

Connector costs for the secondary-service system are based on the typical system shown in Figure 9-3. This system has secondary extending over 4 lots $\left(4\right.$ lots $\left.\times 75 \mathrm{ft} .=300^{\prime}\right)$ and service connection to 12 customers with an average length of $63^{\prime}\left(12 \times 63 \mathrm{ft} .=756^{\prime}\right)$. 
TABLE 9-9

Connector Cost Per Foot of Cable; Based on Application Shown in Figures $9-2$ and $9-3$

(a) Three Phase Primary Feeder (see Figure 9-2)

\begin{tabular}{|c|c|c|c|c|}
\hline \multicolumn{5}{|c|}{ Aluminum ( $c$ per $3 \phi \mathrm{ft})}$. \\
\hline & & $15 \mathrm{kV}$ & $25 \mathrm{kV}$ & $35 \mathrm{kV}$ \\
\hline 250 & MCM & 12.9 & 12.9 & 25.9 \\
\hline 350 & & 12.9 & 12.9 & 25.9 \\
\hline 750 & & 28.5 & 28.5 & $51 . .3$ \\
\hline 1000 & $\mathrm{MCM}$ & 28.5 & 28.5 & 51.3 \\
\hline \multicolumn{5}{|c|}{ Sodium ( $q$ per $3 \phi . f t)}$. \\
\hline & & $15 \mathrm{kV}$ & $25 \mathrm{kV}$ & $35 \mathrm{kV}$ \\
\hline 250 & MCM & 13.4 & 13.4 & 26.4 \\
\hline 350 & & 13.5 & 13.5 & 26.5 \\
\hline 750 & & 30.1 & 30.1 & 52.9 \\
\hline 1000 & MCM & 31.8 & 31.8 & 54.6 \\
\hline
\end{tabular}




\section{TABLE 9-9}

Connector Cost Per Foot of Cable; Based on Application Shown in Figures 9-2 and 9-3

(b) Single Phase Lateral (see Figure 9-2)

\begin{tabular}{|c|c|c|c|c|}
\hline \multicolumn{5}{|c|}{ Aluminum (s per ft. $)$} \\
\hline & & $15 \mathrm{kV}$ & $25 \mathrm{kV}$ & $35 \mathrm{kV}$ \\
\hline 250 & $\mathrm{MCM}$ & 20.5 & 20.5 & 41.2 \\
\hline 350 & & 20.5 & 20.5 & 41.2 \\
\hline 750 & & 45.3 & 45.3 & 81.6 \\
\hline 1000 & MCM & 145.3 & 45.3 & 81.6 \\
\hline \multicolumn{5}{|c|}{ Sodium ( $c$ per $f t$. ) } \\
\hline & & $15 \mathrm{kV}$ & $25 \mathrm{kV}$ & $35 \mathrm{kV}$ \\
\hline 250 & MCM & 21.2 & 21.2 & 41.9 \\
\hline 350 & & 21.4 & 21.4 & 42.1 \\
\hline 750 & & 47.8 & 47.8 & 84.1 \\
\hline 1000 & MCM & 50.4 & 50.4 & 86.8 \\
\hline
\end{tabular}


The total 1,056 ft. of secondary and service requires 3 wire service ( 3 wired cables) $\times 1056 \mathrm{ft} .=3168 \mathrm{ft}$. of insulated $600 \mathrm{~V}$ conductor cable). There are 14 segments in the secondary-service system requiring a total of 84 connections (14 segments $\times 3$ cables $\times 2$ connectors).

For the aluminum system an aluminum bus bar (Figure 12.5-4)

is threaded onto the secondary stud of the pad-mounted transformer. The stranded aluminum conductors are inserted directly into the bus bar and secured by tightening the set screws. The entire assembly is covered with a device as shown in Figure A5-5.

For the sodium cable an identical aluminum bus system is assumed to be used. Again "copper pin type" connectors are first inserted into the sodium cables which are secured to the bus.

Costs for both aluminum and sodium connectors are estimated based on list prices from Reference 80 as shown below:

\section{V Secondary-Service}

\begin{tabular}{lccc} 
Size & $\begin{array}{c}\text { Aluminum } \\
\text { Connector } \\
\text { Costs (\$ ea.) }\end{array}$ & & $\begin{array}{c}\text { Sodium } \\
\text { Connector } \\
\text { Costs }(\$ \text { ea.) }\end{array}$ \\
\cline { 2 - 2 } $250 \mathrm{MCM}$ & $\$ 2.15$ & & $\$ 3.70$ \\
350 & $\$ 2.48$ & & $\$ 4.35$ \\
750 & $\$ 6.24$ & & $\$ 11.45$ \\
$1000 \mathrm{MCM}$ & $\$ 12.50$ & $\$ 23.28$
\end{tabular}

The costs on a per unit length basis are as shown in Table 9-9(c). Examination of Table 9-9(c) data shows a considerable increase in sodium connection costs over aluminum. Many more connections are made in the secondary-service system than in the primary system on a per unit length basis. This results in cost penalty for sodium that negates the savings made in the cable 1tself. 
TABLE 9-9

Connector Cost Per Foot of Cable; Based on

Application Shown in Figures 9-2 and 9-3

(c) $600 \mathrm{~V}$ Secondary and Service Cable ( $c$ per ft.)

$\begin{array}{lcc}250 \mathrm{MCM} & \frac{\text { Aluminum }}{3.7} & \frac{\text { Sudlum }}{9.8} \\ 350 & 5.7 & 11.6 \\ 750 & 6.6 & 30.42 \\ 1000 \mathrm{MCM} & 33.2 & 61.84\end{array}$




\subsubsection{Comparison of Cable Costs for the Applications}

A pictorial representation of the total present worth savings of sodium over aluminum cable systems is given in Figure 9-5. The diagram represents relative costs for the scope of this study in terms of voltage class and cable size.

The message of Figure $9-5$ is three-fold in terms of (1) cable costs, (2) connector costs and (3) present worth of losses.

The cable cost savings of sodium over aluminum increase with conductor size and decrease with increased voltage. On a cable cost basis alone the largest savings occurs at $600 \mathrm{~V}, 1000 \mathrm{MCM}$ because of the relatively large metal content of the cable.

Sodium connectors are more expensive than aluminum and this penalty increases with size. More connectors are needed for the $600 \mathrm{~V}$ secondary-service system so connector costs on a per unit length basis decrease from $600 \mathrm{~V}$ to $15 \mathrm{kV}$ then rise again as voltage increases to $35 \mathrm{kV}$.

Ampacity rating decreases with increasing voltage level. This is required because the thicker insulation for higher voltages results in an increased thermal drop from conductor to ground source. Thus to maintain the same operating temperature of the conductor the load current and subsequently the cable losses must be reduced. Since losses decreaoc for both sndium and aluminum, the present worth savings in losses also decreases with increasing voltage in proportion to the drop in losses. As size increases, the difference in resistance per unit length between sodium and aluminum decreases more slowly than the rate of the current squared. This results in slightly higher present worth loss savings at larger sizes.

It is interesting to extend the reasoning in Figure 9-5 somewhat. The results shown are for the specific sizes of aluminum and sodium cable given the approximate full load ampacity equivalent. If sodium cable sjzes are reduced relative to aluminum sizes then cable 
HISTJGRAM REPRESENTATION OF THE PRESENT WORTH SAVINGS FOR CASE STUDIES

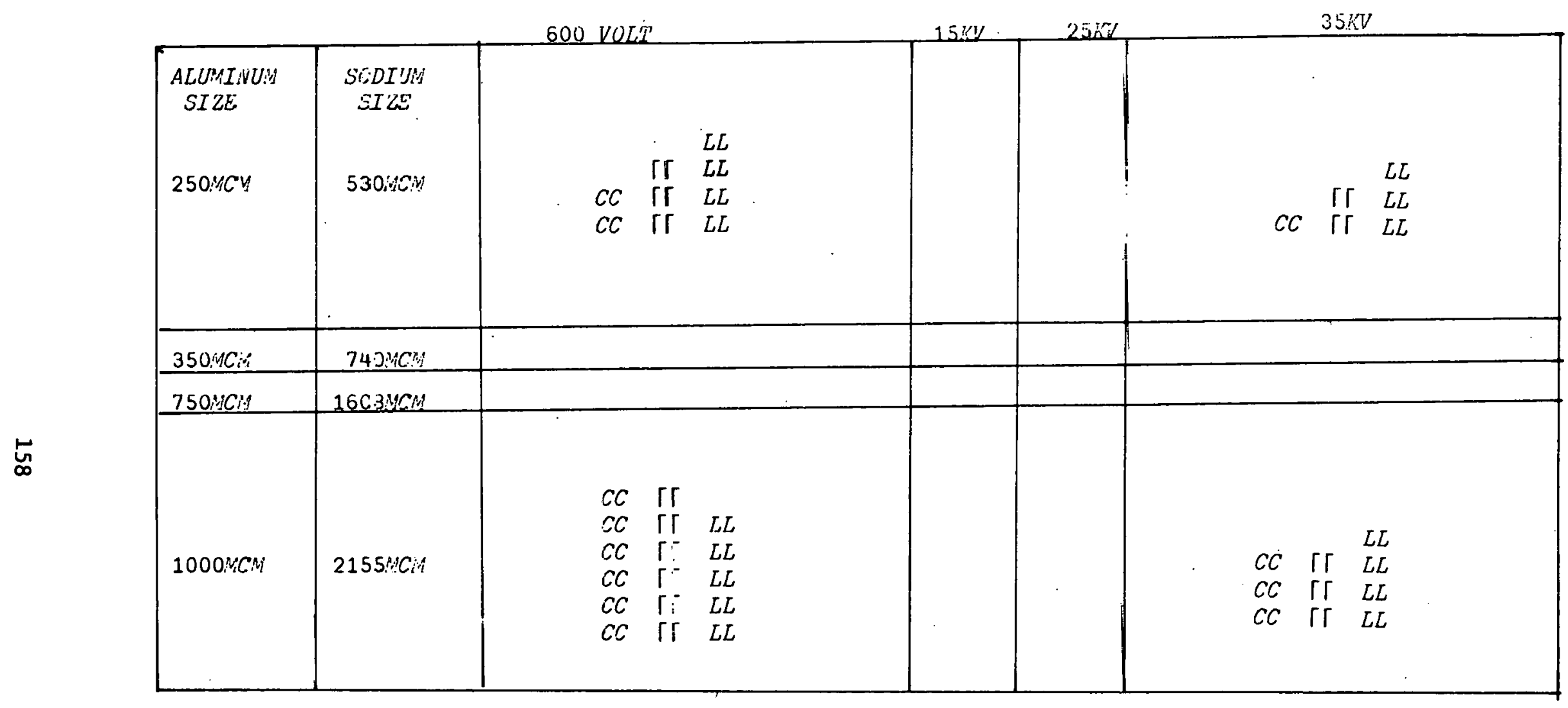

C-CABLE COST SAVINGS SODIUM RELATIVE TO ALURINUM

L-RSLATIYE SODIUM CPERATING LOSS SAVINGS

Г-RELATIVE SODIUM CONNECTOR COST PENALTY

Figure 9-5 
savings increase, connector penalties are reduced, but loss savings reduce and at some point become loss penalties. Likewise if sodium cable sizes are increased relative to aluminum then just the opposite effect occurs.

\subsubsection{Selecting the Optimal Size Sodium and Aluminum Cable}

When selecting either a sodium or an aluminum cable for a particular application one would like the optimal or best selection in either case. The optimal selection here is defined as the one which minimizes the total present worth costs of the cable (Equation 9-1) including installation, cable costs, connector costs and cost of losses. When one selects the optimal cables for a given application, one usually does not arrive at the exact thermal ampacity equivalents shown in Table 9-6. For example, if the cables are "heavily loaded", then larger sizes are dictated to bring cost of losses in line with cable costs. For "lightly loaded" cables, first cost of cable becomes the primary criterion and cable sizes may be reduced as far as voltage regulation limits will allow.

Table 9-10 displays the total present worth savings of sodium over aluminum cable for the different voltage classes and sizes as evaluated for the applications defined by Figures $9-2,9-3$ and $9-4$. In each of the 16 cases shown the phase current is $60 \%$ ( $1 / 2$ of overload current) of the full load ampacity rating of the designated aluminum cable. More detail on the components of the total present worth savings is shown in Table 9-11.

Examination of Tables 9-10 and 9-11 shows that maximum savings for sodium cable occurs at the largest sizes analyzed. Aluminum is less expensive for the $600 \mathrm{~V}$ eecondary applisatinns only because of the cost of connectors. If cost of connectors are disregarded, then the $600 \mathrm{~V}$, $1000 \mathrm{MCM}$ case results in the maximum savings for sodium over aluminum.

The savings for the large sizes (1000 MCM case) stays relatively constant with increasing voltage. Examination of Table 9-11 shows that 
TABLE $9-10$

Total Present Worth Savings ( $\$ / \mathrm{ft}$. ) Including Savings for Cable, Connectors, and Present Worth of Losses

Ranged on $50 \%$ of Overluad

Current of Al Cable

$\begin{array}{lccc}800 \mathrm{~V}^{*} & \frac{15 \mathrm{kV} * *}{(.0881)} & .55 & \frac{25 \mathrm{kV} * *}{35 \mathrm{kV} * *} \\ (.12) & .682 & .67 & .95 \\ (.28) & 1.04 & .981 & 1.20 \\ (.363) & 1.11 & 1.18 & 1.15\end{array}$

* Single Phase Secondary System

**3 Phase Primary Feeder (Balanced)

(Note: Bucl Lle Al and Na cable used in calculating the savings were optillilly slzed. The peak normal load current used was $60 \%$ of ampacity rating ( $50 \%$ of overload rating) allowing margin for emergency overload conditions). 
TABLE 9-11

Details of Present Worth Savings ( $\$ / f t$.

600V, 250 MCM A1 Overload Current Capability (see Figure 9-6 for added details)

Cable Cost Connector Cost Losses. Total

\begin{tabular}{|c|c|c|c|c|}
\hline $\begin{array}{lll}\text { A1 } & 530 & \mathrm{MCM} \\
\mathrm{Na} & 900 & \mathrm{MCM}\end{array}$ & $\begin{array}{r}.8418 \\
.5773 \\
\end{array}$ & $\begin{array}{l}.1481 \\
.5384 \\
\end{array}$ & $\begin{array}{l}1.0499 \\
1.0123 \\
\end{array}$ & $\begin{array}{l}2.0399 \\
2.1280 \\
\end{array}$ \\
\hline Savings & .2645 & $(.3903)$ & .0376 & $(.0991)$ \\
\hline
\end{tabular}

600V, 1000 MCM Al Overload Current Capability

Cable Cost Connector Cost Losses Total

\begin{tabular}{|c|c|c|c|c|}
\hline $\begin{array}{lll}\mathrm{A} 1 & 1200 & \mathrm{MCM} \\
\mathrm{Na} & 1700 & \mathrm{MCM}\end{array}$ & $\begin{array}{l}1.835 \\
1.026 \\
\end{array}$ & $\begin{array}{r}.4185 \\
1.2545 \\
\end{array}$ & $\begin{array}{l}2.0427 \\
2.3787 \\
\end{array}$ & $\begin{array}{l}4.296 \\
4.659 \\
\end{array}$ \\
\hline Savings & .809 & $(.836)$ & $(.336)$ & $(.363)$ \\
\hline
\end{tabular}

$15 \mathrm{kV}, 250$ MCM Al Overload Current Capability

Cable Cost Connector Cost Losses Total

\begin{tabular}{crrrr} 
Al $500 \mathrm{MCM}$ & 3.576 & .204 & 2.310 & 6.09 \\
$\mathrm{Na} 950 \mathrm{MCM}$ & 3.231 & .322 & 1.985 & 5.538 \\
\cline { 2 - 5 } Savings & .345 &.$(118)$ & .325 & .552
\end{tabular}

$15 \mathrm{kV}, 1000 \mathrm{MCM}$ Al Overluad Current Capability

Cable Cost Connector Cost Losses. Total

\begin{tabular}{|c|c|c|c|c|}
\hline $\begin{array}{lll}\mathrm{A} 1 & 1300 & \mathrm{MCM} \\
\mathrm{Na} & 2500 & \mathrm{MCM}\end{array}$ & $\begin{array}{l}6.375 \\
5.643 \\
\end{array}$ & $\begin{array}{l}.388 \\
.624 \\
\end{array}$ & $\begin{array}{l}4.031 \\
3.416 \\
\end{array}$ & $\begin{array}{r}10.794 \\
9.683 \\
\end{array}$ \\
\hline Savings & .732 & $(.236)$ & .615 & 1.111 \\
\hline
\end{tabular}

$35 \mathrm{kV}, 750$ MCM Al Overload Current Capability

Cable Cost Connector Cost Losses Total

\begin{tabular}{lllll} 
Al $850 \mathrm{MCM}$ & 6.450 & .4734 & 4.2912 & 11.215 \\
$\mathrm{Na} 1700 \mathrm{MCM}$ & 6.030 & .6990 & 3.2860 & 10.015 \\
\cline { 2 - 5 } Savings & .420 & $(.2256)$ & 1.0052 & 1.20
\end{tabular}


while savings due to lower sodium cable costs drop with increasing voltage, the loss savings increases. This increase in loss savings is a result of changes in cable size dictated by the optimal selection.

The total present worth savings for sodium over aluminum are about $10 \%$ of the present worth costs.

If the use of HMWPE is substituted for XLPE then an added $\$ .40$ savings is possible for the $35 \mathrm{kV}$ case, thus increasing total savings to $\$ 1.60$ or $14.2 \%$ of aluminum present worth costs.

The following sections present more detail on some of the cases summarized in Tables $9-10$ and 9-11.

\subsubsection{Analysis of $15 \mathrm{kV}$ Direct Buried Cable}

The information in Figure 9-6 and 9-7 provides added detail on the $15 \mathrm{kV}$ case. As shown in Figure 9-6, total present worth costs for sodium are minimum at $950 \mathrm{MCM}$ and for aluminum at $500 \mathrm{MCM}$. The full load current, loss factors and peak responsibility factors are as shown in Figure 9-6. Figure 9-7 shows the present worth cost breakdown for losses, cable, and connectors for both sodium and aluminum. Because of the minimal number of three phase connectors considered in the application, the connector costs for this case are a relatively small addition to total present worth costs.

\subsubsection{Analysis of $15 \mathrm{kV}$ Cable in Ducts}

Section 7 presents the cable engineering details for the sodium and aluminum cable in ducts. Only the costs associated with the $15 \mathrm{kV}$ case are explicitly presented here. The costs for other voltages and sizes are related in the same manner as the $15 \mathrm{kV}$ case. Therefore, no new information could be presented through an exhaustive treatment of these other cases.

Figuxes 9-8 and 9-9 present the detailed data on the $15 \mathrm{kV}$ cable in ducts. A three phase feeder is considered with one phase cable in each non-metallic duct (see Section 7). For the sizes of interest in the study (250 MCM to $1000 \mathrm{MCM}$ ) no change in duct size is necessary. Therefore duct costs are the same for both sodium and aluminum. 


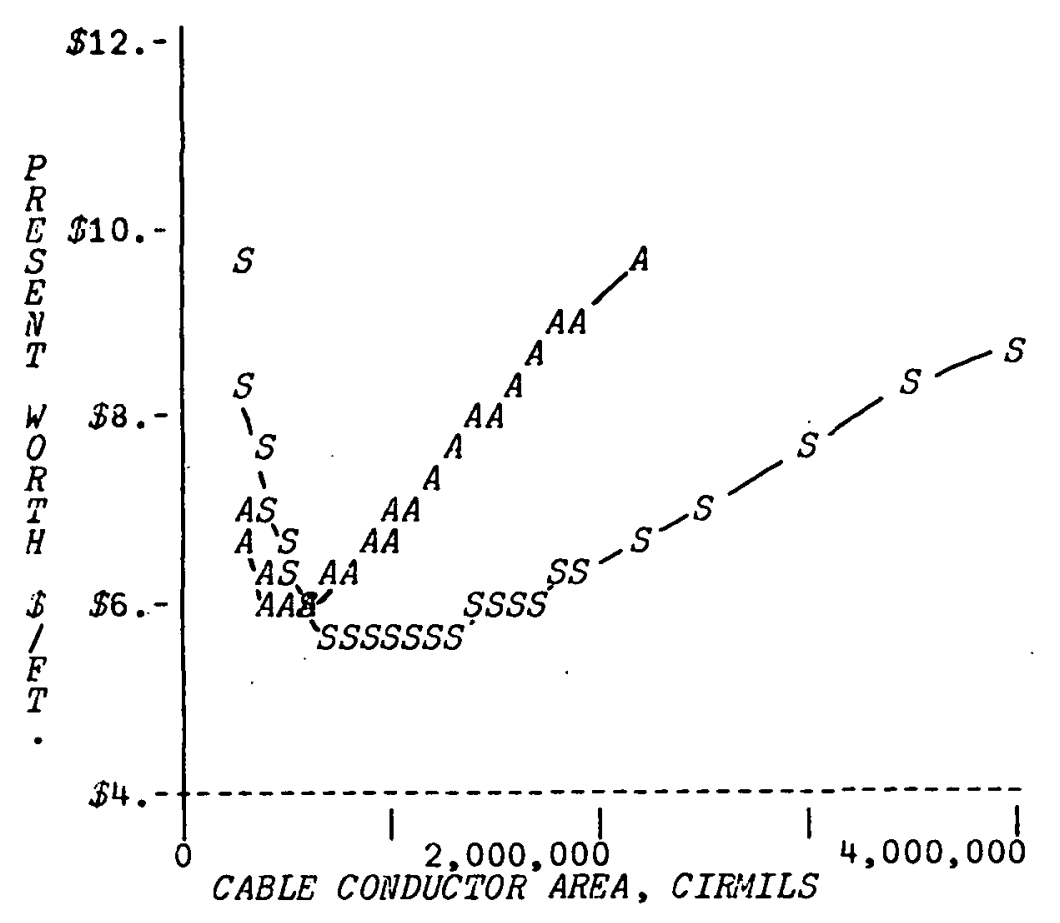

SODIUM AND ALUMINUM CABLE PRESENT WORTH

COSTS VS. CONDUCTOR SIZE-15KV DIRECT BURIED

ALUMINUM OPTIMUM: 500MCM \$6.09 PER FT. SODIUM OPTINUM: 950.YCM \$5.54 PER ET.

CABLE PARAMETERS:

UNIFORNLY LOADED 3 PLASE MAIN FEEDER

175MILS XLPE INSULATION

15 MILS COHDUCTOR SHIELD FOR AL,O FOR HA

30 GILS INSULATION SHIELD EOR HA AND AL

OPERATING PARAMETERS:

LOSS FACTOR $=.18$ PEAK RFSPOSIBILITY EACTOR $=.82$

FEEDER INPUT CURRENT 222 AMPS

FEEDER OUTPUT CURRENT 70 AMPS

PRESEIVT WORTH EACTOR $=12$

AVERAGE AC RESISTAINCE

AL 1.15 IIICROOHISS PER C:A

WA .99 WICROOHWS PER CH

Figure 9-6 

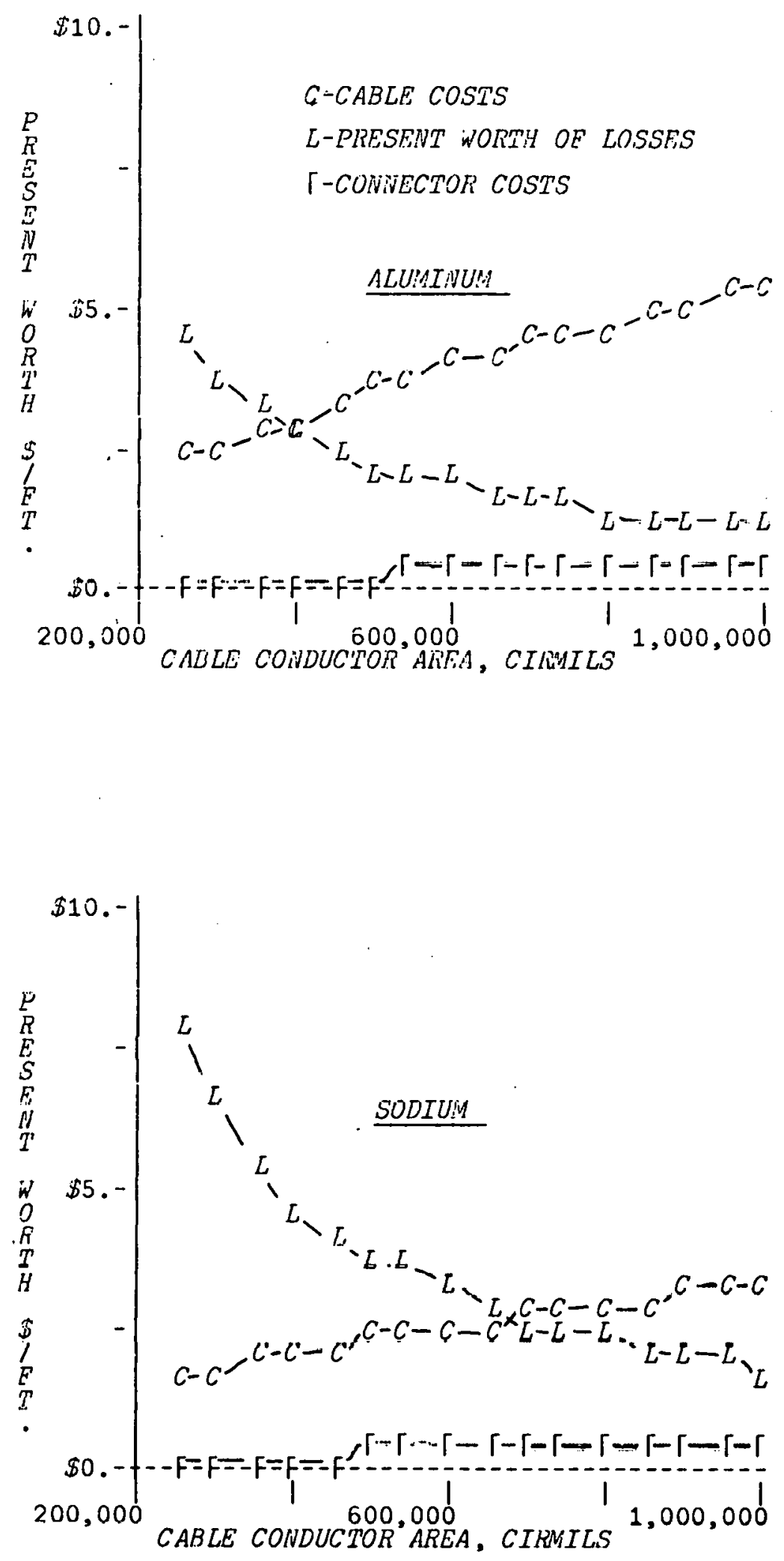

PRESENT WORTH OF CABLE COSTS AND OPERATING LOSSES VS. SIZE-15KV DIKECT BURIED.

Figure 9-7 


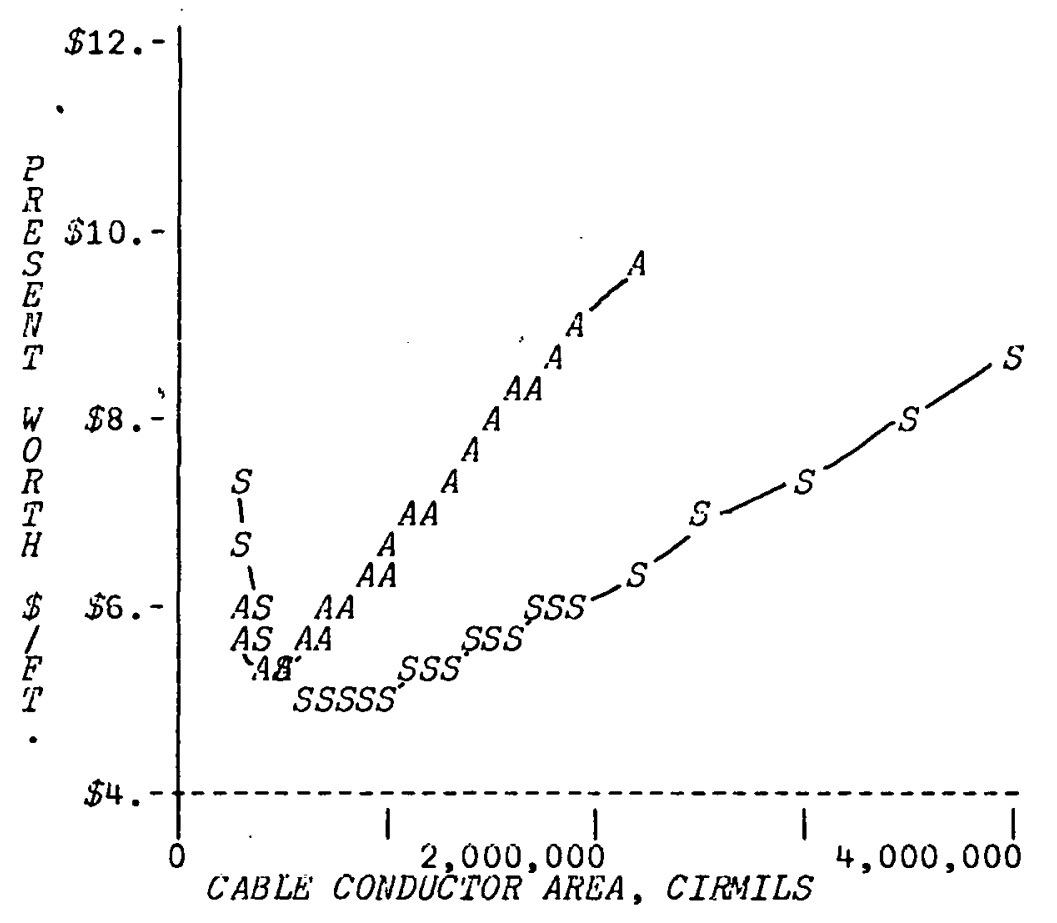

SODIUM AVD ALUMINUM CABLE TOTAL PRESENT WORTH COSTS VS. CONDUCTOR SIZE-15KV IN DUCTS.

ALUMINUM OPTIMUM: 400MCM \$5.38 PER ET.

SODIUM OPTIMUM : $740 M C M$ \$4.99 PER FT:

CABLE PAPAMETERS:

3 PHASE UWIEORMLY LOADED FEEDER

5 IHCH EIBER DUC'T

175 MILS XLPE INSULATION

15 MILS CONDUCTOR SHIELD FOR AL,O FOR NA

30 MILS INSULATION SHIELD FOR AL AND NA

OPERATING PARAMETERS:

LOSS FACTOR $=.18$ PEAK RESPOSIBILTY FACTOR $=.82$

FEEDER INPUT CURRENT 188 AMPS

FEEDER OUTPUT CURRENT 59 AMPS

PRESENT WORTH EACTOR=12

A.VERAGE AC RESISTANCE;MICROOHMS PER CM

$A L 1.45$

NA 1.28

Figure 9-8 

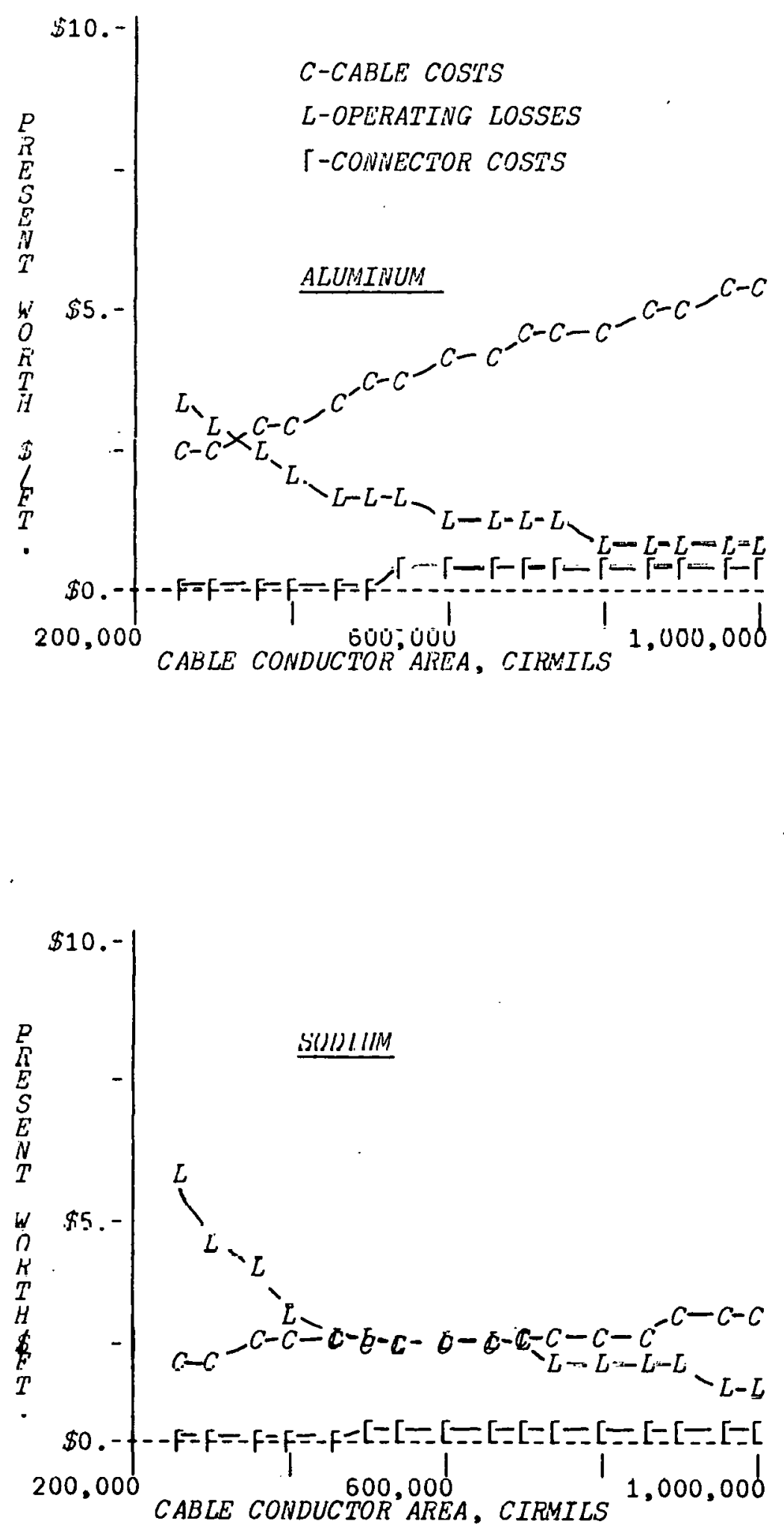

Figure 9-9 
As discussed in Section 7, the thermal resistance is increased because of the added duct air space, therefore ampacity levels are reduced relative to the direct buried case. This results in lower losses (Figure 9-9) for both the sodium and aluminum cables. The reduction in losses results in the optimum sodium and aluminum cable being smaller in size thus reducing the net savings of sodium over aluminum. The optimum aluminum size for the duct case is $400 \mathrm{MCM}$ and for sodium is $740 \mathrm{MCM}$. The total present worth savings for the $15 \mathrm{kV} 250 \mathrm{MCM}$ case is $\$ 0.39$ or about $70 \%$ of that achieved in the direct buried case. The peak load current used in the evaluation is 188 amps or about $85 \%$ of the current in the $15 \mathrm{kV}, 250 \mathrm{MCM}$ direct buried case.

The $30 \%$ reduction in present worth savings may be extrapolated to other sizes and voltage ratings.

\subsubsection{Analysis of the 600 Volt Secondary Application}

Detailed information on the 600 volt secondary application is shown in Figures 9-10 through 9-13. Figures 9-10 and 9-11 present the case with connector costs included while Figures 9-12 and 9-13 neglect connector costs.

\subsubsection{Tota1 Present Worth Savings 10 Years and 25 Years in the Future}

Present worth savings in future years is presented in Tables $9=12$ and 9-13. Cable and connector costs in the future are projected by using the indices in Table 9-3 to estimate component material cost. The indirect costs are escalated at an annual rate of $6 \%$. Power cosis are escalated at $5 \%$ annual to estimate losses in future years.

Since the indices in Table 9-3 project sodium and polyethylene costs to grow more slowly than aluminum costs, cable cost savings increase significantly in the future. Since power costs also are assumed to escalate, the savings in losses increases proportionally.

Savings for the $35 \mathrm{kV}$ case (Table 9-13) increase by 2 in 1988 and by 5.73 by 2003. For the $15 \mathrm{kV}$ case (Table 9-12), savings increase by 2.4 by 1988 and 6.6 by 2003 . 


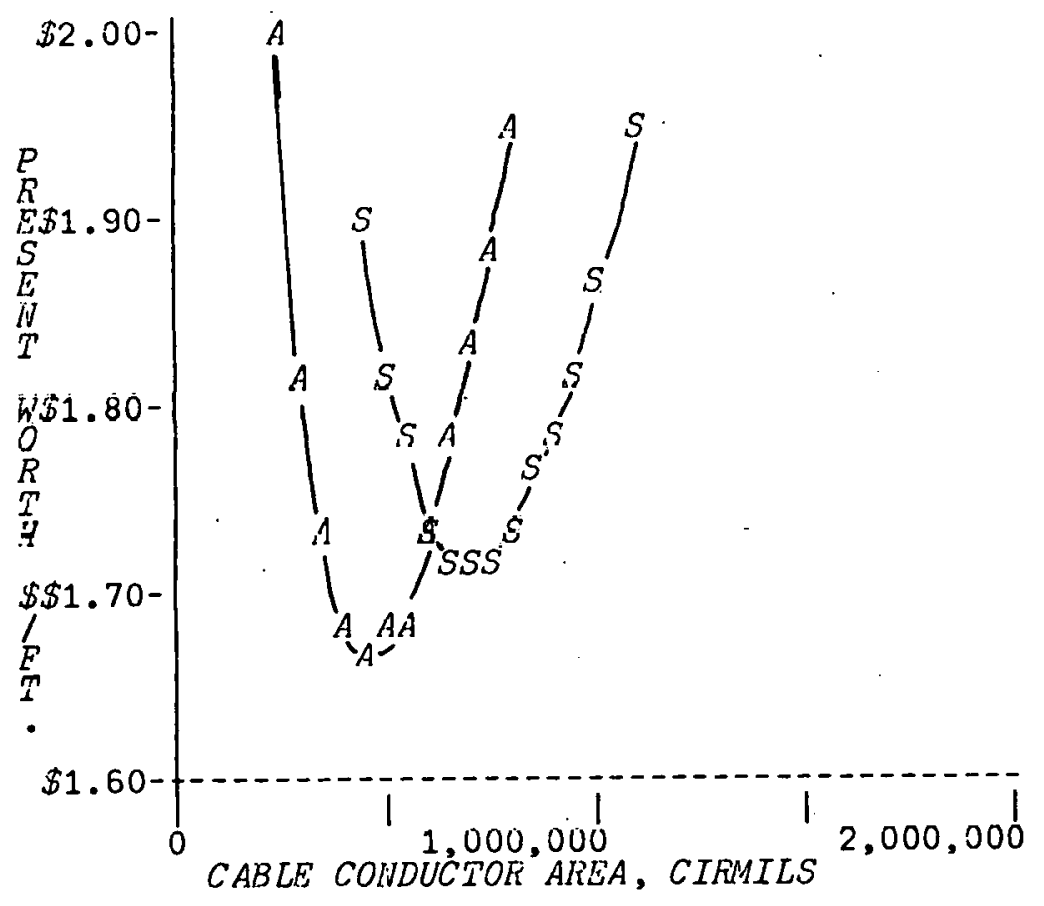

SODIUM AND ALUMINUM CABLE TOTAL P̈RESENT WORT. H COSTS VS. CONDUCTOR SIZE -600 VOLT SECONDARY APPLICATION

$\begin{array}{ll}\text { ALUMLNUY OPTIMUM: } & 530 M C M \\ \text { SODIUM OPTIMUM : } & \$ 2.04 \text { PER ET }\end{array}$

CABLE PARAMETERS:

600 VOLT DIRECT BURIED SINGLE PIIASE SECOIIDARY 125 MILS XLPE INSULATTON

OPERATING PARAMETERS:

LOSS FACTOR $=.074$ PEAK RESPOSIBILITY FACTOR $=.3$ SECONDARY CURRENT 171 AMPS

PRESENT WORTH FACTOR $=12$

Figure 9-10 

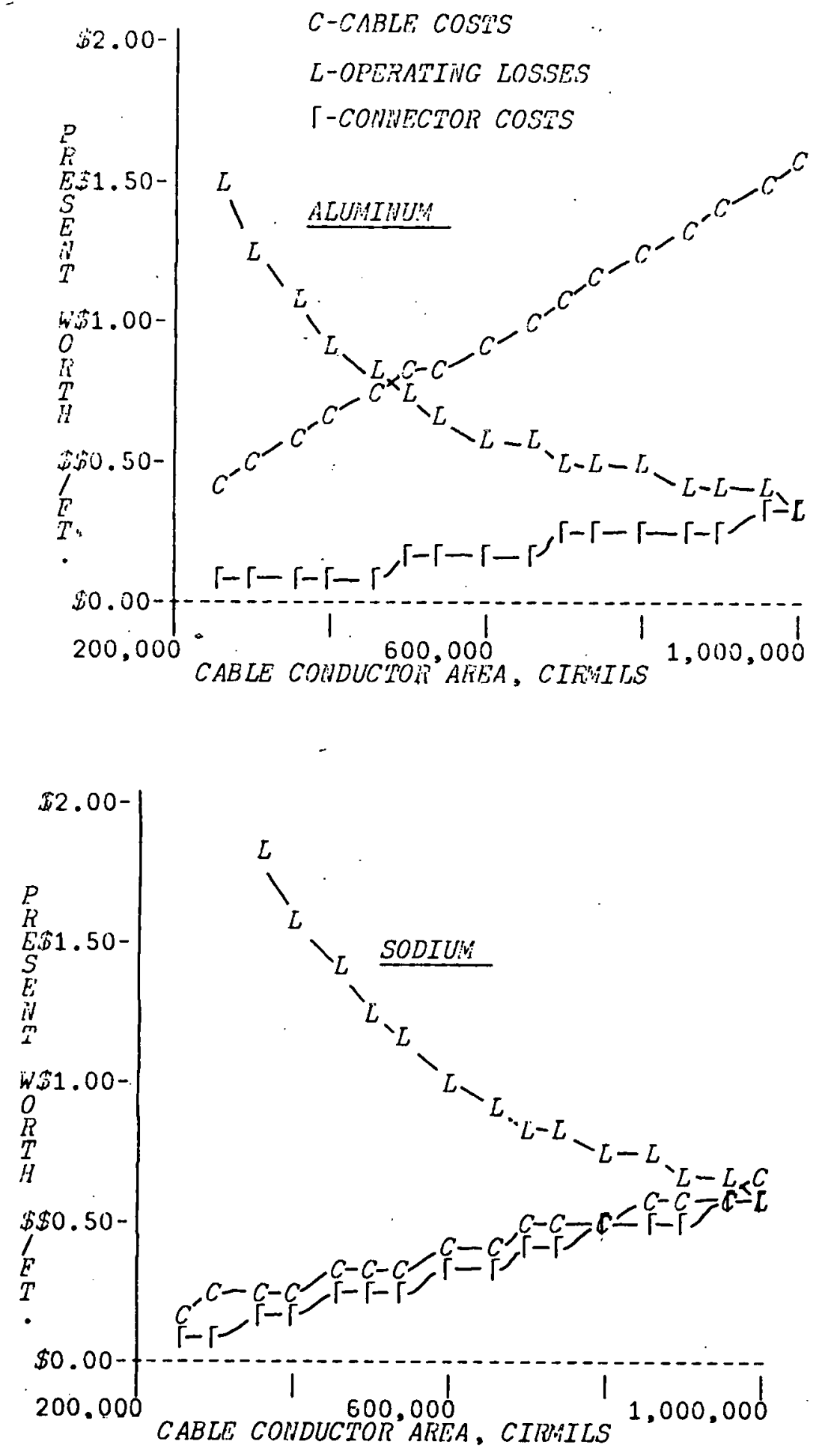

PRESENT WORTH OF CABLE AND OPERATING COSTS VS.. SIZE - 600 VOLT SECONDARY

Figure 9-11 


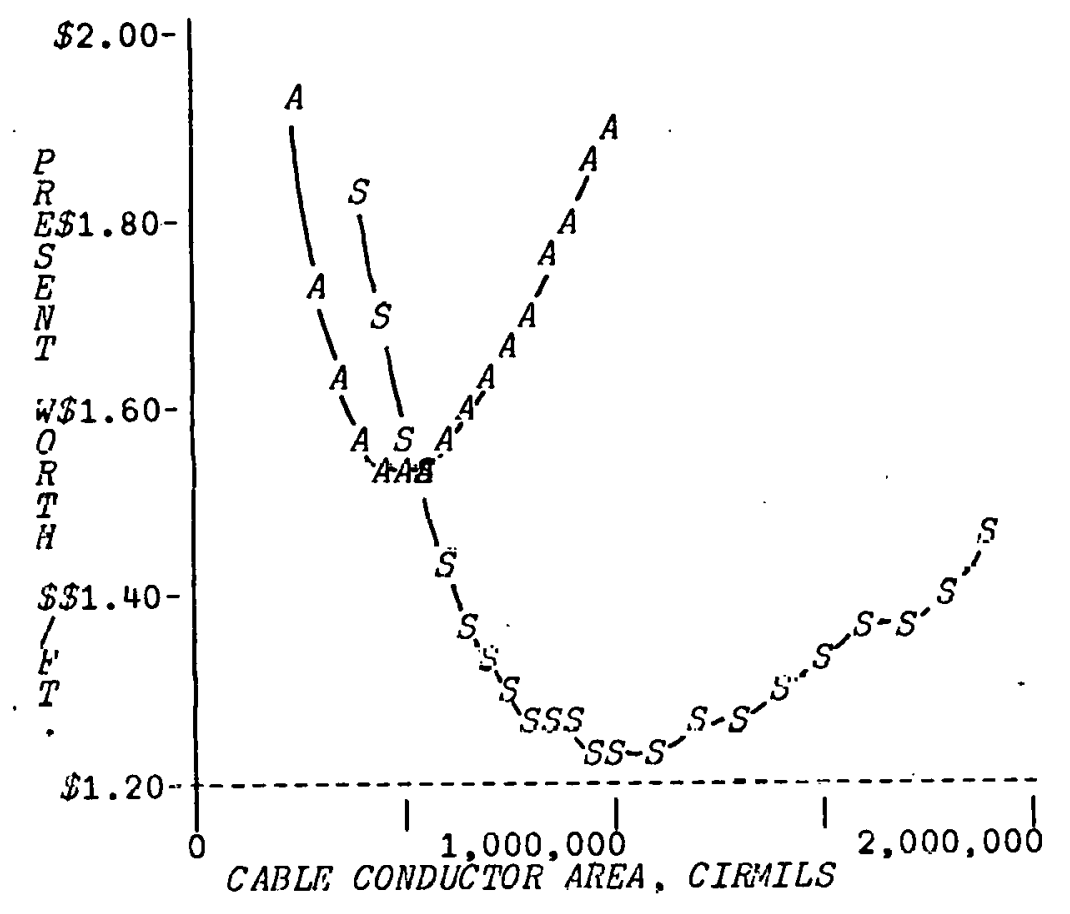

SODIUM AND. ALUMINUM CABLE TOTAL PRESENT WORTH COSTS VS. COWDUCTOK SIZE-600 VOLT SECOHDARY , NEGLER'IING CONWECTOR COSTS.

$\begin{array}{llr}\text { ALUMINUM OPTIVUM: } & 500 M C M & \$ 1.54 \text { PER ET. } \\ \text { SODIUM OPTIVUM:` } 1000 \% C M & \$ 1.24 \text { PER FT. }\end{array}$

SEE FIO. O.10 EOR OPERATINC DFTAILS)

Figure 9-12 

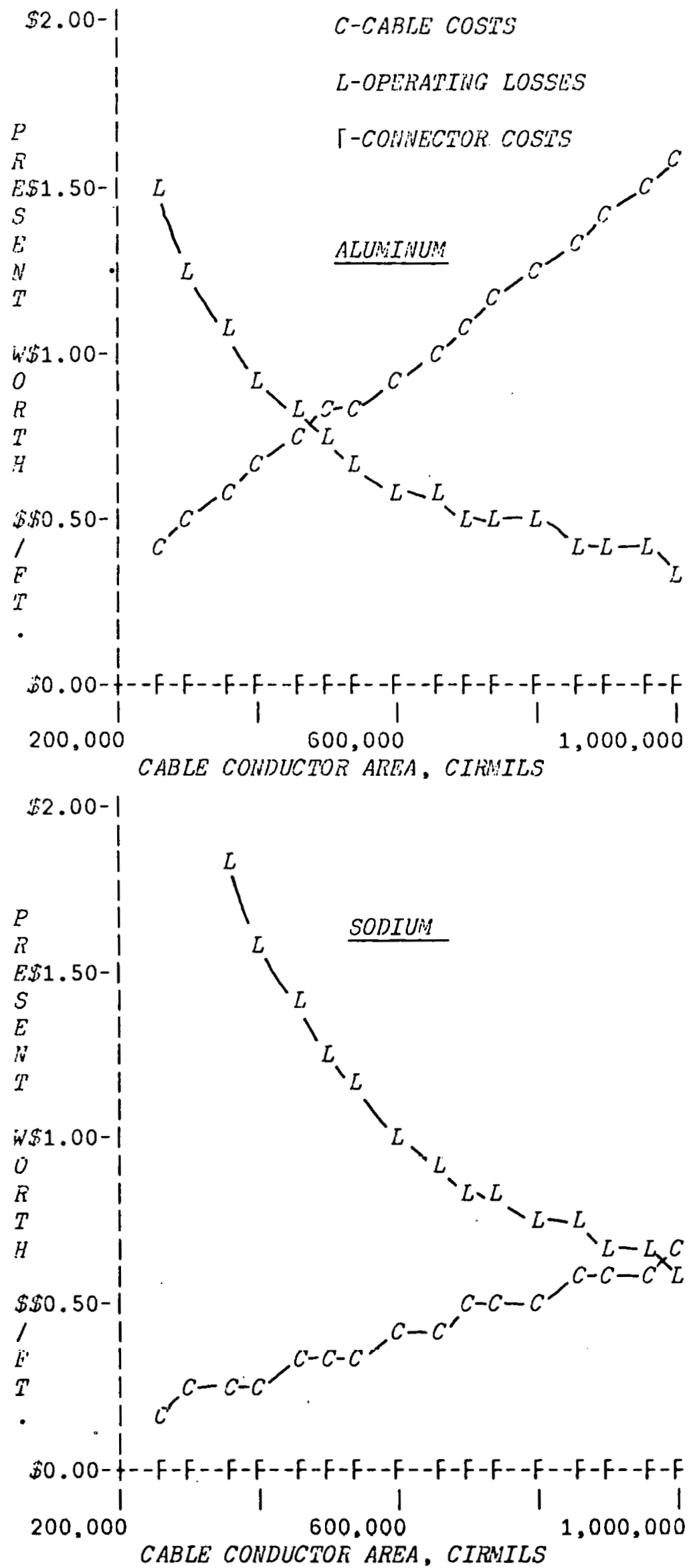

FIGURE 13. PRESENT WORTH OF CABLE COSTS AHD OPERATING LOSSES

VS. COHDUCTOR SIZE-6OOV SECONDARY.NO CONNECTORS.

Figure 9-13 
TABLE $9-12$

Present Worth Savings; Present, 10 Years, and 25 Years In the Future for $15 \mathrm{kV}$ Cable

Present (trom l'able $y-11$ )

$15 \mathrm{kV}, 250 \mathrm{MCM}$ Al Overload Current Capability

Cable Cost Connector Cost Losses Total

\begin{tabular}{|c|c|c|c|c|}
\hline $\begin{array}{lll}\mathrm{A} 1 & 500 & \mathrm{MCM} \\
\mathrm{Na} & 950 & \mathrm{MCM}\end{array}$ & $\begin{array}{l}\$ 3.576 \\
\$ 3.231 \\
\end{array}$ & $\begin{array}{l}\$ .204 \\
\$ .322 \\
\end{array}$ & $\begin{array}{l}\$ 2.310 \\
\$ 1.985 \\
\end{array}$ & $\begin{array}{l}\$ 6.09 \\
\$ 5.538 \\
\end{array}$ \\
\hline & $\$ .345$ & $\$(.118)$ & $\$ .325$ & $\$ .552$ \\
\hline
\end{tabular}

10 Years In Future

Cable Cost Connector Cost Lusses Tutal

\begin{tabular}{|c|c|c|c|c|}
\hline $\begin{array}{lll}\text { Al } & 500 & \mathrm{MCM} \\
\mathrm{Na} & 950 & \mathrm{MCM}\end{array}$ & $\begin{array}{l}\$ 7.120 \\
\$ 6.093 \\
\end{array}$ & $\begin{array}{l}\$ .424 \\
\$ .665 \\
\end{array}$ & $\begin{array}{r}\$ 3.762 \\
\$ 3.233 \\
\end{array}$ & $\begin{array}{l}\$ 11.306 \\
\$ 9.991 \\
\end{array}$ \\
\hline & $\$ 1.027$ & $\$(.241)$ & $\$ .529$ & $\$ 1.315$ \\
\hline
\end{tabular}

25 Years In Future

Cable Cost Connector Cost Losses Tutal

A1 SUU MCM \$16.82 $\$ 1.11 \quad \$ 7.82 \quad \$ 25.75$

Na $950 \mathrm{MCM} \quad \$ 13.71 \quad \$ 1.66 \quad \$ 6.72 \quad \$ 22.09$

$\$ 3.11 \$(.55) \quad \$ 1.10 \quad \$ 3.66$ 


\section{TABLE $9-13$}

Present Worth Savings; Present, 10 Years, and 25 Years In the Future for $35 \mathrm{kV}$ Cable

Present (from Table 9-11)

$35 \mathrm{kV}, 750 \mathrm{MCM}$ Al Overload Current Capability

Cable Cost Connector Cost Losses Total

\begin{tabular}{|c|c|c|c|c|}
\hline \multirow[t]{2}{*}{$\begin{array}{ll}\text { A1 } & 850 \mathrm{MCM} \\
\mathrm{Na} & 1700 \mathrm{MCM}\end{array}$} & $\begin{array}{r}\$ 6.450 \\
6.030 \\
\end{array}$ & $\begin{array}{r}.4734 \\
.6990 \\
\end{array}$ & $\begin{array}{l}4.2912 \\
3.2860 \\
\end{array}$ & $\begin{array}{l}11.215 \\
10.015\end{array}$ \\
\hline & .420 & $(.2256)$ & 1.0052 & 1.20 \\
\hline
\end{tabular}

10 Years in Future

Cable Cost Connector Cost Losses Total

\begin{tabular}{|c|c|c|c|c|}
\hline $\begin{array}{lll}\text { Al } & 850 & \mathrm{MCM} \\
\mathrm{Na} & 1700 \mathrm{MCM}\end{array}$ & $\begin{array}{l}12.636 \\
11.397 \\
\end{array}$ & $\begin{array}{r}.984 \\
1.444 \\
\end{array}$ & $\begin{array}{l}6.99 \\
5.35 \\
\end{array}$ & $\begin{array}{l}20.61 \\
18.10 \\
\end{array}$ \\
\hline & 1.239 & $(.46)$ & 1.64 & 2.42 \\
\hline
\end{tabular}

25 Years in Future

Cahle Cinst Connector Cost Losses Total

\begin{tabular}{|c|c|c|c|c|}
\hline \multirow[t]{2}{*}{$\begin{array}{lll}\text { Al } & 850 & \text { MCM } \\
\mathrm{Na} & 1700 \quad \mathrm{MCM}\end{array}$} & $\begin{array}{l}30.315 \\
25.869\end{array}$ & $\begin{array}{l}2.576 \\
3.603\end{array}$ & $\begin{array}{l}14.53 \\
11.07\end{array}$ & $\begin{array}{l}47.42 \\
40.542\end{array}$ \\
\hline & 4.446 & $(1.027)$ & 3.46 & 6.88 \\
\hline
\end{tabular}


Savings increase from approximately $10 \%$ of total present worth costs in 1978 to $15 \%$ by 2003 .

\subsubsection{Comparison of Installed Costs}

The installed costs for the $15 \mathrm{kV}$ and $600 \mathrm{~V}$ cable systems are shown in Table 9-14. The cable and connector costs are those previously developed based on Figures 9-2, 9-3 and 9-4. Installation costs are taken frum lle Tásk I survey of clcctric utilities.

From the sulvey of utilitics uoing codium cable, it was determined that installation costs were approximately the same for either the sodium or aluminum system. Although conectors were mentioned to be much more expensive for sodium, they were not claimed to be any more time consuming or expensive to insta11.

Examination of Tables $9-11$ and 9-14 shows total present worth savings for the $15 \mathrm{kV}$ system to be approximately $10 \%$ of the sum of total present worth costs and total installed connector and cable costs.

\subsection{Salvage and Disposal Costs}

Once a particular sodium distribution cable has reached the end of its useful life, two logical procedures may be followed. Either the cable is de-energized and abandoned or it is dug up and reprocessed.

Because of the hypothesized hazards of sodium, some have conjectured that the sodium cable must be recovered and recycled. The estimated costs for this recovery and recycle are sluwil in Table 9.5 .

Recovering and recycling results in added cost for the smaller sizes that offsets almost $50 \%$ of the initial savings. Recovery for the larger sizes results in an added scrap value due mainly to the copper recovery.

Consideration of salvage and disposal costs with preceding cost analysis in Tables 9-10 and 9-11 once again emphasizes the increased savings for sodium in larger sizes. 
TABLE 9-14

Estimated Installed Costs Per Foot For Sodium and Aluminum Cable

$15 \mathrm{kV} 3 \phi$ Primary

\begin{tabular}{|c|c|c|}
\hline & $\mathrm{A} 1$ (500 MCM $)$ & $\mathrm{Na}(950 \mathrm{MCM})$ \\
\hline Prepare Ditch & $\$ .45$ & $\$ .45$ \\
\hline Cable Cost & $\$ 3.576$ & $\$ 3.231$ \\
\hline Installing Cable & $\$ .31$ & $\$ .31$ \\
\hline Connector Cost & $\$ .204$ & $\$ .322$ \\
\hline Installing Connectors & $\$ .60$ & $\$ .60$ \\
\hline $\begin{array}{l}\text { Total Installed Connector } \\
\text { and Cable Cost }\end{array}$ & $\$ 5.14$ & $\$ 4.91$ \\
\hline \multicolumn{3}{|c|}{$600 \mathrm{~V}$ Secondary } \\
\hline & $\mathrm{Al}(530 \mathrm{MCM})$ & $\mathrm{Na}(900 \mathrm{MCM})$ \\
\hline Prepare Ditch & $\$ .45$ & $\$ .45$ \\
\hline Cable Cost & $\$ .84$ & $\$ .58$ \\
\hline Installing Cable & $\$ .16$ & $\$ .16$ \\
\hline Connector Cost & $\$ .15$ & $\$ .54$ \\
\hline Installing Connectors & $\$ .09$ & $\$ .09$ \\
\hline $\begin{array}{l}\text { Total Installed Connector } \\
\text { and Cable Cost }\end{array}$ & $\$ 1.69$ & $\$ 1.82$ \\
\hline
\end{tabular}


TABLE 9-15

Cable Salvage and Disposal Costs Pcr Foot

$15 \mathrm{kV} 3 \phi$ Primary

\begin{tabular}{|c|c|c|}
\hline Operation & $\mathrm{Na}(950 \mathrm{MCM})$ & $\mathrm{Na}(2155 \mathrm{MCM})$ \\
\hline B.odigging and Rcfilling Trenil & $3(.45)$ & $\$(.45)$ \\
\hline Land Reclamation & $\$(.20)$ & $\$(.20)$ \\
\hline Pulding Cable & $\$(.31)^{\circ}$ & $\$(.31)$ \\
\hline Cable Reprocessing & $\$(.04)$ & $\$(.08)$ \\
\hline Sodium Salvage Value & .25 & .57 \\
\hline Copper Salvage Value & .53 & 1.03 \\
\hline Net Recovery Value & $\$(.22)$ & $\$ .56$ \\
\hline
\end{tabular}


9.5 Future Market Survey for'Energy Savings

In Table 9-16 the annual energy savings of sodium over aluminum cable for a specified market penetration is estimated. It is assumed that sodium cable would achieve a $10 \%$ market share by $1980,50 \%$ by 1985 and $100 \%$ by 2000 . This optimistic scenario is used only to get a maximum credible savings for sodium. With this scenario and the assumptions footnoted in Table 9-16, almost 2 billion $\mathrm{kWh}$ could be saved annually by year 2000 or equivalently 3.4 million barrels of oil.

\subsection{Conclusions from the Economic Analysis}

A summary of the analyses performed in this section may be expressed in terms of the economic incentives and barriers for using sodium distribution cable.

- The present worth costs of owning and operating sodium cable on a typical underground primary distribution feeder yields a savings of approximately $10 \%$ when compared to aluminum.

- For an "express type feeder" operating at unity load factors a present worth savings of $30 \%$ for sodium relative to aluminum is possible.

- A comparison of equivalent ampacity sodium and aluminum cable costs only, yields a range of savings from $1 \%$ to $15 \%$ depending on size and voltage and choice of insulation. The maximum savings in the scope of this study is the lowest voltage, largest size (Al 600V, 1000 MCM - Na 600V, 2196 MCM).

- With an optimistic market penetration, energy savings could approach 2 billion $\mathrm{kWh}$ annually/ by the year 2000. (One nuclear power plant produces 7 billion kWh annually base load). 
Annual Energy Savings of Sodium Over Aluminum Cable for Specified Market Penetration

$$
\underline{1980} \underline{1985} \quad \underline{2000}
$$

Na Loss Savings Relative to Al

$\begin{array}{llll}\text { peak loss (kW/mi) } & 6.336^{*} & 6.336^{*} & 6.336^{*} \\ \text { avg. loss (kW/mi) } & 1.140 & 1.140 & 1.140 \\ \text { UG Distribution Cable } & 9730 & 11,280 & 17,575\end{array}$

Total UG Distribution Cable Installation each year (mi) ${ }^{* *}$

Sodium UG Distribution Cable Installed Cumulative (mi)

Annual Energy Savings Due to Cumulative Na Cable

Inslallatlon

Electric Generation Fue1 ${ }^{* * *}$ Annua1 Savings
million Btu's
equiv. $10^{6}$ bbls of oil
$.097 \times 10^{6}$ .01 .7
$1.595 \times 10^{6}$
.28
$1.967 \times 10^{7}$
${ }^{*}$ Calculation of peak and average loss assume uniformly loaded $3 \phi$ feeder $250 \mathrm{kcmil}$ cable size used for this estimate since it is closest to typical utility size.
Average ampacities for $15 \mathrm{kV}, 25 \mathrm{kV}$, and $35 \mathrm{kV}$ taken from Tables A3-3 and $\triangle 3-6$ :

\begin{tabular}{|c|c|c|c|}
\hline & & feeder in; $I_{1}$ & feeder out; $\mathrm{I}_{2}$ \\
\hline $\begin{array}{l}\text { amapcity } \\
\text { full load current (amps } \\
\mathrm{R}_{\mathrm{ac}} \mu \Omega / \mathrm{cm} \int_{\mathrm{Al}}^{\mathrm{Na}} \\
\text { Conductor Temp }\left\{\begin{array}{l}\mathrm{A} 1 \\
\mathrm{Na}\end{array}\right.\end{array}$ & $\begin{array}{l}367 \\
367 \\
2.9 \\
2.14 \\
90^{\circ} \mathrm{C} \\
69^{\circ} \mathrm{C} \text {. }\end{array}$ & $\begin{array}{r}367 \\
217 \\
2.73 \\
2.03 \\
\sim 70^{\circ} \mathrm{C} \\
\sim 50^{\circ} \mathrm{C}\end{array}$ & $\begin{array}{r}367 \\
70 \\
2.24 \\
1.75 \\
\sim 20^{\circ} \mathrm{C} \\
7.20^{\circ} \mathrm{C}\end{array}$ \\
\hline
\end{tabular}

$\mathrm{PWL}_{\text {peak }}\left(\mathrm{I}_{1}^{2}+\mathrm{I}_{1} \mathrm{I}_{2}+\mathrm{I}_{2}^{2}\right) \mathrm{R}_{\text {ac (avg. })} \times 30.5 \frac{\mathrm{cm}}{\mathrm{ft}} \times 5.28 \frac{\mathrm{ft}-\mathrm{kW}}{\mathrm{w}-\mathrm{mi}}$

$\mathrm{PWL}_{\text {peak }}(\mathrm{A} 1)=\left(217^{2}+217 \times 70 \times 70^{2}\right) 2.49 \times 30.5 \times 5.28=26.9 \frac{\mathrm{kW}}{\mathrm{m} 1}$

$\mathrm{PWL}_{\text {peak }}(\mathrm{Na})=\left(217^{2}+217 \times 70 \times 70^{2}\right) 1.89 \times 30.5 \times 5.28=20.5 \frac{\mathrm{kW}}{\mathrm{m} 1}$

$\mathrm{PWL}_{\text {peak }}=6.336 \mathrm{~kW} / \mathrm{mi} ; \quad \mathrm{PWL}_{\text {avg }}=\mathrm{PWL}_{\text {peak }} \times \mathrm{LSF} ; \quad \mathrm{PWL}_{\text {avg }}=(6.336)(.18)=1.14 \frac{\mathrm{kW}}{\mathrm{mi}}$

\footnotetext{
** 13 th Electrical World T\&D Survey, August 15, 1978, Reference 81

Single Phase Converted to Equivalent 3 Phase miles

$\star \star \star *$

Assumed 10,000 Btu/kWh Heat Rate
} 
- Connector costs at present are significantly higher ( 1.1 to 2 times) for sodium than aluminum. Even with improved designs there are reasons to believe sodium connector costs will remain significantly above the aluminum.

- A salvage and disposal cost penalty for sodium cable for sizes below 1000 MCM is possible. 


\section{REFERENCES}

1. 0. J. Foust, "Sodium-NaK Engineering Handbook, Volume 1, Sodium Chemistry and Physical Properties," Gordon and Breach, Science Publishers, Inc. (1972).

2. "Sodium Data Sheet E-05229," (10-75), E. I. duPont de Nemours and Co. (Inc.) Industrial Chemicals Department, Wilmington, Delaware 19898.

3. National Fire Protection Assoclalion, 470 Atlantir. Avenue, Boston, Massachusells 02210.

4. Manufacturing Chemists Association, 1823 Conneclicut Avenue, Washington, D.C. 20009, Chemiral Safety Data Sheet SD-47, "Sodium," Revised 1974.

5. L. E. Humphrey, R. C. Hess and G. I. Addis, "Insulated Sodium Conductors," IEEE Summer Power Meeting, New Orleans, Louisiana, July, 1966.

6. I. F. Matthysee and E. M. Scoran, "The Development of Connectors for Insulated Sodium Conductors," IEEE Transactions on Power Apparatus and Systems, Vol. 86, No. 7, July 1967.

7. "Why Sodium Cable Falled," Eleetrical World, November 7, 1966.

8. Frank R. Nickel, "PP\&L Co. Experience with $15 \mathrm{kV}$ Sodium Conductor Cables", Doble Client Conference, Boston,. Massachusetts, April 13, 1970.

9. E. J. Steeve, "D1g-in Tests on Sodium Cables," IEEE Winter Power Meeting, New York, New York, January 28 - February 2, 1968.

10. Eric P. Verheiden, "Sodium Cable? Why Not, Ask PCE," Electric. Light and Power, August 1968.

11. R. L. Garrison, "Field Service Experience with Sodium Conductor Cable", IEEE Conf. Rco. Spertal Tech. Conf. on Underground D1bliliution, Anaheim, California, Pp. 386-95, May 12-15, 1969.

12. Edward J. Steeve and James A. Schneider, "Field Trials on $15 \mathrm{kV}$ and 600 Volt Sodium Cable," IEEE Transactions on Power Apparatus and Systems, Vol. 86, No. 7, July 1967.

13. Nacon Report No. 51 to Louisiana Power and Light Company, Residential Underground Distribution Research Program, Cables with Sodium Conductors, Evaluation of Test Results and In-Service Experience, June 24, 1968. 
14. Nacon Report No. 32 to Louisiana Power and LIght Company, Residential Underground Distribution Research Program, Tests of Cables with Sodium Conductors, March 1, 1966.

15. Nacon Report No. 43 to Louisiana Power and Light Company, Residential Underground Distribution Research Program, Sodium Conductor Test Results at the End of First Six Month Period, May 3, 1967.

16. IPCEA-NEMA Standards Publication P-53-426, "Ampacities Including Effect of Shield Losses for Single-Conductor Solid-Dielectric Power Cable $15 \mathrm{kV}$ through $69 \mathrm{kV}$."

17. AEIC No. 5-69, "Specifications for Polyethylene and Cross-LinkedPolyethylene Insulated Shielded Power Cables Rated 2,001 to 35,000 Volts."

18. IPCEA-NEMA Standards Publication S-61-402, "Thermoplastic-Insulated Wire and Cable for the Transmission and Distribution of Electrical Energy."

19. IPCEA Publication S-66-524, "Cross-Linked Thermosetting Polyethylene Insulation for Power Cables Rated 0 Through 600 Volts."

20. Nacon Engineering Data Sheets ED-1-2 (600 Volt Cables) and ED-3-2 (15 kV URD Cables), Nacon Corporation, 1966.

21. Bulletin 776, The Okonite Company, Ramsey, New Jersey 07446.

22. International Electrotechnical Commission Publication 287, "Calculation of the Continuous Current Rating of Cables." .

23. R. Patsch et al, "Inhomogeneities and Their Significance in SingleLayer Extruded Polyolefine Insulations for Cables," CIGRE Paper 15-11, 1976 Session.

24. G. Grosse-Plankermann and W. D. Schupple,"High-Power Cables with External Water Cooling," CIGRE Paper.21-09, 1974 Session.

25. A. E. Ruprecht and P. H. Ware, "Evaluation of Sodium Conductor Power Cable," IEEE Transactions On Power Apparatus and Systems, Vo1. PAS-86, No. 4, April 1967.

26. L. E. Humphrey, R. C. Hess and G. I. Addis, "Insulated Sodium Conductors," IEEE Transactions on Power Apparatus and Systems, Vo1. PAS-86, No. 7, July 1967, p. 876.

27. Technical Bulletin \#20, "Low, Medium, and High Density Polyethylenes," Phillips Petroleum Company. 
28. I. F. Matthysse and E. M. Scoran, "The Development of Connectors for Insulated Sodium Conductor," IEEE Transactions on Power Apparatus and Systems, Vo. PAS-86, No. 7, July 1967, p. 883.

29. J. Hus, "Bistable Operating Temperatures and the Current Rating of Sodium Conductors," IEEE Transactions on Power Apparatus and Systems, Vo1. PAS-87, No. 2, February 1968, p. 367.

30. R. J. McAnulla, "Sodium Conductor for Power Cables," Electronics and Power, Vol. 14, Nov. 1968, p. 434.

31. R. M. Eichhorn and G. I. Addis, "Irradiated Polyethylene Insulation for Sodium Conductor Cable," IEEE Winter Power Meeting, New York, January 1968, Paper No. 68CP61-PWR.

32. N. Peach, "Sodium is New Cable Conductor," Power, September, 1968.

33. "Why Sodium Cable Failed," Electrical World ; November 7, 1966, p. 19.

34. "Overload Failure Reported for Sodium Cable on Test," Transmission and Distribution, November 1966.

35. R. M. Eichhorn, "Measurement of Water Vapor Transmission Through Polyethylene Electrical Insulation," Polymer Engineering and Science, January 1970, Vo1. 10, p. 32

36. E. J. Steeve and J. A. Schneider, "Field Trials on $15 \mathrm{kV}$ and 600 Volt Sodium Cable," IEEE Transactions on Power Apparatus and Systoms, Vol. PAS-86, No. 7, July 1967, P. 891.

37. T. H. Kelly and C. G. Gnerre, "A Progress Report on Sodium Conductor Power Cables," IEEE Winter Power Meeting, New York, January 1968, Paper No. 68CP62-PWR.

38. "Soil Thermal Characteristics in Relation to Underground Power Cables," AIEE Comm1ttee Report, Trans. AIEE Pt. III, Vo1. 79, Decenber 1960, p. 792.

39. J. H. Neher, "The Temperature.Rise of Buried Cables and P1pes," Trane. AIEE Vol. 68, Pt. I, 1949, P. 9.

40. J. A. Brydson, Plastics Materials, D. Van Nostrand Company Inc., Princeton, New Jersey, 1966, Table 5.10.

41. J. H. Neher and M. H. McGrath, "The Calculation of the Temperature Rise and Load Capability of Cable Systems," AIEE Summer General Meeting, Montreal, Canada, June 1957, Paper No. 57-660. 
42. Radio Engineers' Handbook, McGraw-Hil1 Book Company, Inc., New York (1943), p. 30 ff.

43. H. B. Dwight, "Skin Effect on Tubulax and Flat Conductors," Trans. AIEE Vol. 37, 1918, p. 1379.

44. Standard Handbook for Electrical Engineers, McGraw-Hill Book Company, Inc., New York (1968), Tables 4-7, 4-8, and 4-9.

45. Standard Handbook for Electrical Engineers, McGraw-Hill Book Company, Inc., New York (1968), Table 4-1.

46. Sodium-NaK Engineering Handbook, Vo1. 1, 0. J. Foust, Ed., Gordon Breach Science Publishers, New York, 1972.

47. M. Sittig, Sodium, Its Manufacture, Properties, and Uses, Reinhold Publishing Company, New York, 1956.

48. "Development of Extruded Dielectric Underground Transmission Cables Rated $138 \mathrm{kV}, 230 \mathrm{kV}$ and $345 \mathrm{kV}$," Vol. 1 of Final Report on EPRI EL-428 and ERDA E(49-18)-1827 prepared by General Cable Corporation, May 1977.

49. Private Communication, Dr. Larry Spinadel, Exxon Chemical Corp., Reserach Center, Linden, New Jersey.

50. R. E. Reynolds, "Effects of Continuously Applied Voltage on Moisture Resistance of $15 \mathrm{kV}$ Cable Elastomers," Insulation, August, 1969.

51. M. Salame and S. Steisinger, "Barrier Polymers," Polym.-Plast. Tech. Eng. 8(2), 1977, p. 155.

52. A. Lebovits, "Permeability of Polumers to Gases, Vapors, and Liquids," Modern Plastics 43, 7, 1966, p. 139.

53. S. Gerhard, "Improved Connectors for Insulated Sodium Conductors," IEEE Winter Power Meeting, New York, January 1968, Paper No. 68CP45-PWR.

54. "Sodium Meets Tests as Electrical Conductor," Electrical World, February 21, 1966.

55. "Sodium Cables Were Used for AIl Secondaries in URD Development," P. E. Watson and R. M. Ventura, Transmission and Distribution, April 1967. 
56. "Sodium Cable? Why Not, Asks PGE," E. P. Verheiden, Electric Light and Power, August 1968.

57. "Experience With Sodium - A New Conductor," Electrical World, May 1, 1975, pp. 51-59.

58. "Experiences With Sodium Conductor - Part II," Electrical World, May 15, 1975, pp. 58-59.

59. "Energy Use Patterns in Metallurgical and Nonmetallic Mineral Processing,"

- PB-261 150, Phase 6, "Energy Data and F'lowsheets," July $21,1976$.

- PB-261 151, Phase 7, "Summary of the Results of Phases 4, 5, and 6," September $21,1976$.

- PB-261 152, Phase 8, "Opportunities to Improve Energy Efficiency in Production of High-Priority Commodities Without Major Process Changes," September 17, 1975.

- PB-261 153, Phase 9, "Areas Where Alternative Technologies Should be Developed to Lower Energy Use in Production of High-Priortty Commodities," August 25, 1976.

Prepared for the U.S. Bureau of Mines by Battelle Columbus Laboratories, Columbus, Oh1o.

60. Roberts, F., "Energy Consumption in the Production of Materials," Metals and Materials, p. 167-173, March, 1974.

61. "Energy Conservation with Sod1um Cables," preparcd by Undergrnund Power Corporation, Weston, Massachusetts, 1977.

62. "Energy Use Patterns in Metallurgical and Nonmetallic Mineral Processing," Final Report, Contract No. S0144093, by Battelle Columbus Laboratorles for U.S. Bureau of Mines, September 21, 1976.

63. Lyman, W. S., "Fact Sheet, Copper and Energy," Copper Development Association, January, 1978.

64. Falth, W. L., Keyes, D. B., and Clark, R. L., Induatrial Chemicals; p. 698, Wiley (New York) 1965.

65. Hampel, C. A. (Ed), Encyclopedia of Electrochemistry, "Sodium, Electrolytic Productions," p. 1062, Reinhold (New York) 1964.

66. Madaus, J., Personal Communications, Mine Safety Appliance Company, Evans City, Pennsylvania. 
67. Myers, J., et al, Energy Consumption in Manufacturing, Chapter 31, "Aluminum," pp. 523-573, Ballinger Publishing Company, Cambridge Massachusetts, 1974.

68. Bzura, J., Personal Communication, Arthur D. Little, Inc., Cambridge, Massachusetts.

69. Saltermayer, E., "Metals, the Warning Signals and Up," Fortune Magazine, p. 109, October, 1972.

70. Clark, J. W., and Holland, H. R., "Aluminum, Cement, and Titanium: Effects of Process Changes and Substitutions on Future Use Patterns and Electrical Energy Requirements," Westinghouse Research Report, 75-1D4-MPREE-R1, February 28, 1975,

71. C. L. Wagner and D. L. Nickel, "Transmission and Distribution System Loss Study Final Report," ERDA Contract EC-77-X-01-2628, September, 1977.

72. N. R. Schultz, "Distribution Primary Feeder $I^{2} R$ Losses," IEEE Transactions On Power Apparatus and Systems, Vo1. PAS-97, No. 2, March/April 1978.

73. N. E. Change, "Determination of Primary Feeder Losses," IEEE Transaction on PAS, December 1968.

74. Data Resources Inc. Cost Forecasting Service, "Forecast Review," First Quarter 1978, Volume 3, Number 1.

75. "20th Steam Station Cost Survey," Electrical World, Nov. 15, 1977.

76. "Engineering Data for Copper and Aluminum Conductor Electrical Cables," The Okonite Company, Bulletin 72].1, 1975.

77. "Special Report: Underground Distribution," Electrical World, May 1, 1978.

78. "1976 Underground Transmission and Distribution Conference," IEEE Conference Record.

79. "Elastimold H1gh Voltage Data-Log," 1976.

80. "Utilco Catalogue of Dual Rated Aluminum and Copper Connectors for Secondary and Service Distribution."

81. "13th Annual T\&D Construction Survey," Electrica1 World, August $15,1978$. 
APPENDIX AI

Annotated Bibliography of Publications

Related to Sodium Conductor Cable 


\section{BIBLIOGRAPHY OF PUBLICATIONS RELATED TO \\ SODIUM CONDUCTOR CABLE}

1. "A 4000-Ampere Sodium Conductor", R. H. Boundy, Trans. Electrochem. Soc., 62, (1932).

The installation of a 4000 amp. conductor, 850 feet $(259 \mathrm{~m})$ long consisting of iron piping filled with sodium metal is described in detail. The weight per unit conductivity is decidedly less than for copper, and the cost per running foot of conductor is approximately the same. The installation has been in successful use for several years.

2. "Surface and Volume Phenomena in Dielectric Breakdown of Polyethylene", E. J. McMahon, J. R. Perkins, AIEE Transactions, Vol. PAS-82, pp. 1128-35 (December 1963).

This is a progress report on the authors' studies of the mechanism of long-term dielectric breakdown in polyethylene; the report was first given in 1948. Testing has been accelerated by using higher than power frequencies. Earlier testing concerned the effects of surface ionization on life; current studies include solid breakdown. To date the authors have been unable to produce solid breakdown in polyethylene which was not preceded and caused by surface ionization.

3. "Sodium Meets Tests as Electrical Conductor", Electrical World, February 21, 1966. No Abstract.

4. "Sodium - Cu Wire Replacement", Susan C. Sulzycki, The Purdue Engineer, October 1966. No Abstract.

5. "Sodium Cables were Used for all Secondaries in URD Development", P. E. Watson, R. M. Ventura, Jersey Central Power and Light Co., New Jersey Power and Light Company, April 1967, "Transmission and Distribution." No Abstract. 
6. "Evaluation of Sodium Conductor Power Cable", A. E. Ruprecht and P. H. Ware, IEEE Transactions on Power Apparatus and Systems, Vol. PAS-86, No. 4, April 1967.

The suitability of the newly developed polyethylene insulated sodium conductor for use in electrical power cables was evaluated electrically and mechanically. Polyethylene-insulated sodium conductors are shown to lend themselves to a wide range of constructions manufactured on standard cable-fabricating equipment. Because of the plastic nature of metallic sodium, neither conductor stranding, nor helical assembly in the case of multiconductor cables, is required for flexibility.

Within the limitations of pnlyethylene insulation, sodium conductors withstand greater short circuit currents for any given duration than do copper us dlumilimii cuiductors. Corona lcvelo and over-voltage test results are satisfactory. Conductor shielding appears to be unnecessary up to $15 \mathrm{kV}$. Higher ac step-rise dielectric strengths are obtained than those normally found in conventional cables using the same insulation. Impulse and load cycle tests show normal results.

Polyethylene-insulated sodium conductors may be pulled into conduits much more easily than insulated copper conductors. Experience with field handling of aerial and of direct-buried sodium-conductor cables has been excellent. The cables withstand modcratcly ccvere physical abuse withont damage. They have the unique ability to be stretched 25 percent and then to recover substantially their original length and electrical resistance. 
7. "Sodium as a Conductor of the Future", L. E. Whitmore, New Scientist, May 11, 1967, pp. 347-348. No Abstract.

8. "Drawing of Insulated Sodium Conductor", L. E. Humphrey, G. I. Addis, and Raymond $C$. Hess, IEEE Transactions on Power Apparatus and Systems, Vol. 86, No. 7, July 1967.

The preparation of high strength, small diameter sodium wire is discussed. A new production method consisting of spontaneous extrusion of conductor and insulation followed by high speed drawing and annealing of the composite is described. The influence of polyethylene properties and process conditions on the characteristics of the wire is shown. Resistance to damage through crushing is of particular note because the soft conductor does not act as an anvil to cut the insulation. The wire has high tensile strength, especially in the smaller sizes. Permeability to water vapor is a problem but practical means of combating it already are in use in other services. Development of reliable long life connectors is required for future applications.

9. "Insulated Sodium Conductors", L. E. Humphrey, R. C. Hess, and G. I. Addis, IEEE Transactions on Power Apparatus and Systems, Vol. 86, No. 7, July 1967.

The development and characterization of a new polyethylene insulated sodium conductor are described. The resistivity, specific gravity, and cost of sodium are compared to corresponding properties of copper and aluminum. While the alkali and alkaline earth metals have relatively good electrical conductivity, sodium was chosen because of its light weight, low cost, and availability. Physical properties of the polyethylene insulated sodium conductor were determined. Potential areas of question, such as service life, reaction of water with damaged cables, and combustion characteristics are covered in detail.

10. "The Development of Connectors for Insulated Sodium Conductor", I. F. Matthysse and E. M. Scoran, IEEE Transactions on Power Apparatus and Systems, Vo1. 86, No. 7, July 1967.

The characteristics of insulated sodium conductor required the development of a new type of connector and a new insta1lation technique. The problems involved making stable electrical contact to the sodium, sealing against chemical attack, installation with a minimum exposure of sodium, securely gripping the insulation, effects of the melting point of sodium, and temperature limitations of the insulation. 
11. "Field Trials on 15-kV and 600 Volt Sodium Cable", Edward J, Steeve, and James A. Schneider, IEEE Transaction on Power Apparatus and Systems, Vol. 86, No. 7, July 1967.

The use of sodium conductor cable presents an opportunity for reduction in cost of cable for underground residential distribution systems. In order to evaluate its usage a direct buried test installation was made involving both 15 $\mathrm{kV}$ and 600 volt sodium cable. Testing the $15 \mathrm{kV}$ cables consisted in load cycling, short-circuit faulting, and fault location tests. After the completion of tests on the $15 \mathrm{kV}$ sodium cable, a service installation was made in a rural area west of Chicago. Load cycle tests were also made on the 600 volt sudium cable. This included an overload which resulted in the failure of the cable at the terminal. Insulation damage tests were made to determine the corrosive properties of the conductor. Fault locating tests made on the 600 volt cable, as on the $15 \mathrm{kV}$ cable, showed that presently available equipment should be adequate.

12. "Comparative Costs of European Distribution Cables in Economics of Reliability of Supply", N. B. Hennett, IEEE cont. Pub1. 34, 1967, pp. 277-287. No Abstract.

13. "The Economics of Sodium Cable Changes the Design of Underground Systems", by E. P. Verhelden, Portland General Electric (T\&D). No Abstract.

14. "Improved Connectors for Insulated Sodium Conductors", S. Gerhard, Paper 45, PRN, IEEE Winter Power Confercnce, January 1968.

Progress toward the development of a new connector for insulated sodium power conductor is reported. Performance and design criteria are outlined and the development program to achieve the criteria is discussed. The connector construction and installation techniques are described and preliminary performance test data presented.

15. "Dig-in Tests on Sodium Conductor Cables," E. J. Steeve, IEEE Winter Power Meeting, New York, New York, January 28 - Fehruary 2, 1.968.

Two sets of dig-in tests on sodium conductor, polyethylene insulated cables were made by the Commonwealth Edison Company. The first series of tests were made on de-energized $15 \mathrm{kV}$ and 600 volt cables using both power machinery and hand tools. About one year later, a second series of dig-in tests was made on 600-volt cables energized at $120 / 240$ alternating volts, using three types of power machinery. 
In most cases, the degree of reaction was less than expected despite extremely wet soil conditions from heavy rainfalis previous to the tests. It appears that the probability of causing human injury due to the cutting of an energized sodium conductor cable is no greater than that for either a copper or an aluminum conductor cable. However, during various digging operations, there is always a chance that small raw sodium chips can be brought to the surface of the ground; this presents a possible safety hazard if they are not removed.

16. "A Progress Report on Sodium Conductor Power Cable", T. H. Kelly, IEEE Paper No. 68, CP 62-PWR (1968).

Experimental sodium conductor cables, insulated with polyethylene were manufactured without strand shielding and tested to determine the suitability of this construction. for service under high humidity conditions and for voltages above $15 \mathrm{kV}$. Samples were tested after five months immersion in $75^{\circ} \mathrm{C}$ water with no significant decrease in corona level. Cable samples rated at $34.5 \mathrm{kV}$ and $69 \mathrm{kV}$ and without strand shielding have been evaluated by dielectric strength and load cycle tests with satisfactory results.

17. "Irradiated Polyethylene Insulation' for Sodium Conductor Cable," R. M. Eichhorn and G. I. Addis, IEEE Winter Power Meeting, New York, Paper No. 68 CP 61-PWR (1968).

Laboratory studies of severely overloaded sodium conductor cables, insulated with both normal and irradiated polyethylene, have been made. Excessive overloads cause melting of the sodium and subsequent open circuiting of the conductor. In an overloaded vertical riser, pressure develops from the formation of a hydrostatic head. Irradiated polyethylene provides two advantages over regular polyethylene in this sltuation. First it withstands the hydrostatic pressure and prevents the release of molten sodium and second it provides moderately longer life under the given overload.

18. "Bistable Operating Temperatures and Current Rating of Sodium Conductors", J. Hus, IEEE, 1968, PAS-87, pp. 367-371.

Unlike conventional cables, the operating temperature of sodium cable lies close to its melting point. Although this does not affect the current rating at normal ambients, one cannot reap the full current rating benefits which normally accrue from a lowered ambient temperature. This paper describes how the ambient temperature affects the maximum operating temperature of sodium cable. 
19. "Sodium Cable? 'Why Not, Ask PGE,' " Eric P. Verheiden, Electric Light and Power, August 1968.

Sodium cable is different, not difficult, claims PGE after installing $11,000 \mathrm{ft}$ to serve 36 lots. But a complete review of URD design standards and operating practices may be needed to fully exploit this cable in the future.

20. "Sodium is New Cable Conductor," Norman Peach, Power, September, 1968.

Sodium has many advantages as a cable conductor, among them light weight, extreme Elexib111cy, abundant supply, tase of maliufacture. Its major dioadvantage -- its reactivity with water and oxygen -- can be offset by reasonable precautions.

21. "Sodium Conductor for Power Cables," R. J. McAnulla, Electronics and Power, 1968, 14, pp. 434-436.

Large economies in electricity-supply custs have been achieved in the past few years owing to the changeover from copper to aluminum as a material for cable conductors; the prospect of further sizable savings has prompted the investigation and development of polythene-insulated sodium conductors. As well as giving a possible capital saving of up to $50 \%$ over aluminum cables, the use of sodium cables can also lead to great economies because of the ease of handling and jointing.

22. "Kable Mit Natriumleitern", Von Hans K. Vierfub, Köln-ETZ-B Bd. 20 (1968) H. 9. (Cables with Sod1um Conductors)

In the last few years cables with sodium conductors and polyethylene insulation have been developed in the United States. In order to assess the value of this new type of cable, short lengths of sodium conductor cables have been manufactured dud subjected to tests. Among the facto cotablichod te that sodium conductors withstand practically no tensile forces. After the insulation has been damaged, the conductor in a cable laid in air reacts chemically with the air moisture. The reaction with water may result in explosion. The sodium conductor in an undamaged cable is decomposed only very slowly as a result of diffusion of moisture through the polyethylene insulation. At points where there is a short-circuit it may ignite. Comparisons of costs showed that with the usual types of cable construction in Germany, and the conductor cross-sections generally used, at least when compared with cables having aluminum conductors, no price advantage is to be expected at the moment from the use of sodium cables. 
23. "RF Performance Evaluation of Sodium Conductors", R. S. Hartman and R. Gardner, Tracor Inc. New York, New York Lab, Report No. Trancor-NYL-69-8, March 15, 1969.

The radio frequency performances of equivalent copper and sodium conductors in equivalent typical ground plane configurations were measured and ccmpared. Ground plane losses derived from field measurements of both electrically short, and quarter wavelength, vertical antennas were essentially the same for radial ground planes composed of either sodium or tinned copper radials used on the surface of the ground, or buried six inches. No evidence was found of nonlinear effects in the sodium-copper metal junction used to join the sodium conductor to a copper connector in either the field measurements or in laboratory tests when a good connection and seal was in effect. Laboratory tests, conducted under severe conditions, however, showed probable failure of the connector seal with time.

24. "Sodium Conductors Selected for Both Primary and Secondaries," P. E. Watson, R. A. Siliano, Transmission and Distribution, Vol. 21, No. 5, pp. 102-4, May 1969.' No Abstract.

25. "Sodium Cable Outgrows Trial Status, is Used as Feeder Main," (Author not identified), Electrical World, October 13, 1969. No Abstract.

26. "Sodium Cable Installation Yields Significant Savings in Initial Cost," (Author not identified), Transmission \& Distribution, November 1969. No Abstract.

27. "Insulated Sodium Conductor -- Has it a Future in Britain?", V. S. Davey and J. Rye, Electronics \& Power, pp. 395-99, November 1969. No Abstract.

28. "Sodium Conductors for Power DistrlbuLlun," IB Bentzen-Biekviat, Electrical Construction and Maintenance, Vo1. 68, No. 12, pp. 76-8, December 1969. No Abstract. 
29. "Field Service Experience with Sodium Conductor Cable," R. L. Garrison, IEEE Conf. Rec. Special Tech. Conf. on Underground Distribution, Anaheim, California, pp. 386-95, May 12-15, 1969.

This paper discusses the experience with sodium conductor cables in field service installations. It includes:

1. Summary of the sizes and voltage classes of sodiun cable installed by the utilities.

2. Description of typical installations of various voltage classes.

3. Accessory hardware problems encountered.

4. Observations from the field on work practices and result.s rerorder to date.

5. Product modifications deșigned to assist operating Departments in the handling of the sodium conductor cable.

6. Conclusions.

30. "Measurement of Water Vapor Transmission Through Polyethylene Electrical Insulation," R. M. Eichhorn, Polym. Eng. Sci., Vol. 10, No. 1, pp. 32-7, January 1970.

A method is described for measuring the rate of water vapor transmission through thick sections of polyethylene used as insulation on electrical conductors of pure sodium metal. The technique could be generally useful for materials which do not react with sodium, and for cylindrical samples which can be filled with molten sodium in a dry box. For samples with uniform dimensions the results are extremely precise because sensitive electrical measurements are used. Specimens of products in final form can be employed to determine the effects of variations in processing.

31. "PP\&L Co. Experience with $15 \mathrm{kV}$ Sodium Conductor Cables,"

Frank R. Nickel, Pennsylvania Power \& Light Co., Allcntown, PA, Doble Client Conference, Boston, MA, Apri1 1.3, 1970. Nn Ahstrart.

32. "Sodium Secondary Cable Being Used on a Regular Basis at NW Util1ty," by E. P. Verheiden, Portland General Electric Co., Transmission \& Distribution, August 1970. No Abstract. 
33. "Battle of the Conductors," D. Edgington, Underground Eng. Vol. 1, No. 2, August-September 1970, pp. 31-3. No Abstract.

34. "Hat das Natriumkabel Aussicht in England?", ETZ-B Bd. 22 (1970), H.11. No Abstract.

35. "Kunststoffe beeinflussen Kabeltechnik," Von Ing. Joachim Hospe, Frankfurt/Main, Draft-Welt Dusseldorf 56 (1970), No. 9.

36. "Design Considerations and Applications of Permanent Power Fuse", Foshio Sto, Foshio Miyamoto, Yuichi Waao Mitsubishi Electric Corp., presentation at the IEEE Winter Meeting New York, NY Paper No. C 72 103-5, January 30 - February 4, 1972. No Abstract.

Permanent Power Fuse, which is called by the abbreviated name P.P.F., is an entirely new reusable fuse with excellent current limiting performance developed by Mitsubishi

Electric Corp. of Japan. Since our first announcement on the development of the P.P.F., the low voltage series up to $800 \mathrm{~A}$ has been completed by establishing the refined reasonable design specifications of the P.P.F. The applications of the P.P.F. have thus been remarkably advanced. In this paper, the design considerations and the typical applications of the P.P.F.s are described.

37. "Zum Problem der Rationellen Gestaltung der Leiternennquerschnittsreike für Starkstrombabel", N. Astachov, A. A. Glasunov, V. I. Grieseav, and N. Fetzlow, Moskau, Energientechnik, 23 Jahrang, Heft 10, October 1973. No Abstract.

38. "Experience with Sodium -- A New Conductor", W. L. McVey, Electrical World, pp. 51-59, May 1, 1975. No Abstract.

39. "Experience with Sodium Conductor - Part II", Electrical World, May 15, 1975, pp. 58-59. No Abstract.

40. "Thermal Failure of High Voltage Solid Dielectric Cables", P. Graneau, IEEE Power Eng. Soc. Tempt "A" paper from the Winter Meeting, New York, New York, January 25-30, 1976.

This paper suggests that many of the failures of high voltage sulid dielectric cables are the result of a mismatch in thermal expansion and deformation modulus between the metallic and dielectric components of the cable. For a number of cable designs the differential thermal expansion has been calculated. When this quantity is less than one percent the cable performance appears to be satisfactory. A qualitative analysis of the thermally induced forces and motions is presented. It reveals that a mechanically weak conductor, such as sodium, greatly reduces meshanical stresses and plastic deformation of the high voltage insulation. 
APPFNNTX A?

Questionnaire for Utility Survey 


\section{Utility Survey}

This appendix presents the questionnaire sent to 49 utilities to obtain information about their sodium conductor cable installations. Noted on the questionnaire form are the response rates to each question. A surprising number of utilities (75\%) did respond to the questionnaire, which says much about their interest in sodium cable, and their public spirit. 


\section{QUESTIONNAIRE FOR UTILITY SURVEY}

Date:

Utility Name:

Utility Address:

Telephone Number:

Utility Site or Branch:

1st Person Contacted:

Titie:

2nd Person Contacted:

Title:

3rd Person Contacted:

Title:

How Contact Was Made:

Remarks: 
1.0 SODIUM CABLE EXPERIENCE

Response

Rate

1.1 . How much Na cable have you used or tested?

$100 \%$

1.1.1 Was cable procured for normal service? test?

or special

$97 \%$

1.1.2 Was cable purchased?

If so what price?

$84 \%$

\subsection{Cable Specifications}

1.2.1 Voltage class

$95 \%$

* 1.2.2 Size, ampacity or cu equivalent $89 \%$

1.2.3 Was Polyethylene insulation cross linked? Yes _ No ___ $86 \%$

1.2.4 Does cable have a semiconducting layer? Yes _ No No $86 \%$

1.2 .5 Is there a concentric neutral? Yes No $86 \%$

1.2.6 Is there a Jacket? If so what type? $89 \%$

1.2.7 Does cable meet any industry standards? $51 \%$

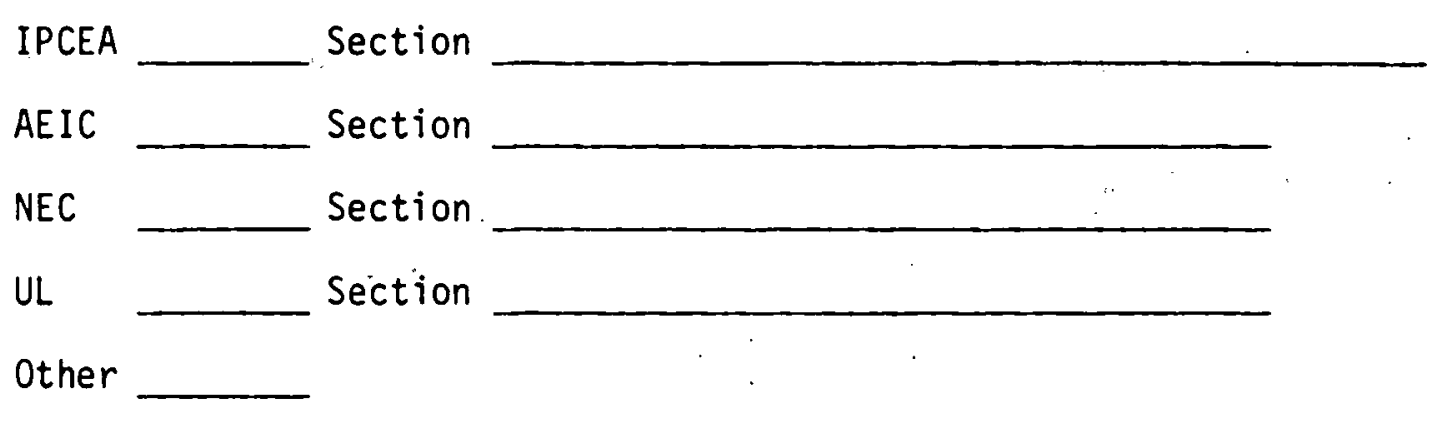

1.3 Cable Installation $\quad 89 \%$

1.3.1 Direct Buried

$\mathrm{ft}$

1.3.2 In Duct

$\mathrm{ft}$

1.3.3 Aertal

$\mathrm{ft}$

1.3.4 Other

"Who determined the CUE Rating? Mfg. Utility 
1.4 Cable Load History

1.4.1 Energized Voltage Time

1.4.2 Avg. Current Duty Cycle

$89 \%$

1.4.3 Maximum Current Time

$65 \%$

$54 \%$

1.5 Operating Experience

1.5.1 Date cable went into service or started testing

$86 \%$

1.5.2 Date cable removed from service or completed test $86 \%$

1.5.3 Were there any operating difficulties or failures? $89 \%$

1.5.4 Was operation any different than with $\mathrm{Cu}$ or Al? $86 \%$

1.6 Operating Expenses

1.6.1 Operating cost in power loss $35 \%$

1.6.2 How does this compare with equally rated $\mathrm{Cu}$ $19 \%$ Al

1.6.3 Other operating costs $30 \%$

1.7 Installed Cable Cost

1.7.1 What was installed cable cost?

1.7.2 How does this compare with Al $32 \%$

1.7.3 How does cost break down?

Digging trench or installing duct

Laying or pulling cable

Cable cost

Making terminations or connections

Connector cost

other 
1.7.4 Depreciation Schedule

Is it the same as for $\mathrm{Al}$

$\mathrm{Cu}$

1.8 Installation Difficulties or Observations

1.8.1 What installation difficulties were encountered

$84 \%$

1.8.2 Compare installation experience with $\mathrm{Al}$ and $\mathrm{Cu}$ of same rating

1.8.3 How many connections or terminations were made? $70 \%$

1.8.4 Compare installation or connector with those for $\mathrm{Al}$ and $\mathrm{Cu}$ $59 \%$

1.9 Maintenance

1.9.1 What were cable maintenance costs? $59 \%$

1.9.2 Were there any maintenance problems? $68 \%$

1.9.3 Compare maintenance with Al , $49 \%$

1.9.4 Were there any special maintenance practices followed for $\mathrm{Na}$ cable?

1.10. Safety Provisions

1.10.1 Were there any special safety provisions followed for:

1. Storing cable $70 \%$

2. Installing cable

3. Operating cable

4. Disconnecting cable

1.10.2 What was done with cut off sections when making connections?

1.10.3 What was done or what do you plan to do with cable when removed from service?

1.10.4 Do you consider an abandoned Na cable a problem? $73 \%$ If so, how? 
2.0 OPINION OF SODIUM CABLE FOR DISTRIBUTION NETWORKS

Response

Rate

2.1 What are your observations and feelings about the sodium cable used $92 \%$ by your organization?

2.2 Would you recommend that your organization use sodium cable if it were readily available and if there was a cost advantage? 
2.3 What do you think is the biggest obstacle to the utilities

$86 \%$ accepting sodium cable for extensive use in distribution systems?

2.4 What other disadvantages are there for using $\mathrm{Na}$ cable?

2.5 What are the benefits of using $\mathrm{Na}$ cable? specify for sodium cable? 
3.1 What is the average installed cost (per ft. or mile) of direct buried $3.1 .1600 \mathrm{~V} \mathrm{A1}$ $250 \mathrm{kcmil}$ :

$3.1 .2600 \mathrm{~V} \mathrm{Cu}$

$3.1 .3 \quad 15 \mathrm{kV} \mathrm{Al}$

$3.1 .415 \mathrm{kV} \mathrm{Cu}$

$32 \%$

$3.1 .525 \mathrm{kV} \mathrm{Al}$

$24 \%$

$3.1 .625 \mathrm{kV} \mathrm{Cu}$

$19 \%$

$3.1 .735 \mathrm{kV} \mathrm{Al}$

$14 \%$

$3.1 .8 \quad 35 \mathrm{kV} \mathrm{Cu}$

$22 \%$

$22 \%$

3.2 What is average operating costs for direct buried $15 \mathrm{kV}$ :

3.2.1 250-kcmil Al

$19 \%$

3.2.2 250-kcmil $\mathrm{Cu}$

$19 \%$

3.2.3 1000-kcmil AI

$16 \%$

$3.2 .4 \quad 1000-\mathrm{kcmi}$ i Cu

$16 \%$

3.3 How do these costs break down?

3.3.1 Preparing ditch or duct

$27 \%$

3.3.2 Installing cable

$27 \%$

3.3.3 Cable cost

$27 \%$

3.3.4 Connector cost

$24 \%$

3.3.5 Installing connectors

$24 \%$

3.3.6 Operating cost

$14 \%$

3.3.7 Maintenance cost

$14 \%$

3.3.8 Other

$8 \%$ 


\section{APPENDIX A3}

Ampacity Tables

In order to calculate the ampacity of a sodium or aluminum cable it is necessary to know the alternating current resistivity of the conductor. This is the product of the skin-effect factor $B$ (see Paragraph 7.4.1 and Fig. 7-4) and the direct-current resistivity. The latter is given for sodium in Table A3-1, calculated by Eq. 7-16, and for aluminum in Table A3-2, calculated by Eq. 7-15. Values are given at $1^{\circ} \mathrm{C}$ temperature intervals from $0^{\circ} \mathrm{C}$ to $98^{\circ} \mathrm{C}$ for sodium. (A supplementary table in the test, Table 7-5, gives some values for molten sodium).

The calculation of ampacities in the tables, when the temperature is given, proceeds straightforwardly by use of Eq. 7-13 for directly buried cable or Eq. 7-26 for cable in duct. This was conveniently done via a programmable disk calculator. When, however, the current is known and the operating temperature is desired, the calculation is not so direct since the dc resistivity (and therefore also the skin-effect factor) depends on the as-yet-unknown temperature. It was found to be very easy to run the calculation for a few temperatures and interpolate to find the temperature which yielded the known current; after a little initial experience this inverted procedure required only two or three repetitions to yield the desired temperatures. For brevity, only the final results of such calculations are tabulated. A11 ampacities are to the nearest ampere, and temperatures are to the closest half-degree centigrade.

Tables A3-3 through A3-6 are those for the calculation, in the direct-burial case, of the equivalent sodium cable, as outlined in Paragraph 7.1.1, for aluminum cable of conductor cross-sections of $1000,750,500$ and $350 \mathrm{kCM}$, in voltage ratings of 15,25 , and $35 \mathrm{kV}$. Tables A3-7 and A3-8 repcat the process but for 600 vollt cable, using the insulation thicknesses specified by IPCEA for that voltage. In 
consideration of the possibility that thicker insulation might be of interest for reasons of mechanical strength (although as concluded In Paragraph 7.3.3 the IPCEA specified thicknesses appear adequate), and in order to illustrate the variation of the equivalent sodium cross-section with choice of insulation thickness for a fixed ampacity, these equivalence calculations were repeated using (for the sodium only, not for the aluminum) greater insulation thicknesses, .160 inches in Table A3-9 and .205 inches in Table A3-10. Tables A3-11 through A3-18 repeat th1s same sequence of calculations for cable in duct. Tables A3-19 and A3-20, which describe the ampacity variation with insulation thickness for a fixed sodium conductor size for direct burial and for cable in duct respectively, are the basis for Fig. 7-2. Tables A3-21 and A3-22 repeat the equivalence calculation of lables A3-3 through A3-6 for the $25 \mathrm{kV}$ case but with $\rho_{e}=1.30$ in Tahle A3-21 and with $\alpha=1$ in Table A3-22, to illustrate that the diameter of the equivalent sodium conductor is very insensitive to the choice of these parameters. Tables A3-23 and A3-24 were prepared in order to verify the calculation procedure of Paragraph 7.4 .1 by comparing its predictions to the IPCEA tables. Differences from the latter, as noted in the. tablco, arc of the order of a pelceul.

The definition and units for the symbols used in the tables are given in the following list. 
DEFINITIONS FOR APPENDIX A3 TABLES

In these tables:

$\delta \mathrm{T}=$ temperature rise from earth ambient to cable conductor (latter assumed isotherma1), ${ }^{\circ} \mathrm{C}$.

$\alpha=$ ratio of shield (neutral, drain wires) losses to core losses.

$\rho_{\mathrm{e}}=$ earth thermal resistivity, ${ }^{\circ} \mathrm{C} \mathrm{cm} /$ watt.

$t_{1}=$ insulation thickness including conductor and insulation semiconducting shields. Values are taken as recommended by IPCEA: conductor shield .015 in., insulation shield .030 in.; insulation thickness $.175 \mathrm{in}$. C $15 \mathrm{kV}, .345 \mathrm{in}$. @ $35 \mathrm{kV}$. AEIC agrees; specifies also .260 in. @ $25 \mathrm{kV}$.

$r_{1}=$ conductor radius, inches, not including conductor shleld.

$\rho_{i}=$ insulation thermal resistivity, ${ }^{\circ} \mathrm{C} \mathrm{cm} /$ watt.

$x=$ horizontal cable separation, inches.

$\mathrm{L}=$ burial depth, inches.

$\rho_{c}=$ conductor dc resistivity at operating temp., $\mu \Omega \mathrm{cm}$.

$A=$ conductor cross sectional area, thousands of circular mils (KCM). $\mathrm{R}_{\mathrm{DC}}=$ conductor $\mathrm{DC}$ resistance at oper. temp., $\Omega / \mathrm{cm}$.

$\beta$ - skin effect ratio, $R_{A C} / R_{D C}$ e $60 \mathrm{IIz}$.

$\mathrm{R}_{\mathrm{AC}}=$ conductor $\mathrm{AC}$ resistance at oper. temp. $\Omega / \mathrm{cm}$.

$I$ = calculated ampacity, amperes RMS.

$\delta \mathrm{T}_{\mathrm{S}}=$ temp. rise at central cable outer surface, or duct outer surface, if present, caused by dissipation of central cable, ${ }^{\circ} \mathrm{C}$.

$\delta \mathrm{T}_{\mathrm{M}}=$ temp. rise at central cable outer surface, or duct outer surface, if present, caused by dissipation of both outer cables together ${ }^{\circ} \mathrm{C}$. $\delta \mathrm{T}_{\mathrm{I}}=$ temp. rise from central cable outer surface to conductor, ${ }^{\circ} \mathrm{C}$. 


\section{DEFINITIONS FOR APPENDIX TABLES (Continued)}

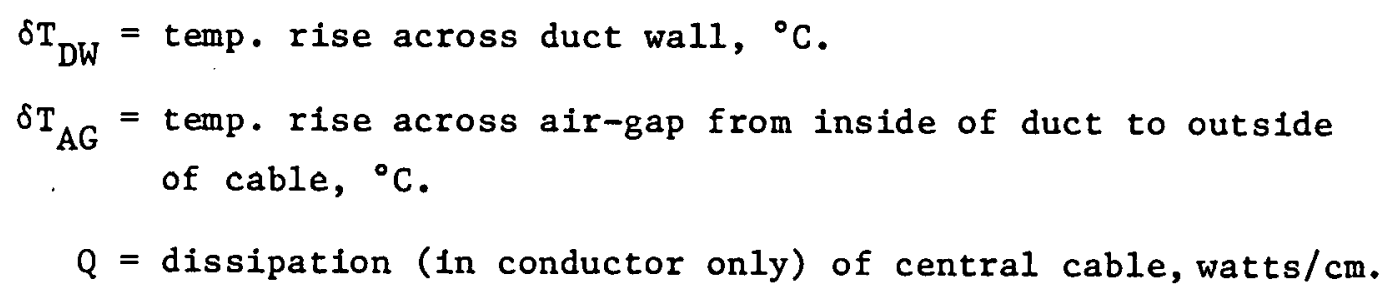


TABLES A3-1 and A3-2. DC Resistivities of Sodium and Aluminum vs. Temperature

\begin{tabular}{|c|c|c|c|c|c|c|c|c|c|c|c|}
\hline & $\mathrm{T}^{\circ} \mathrm{C}$ & 0 & 1 & 2 & 3 & 4 & 5 & 6 & 7 & 8 & 9 \\
\hline & 0 & 4.2900 & 4.3099 & 4.3298 & 4.3498 & 4.3698 & 4.3898 & 4.4099 & 4.4299 & 4.4500 & 4.4701 \\
\hline \multirow{9}{*}{$\begin{array}{l}\text { Table } \\
\text { A3-1 } \\
\text { Sodium }\end{array}$} & 10 & 4.4902 & 4.5104 & 4.5305 & 4.5507 & 4.5911 & 4.5911 & 4.6114 & 4.6316 & 4.6519 & 7.6722 \\
\hline & 20 & 4.6925 & 4.7128 & 4.7332 & 4.7535 & 4.7739 & 4.7944 & 4.8148 & 4.8352 & 4.8557 & 4.8762 \\
\hline & 30 & 4.8967 & 4.9172 & 4.9378 & 4.9584 & 4.9790 & 4.9996 & 5.0202 & 5.0408 & 5.0615 & 5.0822 \\
\hline & 40 & 5.1029 & 5.1236 & 5.1144 & 5.1651 & 5.1859 & 5.2067 & 5.2276 & 5.2484 & 5.2693 & 5.2902 \\
\hline & 50 & 5.3111 & 5.3320 & 5.3529 & 5.3739 & 5.3949 & 5.4159 & 5.4369 & 5.4580 & 5.4790 & 5.5001 \\
\hline & 60 & 5.5212 & 5.5423 & 5.5635 & 5.5846 & 5.6058 & 5.6270 & 5.6482 & 5.6695 & 5.6907 & 5.7120 \\
\hline & 70 & 5.7333 & 5.7546 & 5.7760 & 5.7973 & 5.8187 & 5.8401 & 5.8616 & 5.8829 & 5.9044 & 5.9259 \\
\hline & 80 & 5.9474 & 5.9689 & 5.9904 & 6.0120 & 6.0336 & 6.0552 & 6.0768 & 6.0984 & 6.1201 & 6.1417 \\
\hline & 90 & 6.1634 & 6.1851 & 6.2069 & 6.2286 & 6.2504 & 6.2722 & 6.2940 & 6.3158 & 6.3377 & \\
\hline & & \multicolumn{10}{|c|}{$\rho_{\mathrm{Na}}$} \\
\hline & 0 & 2.6324 & 2.6439 & 2.6554 & 2.6669 & 2.6784 & 2.6899 & 2.7014 & 2.7129 & 2.7244 & 2.7359 \\
\hline & 10 & 2.7474 & 2.7589 & 2.7704 & 2.7819 & 2.7934 & 2.8049 & 2.8164 & 2.8279 & 2.8394 & 2.8509 \\
\hline \multirow{9}{*}{$\begin{array}{l}\text { Tajle } \\
\text { A3-2 } \\
\text { Al:minum }\end{array}$} & 20 & 2.8624 & 2.8739 & 2.8854 & 2.8969 & 2.9084 & 2.9199 & 2.9314 & 2.9429 & 2.9544 & 2.9659 \\
\hline & 30 & 2.9774 & 2.9889 & 3.0004 & 3.0119 & 3.0234 & 3.0349 & 3.0464 & 3.0579 & 3.0694 & 3.0809 \\
\hline & 40 & 3.0924 & 3.1039 & 3.1154 & 3.1269 & 3.1384 & 3.1499 & 3.1614 & 3.1729 & 3.1844 & 3.1959 \\
\hline & 50 & 3.2074 & 3.2189 & 3.2304 & 3.2419 & 3.2534 & 3.2649 & 3.2764 & 3.2879 & 3.2994 & 3.3109 \\
\hline & 60 & 3.3224 & 3.3339 & 3.3454 & 3.3569 & 3.3684 & 3.3799 & 3.3914 & 3.4029 & 3.4144 & 3.4259 \\
\hline & 70 & 3.4374 & 3.4489 & 3.4604 & 3.4719 & 3.4834 & 3.4949 & 3.5064 & 3.5179 & 3.5294 & 3.5409 \\
\hline & 80 & 3.5524 & 3.5639 & 3.5754 & 3.5869 & 3.5984 & 3.6099 & 3.6214 & 3.6329 & 3.6444 & 3.6559 \\
\hline & 90 & 3.6674 & 3.6789 & 3.6904 & 3.7019 & 3.7134 & 3.7249 & 3.7364 & 3.7479 & 3.7594 & 3.7708 \\
\hline & 100 & 3.7824 & & & & & & . & & & \\
\hline
\end{tabular}


TABLE A3-3. Aluminum Cable Ampacity at Vornal Load Direct Burial (Conductor at $90^{\circ} \mathrm{z}$ )

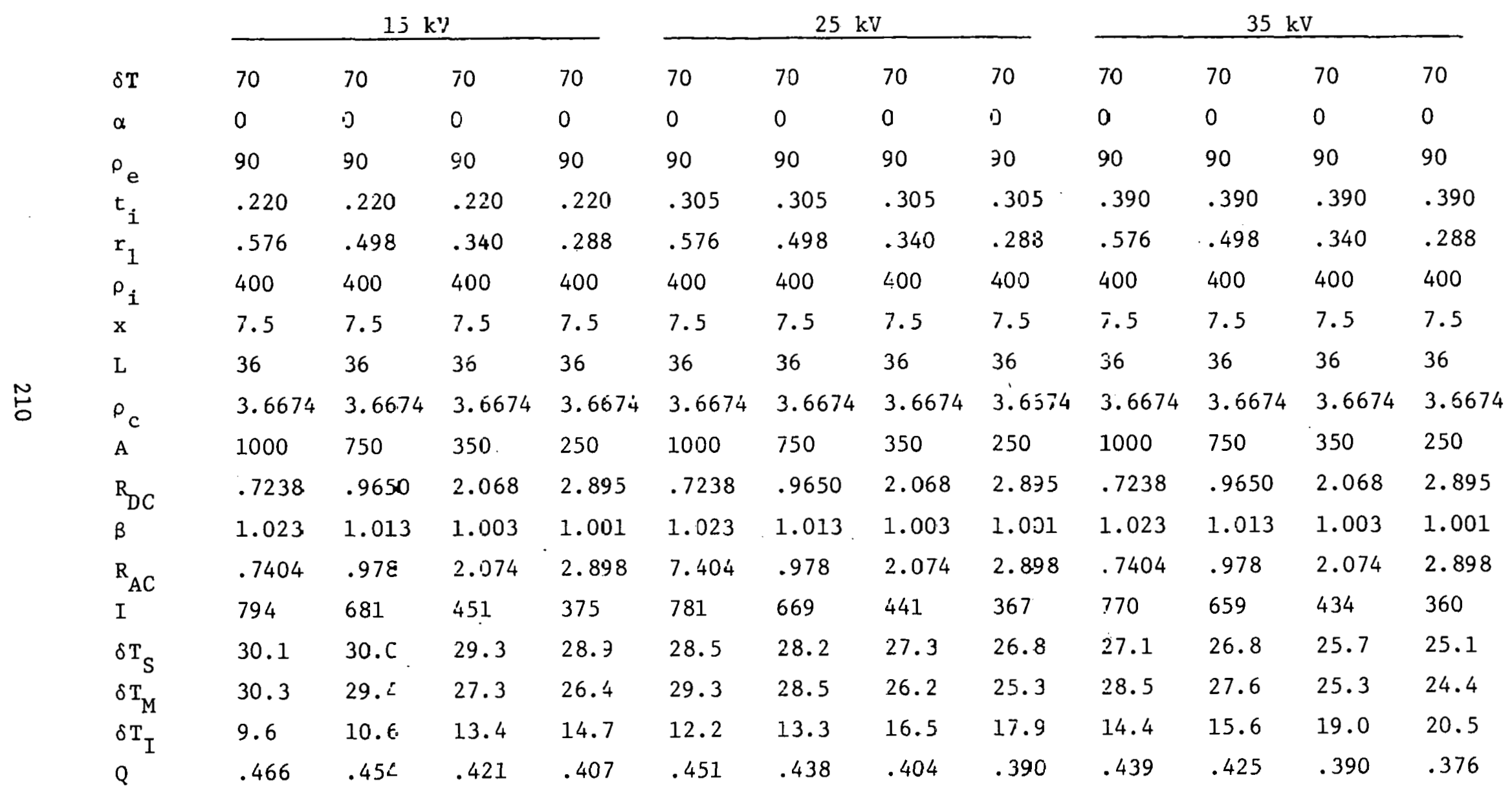


TABLE A3-4: Aluminum Cable Ampacity at Overload

Direct Burial (Conductor at $130^{\circ} \mathrm{C}$ )

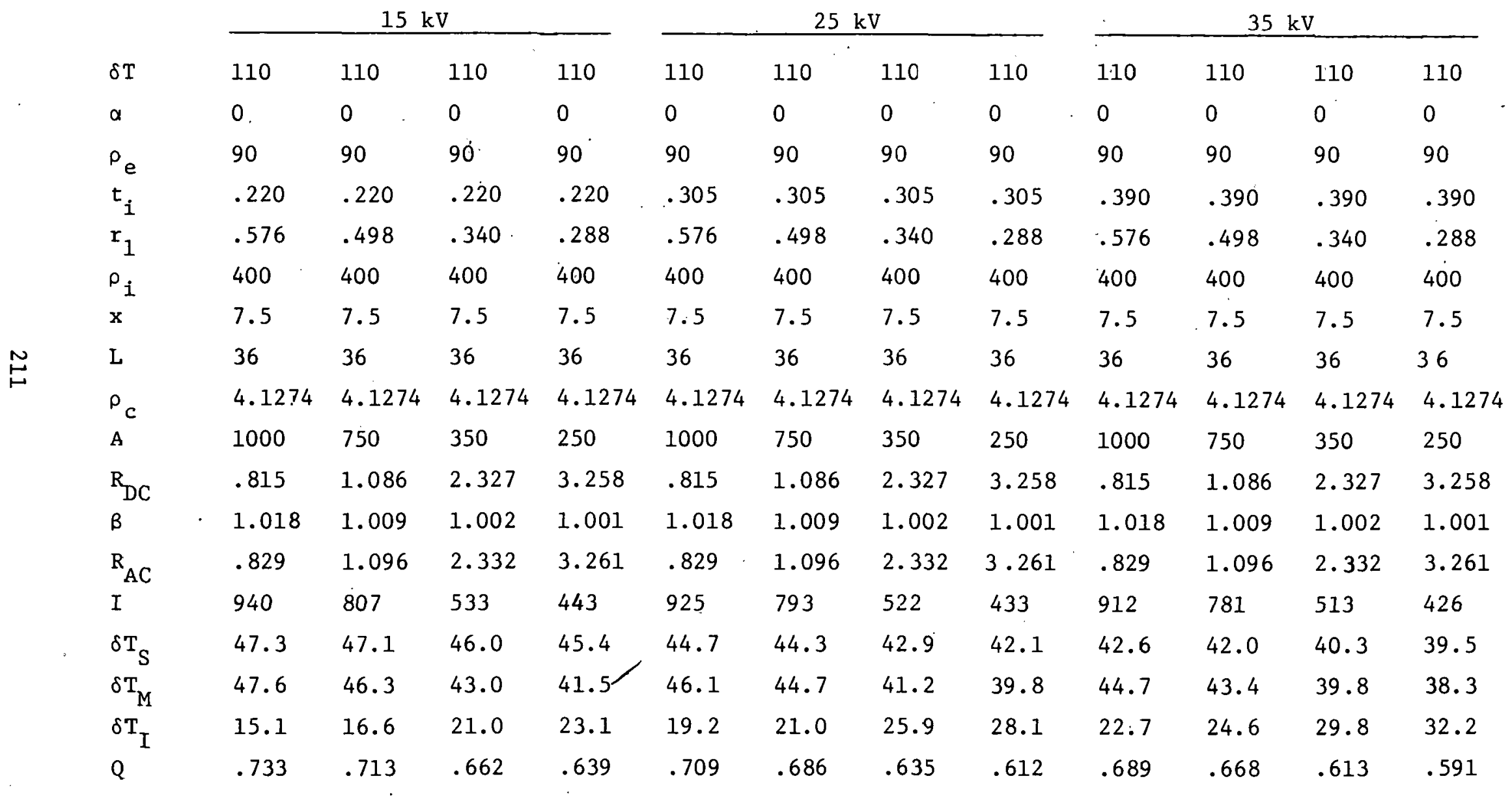


TABLE A3-5. Scdium Cable Amnacity at Querload

Direct Eurial (Conductor at $95^{\circ} \mathrm{C}$ )

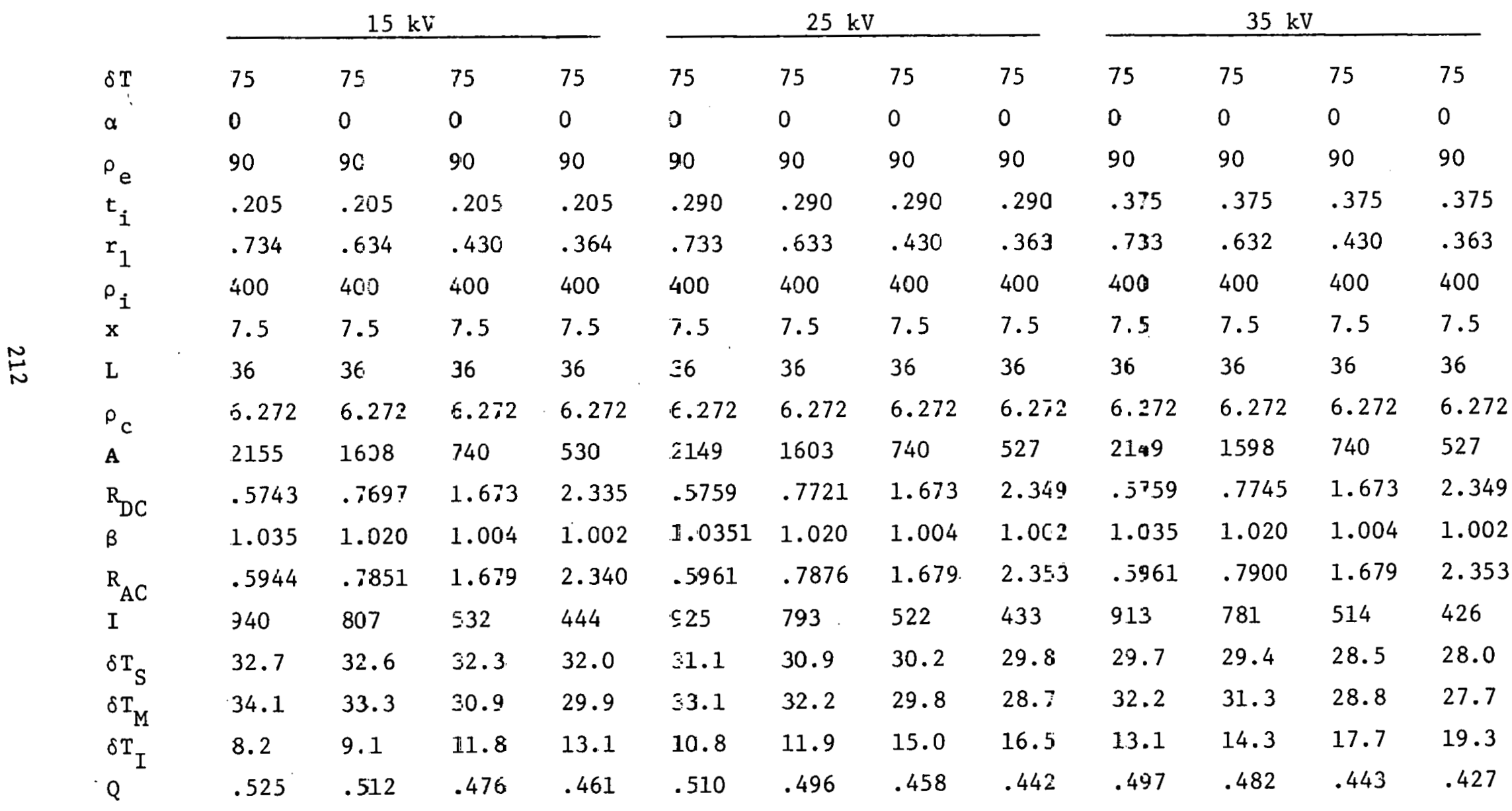


TABLE A3-6. Sodium Cable Conductor Temperature at Normal Load Current Direct Burial

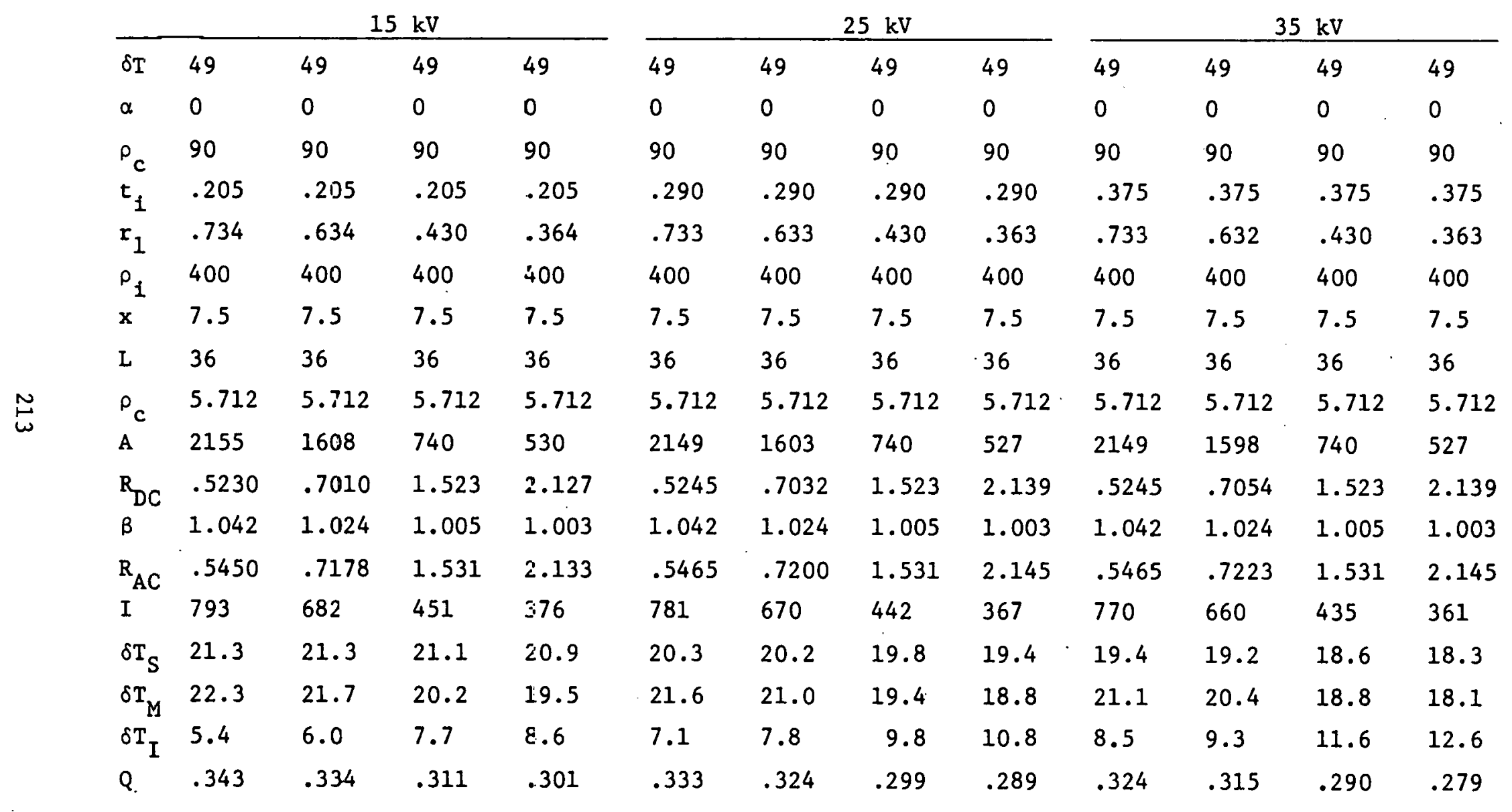


TABLE A3-7. Aluminum Cable Ampa:ity at Normal Load (Conductor at $90^{\circ} \mathrm{C}$ ) and at Overload (Conductor at $130^{\circ} \mathrm{C}$ ) Direct Burial, 600 Volt Cable

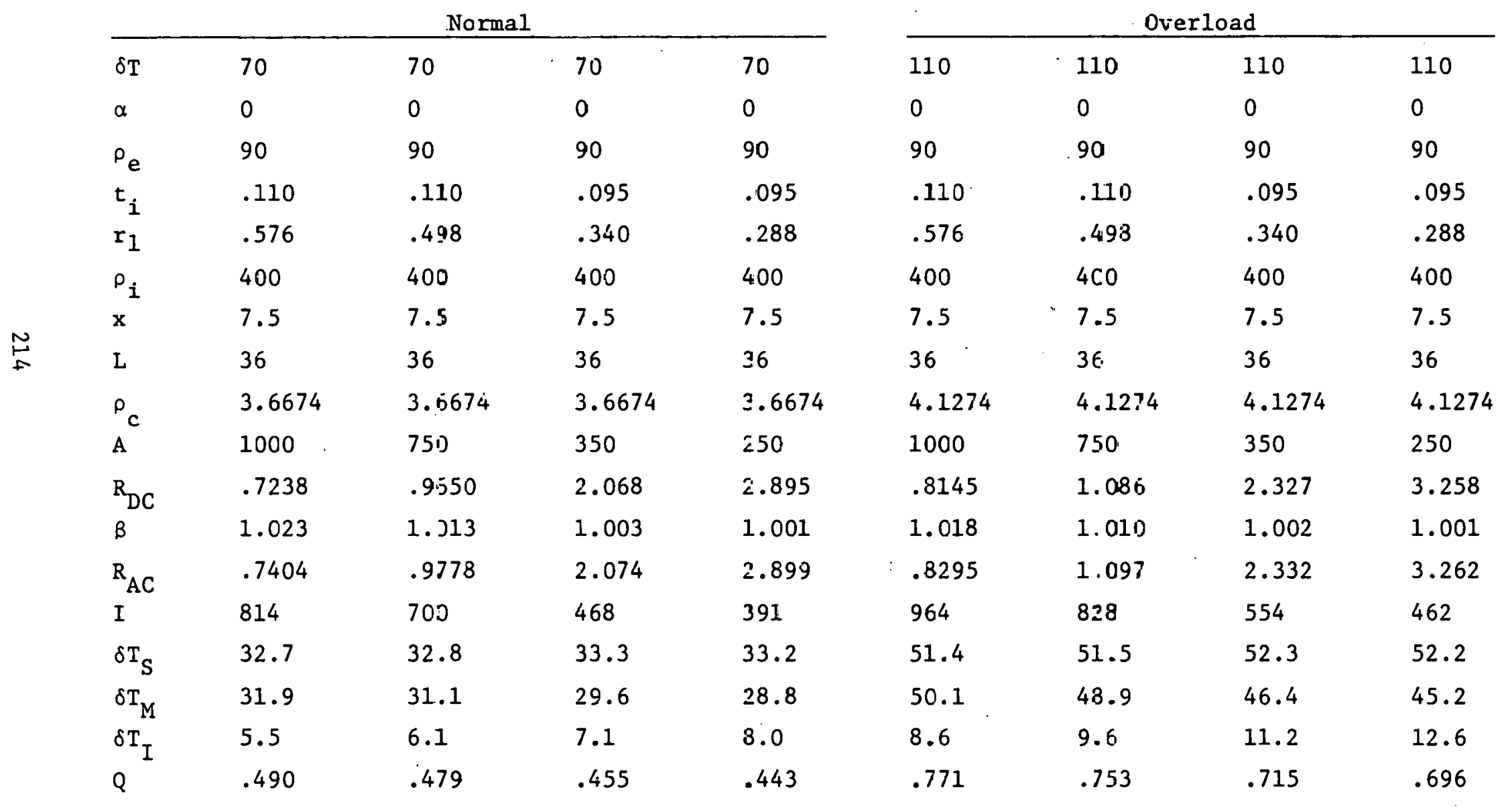

Insulation thicknesses employed above are those specified by IPCEA S61 402 for normal HMWPE. 
TABLE A3-8. Sodium Cable Ampacity at Overload (Conductor at $95^{\circ} \mathrm{C}$ ) and Conductor Temperature at Normal Load Current Direct Burial, 600 volt Cable

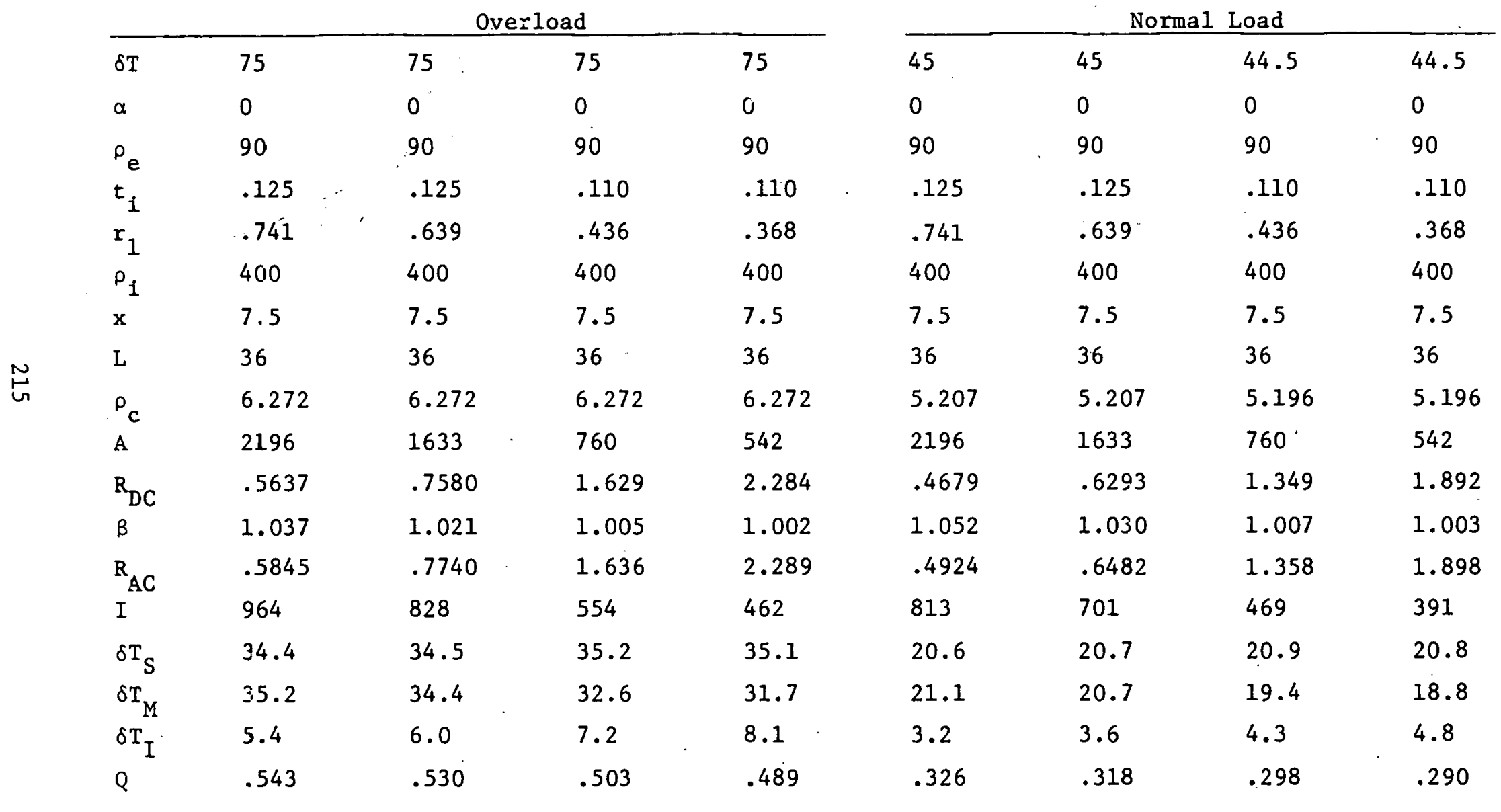

Insulation thicknesses employed above are those specified by IPCEA S61 402 for normal HMWPE. 
TABLE A3-9. Sodium Cable Ampacity at Overload (Conductor at $95^{\circ} \mathrm{C}$ ) and Confuctor Temperature at Normal Load Current Jrect Burial, 600 Volt Cable

\begin{tabular}{|c|c|c|c|c|c|c|c|c|}
\hline & & & & & & & Load & \\
\hline$\delta \mathrm{T}$ & 75 & 75 & 75 & 75 & 45 & $\angle 5$ & 44.5 & 44.5 \\
\hline$\alpha$ & 0 & 0 & 0 & 0 & 0 & 0 & 0 & 0 \\
\hline$\rho_{\mathrm{e}}$ & 90 & 90 & 90 & 90 & 90 & $\subseteq 0$ & 90 & 90 \\
\hline$t_{1}$ & .160 & .160 & .160 & .160 & .160 & .150 & .160 & .160 \\
\hline$r_{1}$ & .746 & .644 & .441 & .373 & .746 & .644 & .441 & .373 \\
\hline$\rho_{1}$ & 400 & 400 & 400 & 400 & 400 & $400^{\circ}$ & 400 & 400 \\
\hline$x$ & 7.5 & 7.5 & 7.5 & 7.5 & 7.5 & 7.5 & 7.5 & 7.5 \\
\hline L & 36 & 36 & 36 & 36 & 36 & 35 & 36 & 36 \\
\hline$\rho_{c}$ & 6.272 & 6.272 & 6.272 & Б. 272 & 5.207 & 5.207 & 5.196 & 5.196 \\
\hline A & 2226 & 1659 & 778 & 557 & 2226 & 1659 & 778 & 557 \\
\hline $\mathrm{R}_{\mathrm{DC}}$ & .5561 & .7461 & 1.591 & 2.222 & .4616 & .619 & 1.318 & 1.841 \\
\hline$\beta$ & 1.038 & 1.022 & 1.005 & 1.002 & 1.054 & 1.031 & 1.007 & 1.004 \\
\hline $\mathrm{R}_{\mathrm{AC}}$ & .5771 & .7623 & 1.599 & z. 228 & .4864 & .6 .336 & 1.327 & 1.848 \\
\hline I & 964 & 828 & 553 & 462 & 813 & $7 C 1$ & 468 & 391 \\
\hline$\delta \mathrm{T}_{\mathrm{S}}$ & 33.6 & 33.7 & 33.6 & 33.4 & 20.1 & 20.2 & 19.9 & 19.8 \\
\hline$\delta \mathrm{T}_{\mathrm{M}}$ & 34.8 & 34.0 & 31.8 & 30.8 & 20.9 & 20.4 & 18.9 & 18.3 \\
\hline$\delta \mathrm{T}_{I}$ & 6.6 & 7.4 & 9.6 & 10.8 & 4.0 & 4.4 & 5.7 & 6.4 \\
\hline$Q$ & .536 & .523 & .490 & .475 & .321 & .314 & .290 & .282 \\
\hline
\end{tabular}

Insulation thicknesses above $9 r e$ a11 .161 in. 
TABLE A3-10. Sodium Cable Ampacity at Overload (Conductor at $95^{\circ} \mathrm{C}$ ) and Conductor Temperature at Normal Load Current Direct Burial, 600 Volt Cable

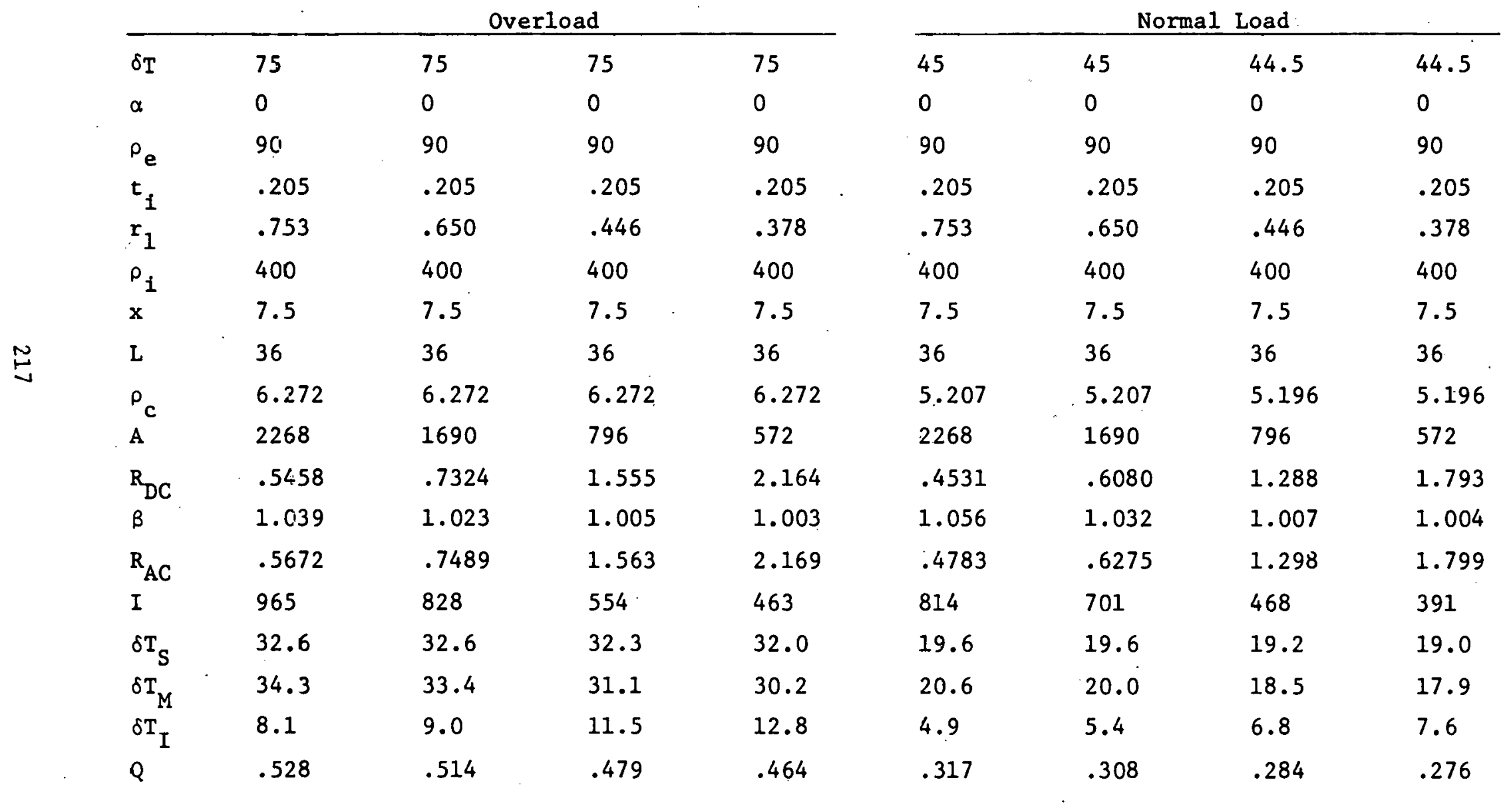

Insulation thicknesses above are all .205 in. 
TABLE A3-11. Aluminum Cable Ampacity at Normal Load,Cable ir Duct (Conductor at $90^{\circ} \mathrm{C}$ )

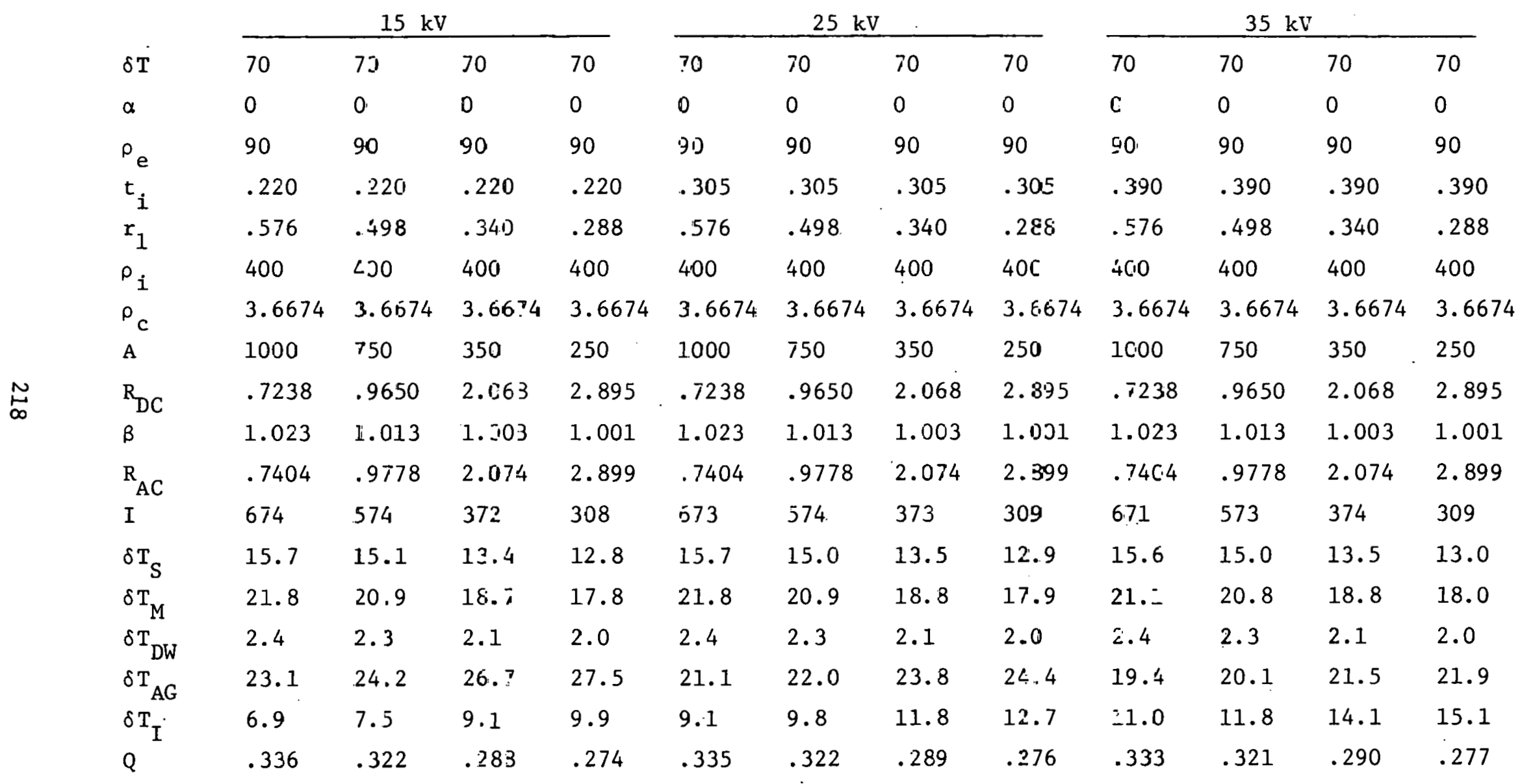


TABLE A3-12. Aluminum Cable Ampacity at Overload, Cable in Duct (Conductor at $130^{\circ} \mathrm{C}$ )

\begin{tabular}{|c|c|c|c|c|c|c|c|c|c|c|c|c|}
\hline & & $15 \mathrm{kV}$ & & & & $25 \mathrm{kV}$ & . & & & $35 \mathrm{kV}$ & & \\
\hline$\delta \mathrm{T}$ & 110 & 110 & $1: 0$ & 110 & 110 & 110 & 110 & 110 & 110 & 110 & 110 & 110 \\
\hline$\alpha$ & 0 & 0 & 0 & 0 & 0 & 0 & 0 & 0 & 0 & 0 & 0 & 0 \\
\hline$\rho_{\mathrm{e}}$ & 90 & 90 & 90 & 90 & 90 & 90 & 90 & 90 & 90 & 90 & 90 & 90 \\
\hline$t_{i}$ & .220 & .220 & .220 & .220 & .305 & .305 & .305 & .305 & .390 & .390 & .390 & .390 \\
\hline$r_{1}$ & .576 & .498 & .340 & .288 & .576 & .498 & .340 & .288 & .576 & .498 & .340 & .288 \\
\hline$\rho_{i}$ & 400 & 400 & 400 & 400 & 400 & 400 & 400 & 400 & 400 & 400 & 400 & 400 \\
\hline$\rho_{c}$ & 4.1274 & 4.1274 & 4.1274 & 4.1274 & .4 .1274 & 4.1274 & 4.1274 & 4.1274 & 4.1274 & 4.1274 & 4.1274 & 4.1274 \\
\hline A & 1000 & 750 & 350 & 250 & 1000 & 750 & 350 & 250 & 1000 & 750 & 350 & 250 \\
\hline $\mathrm{R}_{\mathrm{DC}}$ & .8145 & 1.086 & 2.327 & 3.258 & .8145 & 1.086 & 2.327 & 3.258 & .8145 & 1.086 & 2.327 & 3.258 \\
\hline$\beta$ & 1.018 & 1.010 & 1.002 & 1.001 & 1.018 & 1.010 & 1.002 & 1.001 & 1.018 & 1.010 & 1.002 & 1.001 \\
\hline $\mathrm{R}_{\mathrm{AC}}$ & .8295 & 1.097 & 2.332 & 3.262 & .8295 & 1.097 & 2.332 & 3.262 & .8295 & 1.097 & 2.332 & 3.262 \\
\hline$I$ & 821 & 699 & 454 & 375 & 818 & 697 & 454 & 376 & 814 & 695 & 453 & 375 \\
\hline$\delta T_{S}$ & 26.1 & 25.1 & 22.5 & 21.5 & 25.9 & 25.0 & 22.5 & 21.5 & 25.7 & 24.8 & 22.4 & 21.5 \\
\hline$\delta \mathrm{T}_{\mathrm{M}}$ & 36.3 & 34.9 & 31.3 & 29.8 & 36.0 & 34.7 & 31.3 & 29.9 & 35.7 & 34.4 & 31.1 & 29.8 \\
\hline$\delta \mathrm{T}_{\mathrm{DW}}$ & 4.1 & 3.9 & 3.5 & 3.3 & 4.0 & 3.7 & 3.5 & 3.3 & 4.0 & 3.8 & 3.5 & 3.3 \\
\hline$\delta \mathrm{T}_{\mathrm{AG}}$ & $32: 0$ & 33.7 & 37.4 & 38.8 & 29.0 & 30.3 & 33.1 & 34.1 & 26.5 & 27.5 & 29.6 & 30.3 \\
\hline$\delta \mathrm{T}_{\mathrm{I}}$ & 11.5 & 12.5 & 15.3 & 16.6 & 15.0 & 16.2 & 19.6 & 21.2 & 18.1 & 19.5 & 23.3 & 25.1 \\
\hline$Q$ & .559 & .537 & .482 & .459 & .555 & .534 & .481 & .460 & .550 & .530 & .480 & .460 \\
\hline
\end{tabular}


TABLE A3-13. Sodiun Cable Ampacity at 0yerload, Cable in Duct

(Conductor at $95^{\circ} \mathrm{C}$ !

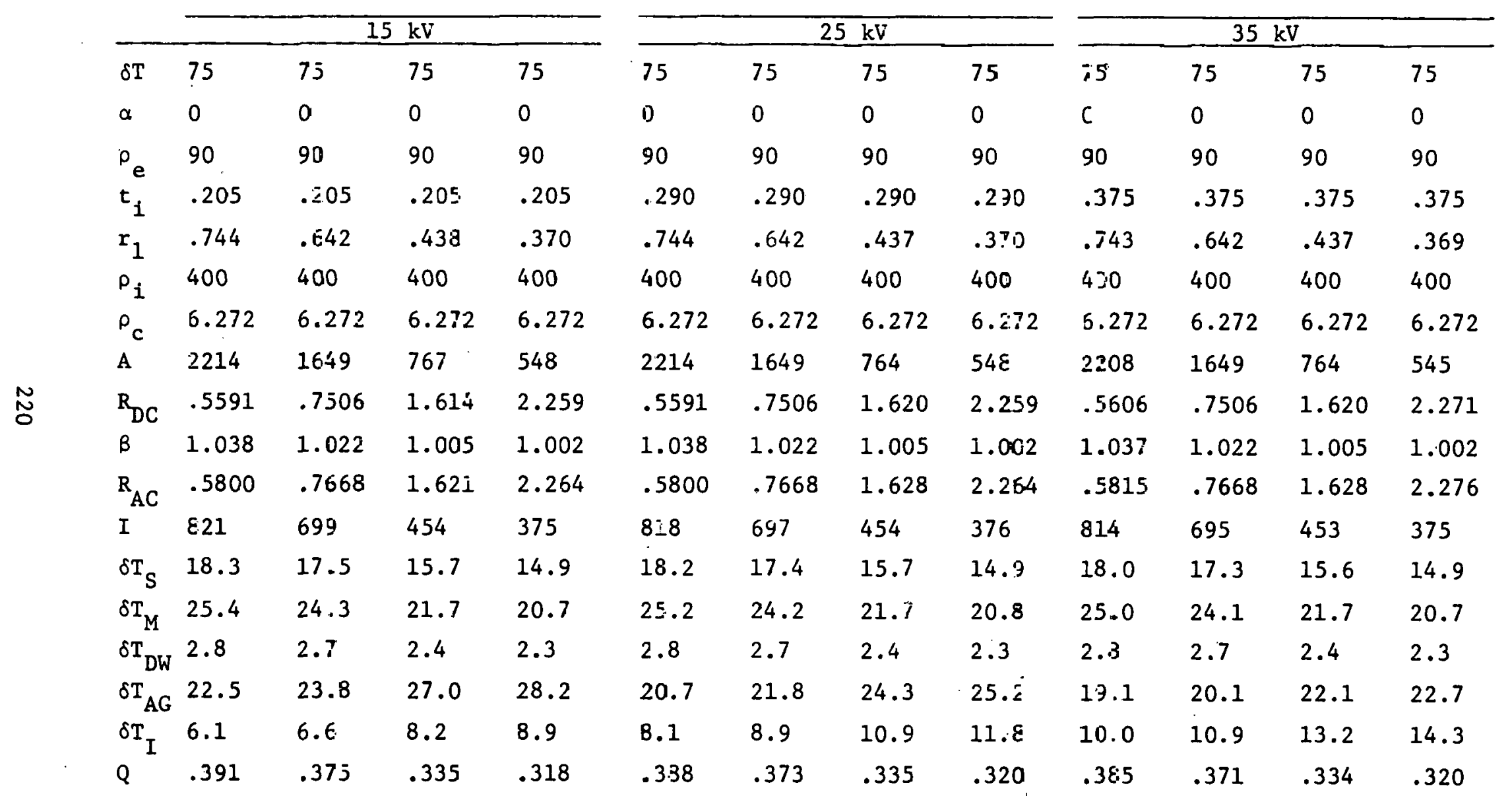


TABLE A3-14. Sodium Cable Conductor Temperature at Normal Load Current Cable in Duct

\begin{tabular}{|c|c|c|c|c|c|c|c|c|c|c|c|c|}
\hline & & $15 \mathrm{kV}$ & & & & $25 \mathrm{kV}$ & & & & $35 \mathrm{kV}$ & & \\
\hline$\delta \mathrm{T}$ & 48.5 & 48.5 & 48.5 & 48.5 & 48.5 & 48.5 & 48.5 & 48.5 & 48.5 & 48.5 & 48.5 & 48.5 \\
\hline$\alpha$ & 0 & 0 & 0 & 0 & 0 & 0 & 0 & 0 & 0 & 0 & 0 & 0 \\
\hline$\rho_{e}$ & 90 & 90 & 90 & 90 & 90 & 90 & 90 & 90 & 90 & 90 & 90 & 90 \\
\hline$t_{i}$ & .205 & .205 & .205 & .205 & .290 & .290 & .290 & .290 & .375 & .375 & 3.75 & .375 \\
\hline$r_{1}$ & .744 & .642 & .438 & .370 & .744 & .642 & .437 & .370 & .743 & .642 & .437 & .369 \\
\hline$\rho_{i}$ & 400 & 400 & 400 & 400 & 400 & 400 & 400 & 400 & 400 & 400 & 400 & 400 \\
\hline$\rho_{c}$ & 5.7014 & 5.7014 & 5.7014 & 5.7014 & 5.7014 & 5.7014 & 5.7014 & 5.7014 & 5.7014 & 5.7014 & 5.7014 & 5.7014 \\
\hline A & 2214 & 1649 & 767 & 548 & 2214 & 1649 & 764 & 548 & 2208 & 1649 & 764 & 545 \\
\hline $\mathrm{R}_{\mathrm{DC}}$ & .50182 & .6823 & 1.467 & 2.053 & .5082 & .6823 & 1.473 & 2.053 & .5096 & .6823 & 1.473 & 2.065 \\
\hline$\beta$ & 1.0145 & 1.026 & 1.006 & 1.003 & 1.045 & 1.026 & 1.006 & 1.003 & 1.045 & 1.026 & 1.006 & 1.003 \\
\hline $\mathrm{R}_{\mathrm{AC}}$ & $.5 \$ 10$ & .6999 & 1.475 & 2.059 & .5310 & .6999 & 1.481 & 2.059 & .5323 & .6999 & 1.481 & 2.070 \\
\hline I & 674 & 575 & 373 & 308 & 673 & 574 & 374 & 309 & 671 & 573 & 374 & 309 \\
\hline$\delta \mathrm{T}_{\mathrm{S}}$ & 11.3 & 10.8 & 9.6 & 9.1 & 11.3 & 10.8 & 9.7 & 9.2 & 11.2 & 10.8 & 9.7 & 9.2 \\
\hline$\delta \mathrm{T}_{\mathrm{M}}$ & 15.7 & 15.0 & 13.4 & 12.7 & 15.6 & 15.0 & 13.4 & 12.8 & 15.6 & 14.9 & 13.4 & 12.8 \\
\hline$\delta \mathrm{T}_{\mathrm{DW}}$ & 1.8 & 1.7 & 1.5 & 1.4 & 1.7 & 1.7 & 1.5 & 1.4 & 1.7 & 1.7 & 1.5 & 1.4 \\
\hline$\delta T_{A G}$ & 16.0 & 16.9 & 19.0 & 19.8 & 14.8 & 15.6 & 17.2 & 17.8 & 13.8 & 14.4 & 15.7 & 16.2 \\
\hline$\delta \mathrm{T}_{I}$ & 3.7 & 4.1 & 5.0 & 5.5 & 5.0 & 5.5 & 6.7 & 7.3 & 6.2 & 6.7 & 8.2 & 8.8 \\
\hline $\mathrm{Q}$ & .242 & .231 & .206 & .195 & .241 & .231 & .207 & .197 & .240 & .230 & .207 & .198 \\
\hline
\end{tabular}


TABLE A3-15. Alum.inum Cable Ampacity at Norma1 Load (Conductor at $90^{\circ} \mathrm{C}$; and at Overload (Conductor at $130^{\circ} \mathrm{C}$ ) Cable in Duct, 600 Volt Cable

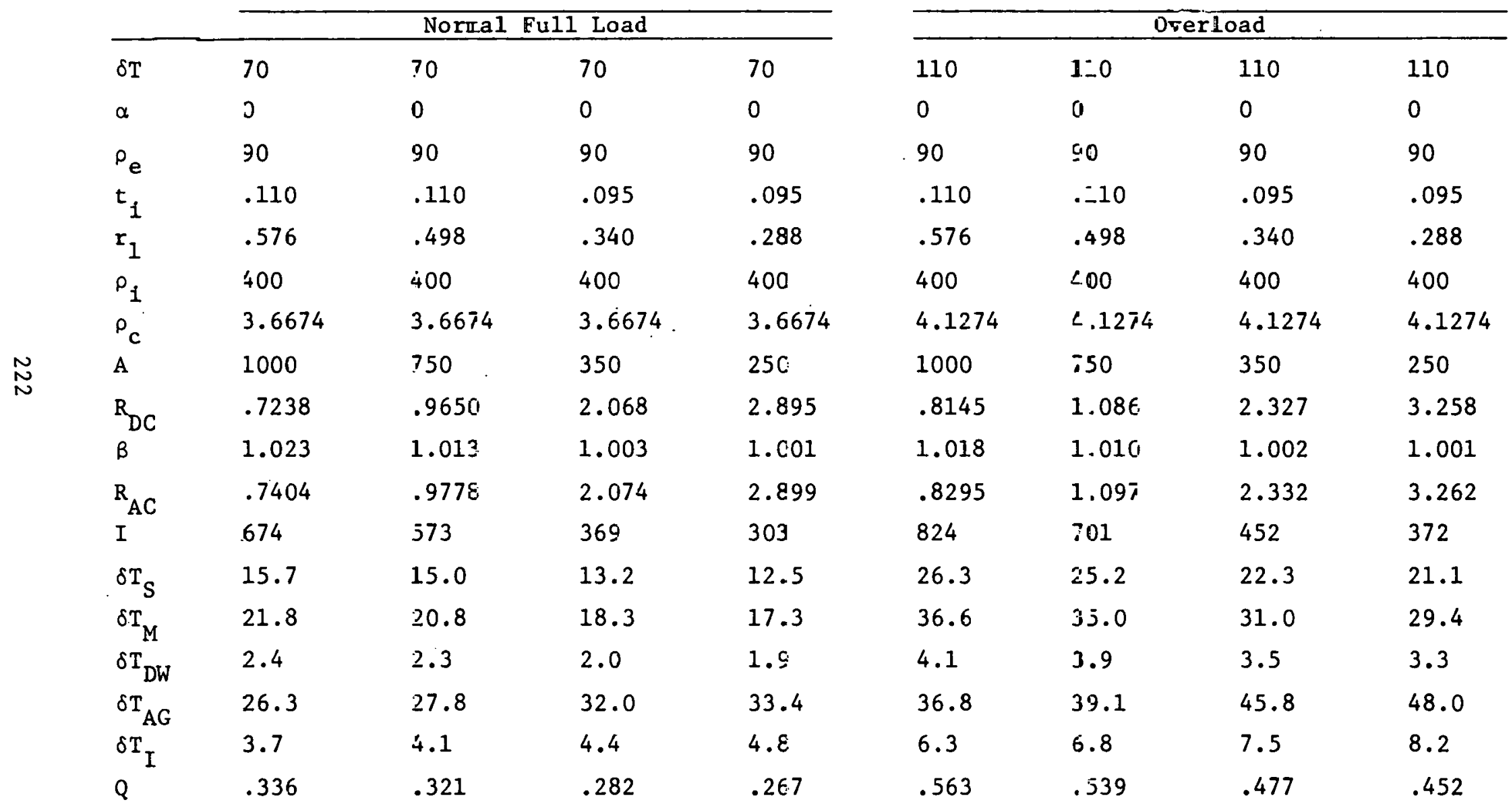

Insulation thicknesses employed above are those specified by IPCEA S61 402 For normal HMWPE. 
TABLE A3-16. Sodium Cable Ampacity at Overload (Conductor at $95^{\circ} \mathrm{C}$ ) and Conductor Temperature at Normal Load Current, Cable in Duct, 600 Volt Cable

\begin{tabular}{|c|c|c|c|c|c|c|c|c|}
\hline \multirow[b]{2}{*}{$\delta \mathrm{T}$} & \multicolumn{4}{|c|}{ Overload } & \multicolumn{4}{|c|}{ Normal Load } \\
\hline & 75 & 75 & 75 & 75 & 44.5 & 44.5 & 44.5 & 44.5 \\
\hline$\alpha$ & 0 & 0 & 0 & 0 & 0 & 0 & 0 & 0 \\
\hline$\rho_{e}$ & 90 & 90 & 90 & 90 & 90 & 90 & 90 & 90 \\
\hline$t_{i}$ & .125 & .125 & .110 & .110 & .125 & .125 & .110 & .110 \\
\hline$r_{1}$ & .745 & .643 & .437 & .369 & .745 & .643 & .437 & .369 \\
\hline$P_{i}$ & 400 & 400 & 400 & 400 & 400 & 400 & 400 & 400 \\
\hline$\rho_{\mathrm{c}}$ & 6.272 & 6.272 & 6.272 & 6.272 & 5.1963 & 5.1963 & 5.1963 & 5.1963 \\
\hline A & 2220 & 1654 & 764 & 545 & 2220 & 1654 & 764 & 545 \\
\hline $\mathrm{R}_{\mathrm{DC}}$ & .5576 & .7484 & 1.620 & 2.271 & .4619 & .6200 & 1.342 & 1.882 \\
\hline 6 & 1.038 & 1.022 & 1.005 & 1.002 & 1.054 & 1.031 & 1.007 & 1.003 \\
\hline${ }^{\mathrm{R}}{ }_{\mathrm{AC}}$ & .5786 & .7645 & 1.628 & 2.276 & .4867 & .6392 & 1.351 & 1.888 \\
\hline I & 824 & 701 & 452 & 372 & 673 & 573 & 370 & 304 \\
\hline$\delta \mathrm{T}_{\mathrm{S}}$ & 18.4 & 17.6 & 15.6 & 14.7 & 10.3 & 9.8 & 8.6 & 8.2 \\
\hline$\delta T_{M}$ & 25.5 & $24: 4$ & 21.6 & 20.4 & 14.3 & 13.6 & 12.0 & 11.3 \\
\hline$\delta \mathrm{T}_{\mathrm{DW}}$ & 2.8 & 2.7 & 2.4 & 2.3 & 1.6 & 1.5 & 1.3 & 1.3 \\
\hline$\delta \mathrm{T}_{\mathrm{AG}}$ & 24.4 & 26.0 & 30.7 & 32.3 & 16.1 & 17.1 & 19.9 & 20.8 \\
\hline$\delta T_{I}$ & 3.9 & 4.3 & 4.8 & 5.2 & 2.2 & 2.4 & 2.6 & 2.9 \\
\hline Q & .393 & .376 & .333 & .315 & .220 & .210 & .185 & .175 \\
\hline
\end{tabular}


TABLE A3-17. Sodium Catle Ampacity at Dverload (Conductor at $95^{\circ} \mathrm{C}$ ) and Conductor Temperature at Normal Load Current, Cable in Duct, 600 Volt Cajle

\begin{tabular}{|c|c|c|c|c|c|c|c|c|}
\hline \multirow[b]{2}{*}{$\delta \mathrm{T}$} & \multicolumn{4}{|c|}{ Overload } & \multicolumn{4}{|c|}{ Normal Load } \\
\hline & 75 & 75 & 75 & 75 & 44.5 & 44.5 & 44.5 & 44.5 \\
\hline$\alpha$ & $D$ & 0 & 0 & 0 & 0 & $a$ & 0 & 0 \\
\hline$\rho_{e}$ & 30 & 90 & 90 & 90 & 90 & $\leqq 0$ & 90 & 90 \\
\hline$t_{1}$ & .160 & .160 & .160 & .160 & .160 & .160 & .160 & .160 \\
\hline$r_{1}$ & .746 & .643 & .436 & $.3 \in 8$ & .746 & .643 & .436 & .368 \\
\hline$\rho_{i}$ & 400 & 400 & 400 & 400 & 400 & 400 & 400 & 400 \\
\hline$\rho_{c}$ & 6.272 & 6.272 & 6.272 & 6.272 & 5.1963 & 5.1963 & 5.1963 & 5.1963 \\
\hline A & 2226 & 1654 & 760 & 542 & 2226 & 1654 & 760 & 542 \\
\hline $\mathrm{R}_{\mathrm{DC}}$ & .5561 & .7484 & 1.629 & 2.284 & .4607 & .6200 & 1.349 & 1.892 \\
\hline$B$ & 1.038 & 1.022 & 1.005 & 1.002 & 1.054 & 1.031 & 1.007 & 1.003 \\
\hline $\mathrm{R}_{\mathrm{AC}}$ & .5771 & .7645 & 1.636 & 2.289 & .4855 & .639 .2 & 1.358 & 1.898 \\
\hline I & 824 & 701 & 452 & 372 & 674 & 574 & 370 & 305 \\
\hline$\delta \mathrm{T}_{\mathrm{S}}$ & 18.3 & 17.6 & 15.6 & 14.8 & 10.3 & 9.8 & 8.7 & 8.2 \\
\hline$\delta \mathrm{T}_{\mathrm{M}}$ & 25.5 & 24.4 & 21.7 & 20.6 & 14.3 & 13.7 & 12.1 & 11.4 \\
\hline$\delta T_{D W}$ & 2.8 & 2.7 & 2.4 & 2.3 & 1.6 & 1.5 & 1.3 & 1.3 \\
\hline$\delta T_{A G}$ & 23.5 & $25.1)$ & 28.7 & 30.1 & 15.6 & 16.5 & 18.7 & 19.5 \\
\hline$\delta \mathrm{T}_{\mathrm{I}}$ & 4.9 & 5.3 & 6.6 & 7.3 & 2.7 & 3.0 & 3.7 & 4.0 \\
\hline$Q^{2}$ & .392 & .376 & .333 & .317 & .220 & .210 & .186 & .176 \\
\hline
\end{tabular}

Insulation thicknesses above a=e all .160 in. 
TABLE A3-18. Sodium Cable Ampacity at Overload (Conductor at $95^{\circ} \mathrm{C}$ ) and Conductor Temperature at Normal Load Current, Cable in Duct, 600 Vo1t Cable

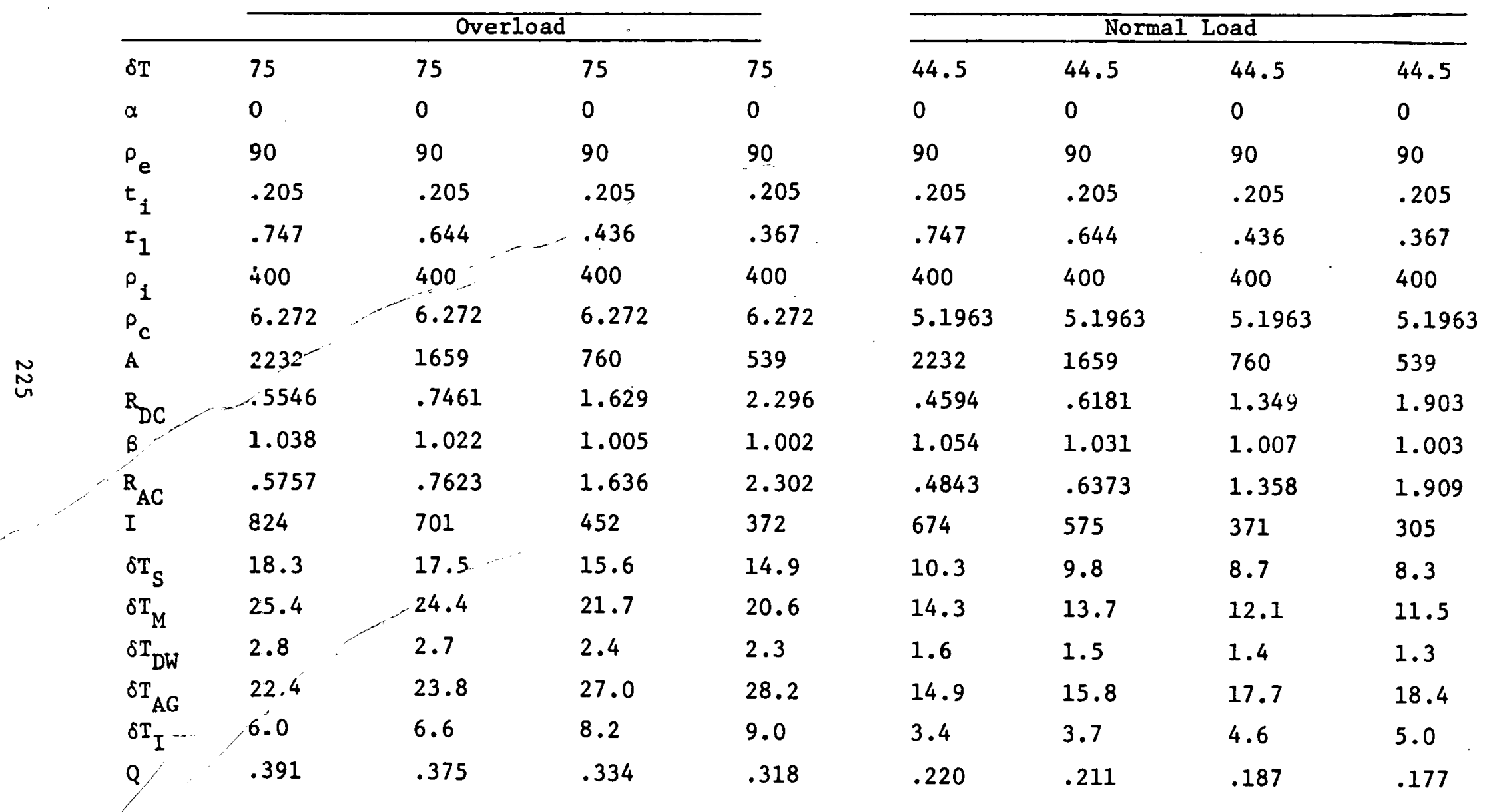

Insulation thicknesses above are all .205 in. 
TABLE A3-19. Sensitivity of Sodium Cable Ampacity tc Insulation Thickness Lirect Burial, Sodium at $69^{\circ} \mathrm{C}$

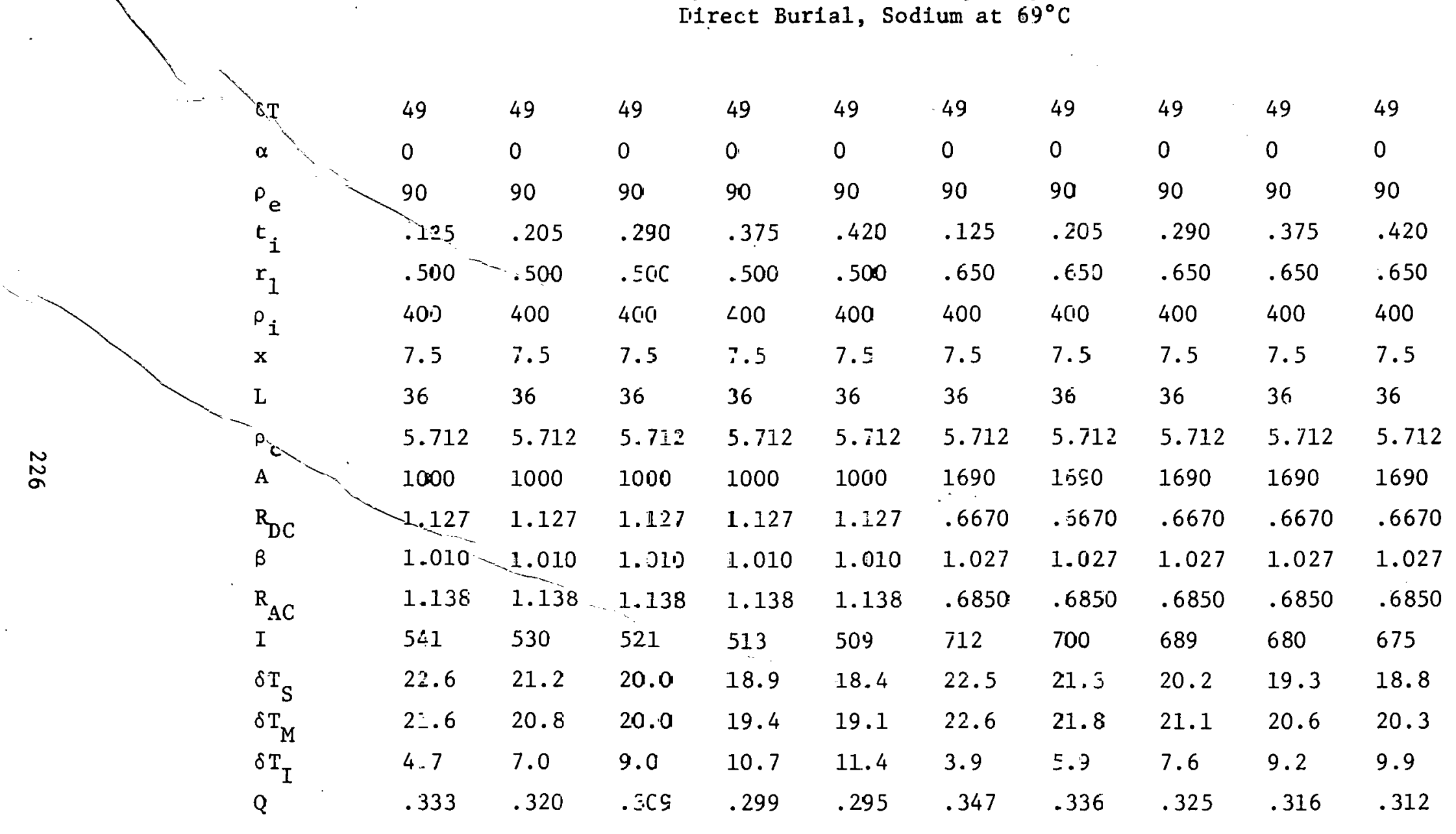

This table ccntinced on next paze. 
TABLE A3-19 cont. Sensitivity of Sodium Cable Ampacity to Insulation Thickness Direct Burial; Sodium at $69^{\circ} \mathrm{C}$

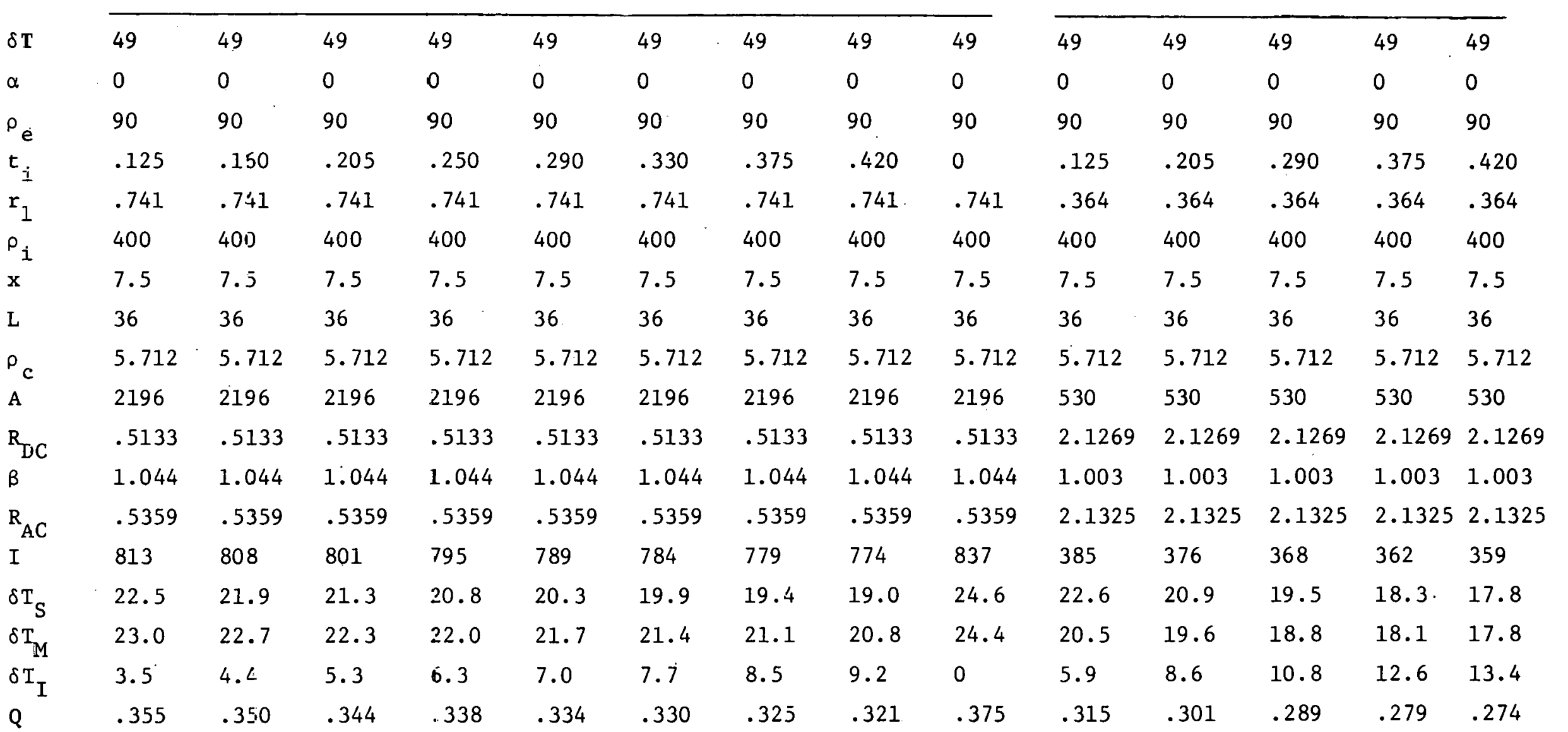


ZABLE A3-20. Sensitivity of Sodium Cable Ampacity to Insulation Thickness Cable in Duct; Sodium at $E 9^{\circ} \mathrm{C}$

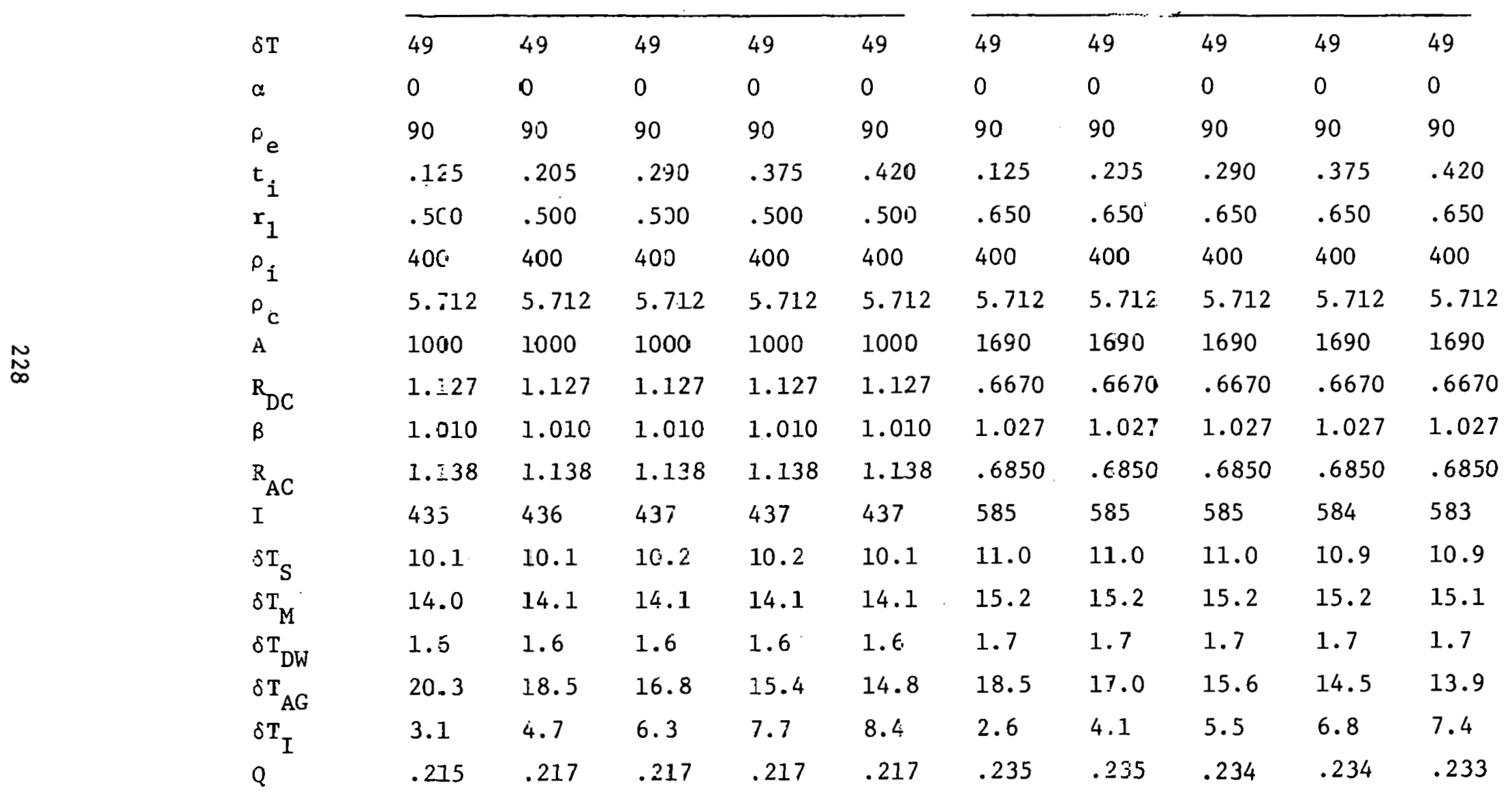

This tajle continued on next page. 
TABLE A3-20 cont. Sensitivity of Sodium Cable Ampacity to Insulation Thickness Cable in Duct; Sodium at $69^{\circ} \mathrm{C}$

\begin{tabular}{|c|c|c|c|c|c|c|c|c|c|c|c|c|c|}
\hline$\delta \mathrm{T}$ & 49 & 49 & 49 & 49 & 49 & 49 & 49 & 49 & 49 & 49 & 49 & 49 & 49 \\
\hline$\alpha$ & 0 & 0 & 0 & 0 & 0 & 0 & 0 & 0 & 0 & 0 & 0 & 0 & 0 \\
\hline$\rho_{e}$ & 90 & 90 & 90 & 90 & 90 & 90 & 90 & 90 & 90 & $90^{\circ}$ & 90 & 90 & 90 \\
\hline$t_{i}$ & .125 & .160 & .205 & .250 & .290 & مذjز . & .375 & .420 & .125 & .205 & .290 & .375 & .420 \\
\hline$r_{1}$ & .741 & .741 & .741 & .741 & .741 & .741 & .741 & .741 & .364 & .364 & .364 & .364 & .364 \\
\hline$\rho_{i}$ & 400 & 400 & 400 & 400 & 400 & 400 & 400 & 400 & 400 & 400 & 400 & 400 & 400 \\
\hline$\rho_{c}$ & 5.712 & 5.712 & 5.712 & 5.712 & 5.712 & 5.712 & 5.712 & 5.712 & 5.712 & 5.712 & 5.712 & 5.712 & 5.712 \\
\hline A & 2196 & 2196 & 2196 & 2196 & 2196 & 2196 & 2196 & 2196 & 530 & 530 & 530 & 530 & 530 \\
\hline$R_{D C}$ & .5133 & .5133 & .5133 & .5133 & .5133 & .5133 & .5133 & .5133 & 2.127 & 2.127 & 2.127 & 2.127 & 2.127 \\
\hline$\beta$ & 1.044 & 1.044 & 1.044 & 1.044 & 1.044 & 1.044 & 1.044 & 1.044 & 1.003 & 1.003 & 1.003 & 1.003 & 1.003 \\
\hline $\mathrm{R}_{\mathrm{AC}}$ & .5359 & .5359 & .5359 & .5359 & .5359 & .5359 & .5359 & .5359 & 2.132 & 2.132 & 2.132 & 2.132 & 2.132 \\
\hline I & 675 & 675 & 675 & 674 & 674 & 673 & 672 & 671 & 302 & 304 & 305 & 306 & 306 \\
\hline$\delta \mathrm{T}_{\mathrm{S}}$ & 11.4 & 11.4 & 11.4 & 11.4 & 11.4 & 11.3 & 11.3 & 11.3 & 9.1 & 9.2 & 9.3 & 9.3 & 9.3 \\
\hline$\delta \mathrm{T}_{\mathrm{M}}$ & 15.9 & 15.9 & 15.8 & 15.8 & 15.8 & 15.8 & 15.7 & 15.7 & 12.6 & 12.8 & 12.9 & 12.9 & 12.9 \\
\hline$\delta \mathrm{T}_{\mathrm{DW}}$ & 1.8 & 1.8 & 1.8 & 1.8 & 1.8 & 1.8 & 1.8 & 1.7 & 1.4 & 1.4 & 1.4 & 1.4 & 1.4 \\
\hline$\delta \mathrm{T}_{\mathrm{AG}}$ & 17.5 & 16.9 & 15.2 & 15.5 & 15.0 & 14.5 & 13.9 & 13.4 & 22.3 & 20.0 & 18.0 & 16.3 & 15.6 \\
\hline$\delta \mathrm{T}_{\mathrm{I}}$ & 2.4 & 3.0 & 3.8 & 4.5 & 5.1 & 5.7 & 6.3 & 6.9 & 3.6 & 5.6 & 7.4 & 9.0 & 9.7 \\
\hline $\mathrm{Q}$ & .244 & .244 & .244 & .244 & .243 & .243 & .242 & .241 & .194 & .197 & .198 & .199 & .199 \\
\hline
\end{tabular}


TABLE A3-21. An Example of Na-Al Equivalence at $\rho_{e}=130$ $25 \mathrm{kV}$ Insulation; A1 $1000 \mathrm{KCM}$ Direct Burial

\begin{tabular}{|c|c|c|c|c|}
\hline & $\begin{array}{c}\text { A1 } \\
\text { Nozina } 1 \\
\end{array}$ & $\begin{array}{c}\text { Al } \\
\text { Overload }\end{array}$ & $\begin{array}{c}\text { Na } \\
\text { Overload }\end{array}$ & $\begin{array}{l}\mathrm{Na}^{-\cdots} \\
\text { Normal }\end{array}$ \\
\hline $8 \mathrm{~T}$ & 70 & 110 & 75 & 49 \\
\hline$\alpha$ & 0 & 0 & 0 & 0 \\
\hline$\rho_{e}$ & 130 & 130 & 130 & 130 \\
\hline$t_{1}$ & .305 & .305 & .290 & .290 \\
\hline$r_{1}$ & .576 & .576 & .736 & .736 \\
\hline$\rho_{i}$ & 400 & 400 & 400 & 400 \\
\hline $\mathrm{x}$ & 7.5 & 7.5 & 7.5 & 7.5 \\
\hline L & 36 & 36 & 36 & 36 \\
\hline$\rho_{\mathrm{c}}$ & 3.6674 & 4.1274 & 6.272 & 5.712 \\
\hline A & 1000 & $10 n n$ & 2167 & 2167 \\
\hline $\mathrm{R}_{\mathrm{DC}}$ & .7237 & .8145 & .5711 & .5201 \\
\hline$\beta$ & 1.0230 & 1.018 & 1.035 & 1.042 \\
\hline $\mathrm{R}_{\mathrm{AC}}$ & .7404 & .8292 & .5911 & .5420 \\
\hline I & 667.9 & 791 & 791 & 667.5 \\
\hline$\delta \mathrm{T}_{\mathrm{S}}$ & 30.1 & 47.3 & 32.5 & 21.2 \\
\hline$\delta \mathrm{T}_{\mathrm{M}}$ & 31.0 & 48.7 & 34.7 & 22.7 \\
\hline$\delta \overline{\mathrm{T}}_{\mathrm{I}}$ & 8.9 & 14.0 & 7.8 & 5.1 \\
\hline$Q$ & .330 & .519 & .370 & .241 \\
\hline
\end{tabular}


TABLE A3-22. An Example of Na-Al Equivalence at $\alpha=1$

$25 \mathrm{kV}$ Insulation; Al $1000 \mathrm{KCM}$

Direct Burial

\begin{tabular}{|c|c|c|c|c|}
\hline & $\begin{array}{c}\text { A1 } \\
\text { Normal }\end{array}$ & $\begin{array}{c}A 1 \\
\text { Overload }\end{array}$ & $\begin{array}{c}\mathrm{Na} \\
\text { Overload }\end{array}$ & $\begin{array}{c}\text { Na } \\
\text { Normal }\end{array}$ \\
\hline$\delta \mathrm{T}$ & 70 & 110 & 75 & 49 \\
\hline$\alpha$ & 1 & 1 & 1 & 1 \\
\hline$\rho_{\mathrm{e}}$ & 90 & 90 & 90 & 90 \\
\hline$t_{i}$ & .305 & .305 & .290 & .290 \\
\hline$r_{1}$ & .576 & .576 & .739 & .739 \\
\hline$\rho_{1}$ & 400 & 400 & 400 & 400 \\
\hline$x$ & 7.5 & 7.5 & 7.5 & 7.5 \\
\hline L & 36 & 36 & 36 & 36 \\
\hline$\rho_{c}$ & 3.6674 & 4.1274 & 6.272 & 5.712 \\
\hline $\mathrm{A}$ & 1000 & 1000 & 2184 & 2184 \\
\hline $\mathrm{R}_{\mathrm{DC}}$ & .7237 & .8145 & .5667 & .5161 \\
\hline$B$ & 1.023 & 1.018 & 1.036 & 1.043 \\
\hline $\mathrm{R}_{\mathrm{AC}}$ & .7404 & .8292 & .5871 & .5383 \\
\hline I & 578 & 684.6 & 684.5 & 578 \\
\hline$\delta \mathrm{T}_{\mathrm{S}}$ & 31.2 & 49.0 & 33.5 & 21.9 \\
\hline$\delta \mathrm{T}_{\mathrm{M}}$ & 32.1 & 50.5 & 35.7 & 23.3 \\
\hline$\delta T_{I}$ & 6.7 & 10.5 & 5.8 & 3.8 \\
\hline$Q$ & .247 & .389 & .275 & .180 \\
\hline
\end{tabular}


TABLE A3-23. Cable In Duct Ampacity Salculations to Ver-fy Against IPCEA Tables

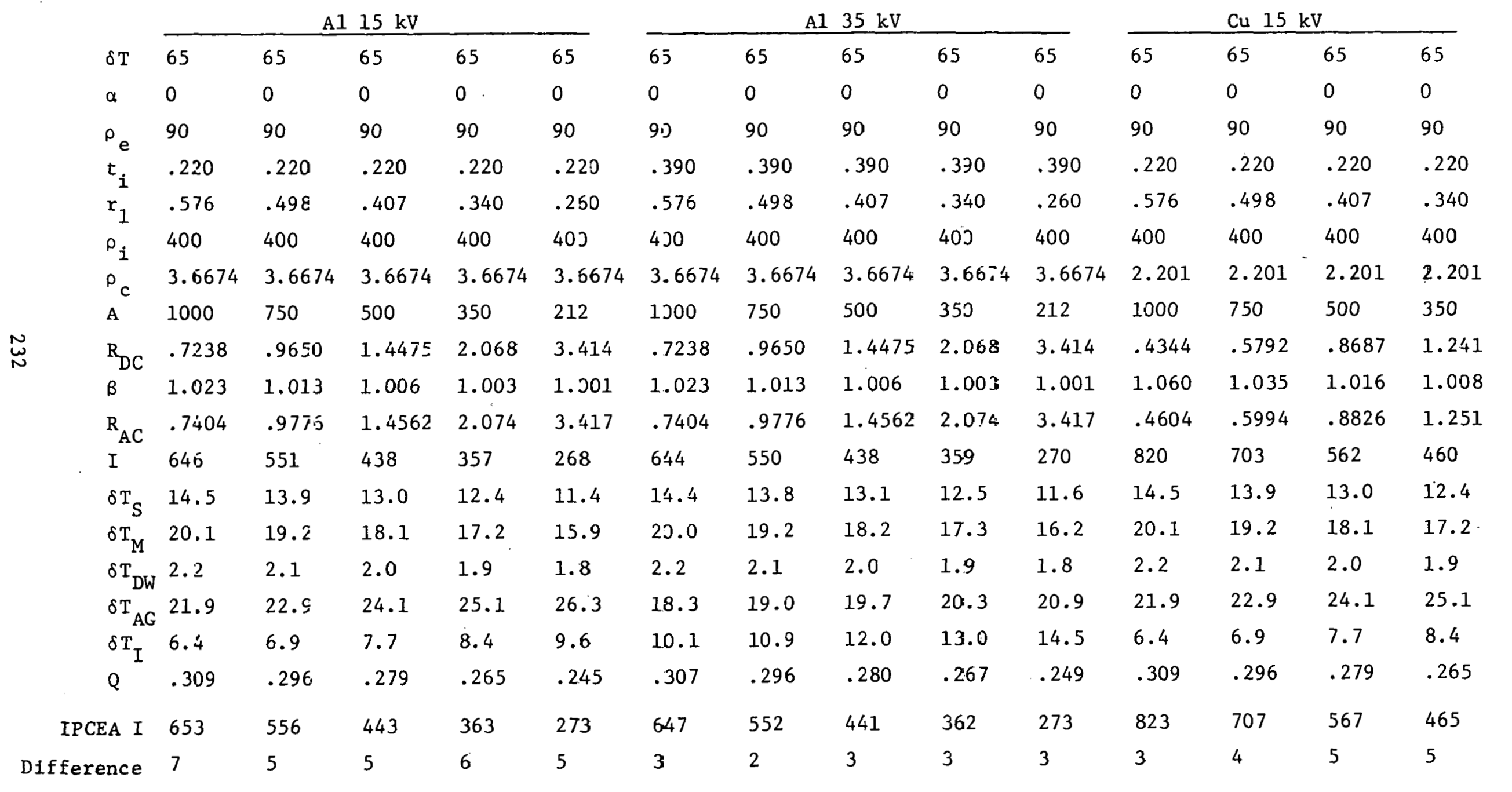


TABLE A3-24. Direct Burial Ampacity Calculations to Verify Against IPCEA Tables

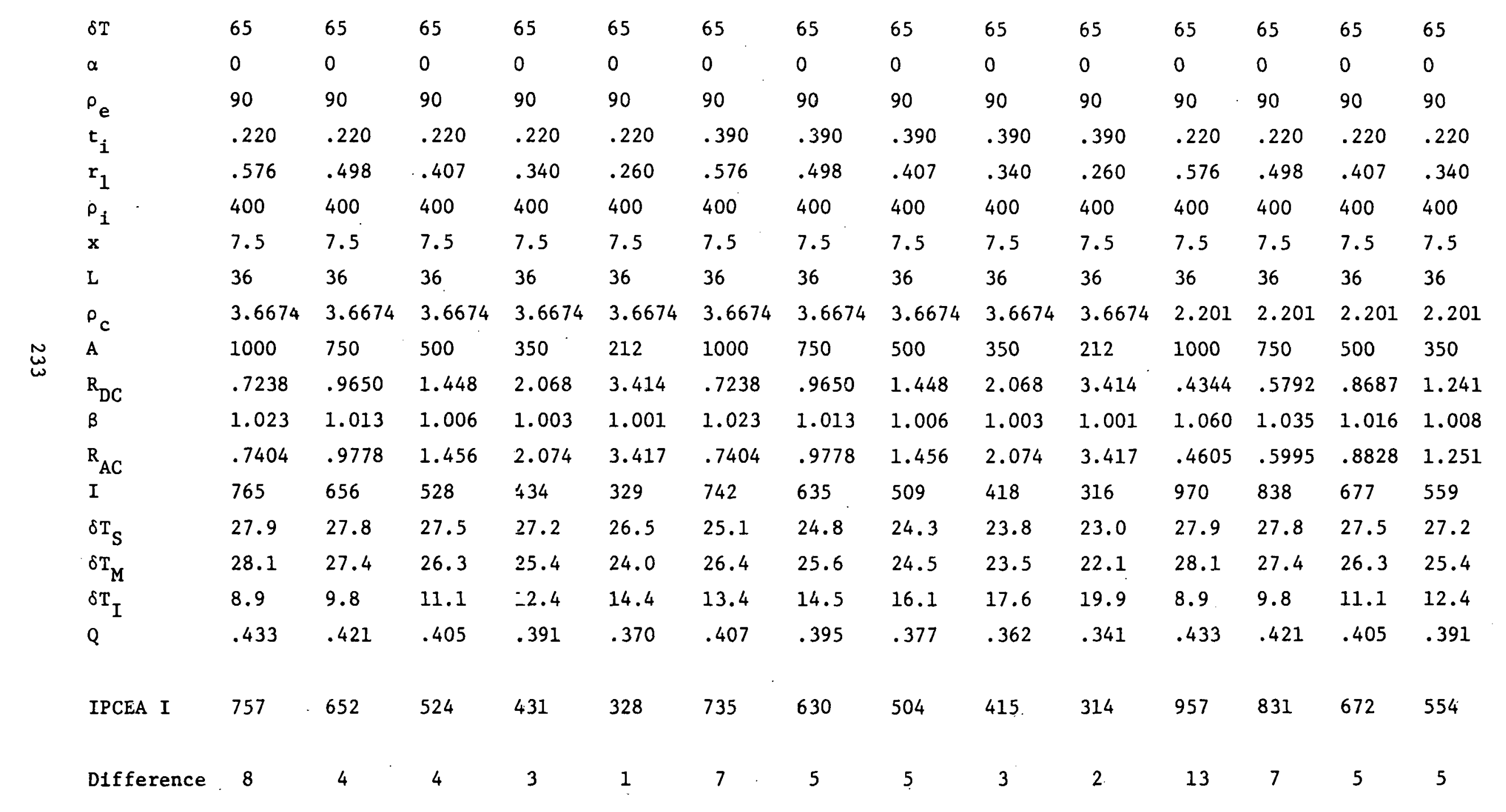




\section{APPENDIX A4}

Aluminum and Sodium Cable Cost Details 
TABLE A4-1

$15 \mathrm{kV}$ Aluminum and Sodium Cost Details

$15 \mathrm{~kg}$ Aluminum Distribution Cable Costs ( $\mathrm{c} / \mathrm{ft.}$ )

$250 \mathrm{MCM} \quad 350 \mathrm{MCM} \quad \underline{750 \mathrm{MCM}} \quad 1000 \mathrm{MCM}$

Cost Allocation

$\begin{array}{lrrrr}\text { Conductor } & 12.79 & 17.91 & 38.38 & 51.17 \\ \text { Conductor Screen } & 1.02 & 1.21 & 1.75 & 2.02 \\ \text { Insulation } & 10.02 & 11.38 & 15.43 & 17.41 \\ \text { Insulation Screen } & 3.41 & 3.78 & 4.87 & 5.41 \\ \text { Concentric Neutral } & 10.59 & 14.83 & 31.77 & 42.37 \\ \text { Material Subtotal } & 37.85 & 49.10 & 92.21 & 118.38 \\ \text { Other Direct and } & 40.50 & 44.22 & 42.98 & 63.00 \\ \quad \text { Indirect Product Costs } & & & & \\ \text { Electric Utility Price } & 78.35 & 93.32 & 135.19 & 181.38\end{array}$

$15 \mathrm{kV}$ Sodium Distribution Cable Costs (c/ft.)

$250 \mathrm{MCM} \quad 350 \mathrm{MCM} \quad 750 \mathrm{MCM} \quad 1000 \mathrm{MCM}$

\section{Cost Allocation}

Conductor
Conductor Screen
Insulation
Insulation Screen
Concentric Neutral
terial Subtotal
Indirect Product Costs

$\begin{array}{rrrr}3.14 & 4.40 & 9.43 & 12.58 \\ 0.00 & 0.00 & 0.00 & 0.00 \\ 8.68 & 9.85 & 13.38 & 15.10 \\ 3.05 & 3.37 & 4.32 & 4.78 \\ 6.39 & 8.95 & 19.17 & 25.56 \\ 21.26 & 26.57 & 46.30 & 58.02 \\ 30.78 & 33.81 & 44.00 & 55.65\end{array}$

Electric Utility Price

52.04

$60.18 \quad 90.30$

113.67 
TABLE $14-2$

$25 \mathrm{k}: \mathrm{V}$ Aluminum and Sodium Cable Cost Details

$25 \mathrm{EV}$ Aluminum Distribution Cable Costs (c/ft.)

$250 \mathrm{MCM} \quad 350 \mathrm{MCM} \quad 750 \mathrm{FCM} \quad 1000 \mathrm{MCM}$

Cost Allocation

$\begin{array}{lccrr}\text { Conductor } & 12.79 & 17.91 & 38.58 & 51.17 \\ \text { Conductor Screen } & 1.02 & 1.21 & 1.75 & 2.02 \\ \text { Insulation } & 16.52 & 18.53 & 24.55 & 27.50 \\ \text { Insulation Screen } & 4.00 & 4.37 & 5.56 & 5.00 \\ \text { Concentric Neutral } & 10.59 & 14.83 & 31.78 & 42.37 \\ \text { Material Subtota: } & 44.93 & 56.84 & 101.52 & 129.05 \\ \text { Other Direct and Indirect } & 40.6 & 49.3 & 70.7 & 80.2 \\ \text { Product Costs. } & & & & \end{array}$

$\begin{array}{lllll}\text { Electric Ut:lity Price } & 85.53 & 106.14 & 172.6 .2 & 207.25\end{array}$

25: EV Sodium Distribution Cable Costs (c/ft.)

$250 \mathrm{MCM} \quad 350 \mathrm{MCM} \quad 250 \mathrm{MCM} \quad 1000 \mathrm{MCM}$

\section{Cost Allocation}

$\begin{array}{lrrrr}\text { Conductor } & 3.14 & 4.40 & 9.43 & 12.58 \\ \text { Conductor Screen } & 0.0 \mathrm{C} & 0.00 & 0.010 & 0.00 \\ \text { Insulation } & 14.51 & 16.26 & 21.5 .0 & 24.06 \\ \text { Insulation Screen } & 3.64 & 3.96 & 4.91 & 5.37 \\ \text { Concentric Neutral } & 6.39 & 8.95 & 19.17 & 25.56 \\ \text { Material Subtota- } & 27.69 & 33.57 & 55.01 & 67.57 \\ \text { Other Direct and Indirect } & 28.42 & 34.51 & 49.49 & 55.14 \\ \quad \text { Product Costs. } & & & & \\ \text { Electric Utility Price } & 56.11 & 68.08 & 104.50 & 123.71\end{array}$


TABLE A4-3

$35 \mathrm{kV}$ Aluminum and Sodium Cost Details

$35 \mathrm{kV}$ Aluminum Distribution Cable Costs (c/ft.)

$250 \mathrm{MCM} \quad \underline{350 \mathrm{MCM}} \quad \underline{750 \mathrm{MCM}} \quad 1000 \mathrm{MCM}$

\section{Cost Allocation}

\begin{tabular}{|c|c|c|c|c|}
\hline $\begin{array}{l}\text { Conductor } \\
\text { Conductor Screen } \\
\text { Insulation } \\
\text { Insulation Screen } \\
\text { Concentric Neutral } \\
\text { terial Subtotal } \\
\text { her Direct and Indirect } \\
\text { Product Costs }\end{array}$ & $\begin{array}{r}12.79 \\
1.02 \\
24.06 \\
4.59 \\
10.59 \\
53.07 \\
44.53\end{array}$ & $\begin{array}{r}17.91 \\
1.21 \\
26.74 \\
4.96 \\
14.83 \\
65.64 \\
51.0\end{array}$ & $\begin{array}{r}38.38 \\
1.75 \\
34.73 \\
6.05 \\
31.78 \\
112.69 \\
83.20\end{array}$ & $\begin{array}{r}51.17 \\
2.02 \\
38.64 \\
6.58 \\
42.37 \\
140.78 \\
98.02\end{array}$ \\
\hline $\begin{array}{l}\text { lectric Utility Price } \\
35 \mathrm{kV} \text { Sodium }\end{array}$ & 97.60 & 116.64 & $\begin{array}{l}195.89 \\
(c / f t .) \\
\end{array}$ & 238.80 \\
\hline & $50 \mathrm{M}$ & $350 \mathrm{MCM}$ & $750 \mathrm{MCM}$ & $1000 \mathrm{MCM}$ \\
\hline
\end{tabular}

\section{Cost Allocation}

$\begin{array}{lcccc}\text { Conductor } & 3.14 & 4.40 & 9.43 & 12.58 \\ \text { Conductor Screen } & 0.0 & 0.0 & 0.0 & 0.0 \\ \text { Insulation } & 21.41 & 23.73 & 30.68 & 34.08 \\ \text { Insulation Screen } & 4.23 & 4.55 & 5.50 & 5.96 \\ \text { Concentric Neutral } & 6.39 & 8.95 & 19.17 & 25.56 \\ \text { Material Subtotal } & 35.17 & 41.63 & 64.79 & 78.18 \\ \text { Other Direct and Indirect } & 28.50 & 32.64 & 53.24 & 62.73 \\ \quad \text { Product Costs } & & & & \\ \text { Electric Utility Price } & 63.67 & 74.27 & 118.03 & 140.91\end{array}$


TABLE $\quad A 4-4$

600V Aluminum and Sodium Cost Details

60.JV Aluminum Distribution Cable Costs (c/ft.)

$250 \mathrm{MCM} \quad \underline{350 \mathrm{MCM}} \quad \mathbf{7 5 0 \mathrm { KCM }} \quad 1000 \mathrm{MCM}$

Cost Allocation

$\begin{array}{lrrrr}\text { Conductor } & 12.79 & 17.91 & 38.38 & 51.17 \\ \text { Conductor Screen } & 0.00 & 0.00 & 0.00 & 6.00 \\ \text { Insulation } & 4.96 & 5.73 & 8.05 & 9.18 \\ \text { Insulation Screen } & 0.00 & 0.00 & 0.00 & 0.00 \\ \text { Con:entric Neutral } & 0.00 & 0.00 & 0.03 & 0.00 \\ \text { aterial Subtotal } & 17.75 & 23.64 & 46.43 & 60.35 \\ \text { ther Direct and Indirect } & 23.0 & 33.5 & 63.0 & 93.13 \\ \text { Product Costs } & & & & \\ \text { lectric Utilitg Price } & 40.75 & 57.14 & 109.43 & 153.48\end{array}$

600V Sodium Distribution Cable Costs (c/ft. i

250 MCM $\quad 350$ MCM $\quad 750 \mathrm{MCM} \quad 1000 \mathrm{MCM}$

\section{Cost Allocation}

$\begin{array}{lrrrr}\text { Conductor } & 3.14 & 4.40 & 9.4 \Xi & 12.57 \\ \text { Conductor Screen } & 0.00 & 0.00 & 0.00 & 0.00 \\ \text { Insulation } & 4.41 & 5.08 & 7.09 & 8.08 \\ \text { Insulation Screen } & 0.00 & 0.00 & 0.00 & 0.00 \\ \text { Concentric Neutral } & 0.00 & 0.00 & 0.00 & 0.00 \\ \text { Material Subtotai } & 7.55 & 9.48 & 16.53 & 20.65 \\ \text { ther Direct and Indirect } & 10.58 & 15.41 & 33.47 & 42.85 \\ \text { Product Costs } & & & & \\ \text { lectric Utility Price } & \mathbf{1 8 . 1 3} & 24.89 & 50.00 & 63.50\end{array}$


APPENDIX A5

Connector Cost Details 
154LR

200-Amp Elbow Connector

(Deadbreak)

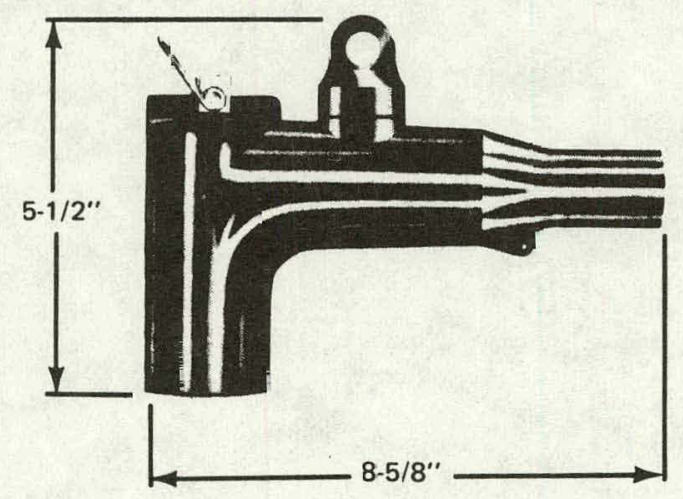

- One-piece molded rubber; fully shieldec

- For use on dead-tront transformers, switchgea! and motors.

- Hot-stick operable; plugs onto bushings installed on apparatus.

- $100 \%$ procuction test.

Voltage class $\ldots \ldots \ldots \ldots \ldots \ldots \ldots$ thru $25 \mathrm{kv}$ Current ratirg $\ldots \ldots \ldots \ldots \ldots \ldots \ldots \ldots .200$ amps
Cable insulation range $\ldots \ldots \ldots \ldots .495^{\prime \prime}$ to $1.175^{\prime \prime}$ Cable insulation range $\ldots \ldots \ldots \ldots . .495$ to $1.175^{4}$ Conducior renge ........ No. $4 \mathrm{Al} / \mathrm{Cu}$ thr $4{ }^{\prime}, 0 \mathrm{Al} / \mathrm{Cu}$
650LR

600-Amp, 15-kv and 25-kv Elbow Connector

(Deadbreak)

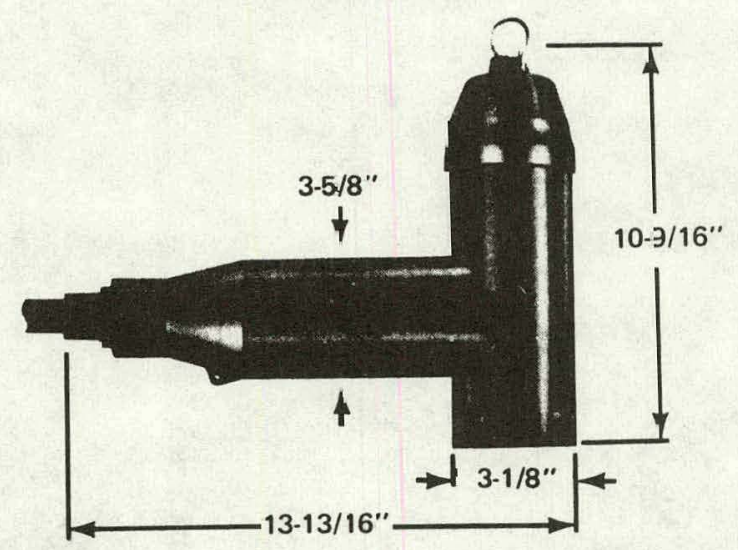

- One-piece molded rubber; fully st ielded.

- For use on dead-front transfcrme-s, switchgear and motors.

- Plugs onto bushirgs installed on apparatus or can be used with accessori modular splices (see pages 23 and 49).

- $100 \%$ production test.

Voltage class $\ldots \ldots \ldots \ldots \ldots \ldots \ldots . . \ldots \ldots$ thru $25 \mathrm{kv}$ Cable insulation range ......... $875^{\prime \prime}$ to $1.785^{\prime \prime}$ (22,2 $\mathrm{mm}$ to $45,3 \mathrm{~mm}$ ) Conductor range ...No. $2 \mathrm{Al} / \mathrm{Cu}$ thr $750 \mathrm{kcmil} \mathrm{Al} / \mathrm{Cu}$ $800 \mathrm{k.cmil} \mathrm{Al} \mathrm{thru} 1000 \mathrm{kcmil}$ Al

Figure A5-1. TYPICAL CABLE CONNECTORS SIVILAR TO THOSE ISED IN ESTIMAMING COSMS FOR 15 AHD $25 \mathrm{KV}$. WROM ELASTIMOLD CATALOGUE) 


\section{LR 200-Amp, 35-kv Elbow Connector (Deadbreak)}

\section{LR \\ 600-Amp 35-kv Elbow Connector (Deadbreak)}

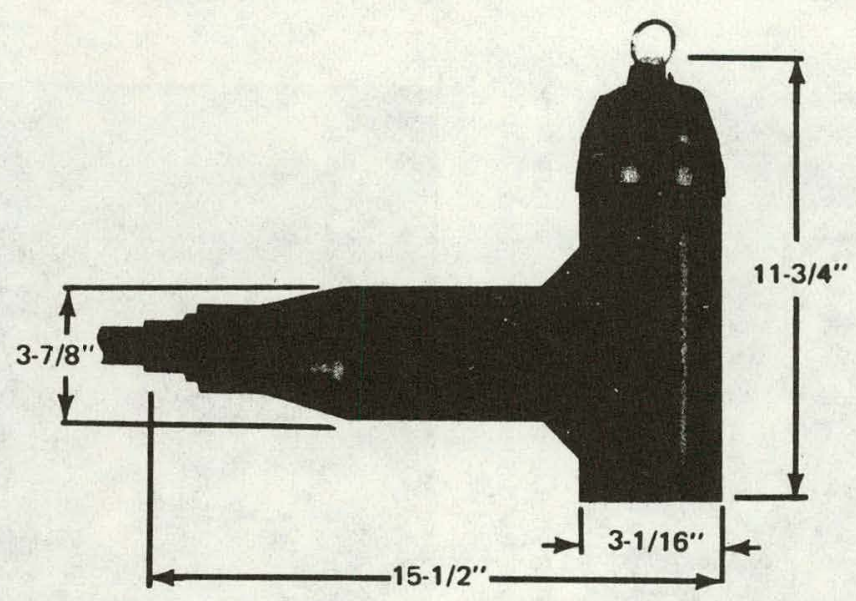

- One-piece molded rubber; fully shielded.

- For use on dead-front transformers, switchgear and motors.

- Plugs onto bushings installed on apparatus or can be used with accessories to form modular splices (see pages 26 and 51 ).

- $100 \%$ production test.

Voltage class

Current rating . . . . . . . . . Cable insulation range ......... $875^{\prime \prime}$ to $2.235^{\prime \prime}$

$(22,2 \mathrm{~mm}$ to $56.8 \mathrm{~mm}$

Conductor range ... 1/0 Al/Cu thru $750 \mathrm{kcmil} \mathrm{Al} / \mathrm{Cu}$ $800 \mathrm{kcmil} \mathrm{Al} \mathrm{thru} 1000 \mathrm{kcmil} \mathrm{Al}$ 


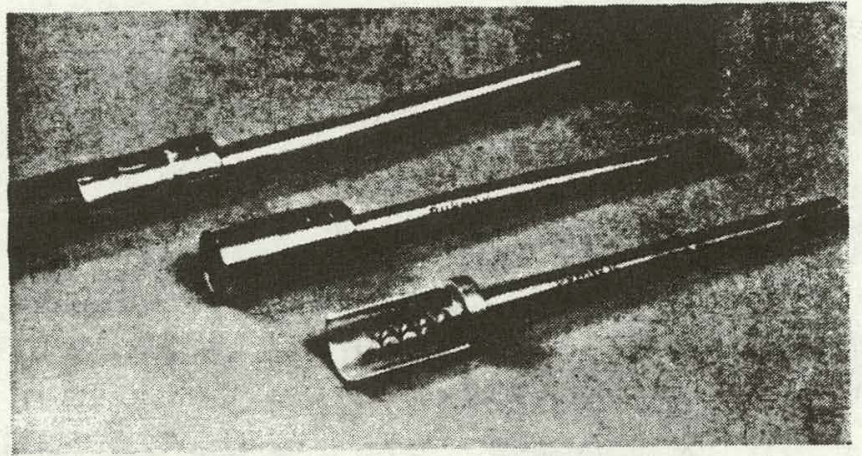

CORKSCREW CONNECTORS, shown completed, before connection and cut open, are used principally with $15-\mathrm{kV}$ cable

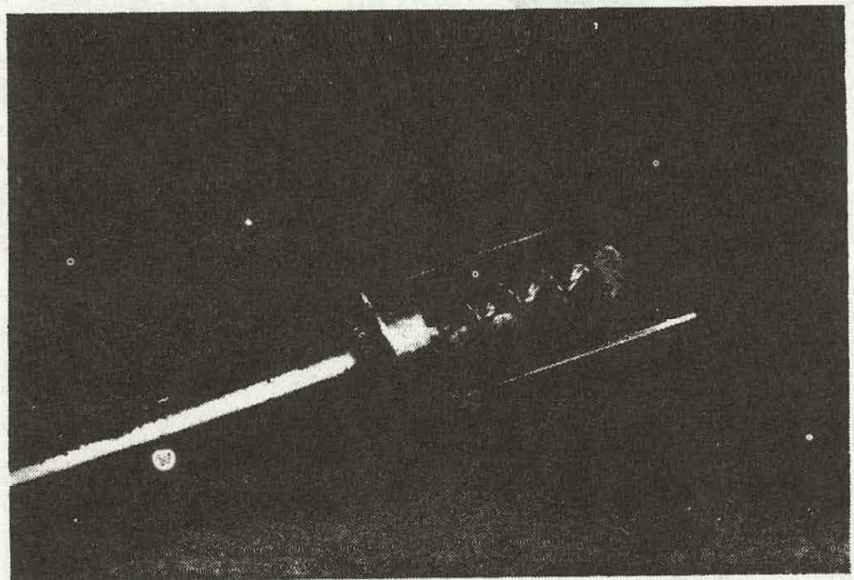

EXPOSED END of the conductor is completely enclosed by the connector before any penetration of the sodium by the screw

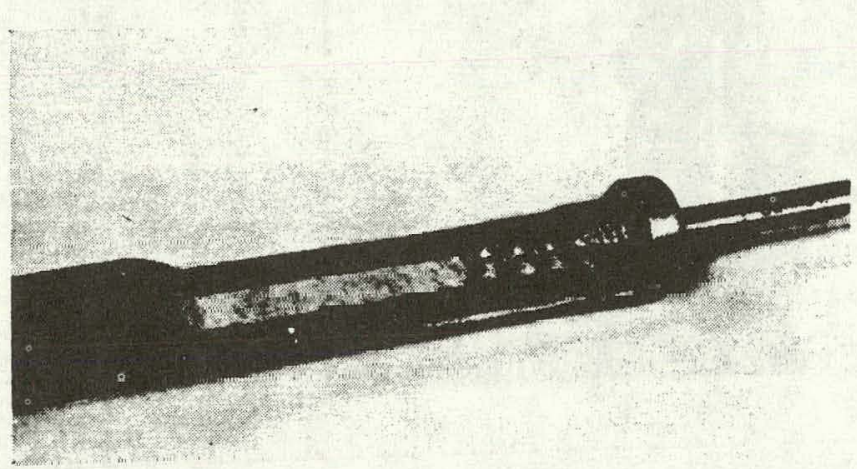

JOINT IS SEALFD by compressing the sleeve willı standard compression tool. Section view shows completed installation

Figure A5-3. SODIUM CABLE CONNECTORS (EROM 'SODIUM IS NEW CABLE CONDUCTOR' POWER , SEPT. 1968) 
Figure A5-4. TYPICAL 600 VOLT SECODARY CONNECTION SCHEME USED IN ESTIMATING COSTS.

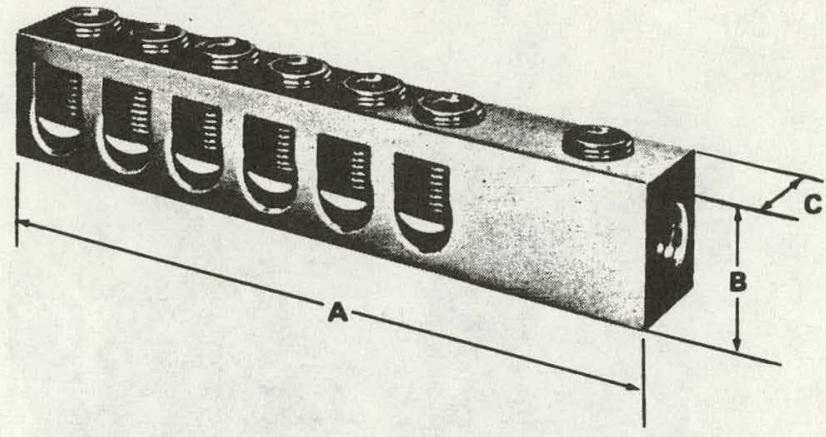

FOR USE ON TRANSFORMERS WITH THREADED STUD SECONDARY. DESIGNED FOR QUICK DISCONNECT WITHOUT REMOVING CONDUCTORS. INHIBITOR SUPPLIED IN STUD HOLE.

\begin{tabular}{|c|c|c|c|c|c|c|c|c|c|}
\hline \multirow{2}{*}{$\begin{array}{c}\text { Catalog } \\
\text { No. }\end{array}$} & \multicolumn{2}{|c|}{ Price Each } & \multirow{2}{*}{$\begin{array}{l}\text { No. of } \\
\text { Cond. }\end{array}$} & \multirow{2}{*}{$\begin{array}{l}\text { Cond. Range } \\
\text { AWG-MCM }\end{array}$} & \multirow{2}{*}{$\begin{array}{c}\text { For } \\
\text { Transformer } \\
\text { Stud }\end{array}$} & \multirow{2}{*}{$\begin{array}{l}\text { Lbs. Wt. } \\
\text { Per } 100\end{array}$} & \multicolumn{3}{|c|}{ Dimensions } \\
\hline & $1-99$ & 100 and Over & & & & & A & B & c \\
\hline PTF2-250-J & $\$ 4.95$ & $\$ 4.30$ & 2 & \multirow{6}{*}{$250-12$} & $5 / 8-11$ & 32 & $3-5 / 8$ & $1.1 / 8$ & $7 / 8$ \\
\hline PTF3-250-J & 6.25 & 5.45 & 3 & & $5 / 8-11$ & 36 & $4-3 / 8$ & $1-1 / 8$ & $7 / 8$ \\
\hline PTF4-250-J & 7.60 & 6.60 & 4 & & $5 / 8-11$ & 41 & $5-1 / 4$ & $1.1 / 8$ & $7 / 8$ \\
\hline PTF5-250-J & 8.85 & 7.70 & 5 & & $5 / 8-11$ & 45 & 6 & $1-1 / 8$ & $7 / 8$ \\
\hline PTF6-250-J & 10.25 & 8.90 & 6 & & 5/8-11 & 50 & $6-3 / 4$ & $1-1 / 8$ & $7 / 8$ \\
\hline PTF8-250-J & 12.30 & 10.70 & 8 & & $5 / 8-11$ & 58 & $8-3 / 8$ & $1-1 / 8$ & $7 / 8$ \\
\hline PTF2-350-J & 6.20 & 5.40 & 2 & \multirow{6}{*}{$350-12$} & $5 / 8-11$ & 40 & $4-1 / 4$ & $1-3 / 8$ & 1 \\
\hline PTF3-350-J & 7.65 & 6.65 & 3 & & $5 / 8-11$ & 46 & $5-1 / 8$ & $1.3 / 8$ & 1 \\
\hline PTF4-350-J & 9.10 & 7.90 & 4 & & $5 / 8-11$ & 52 & 6 & $1-3 / 8$ & 1 \\
\hline PTF5-350-J & 10.60 & 9.20 & 5 & & $5 / 8-11$ & 58 & $6-7 / 8$ & $1-3 / 8$ & 1 \\
\hline PTF6-350-J & 12.00 & 10.15 & 6 & & 5/8-11 & 65 & $7-3 / 4$ & $1-3 / 8$ & 1 \\
\hline PTF8-350-J & 14.95 & 13.00 & 8 & & 5/8-11 & 77 & $9.5 / 8$ & $1-3 / 8$ & 1 \\
\hline PTF2.500-J & 7.70 & 6.70 & 2 & \multirow{6}{*}{$500-2$} & $1-14$ & 48 & $4-3 / 8$ & $1.3 / 4$ & $1.3 / 8$ \\
\hline PTF3 $500 \mathrm{~J}$ & 9.50 & 8.25 & 3 & & $1-14$ & 58 & $5-1 / 2$ & $1-3 / 4$ & $1-3 / 8$ \\
\hline PTF4-500-J & 11.30 & 9.85 & 4 & & $1-14$ & 67 & $65 / 8$ & $1-3 / 4$ & $1-3 / 8$ \\
\hline PTF5-500-J & 13.15 & 11.45 & 5 & & 1.14 & 77 & $7.3 / 4$ & $1-3 / 4$ & $1-3 / 8$ \\
\hline PTF6-500-J & 14.95 & 13.00 & 6 & & 1.14 & 87 & $8-7 / 8$ & $1-3 / 4$ & $1-3 / 8$ \\
\hline PTF8-500-J & 18.50 & 16.10 & 8 & & $1-14$ & 103 & $11-1 / 8$ & $1-3 / 4$ & $1-3 / 8$ \\
\hline PTF3-750-J & 22.35 & 19.45 & 3 & \multirow{5}{*}{$750-1 / 0$} & $1-14$ & 235 & 6 & 2 & $2-1 / 2$ \\
\hline PTF 4.750-J & 26.45 & 23.00 & 4 & & $1-14$ & 282 & $8-5 / 8$ & 2 & $2 \cdot 1 / 2$ \\
\hline PTF5-750-J & 30.55 & 26.55 & 5 & & $1-14$ & 330 & $10-1 / 4$ & 2 & $2-1 / 2$ \\
\hline PTF6-750-J & 34.65 & 30.15 & 6 & & $1-14$ & 390 & $11-7 / 8$ & 2 & $2-1 / 2$ \\
\hline PTF8-750-J & 42.90 & 37.30 & 8 & & $9-14$ & 480 & $15-1 / 4$ & 2 & $2-1 / 2$ \\
\hline
\end{tabular}

NOTE. Tap for street light available.

For packaging with grease inhibitor add suffix "P" and $\$ 0.20$ each to price for $250 / 350$ and $\$ 0.30$ each for sUU connectors.

"For covers - Contact factory for price and delivery.

\section{THE UTILCO company}

4730 MADISON ROAD, CINCINNATI, OHIO 45227 - TELEPHONE 871-4000 AREA CODE 513 


\section{PLASTISOL COVERS FOR PTF STYLE CONNECTORS FITS PTF AND PTF-J}

Figure A5-5. TYPICAL CONNECTOR COVER USED IN COST ESTIMATING.

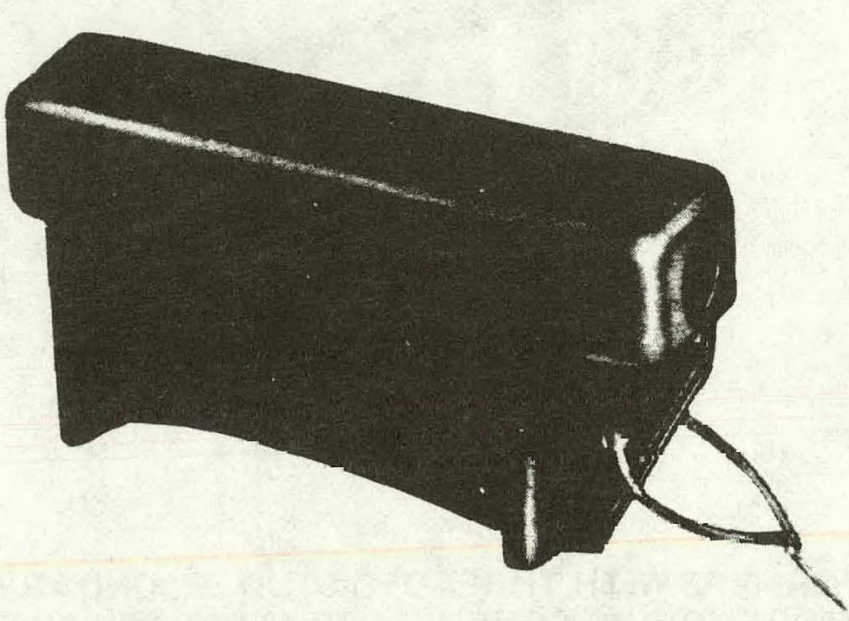

\begin{tabular}{|c|c|c|c|}
\hline \multirow{2}{*}{$\begin{array}{l}\text { Connector } \\
\text { Catalog } \\
\text { Number } \\
\text { PTF or PTF-J }\end{array}$} & \multicolumn{2}{|c|}{ Price Each } & \multirow{2}{*}{$\begin{array}{l}\text { Cover } \\
\text { Catalog } \\
\text { Number }\end{array}$} \\
\hline & $1-99$ & $100 \&$ Up & \\
\hline $\begin{array}{l}\text { PTF3-250 } \\
\text { PTF } 4-250 \\
\text { PTF5-250 } \\
\text { PTF 6-250 } \\
\text { PTF8-250 }\end{array}$ & $\begin{array}{r}\$ 3.45 \\
3.45 \\
3.45 \\
4.20 \\
4.90\end{array}$ & $\begin{array}{r}\$ 3.00 \\
3.00 \\
3.00 \\
3.65 \\
4.25\end{array}$ & $\begin{array}{l}R 6875 \\
R 6875 \\
R 6875 \\
R 6830 \\
R 6829\end{array}$ \\
\hline $\begin{array}{l}\text { PTF3-350 } \\
\text { PTF } 4350 \\
\text { PTF5-350 } \\
\text { PTF6-350 } \\
\text { PTF8-350 }\end{array}$ & $\begin{array}{l}3.45 \\
3.45 \\
4.20 \\
4.20 \\
4.90\end{array}$ & $\begin{array}{l}3.00 \\
3.00 \\
3.65 \\
3.65 \\
4.25\end{array}$ & $\begin{array}{l}\text { R } 6875 \\
R 6875 \\
R 6830 \\
R 6830 \\
R 6829\end{array}$ \\
\hline $\begin{array}{l}\text { PTF3-500 } \\
\text { PTF4-500 } \\
\text { PTF5-500 } \\
\text { PTF6-500 } \\
\text { PTF8-500 }\end{array}$ & $\begin{array}{l}\mathbf{5 . 2 5} \\
\mathbf{5 . 2 5} \\
\mathbf{5 . 5 5} \\
\mathbf{5 . 5 5} \\
\mathbf{5 . 9 0}\end{array}$ & $\begin{array}{l}4.55 \\
4.55 \\
4.85 \\
4.85 \\
5.15\end{array}$ & $\begin{array}{l}R 6260 \\
R \quad 6260 \\
R \quad 6265 \\
R \quad 6265 \\
R \quad 6831\end{array}$ \\
\hline $\begin{array}{l}\text { PTF-33-250 } \\
\text { PTF-44-250 } \\
\text { PTF } 33-250-1 \\
\text { PTF }-44-250-1\end{array}$ & $\begin{array}{l}5.3 n \\
5.30 \\
5.30 \\
5.30\end{array}$ & $\begin{array}{l}1.60 \\
4.60 \\
4.60 \\
4.60\end{array}$ & $\begin{array}{l}\text { R } 6880 \\
\text { R } 6880 \\
\text { R } 6880 \\
\text { R } 6880\end{array}$ \\
\hline $\begin{array}{l}\text { PTF-33-350 } \\
\text { PTF- } 44-350 \\
\text { PTF-33-350-1 } \\
\text { PTF-44-350-1 }\end{array}$ & $\begin{array}{l}5.30 \\
5.30 \\
5.30 \\
5.30\end{array}$ & $\begin{array}{l}4.60 \\
4.60 \\
1.60 \\
4.60\end{array}$ & $\begin{array}{l}R 6880 \\
R 6880 \\
R \quad 6880 \\
R 6880\end{array}$ \\
\hline $\begin{array}{l}\text { PTF-33-500 } \\
\text { PTF-44-500 }\end{array}$ & $\begin{array}{l}6.25 \\
6.25\end{array}$ & $\begin{array}{l}5.45 \\
5.45\end{array}$ & $\begin{array}{l}R 6881 \\
R 6881\end{array}$ \\
\hline
\end{tabular}




\section{TYPE CRA \& B}

FIgure A5-6. TYPICAL COPPER TYPE SECONDARY COINNECTORS USED IN DEVELOPING THE 'PIN TYPE' CONNECIION COSTS IN THIS REPORT.

TYPE CRA \& B

CRIMP TYPE TERMINAL LUGS SINGLE INDENT

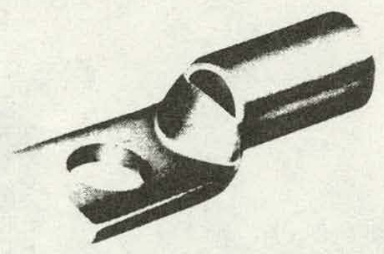

\begin{tabular}{|c|c|c|c|c|c|c|c|c|c|}
\hline \multirow[b]{2}{*}{$\begin{array}{c}\text { Catalog } \\
\text { No. }\end{array}$} & \multicolumn{2}{|c|}{ Price Per 100} & \multirow[b]{2}{*}{ Wire Size } & \multirow{2}{*}{$\begin{array}{l}\text { Pcs. } \\
\text { Per } \\
\text { Carton }\end{array}$} & \multirow[b]{2}{*}{$\begin{array}{l}\text { Shpg. Wt. } \\
\text { Lbs/100 }\end{array}$} & \multirow[b]{2}{*}{$\begin{array}{l}\text { Bolt } \\
\text { Size }\end{array}$} & \multirow[b]{2}{*}{$\begin{array}{c}\text { Tang } \\
\text { Length }\end{array}$} & \multirow[b]{2}{*}{$\begin{array}{l}\text { Overall } \\
\text { Length }\end{array}$} & \multirow[b]{2}{*}{ Width } \\
\hline & Carton & $\begin{array}{c}10 \text { or More } \\
\text { Cartons }\end{array}$ & & & & & & & \\
\hline CRA.8 & $\$ 26.30$ & $\$ 22.70$ & 8 Str. & 50 & 1.5 & $3 / 16$ & $1 / 2$ & $1.1 / 8$ & $13 / 32$ \\
\hline CRA-6 & 29.30 & 25.25 & 6. Str. & 50 & 1.8 & $3 / 16$ & $1 / 2$ & $1.1 / 2$ & $13 / 32$ \\
\hline CRB-6 & 29.30 & 25.25 & 6 Str. & 50 & 1.8 & $1 / 4$ & $1 / 2$ & $1.1 / 2$ & $13 / 32$ \\
\hline CRA-4 & 38.95 & 33.60 & 4 Str. & 50 & 2.1 & $3 / 16$ & $1 / 2$ & $1-1 / 2$ & $1 / 2$ \\
\hline CRB-4 & 38.95 & 33.60 & 4 Str. & 50 & 2.1 & $1 / 4$ & $1 / 2$ & $1-1 / 2$ & $1 / 2$ \\
\hline CRA-2 & 74.70 & 64.30 & 2 Str. & 25 & 3.6 & $1 / 4$ & $3 / 4$ & $1.27 / 32$ & $19 / 32$ \\
\hline CRB-2 & 74.70 & 64.30 & 2 Str. & 25 & 3.6 & $5 / 16$ & $3 / 4$ & $1.27 / 32$ & $19 / 32$ \\
\hline CRA-1 & 79.95 & 68.80 & $1 \mathrm{Str}$ & 10 & 3.6 & $5 / 16$ & $3 / 4$ & $1.7 / 8$ & $11 / 16$ \\
\hline CRA.O & 83.90 & 72.35 & $1 / 0$ Str. & 10 & 4.3 & $5 / 16$ & $3 / 4$ & $1.7 / 8$ & $3 / 4$ \\
\hline CRB-0 & 83.90 & 72.35 & $1 / 0 \mathrm{Str}$. & 10 & 4.3 & $3 / 8$ & $3 / 4$ & $1.7 / 8$ & $3 / 4$ \\
\hline CRA2/0 & 98.75 & 85.15 & $2 / 0 \mathrm{Str}$. & 10 & 6.2 & $3 / 8$ & $7 / 8$ & $2-3 / 32$ & $13 / 16$ \\
\hline CRA $3 / 0$ & 116.75 & 100.70 & $3 / 0 \mathrm{Str}$. & 10 & 7.6 & $3 / 8$ & 1 & $2-5 / 16$ & $29 / 32$ \\
\hline CRB $3 / 0$ & 116.75 & 100.70 & $3 / 0 \mathrm{str}$. & 10 & 7.6 & $1 / 2$ & 1 & $2-5 / 16$ & $29 / 32$ \\
\hline CRA4/0 & 133.00 & 114.70 & $4 / 0 \mathrm{Str}$. & 10 & 7.7 & $3 / 8$ & 1 & $2 \cdot 11 / 32$ & 1 \\
\hline CRB4/0 & 133.00 & 114.70 & $4 / 0$ Str. & 10 & 7.7 & $1 / 2$ & 1 & $2 \cdot 11 / 32$ & 1 \\
\hline CRA-250 & 154.70 & 133.45 & $250 \mathrm{mcm}$ & 10 & 13 & $1 / 2$ & $1.1 / 8$ & $2-5 / 8$ & $1-3 / 32$ \\
\hline CRA-300 & 179.55 & 154.70 & $300 \mathrm{mcm}$ & 10 & 14. & $1 / 2$ & $1.1 / 8$ & $2-5 / 8$ & $1 \cdot 3 / 16$ \\
\hline CRA-350 & 186.80 & 161.05 & $350 \mathrm{mcm}$ & 10 & 19. & $1 / 2$ & $1.1 / 8$ & $2-11 / 16$ & $1.9 / 32$ \\
\hline CRA.400 & 220.65 & 190.25 & $400 \mathrm{mcm}$ & 10 & 25. & $5 / 8$ & $1.1 / 2$ & $3-5 / 16$ & $1 \cdot 3 / 8$ \\
\hline CRA.500 & 268.70 & 231.60 & $500 \mathrm{mcm}$ & 10 & 40. & $5 / 8$ & $1 \cdot 1 / 2$ & $3-1 / 2$ & $1-17 / 32$ \\
\hline CRA.750 & 520.55 & 448.75 & $750 \mathrm{mcm}$ & 6 & 82. & $5 / 8$ & $1.15 / 16$ & $4-11 / 32$ & $1-29 / 32$ \\
\hline CRA-1000 & 1078.75 & 930.05 & $1000 \mathrm{mcm}$ & 6 & 120 & $5 / 8$. & $2 \cdot 1 / 8$ & $4-7 / 8$ & $2-3 / 16$ \\
\hline
\end{tabular}

One piece construction for strength. Pure Copper for maximum conductivity. Flared cable hole for easy wire insertion. Sight hole for visual cable inspection. Dimensions in inches - approximate.

Maximum Contact surface. Uniform construction - precision made, electro-tin plated to minimize corrosion. Wire ranges clearly marked.

Designed to fit most compression dies. 


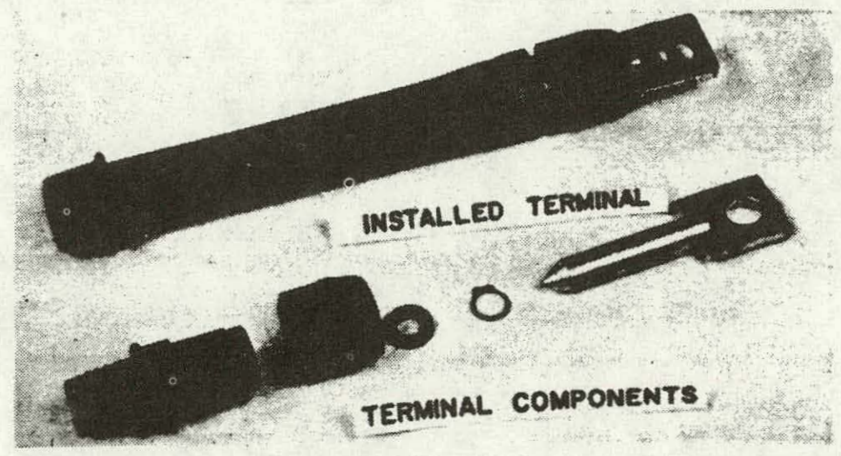

PIN-AND-NUT CONNECTOR can be installed using an adjustable wrench. This latest design is specifically made for $600 \mathrm{~V}$

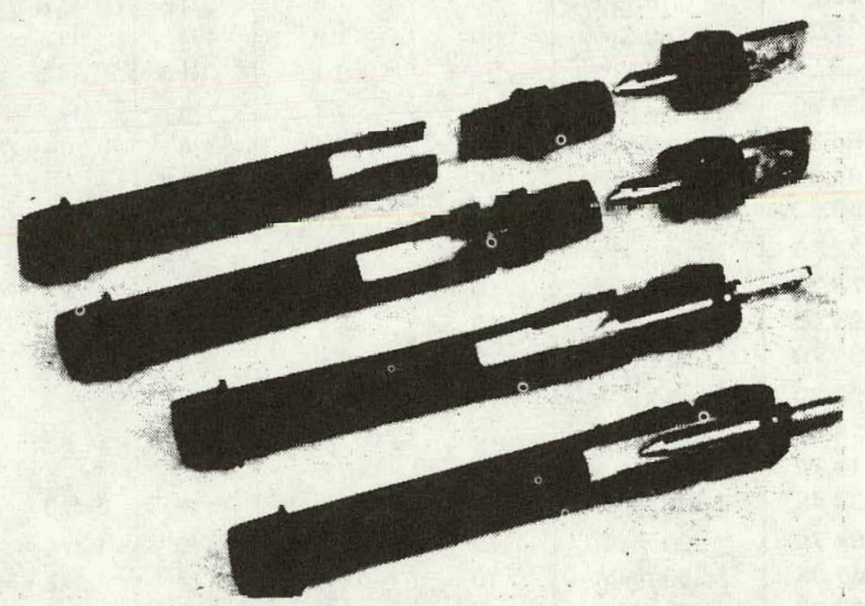

INSTALLATION SEQUENCE, after cable preparation, is shüwn top to bottuil. Pin is advanced into sodium by tightening nut

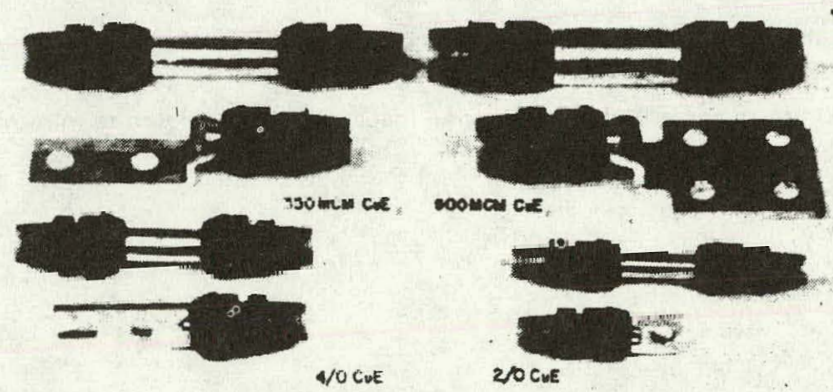

SPI ICES are shown top and third row along with several connector variations. Ratings are in copper equivalents (CuE)

\footnotetext{
Figure A5-7. 600 VOLT SODIUM CABLE CONNECTORS (FROM 'SODIUM IS NF'W CABLE CONDUCTOR' BY N. PEACH ,POWER, SEPT. 1968)
} 
APPENDIX A6

Additional Application Cost Data 


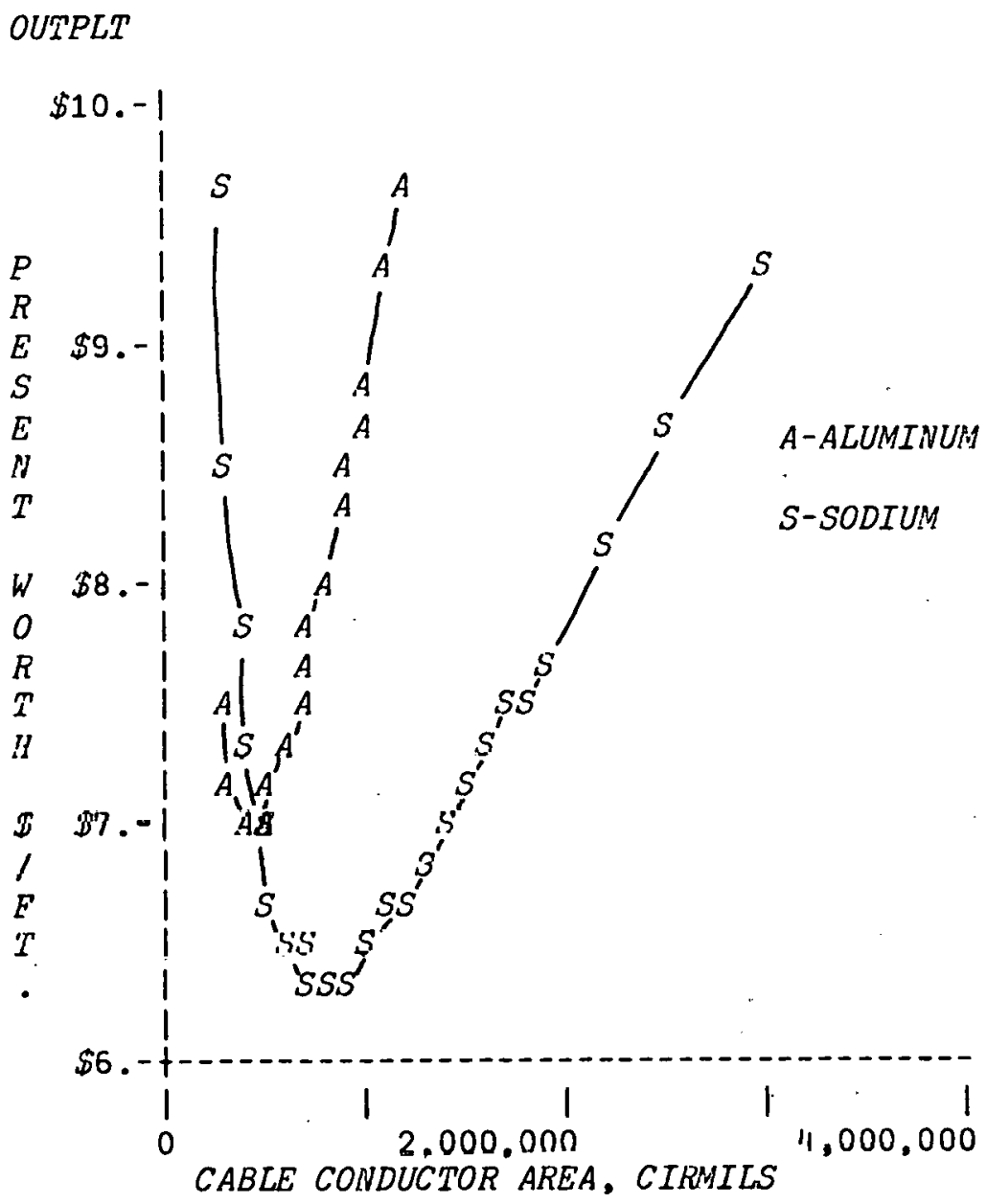

Figure A6-1. TOTAL PRESENT WORTH COSTS VERSIIS CONDUCTOR SIZE $35 K V$ DIRECT BURIED.

CABLE PARAMETERS:

UNIFORMLY LOADED 3 PHASE MAIN FEEDER

345 .MILS XLPE INSULATION

15 MILS CONDUCTOR SCREEN FOR AL, O FOR NA

30 MILS INSULATION SCREEN

OPERATING FARAMETERS:

LOSS EACTOR $=.18$ PEAK RESPOSIBILITY FACTOR $=.82$

EEEDER INPUT CURREENT 213 AMPS

FEEDER OUTPUT CURRENT 67 AMPS 

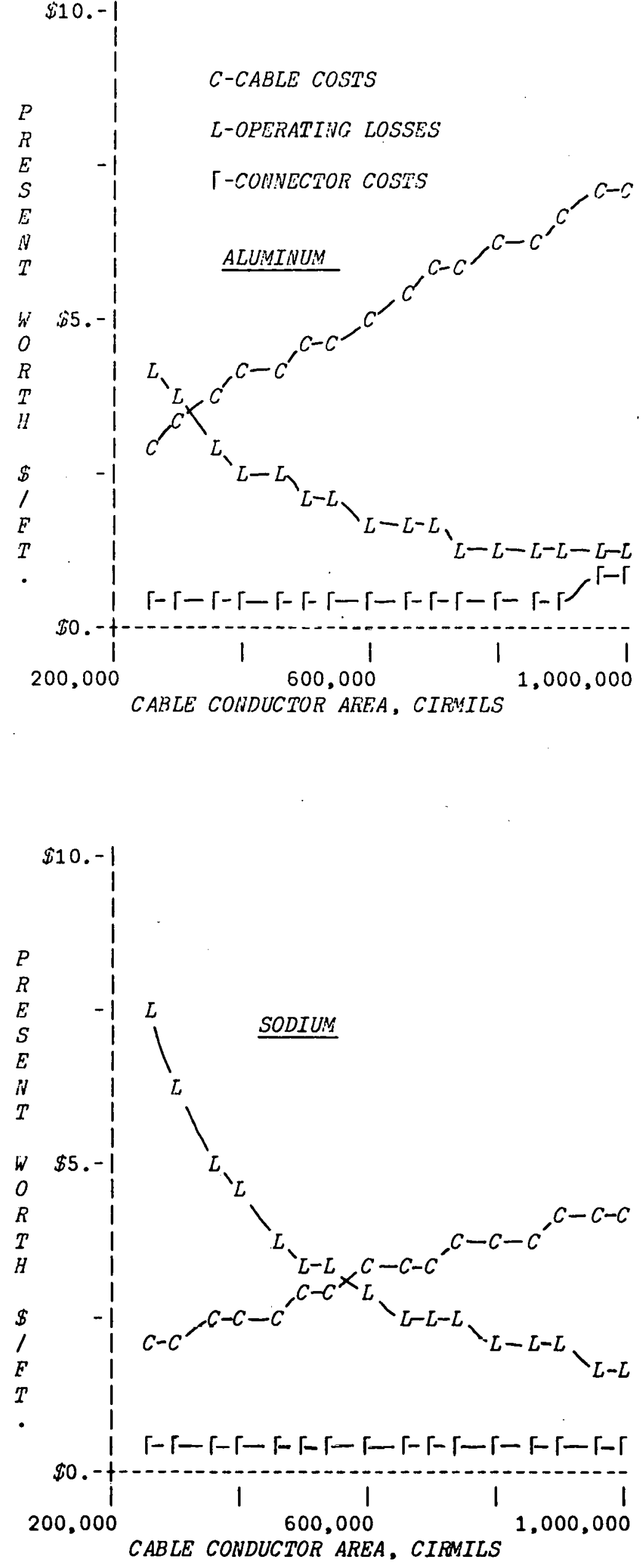

FIgure A6-2. PRESENT WORTH COSTS VS. CONDUCTOR SIZE 35KV MAIN EEEDER, 3PHASE. 


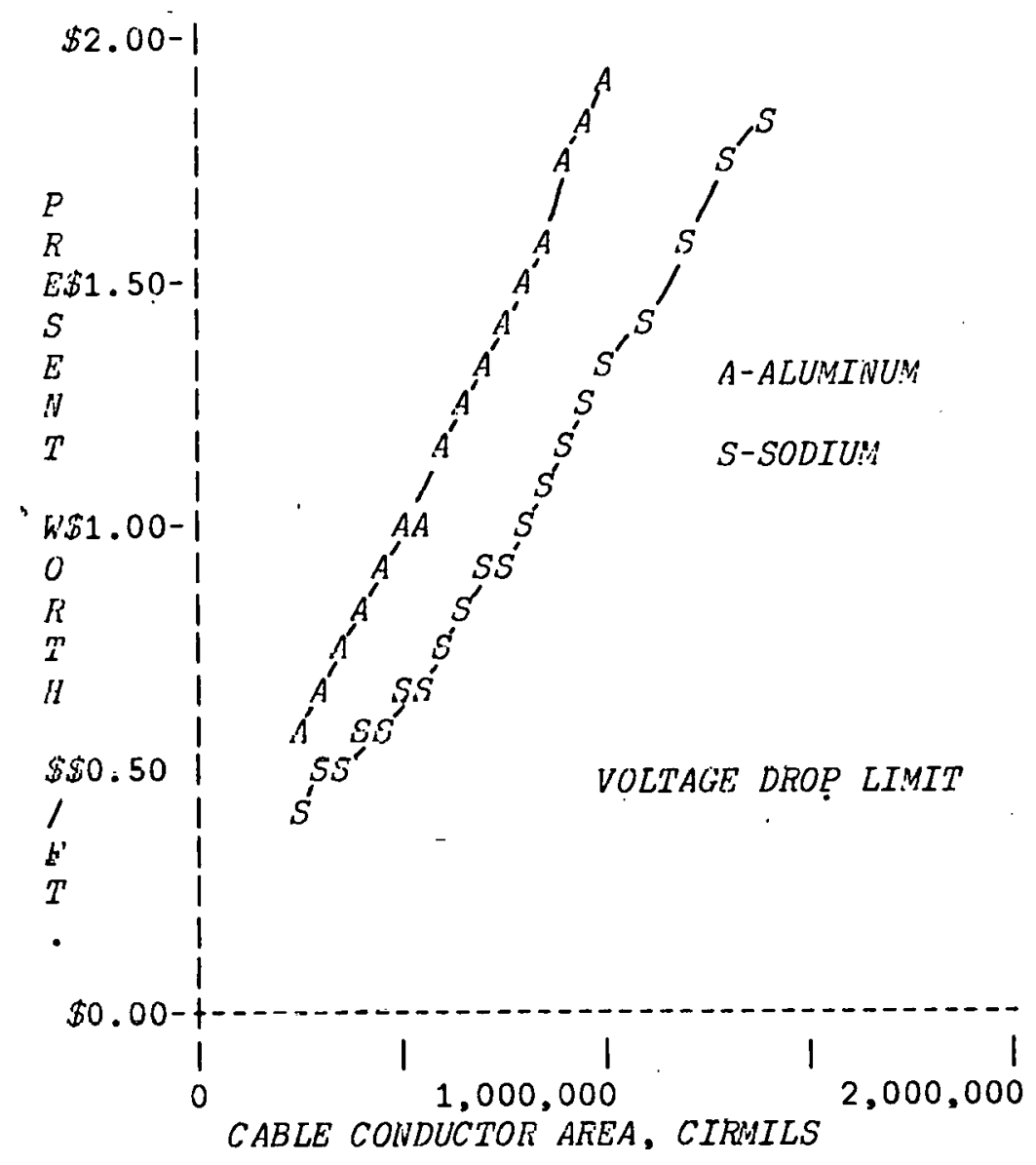

Figure A6-3. TOTAL PRESENT WOKTH COSTS VS. CONDUCTOR SIZE-600 VOLT SERVICE.

CABLE PARAMETERS : 60OV DIRECT BURIED SINGLE YHASF, SFRVICE

125 MILS XLLE INSULATTON

OPERATING PARAMETERS:

LOSS FACTOR $=.06$ PEAK RESTOSIBILITY EAC''OR=.3

SERVICE CURRENT EROM SECONDAKY 40 AUPS 

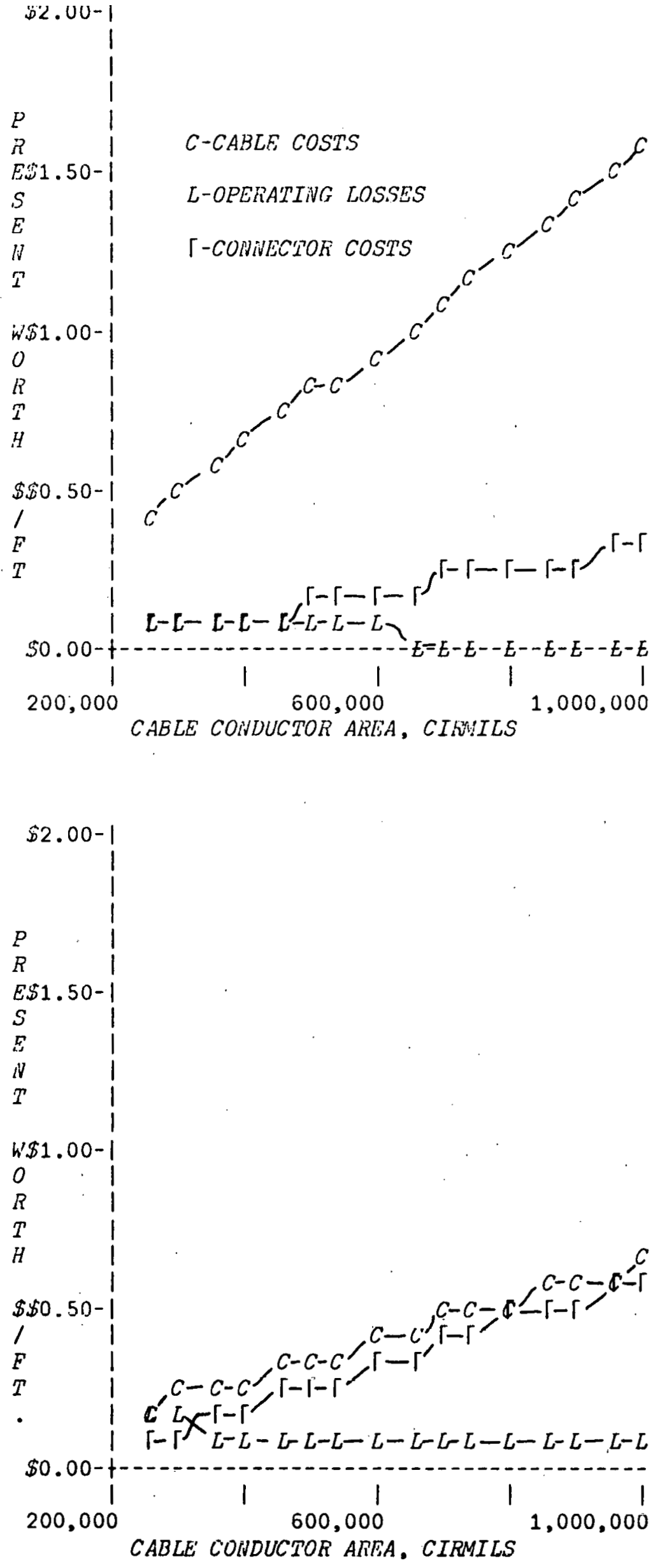

F1gure A6-4. PRESENT WORTH OF CABLE, CONNECTOR AND OPERATING LOSSES-600 VOLT SERVICE. 
APPENDIX A7

Functions Used In Computer Analysis of Present Worth Costs and Cable Material Costs

(APL Language Used on Scientific

Time Sharing Corporation System) 
$\nabla C A B L E C S T:[] \nabla$

$\nabla$ CABLECST

[1] $T P \bigcirc D C+(A R E A C) \star 0.5$

[2] $D C D+D C \times D C S T R D$

[3]. $D C S+D C D+C S T$

[4] DIVS+DCS+INSLT

-5] $\quad D I V S R+D I N S+I S T$

[6] $\quad D C N+D I N S R+C N T$

[7] $\quad D J+D C N+J T$

8] $\quad W C O N D+(D C \star 2) \times C O N D S G \times 1.03$

[9] CSTCOND WCOND $\times P C O N D$

1..10] $C S T C S+(((D C S \star 2)-(D C D \star 2)) \times S G S C) \times P C S$

(11] CSTINS+(((DINS*2)-(DCS*2)) $\times S G I N S) \times P I N S$

(12] $C S T I N S R+(((D I N S R \star 2)-(D I N S \star 2)) \times S G S C) \times P C S$

[13] $C S T C N+(((D C N T \star 2) \times C N C \times C N S G) \times P C N) \times 1.03$

[14] $\operatorname{CST} J+\left(((D J * 2)-(D C N * 2)) \times 4.7 E^{-} 7\right) \times P J$

15] CBLCSTM+CSTCOND+CSTCS+CSTINS+CSTINSR+CSTCW+CSTJ

[16] CBLSP+ $(C B L C S T M \div E A B E C T)+O C S T$

17] $\rightarrow 19 \times 1(T Y P=1)$

18] $C A B H A+C B L S P \diamond C A B N A 3 P+3 \times C A B N A \diamond \rightarrow 35$

19] $C A B A L+C B L S P$

[20] $C A B A L 3 P+3 \times C A B A L$

$\nabla$

$\nabla T P[\square] \nabla$

$\nabla T P$

i.1] $\rightarrow 9 \times(T Y P=1)$

[2] DCSTRD -1

[3] DCNT $4(A R E A C \times 0.368) \star 0.5$

[4] $\quad \operatorname{CST} 40$

5] CONDSG $+3.3 E^{-} 7$

46] $P C O N D \leftarrow P N A$

:7] PINS+PINSHA

8] FABFCT+FABEC CNA $\hat{\vee}+16$

9] DCSTRD+1.15

[10] $D C N T+(A R E A C \times 0.61) * 0.5$

[11] $C S T+30$

[12] CONDSG+9.2 $2 E^{-7}$

[13] $P C O N D+P A L$

[14] PINS+PINSAL

:15] $\quad F A B E C T+F A B F C^{\prime \prime} I A L$

$\nabla$

$\nabla P W C B C[] \nabla$

$\nabla$ PWCB

(1] $D+((1+D)-(((1+G) * 2) \times(1+E))) \div(((1+G) * 2) \times(1+E))$

[2] $P W F+(1-(1+D T) \star(N)) \div D T$

.3] $I C O N+((I 1 * 2)+(I 1 \times I 2)+(I 2 \star 2))$

[4] PWRAL+KPXICON $\times R A C A L \times 3.05 E^{-5}$

5] WWRNA+KP $I C O N \times R A C N A \times 3.05 E^{-5}$

[6] $L O A L+P W R A L \times L S E$ 


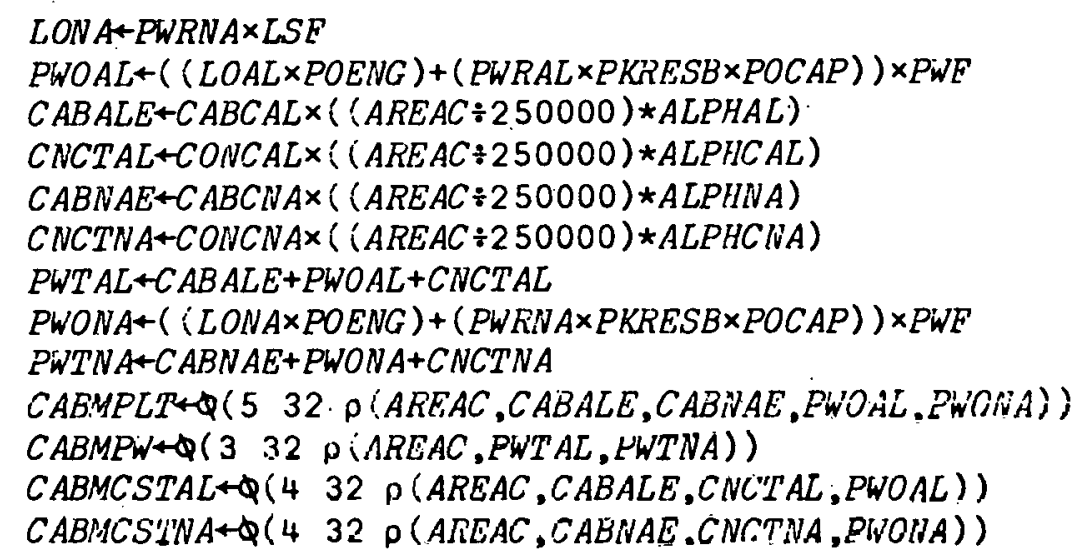


United States

Department of Energy

Washington, DC 20585

UENALTY FOR PRIVATE

OF POSTAGE, $\$ 300$

DOE 350

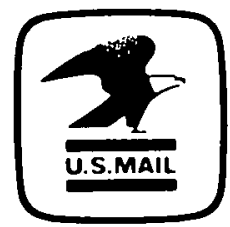

Official Business

Penalty for Private Use, $\$ \mathbf{3 0 0}$

\section{THIRD CLASS MAIL}

